\title{
Teaching in the Age of Covid-19-1 Year Later
}

\section{Petar Jandrić ${ }^{1,2}(\mathbb{D}$, et al. [full author details at the end of the article]}

Published online: 10 August 2021

( ) The Author(s), under exclusive licence to Springer Nature Switzerland AG 2021

\section{Teaching in the Age of Covid-19-1 Year Later}

Petar Jandrić, Zagreb, Croatia, 15 May

[Unchanged biography.] Petar Jandrić is a professor at the Zagreb University of Applied Sciences, Croatia, and visiting professor at the University of Wolverhampton, UK. He is founding editor-in-chief of Postdigital Science and Education. Petar is 43 years old, and lives in Zagreb, Croatia, with his partner and son.

$$
* * *
$$

In March 2020 I published the 'emergency editorial' in Postdigital Science and Education and invited the community to 'explore all imaginable aspects of this large social experiment that the Covid-19 pandemic has lain down in front of us' (Jandrić 2020a: 237). Articles immediately started pouring in; within weeks, the journal's contributions had been recognized by institutions such as the World Health Organization, the US National Library of Medicine's Nature Public Health Emergency Collection, and UNESCO (see Jandrić 2021 for details). After publication of the October 2020 issue of Postdigital Science and Education, ${ }^{1}$ consisting of almost 60 articles on the Covid-19 pandemic, the first wave of pandemic research has wound down. As it has become obvious that Covid-19 is here to stay, research on immediate Covid-19 experiences and responses slowly gives way to research which 'reaches beyond the pandemic to the point where the pandemic experience is transformed from an object of research to an intrinsic part of our theories, approaches, research methodologies, and social struggles' (Jandrić 2021: 262).

An important part of our early efforts to make sense of the pandemic, and the one very close to my heart, is 'Teaching in the Age of Covid-19' (Jandrić et al. 2020), which is a collection of short testimonies and workspace photographs submitted between 18 March and 5 May 2020.

In numbers, the collection consists of 81 textual testimonies and 80 workspace photographs submitted by 84 authors from 19 countries: USA (13), UK (11), China (9), India (7), Australia (7), New Zealand (7), Denmark (6), Sweden (6), Croatia (5), Canada (2), Spain (2), Nigeria (2), Finland (2), Ireland (2), Malta (1), Tanzania (1),Malaysia (1), Latvia (1), and South Africa (1). (Jandrić et al. 2020: 1070)

\footnotetext{
${ }^{1}$ See https://link.springer.com/journal/42438/volumes-and-issues/2-3. Accessed 15 May 2021.
} 
A year and a half into the pandemic, this article is important historical material (see Jandrić and Hayes 2020) which provides an in-depth understanding of people's immediate reactions to the Covid-19 pandemic. $^{2}$

As we move into the 'new normal' marked by vaccinations, occasional pandemic outbursts, and mashups of lockdowns and openings, partisan responses in the form of 'emergency online teaching' (Hodges et al. 2020) are being replaced by more permanent solutions. Governments, institutions, and companies are now putting a lot of effort into regulating remote work; Covid-19 passports are in advanced stages of preparation; institutes, schools, and universities are transforming their research, teaching, and learning. These developments strongly impact workers' rights, ways we spend our work and leisure time, and our physical and emotional well-being. They also reconfigure global geopolitical and social order, including but far from limited to, the ancient colonial and economic borders between the Global North and Global South. In this context, testimonies and histories are far from enough: the world urgently needs ideas, critiques, and recommendations for shaping the "new normal.'

On 17 March 2021 we invited all authors of 'Teaching in the Age of Covid-19' (Jandrić et al. 2020) to reflect on their pandemic experience 1 year later. ${ }^{3}$ Mirroring the original article's format, in 'Teaching in the Age of Covid-19-1 Year Later', we requested short testimonies, biographies, and workspace photographs. In numbers, the 1-year-later collection consists of 74 textual testimonies and 76 workspace photographs submitted by 77 authors from 20 countries: USA (14), UK (7), China (3), India (7), Australia (6), New Zealand (8), Denmark (5), Sweden (6), Croatia (3), Canada (4), Spain (2), Nigeria (1), Finland (2), Ireland (2), Malta (1), Tanzania (2), Malaysia (1), Latvia (1), South Africa (1), and Germany (1). 'As it is common in academia, many authors are expats and carry multiple identities; the collection reflects places of writing their testimonies rather than places of their origin.' (Jandrić et al. 2020: 1070) Some contributors have submitted unchanged biographies; others have experienced various life changes and sent us updates. ${ }^{4}$ Some contributors have told us that their workspaces have remained the same; others submitted images of their new or upgraded workspaces. ${ }^{5}$

Unfortunately, 7 original contributors never responded to our 1-year-later call for contributions. This can be partially explained by simple loss of contact. Our only way of communicating with the contributors is email: students graduated, teachers changed jobs, and their institutional emails are no longer active. However, I am

\footnotetext{
${ }^{2}$ See Jandrić (2020b) for an overview of pandemic-related work in Postdigital Science and Education community in 2020.

${ }^{3}$ The Call for Contributions for 'Teaching in the Age of Covid-19' (Jandrić et al. 2020) was launched on 17 March 2020. The Call for Contributions for 'Teaching in the Age of Covid-19-1 Year Later' was launched on 17 March 2021.

${ }^{4}$ Each biography is labeled as [Unchanged biography.] or [Updated biography.]. For updated biographies, readers are encouraged to refer to 'Teaching in the Age of Covid-19' (Jandrić et al. 2020) for comparison.

${ }^{5}$ New workspace images are labeled as [New figure.]. Workspace images republished from Jandrić et al. (2020) are labeled as [Unchanged figure.].
} 
happy to report that 'Teaching in the Age of Covid-19-1 Year Later' has almost $92 \%$ of the original contributors, which is a number large enough for a meaningful comparative analysis.

A journey of a thousand miles begins with a single step; our ideas, critiques, and recommendations for the future need solid bases in past and present. Taken separately, testimonials in 'Teaching in the Age of Covid-19' (Jandrić et al. 2020) and 'Teaching in the Age of Covid-19-1 Year Later' provide snapshots into the realities of teaching and learning at two very different moments of the pandemic. Taken together, these articles offer an in-depth textual and visual insight into individual changes and adjustments made by global teachers and learners as the Covid-19 pandemic has progressed from a once-in-a-lifetime disruptive event into a new normal. In the words of Christine Sinclair (2021), 'I have been using "our" and "we" a great deal throughout this review: we are the readers, but we are also the objects or possibly the subjects of what is going on in the conflux of biology, technology and culture'. This is very valuable material, not least because this pair of articles can be used as input for one of the first longitudinal studies of pandemic impacts to global teaching and learning. Based on this material, we will do our best to publish a follow-up analysis article. We also warmly invite all other researchers, who find this material of interest, to freely use it in own research - and kindly ask them to let us know what they found out.

We sincerely hope that the Covid-19 pandemic will cease in the foreseeable future, and that, on 17 March 2022, there will be no need to issue a call for 2-yearlater contributions. However, we are ready for the challenge and will continue this longitudinal collection of (post)-pandemic experiences for as long as is needed. Our aim in this effort is twofold. First, we need to record individual stories and histories, because future generations deserve to know their ancestors' thoughts and feelings at this daring historical moment. Second, as academics, teachers, and public intellectuals, we have a responsibility to actively contribute to development of the so-called new normal, and this material provides important insight into the temporal development of the pandemic responses. It is with this hope that we thank all contributors who gave us the precious gift of their time and made this series of testimonials happen.

\section{Call for Testimonies: Teaching in the Age of Covid-19-1 Year Later}

This is a verbatim transcript of the Call for Testimonies sent out on 17 March 2020 to all authors of 'Teaching in the Age of Covid-19'. (Jandrić et al. 2020).

$$
* * *
$$

On 17 March 2020, Postdigital Science and Education launched a call for testimonies about teaching and learning during the very first Covid-19 lockdowns. The resulting article, 'Teaching in the Age of Covid-19', presents 81 written testimonies and 80 workspace photographs submitted by 84 authors from 19 countries between 18 March and 5 May 2020. Thank you a lot for co-authoring this important article! 
Today, 17 March 2021, exactly 1 year after the original call, we now launch a call for sequel. In 'Teaching in the Age of Covid-19-1 Year Later', we would like to hear about ways in which you-contributors to the original article-have dealt with the pandemic. Your 500-word contributions should contain roughly the following: Before you begin:

- On top of your submission, please write your name, location, and date of writing your submission in the following format: Petar Jandrić, Zagreb, Croatia, 1 June.

- Please update your biography published in the original article. If you do not update your biography, we will reproduce last year's one.

Then, please cover the following themes:

- Where, and when, are you writing this testimony? Did you perhaps move to another house, or country?

- A sentence or two about context. Do you still work at the same place; did you perhaps change your job? Did you experience any major changes in private life?

- How has your university/institution adapted to continuation of pandemic lockdowns? What is expected from you at this stage?

- How are you dealing with these expectations? Which major challenges (professional, private, personal, family...) are you finding along the way?

- What are your main feelings at the moment (stress, anxiety, excitement, happiness, calm...)? How are you coping with those feelings?

- How has your thinking about the Covid-19 pandemic developed during the past year?

- And, of course, anything else you would like to tell the world about your experience.

Last but not least, please send us a photo of your current workspace!

This Call is aimed only at co-authors of last year's 'Teaching in the Age of Covid19' article! Please do not share this Call or invite new co-authors. Those of you who wrote collective replies, please try and replicate last year's author setup.

Please write your ca 500-word response and return it Petar Jandrić, pjandric@tvz. hr. Responses will be collated into a collectively authored article and prepared for publication in Postdigital Science and Education, 3(3), October.

Deadline for submitting your responses is 5 May 2021. Please contact Petar Jandrić for any questions. 


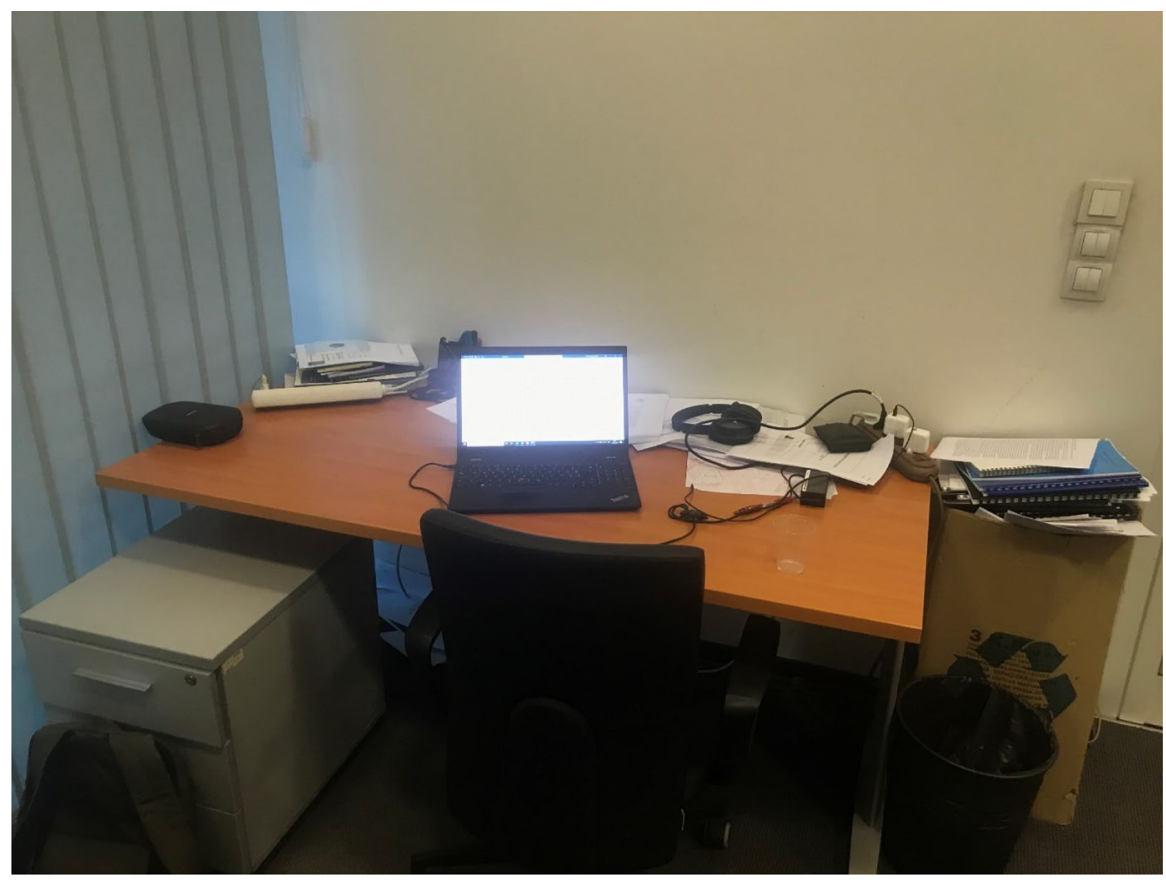

Fig. 1 [New figure.] My workspace at Zagreb University of Applied Sciences, to which I returned as soon as the building has opened. At this desk, I wrote the Call for Testimonies and edited this article

\section{Volunteering and Covid-19, One Year On}

David Hayes, Further Education, Worcester, UK, 17 March

[Unchanged biography.] David Hayes felt privileged to teach for over 30 years. He found those he taught, and taught with, more interesting than his subject. That subject was often mathematics. Originally from Scotland, Dave enjoys life in Worcester, UK, with an all-too-observant partner, two sons, and a disrespectful cat called Jasmine.

I stated, roughly a year ago, that I was a retired Maths teacher, who had provided some volunteer support to students for some years. Such support was always given at local schools or colleges. These students, whether at school or college, were generally between 16 and 18 years of age. Such support was given face-to-face, to individual students or to small groups where it complemented other tuition. In one particular case, that other tuition consisted of packages delivered online: traditional teaching could not be justified for such a small group at that school. Generally, I 
gave low-tech support, where help was usually given on paper. Often, it involved merely assisting students in answering Maths questions.

The decision taken nationally to move all teaching online removed the opportunity to give that sort of extra support easily. Like many others, I had not anticipated that the change to normal teaching would last quite so long. While my offers of future support to local schools and colleges have been met positively, volunteers will not be wanted until September 2021 at the very earliest. Schools and colleges understandably remain hesitant. The pandemic has made all teaching very challenging. The effects of the hiatus to normal teaching have been profound. One does not need to look past the complications with exams, with the ensuing political fall-out, to appreciate the gravity of the ongoing situation.

Of course, not all is gloom and doom. It is apparent that online teaching has improved markedly, in many areas. This is as expected and was widely anticipated. Packages are more reliable, and providers have become more expert in how they deliver online material. The idea that online tuition is somehow not real teaching seems to be disingenuous. The old adage that necessity is the mother of invention seems entirely relevant here, as progress has been made in managing online resources that might otherwise have taken many years. It is equally apparent that more mature and better situated students can exploit the possibilities of online tuition much better than others. There has been a growing concern at how some students have been disadvantaged. Home schooling, for many students, has been as much a euphemism as it has been a vain hope.

Socio-economic factors have been just as much of a key to understanding inequalities as has been the age of students. Addressing these issues has not been (and will not be) at all straightforward. All governments can be forgiven for struggling with these challenges. Thus, support for the more vulnerable General Certificate of Secondary Education (GCSE) students would seem to be particularly urgent. In the future, my attention will be directed toward these disadvantaged GCSE students. Previously, I have been more involved in supporting the higher level of A' level Maths. I look forward to the opportunity of helping out where I can.

I stated last year that I felt that just as parenting could not be relegated to online provision then neither could effective teaching, particularly for more dependent students. This is still my view. 


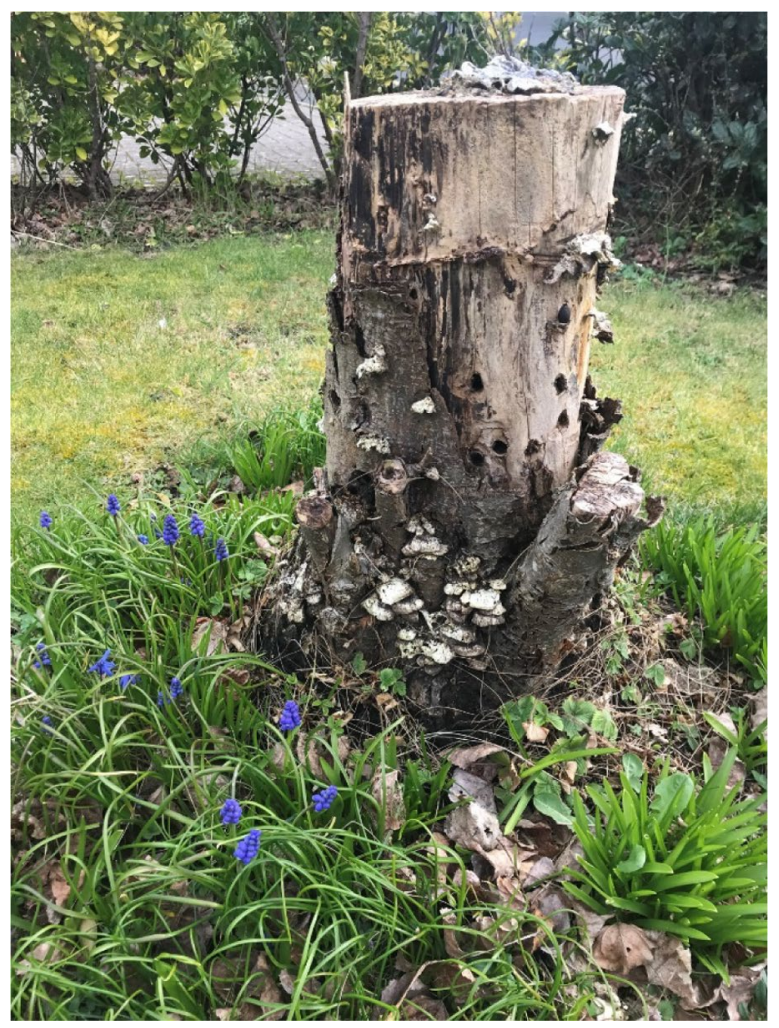

Fig. 2 [New figure.] A year later

\section{Even Better Than I Expected}

Paul Levinson, New York City, USA, 17 March

[Unchanged biography.] Paul Levinson has published 10 books about media theory (e.g., The Soft Edge, Digital McLuhan, New New Media) translated into 15 languages and 6 science fiction novels (e.g., The Silk Code, The Plot to Save Socrates), and is a singer-songwriter (Twice Upon a Rhyme, Welcome Up: Songs of Space and Time). He is a professor at Fordham University in New York City and appears on CNN, MSNBC, NPR, the BBC and numerous news outlets.

$$
* * *
$$

Teaching in the age of Covid-19 has actually worked out even better than I had expected a year ago, and I had expected remote online learning to provide all sorts of benefits back then. 
I have gotten to know my students even better than I had expected a year ago, via the combination of live Zoom sessions and asynchronous email. I am the kind of person who reads and writes email at least 16-17 $\mathrm{h}$ a day, and this affords me far more possibilities for interaction with students than in a totally in-person educational environment.

Note that this is a hybrid form of synchronous and asynchronous teaching-both remote-rather than the purely asynchronous mode of remote online education I foresaw and praised here last year. The combination of live and asynchronous, of audio-visual and written, gave the students a maximum diversity of sensory input.

The online mode allowed students from across the USA and as far away as China to take courses with me via the Internet from New York. But the student in China was unable to attend all of the live Zoom sessions due to the difference in time zones. Panopto, which provided transcribed recordings of the Zoom sessions, came to the rescue. Other than the live interactions, the student in China received all the audio-visual benefits of the Zoom session, plus the transcription.

In addition to the advantages of this live and asynchronous mode of online learning as the pandemic raged, teaching from home saved me the time of driving to and from the campus of Fordham University several times a week. I put this time to good use. In addition to lavishing attention on my garden, the output of the nonfiction and fiction I write increased dramatically in the past year. In December, I sent out a note to my friends with links to four publications by me in just that month. These included:

- 'Tetrads and Chiasmus: A Reclamation of the Tetrad Wheel' (Lindia and Levinson 2020, b, c) — a scholarly article by Matt Lindia and me about Marshall McLuhan's (1975) 'Laws of the Media'.

- 'Popper and Evolution Over the Decades' (Levinson 2020a)—how I met the great philosopher.

- 'The Missing Orientation' (Levinson 2020b)—essay about space exploration, sense of wonder, and religion.

- 'Foreseeable' (Levinson 2020c)—brand new science fiction story.

And 1 month after that, my 'I'm a First Amendment scholar - and I think Big Tech should be left alone' (Levinson 2021) was published in The Conversation.

The pandemic has been an unparalleled tragedy for our species across this planet. But while there is life there is hope, and with the Internet at its behest, the intellect can embody that hope in effective, rewarding teaching, and vigorous scholarly production. 


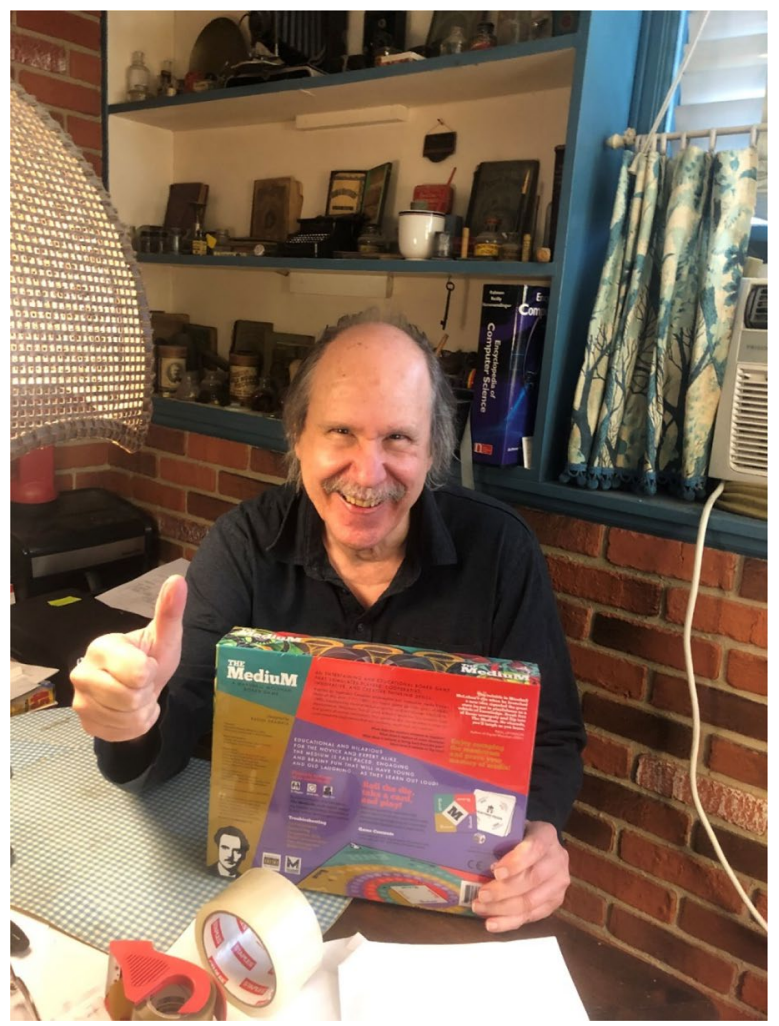

Fig. 3 [New figure.] I'm holding a new board game, The Medium, in which McLuhan's laws of the media are the way playing the game. (I wrote a blurb for the game, which you can see in the upper right corner of the box.)

\section{The New 'Normal'}

Line Lisberg Christensen, Aalborg, Denmark, 17 March

[Unchanged biography.] Line Lisberg Christensen is a research assistant at the Department of Communication and Psychology, Aalborg University, Denmark. Line is 29 years old and lives in Aalborg, Denmark, with her partner.

$* * *$

With my home-office still in my living room, which I share with my partner and two cats, nothing much has changed professionally. My employment as a research 
assistant is coming to an end, which is stressful and frustrating. I feel more limited than ever in my options for future employment at Aalborg University. Being physically far away from colleagues makes it difficult to network and discuss potential collaborations.

Alongside the uncertainty of my future employment, many things have happened on the home front as well. Our (parked) car was damaged beyond repair by a 40-ton truck, and major water damage to our apartment left it uninhabitable for several months, forcing us to relocate to a new, temporary home. Almost 7 months have passed and though we have returned to our apartment, many final changes are still not finished.

To say the least, the past year has been stressful and almost too eventful. Dealing with future uncertainties and thoughts on the current state of things has become more tangible over the past few weeks as our research group re-initiated Mondaymeetings on Zoom in which we have no specific agenda or designated 'work-talk'. Instead, we find ourselves talking about our families, our damaged cars, hobbies, and reopening of the Danish society. This seems to be beneficial to many of us, because the meetings serve as an active forum in which we can 'vent' our emotions and challenges, while we lessen the feeling of lonesomeness.

My understanding of the Covid-19 pandemic has developed drastically over the past year. I am no longer nervous about going shopping in our local market, and hugs are welcome once again (at least from those closest to me). I still find myself cringing every time someone coughs loudly in public, and I stay in bed if I feel under the weather, with weekly PCR tests for Covid-19 as part of the new practice of 'normal life.'

I often wonder what the future will look like, post pandemic. What practices will we embody (or maintain) in the nearby future because of the pandemic? What can we expect of those refusing to vaccinate? Will they keep the disease alive, forcing the rest of us to maintain weekly tests, avoid simple things like hugs and handshakes, wear masks, and constantly use hand-sanitizer? Alternatively, should we simply accept these as new practices? 


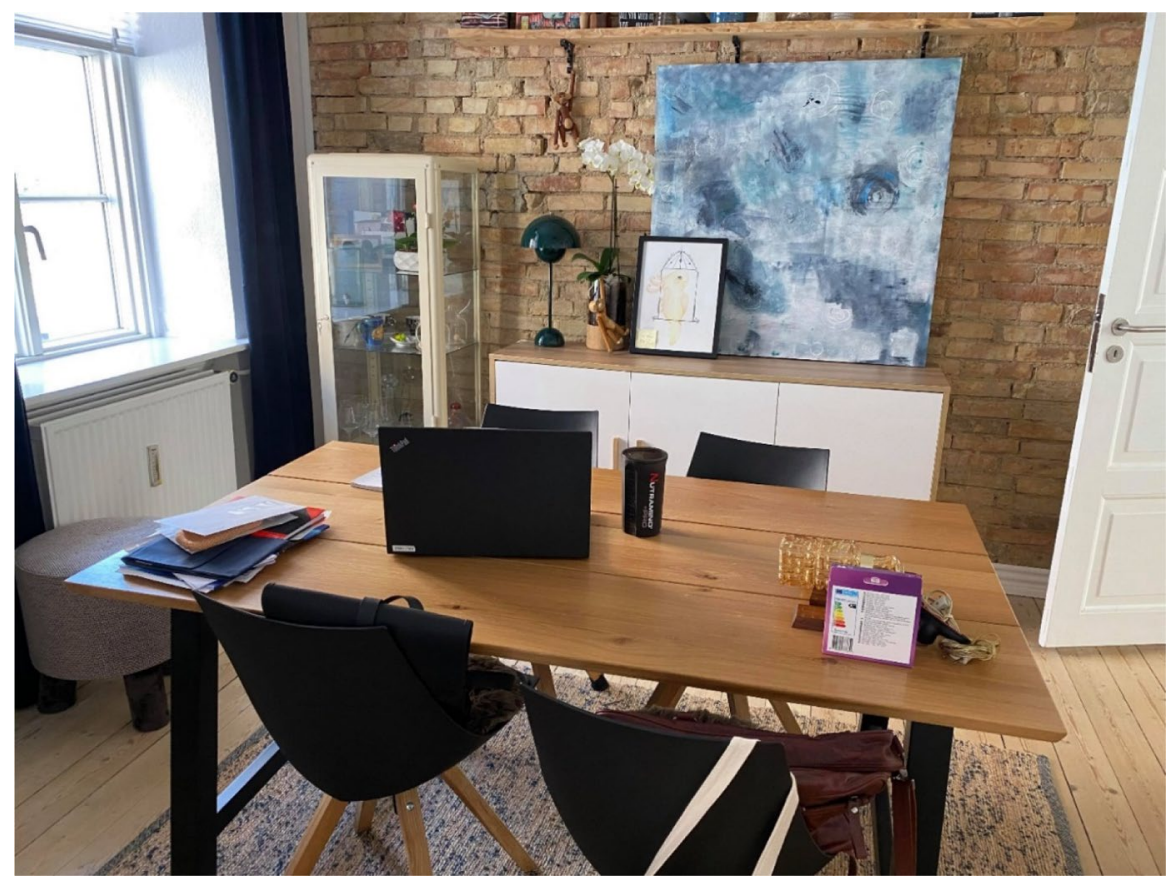

Fig. 4 [New figure.] Workspace remains a combination of living room, dining room and office. The cats and my boyfriend are hiding somewhere in the apartment

\section{Pressure and Panic in Teaching and Learning During Covid-19}

Happiness Onesmo Lukoko, Dar es Salaam, Tanzania, 18 March

[Updated biography.] Happiness Onesmo Lukoko is a part time Assistant Lecturer in the Institute of Development Studies at University of Dar es Salaam (UDSM). Happiness is 26 years old and lives in Dar es Salaam, Tanzania.

I just finished my Zoom meeting. Saddened by news of the loss of our president Dr. John Pombe Magufuli. The whole country is mourning for 14 days as burial arrangements are made. During this time, all flags in Tanzania will fly at half-mast. 
I feel so sad and shocked. Our late president helped us in overcoming Covid-19 and for that I'm very grateful for his life. Ours is a difficult and challenging time, but I hope we will get through together as a country. Such a huge loss to Tanzania and Africa at large.

Since last year, I finished my Master's degree in Beijing, China, and moved back to Tanzania. I currently work as a part time Assistant Lecturer at the Institute of Development Studies at University of Dar es Salaam (UDSM), which is the oldest and biggest university in Tanzania. Working at UDSM is a dream come true to me, and I am so glad to have this opportunity. Much has happened since the outbreak of the coronavirus. Completing my studies, and especially online graduation, was a challenging experience. It was hard to go back home from China, since Covid-19 had led to a halt on all flights. Luckily for some of us, the Tanzanian embassy in China organized a special flight (The Wings of Kilimanjaro). The plane could only take 250 people, which means that others remained in China.

I experienced Covid-19 in two countries that responded to the pandemic in different ways: China with lockdowns and Tanzania without lockdowns. In Tanzania, we have adapted pretty well. Since my return from China in July 2020, things are calm, schools and universities are open, and major precautions have been taken: washing hands, wearing masks, and some are using traditional medicine to cure the early symptoms.

The university has placed water stations and sanitizers in every lecture room and office. I, and everyone else, am expected to take precautions against the disease. Having experienced Covid-19 in two countries, I am very composed and avoid panic. I think, at this stage, that we all need to be calm. People should not fear the disease, yet we should handle it with caution. Spreading false news or terrifying people with ruthless news is not good because it leads to stress and anxiety which can cause the loss of body immunity.

I'm concerned about how fear of disease and panic can affect education and especially students. It is really important to educate them about precautions without pressure, as stress and anxiety will negatively affect their educational performance. I believe that developed safety measures will be able to fight against Covid-19 as well as any other diseases that may arrive in the future. 


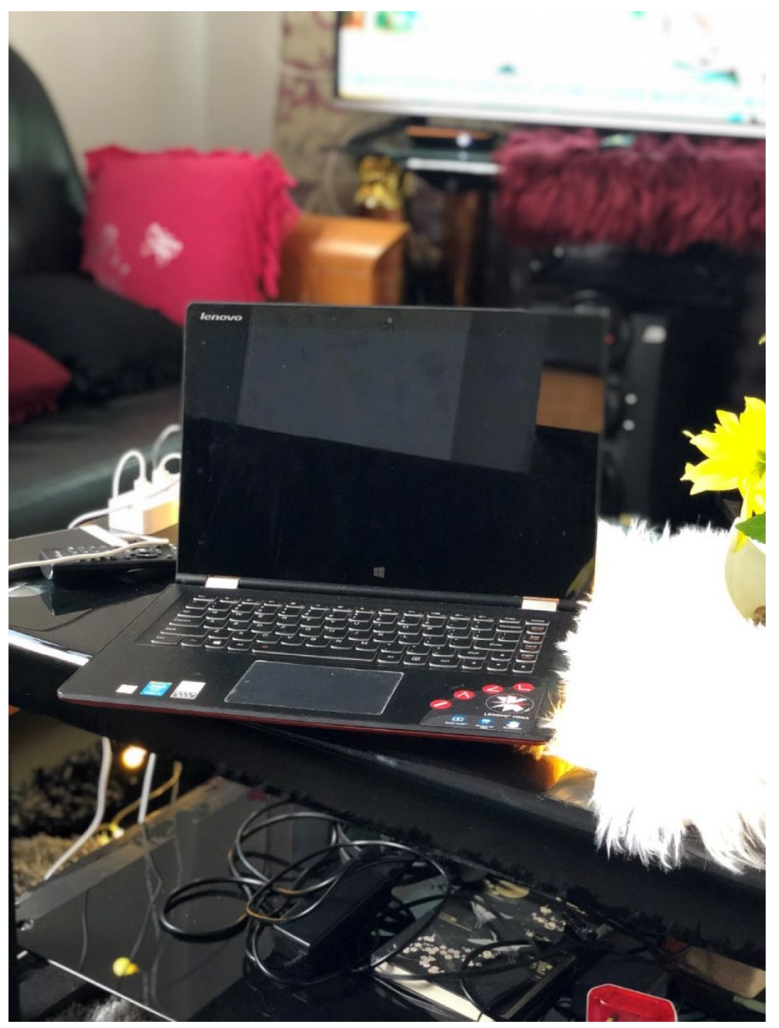

Fig. 5 [New figure.] This is my sitting room where I work and spend most of my time. I am usually alone most of the time

\section{Mental Health in Teaching and Learning During Covid-19}

Jimmy Ezekiel Kihwele, Morogoro, Tanzania, 18 March

[Updated biography.] Jimmy Ezekiel Kihwele is a Lecturer at Mzumbe University, Tanzania, and a Ph.D. Candidate at Beijing Normal University, China. Jimmy is 36 years old and lives in Morogoro, Tanzania, with his partner and two daughters.

I am writing the testimony from the very same place in which I wrote my last year's testimony. I still work as a lecturer at Mzumbe University, while continuing my Ph.D. studies online. I live in the same place, which is somehow comfortable and ensures access to electricity, Internet, and water. The government has declared that Tanzania is at low risk of Covid-19 and has urged people to take precautions directed by the World Health Organization and the Ministry of Health.

Since the end of lockdown in June 2020, teaching and learning have been stressful. Every day, I work extra hours to accomplish my Ph.D. project. I spend less time 
with my family. Searching for a quiet space, I shifted from working from home to working in my small university office. The university has provided hand sanitizer to all offices, added hand washing places with more soap, and insisted on wearing face masks. But overcrowded classrooms are the same, and lecturers, who are required to continue with teaching and research as usual, have been worried about their safety.

My Ph.D. studies have also been affected, so I have been given a study leave to concentrate on completing my thesis. The pandemic had affected data collection and which I completed 4 months later than planned, impacting scheduled analysis and writing. I face the challenge of working with my supervisor at a distance. Lack of face-to-face meetings has slowed down my progress and I am expected to submit my final thesis report on 31 March.

I am anxious because my employer expects me to graduate on time, my thesis is not ready yet, and I need to take care of my family. Pressured by the fact that failing to complete my studies on time might lead to termination of my job contract, I have experienced some sleepless nights. I am trying to cope by putting extra work hours. I am also hoping that it will be possible to apply for a 6- or 12-month extension.

Covid-19 is a life-threatening disease. Few Covid-19-related deaths have been reported in my area, yet I lost my brother in-law who lived in another region. Employers should consider their employees' working environment and workload during the pandemic. Universities should consider the mental health of their students. Some graduate students are taking study breaks, some drop out, and some are struggling with mental health. The pandemic should not result with mental health issues, so I urge all people to seriously take care of their health.

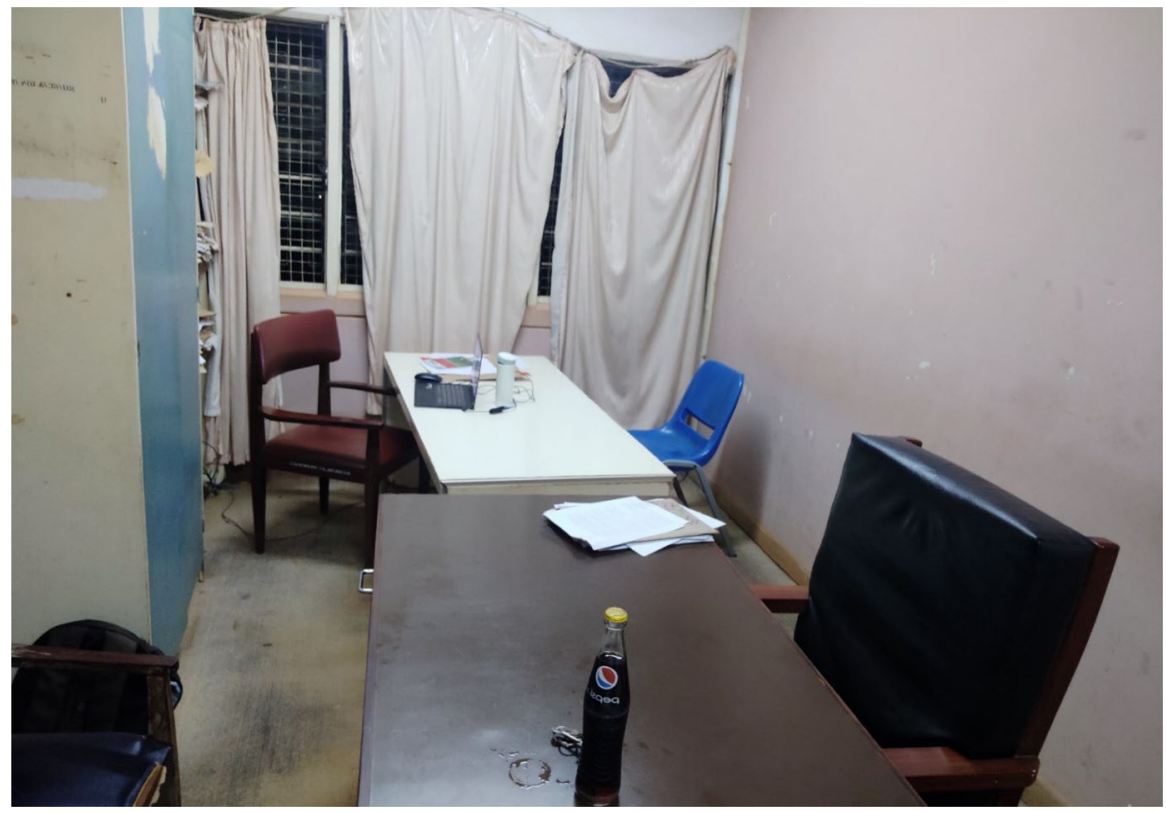

Fig. 6 [New figure.] The office I share with my two colleagues who are also students, one at Masters and the other at Ph.D. level 


\section{Those Who Cannot Remember the Past Are Condemned to Repeat It}

James Benedict Brown, Södra Västerselet, Vännäs, Sweden, 18 March

[Updated biography.] James Benedict Brown is an Associate Professor of Architecture at Umeå School of Architecture in northern Sweden. James' research is concerned with architectural pedagogies and representation. His teaching innovations in the last year have led to him receiving Umeå University's 2021 Faculty Award for Education.

$$
\text { *** } *
$$

I am sitting at my desk at home in the northern Swedish countryside. Today, for the first time this spring, more than $12 \mathrm{~h}$ will elapse between sunrise and sunset. The bright sunlight reflects off the deep snow. A woodpecker hangs on a bird feeder. A horse-and-trap rides past on the quiet gravel lansväg (county road). Beyond are hundreds of square kilometers of forest: an entirely manmade landscape where in the winter, locals hunt bear and moose and in the summer, seasonal workers from Thailand pick thousands of kilos of berries. At a moment's notice, a stand of trees can disappear when lone operators of industrial forest machines clear-cut the land, followed a few months later by gangs of tree planters.

It is with sombre emotions that I re-read our collective article from Spring 2020. In the picture above, my contribution was the young dog Guillam. We adopted him the weekend before Covid-19 sent us all home. Guillam has been re-homed once more. The first 6 months of life under the coronavirus pandemic were entangled with the consequences of overestimating my ability to care for an animal that had been mishandled. No amount of positive reinforcement or joyful-voice-sing-song name calling helped. We were not right for him.

Today, I am working from a different home. We have left the suburbs for the last house in a hamlet that has slipped off the map. My role has shifted from teaching architectural design to history. In the Summer and Autumn, I reconfigured five courses from proximate to distance learning, working with a wonderful colleague who 'Zooms in' from Catalonia.

Last year, I wrote about the challenges faced by educators who sought to recreate the complex physical, temporal, pedagogical, and cultural space of the architecture design studio in the world of Zoom (Brown 2020). That experience taught me that it would be inappropriate to recreate proximal lectures online. So, we fragmented existing 1- and 2- $\mathrm{h}$ lectures into shorter 20-min pre-recorded videos that students could watch asynchronously, whenever they liked and as little or as often as they liked. We concentrated our synchronous contact with students into live seminars and worked hard to use enlarged facial expressions and unusually extravagant body language to communicate our enthusiasm through the webcam. Course evaluations at the end of the autumn semester showed that our students appreciated our efforts, and in February 2021, I received an award from the university for pedagogical innovation. 
Teaching history forces us to reflect critically on our own past. Are these reading lists still relevant? Do our case studies still matter? Is the curriculum better or worse because of our switch to distance learning? Are we doing better than we were doing a year ago? Twelve months have not brought answers, but this brings me back to preceding sentences of George Santayana's oft-quoted aphorism in The Life of Reason. Despite everything, our collective infancy is hard to escape.

Progress, far from consisting in change, depends on retentiveness. When change is absolute there remains no being to improve and no direction is set for possible improvement: and when experience is not retained, as among savages, infancy is perpetual. Those who cannot remember the past are condemned to repeat it. (Santayana 1905: 284)

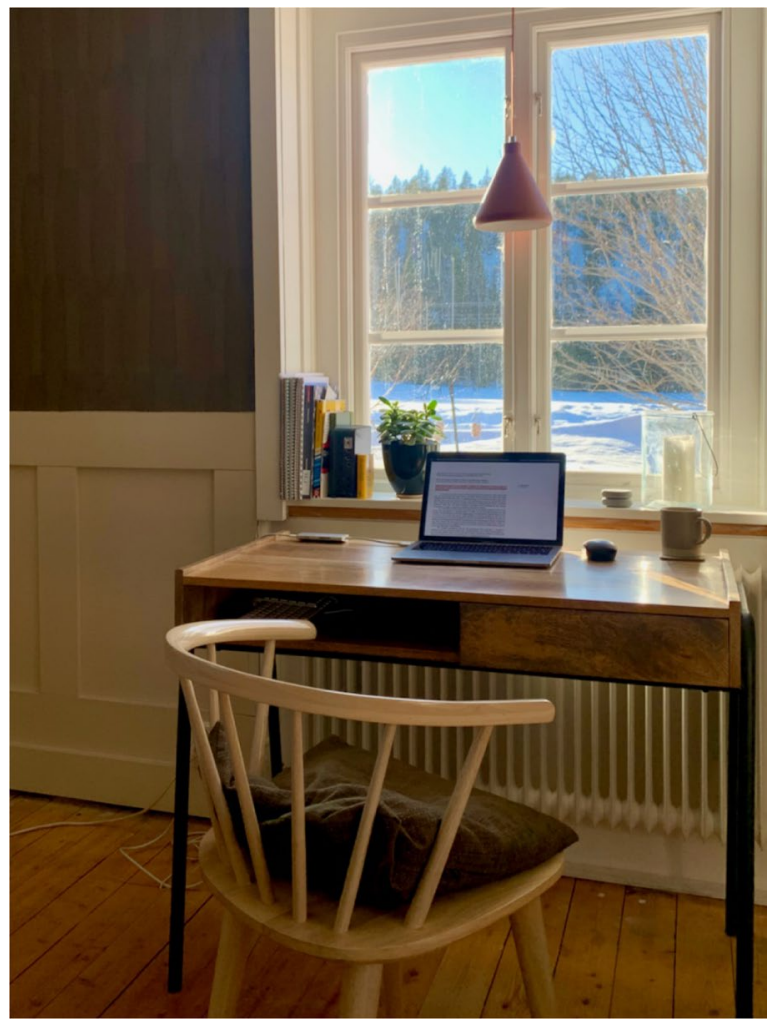

Fig. 7 [New figure.] My desk, now aligned with a view into the northern Swedish forest 


\section{Black Lives Matter! Writing Helps Recovery!}

Charles Reitz, Kansas City, MO, USA, 19 March 2021

[Updated biography.] Emeritus professor of philosophy, Kansas City Kansas Community College, with three recent books: Crisis \& Commonwealth: Marcuse, Marx McLaren (Lexington Books 2015); Philosophy \& Critical Pedagogy (Peter Lang 2016); Ecology \& Revolution: Herbert Marcuse and the Challenge of a New World System Today (Routledge 2019).

$$
* * *
$$

I caught Covid-19. Twenty-one days bedridden in hospital isolation; 9 more in pulmonary rehab; now at home, recovery will be slow.

But what a year! The world has witnessed two momentous events: a massive wave of protests against a series of racist police killings, and the neofascist attack on the US Capitol by white supremacist street-fighting organizations mobilized by Donald Trump.

The Black Lives Matter demonstrations were everywhere! They were countered by militarized police forces across the country engaging in identical scenarios of unwarranted, excessive, and unaccountable armed force (Bogel-Burroughs 2021a, b).

Angry white men are said to be the cause of the rise of an authoritarian populism. A personal sense of superiority over others in religion, culture, gives them a license to kill and dominate. But institutional structures undergird this bigotry: a Supreme Court in which 'money-is-speech' and a cross burning at a Black family's home is protected by the First Amendment (Scalia 1992). So too, intensifying inequalities within the US political economy stem from financial and monetary policies of the Federal Reserve Bank (Petrou 2021). Then, there is the police-state USA Patriot Act and the global 'Terror Wars' of the US military, its President and Congress (Kellner 2003). This is Imperial America; extensively documented by Bevins (2020), Stone and Kuznik (2019), Robinson (2020), Harcourt (2018), Vine (2015), and Greene (1970).

The lesson here is that, when teaching and otherwise engaged politically, we must use the system as our unit of analysis, not the individual. Without a sufficient negation of finance capital by an egalitarian, multicultural, ecosocialist counteroffensive (Reitz 2019), that which occurred as tragedy in Germany in the 1930s may return as farce in the 2030s in the USA and around the globe. 


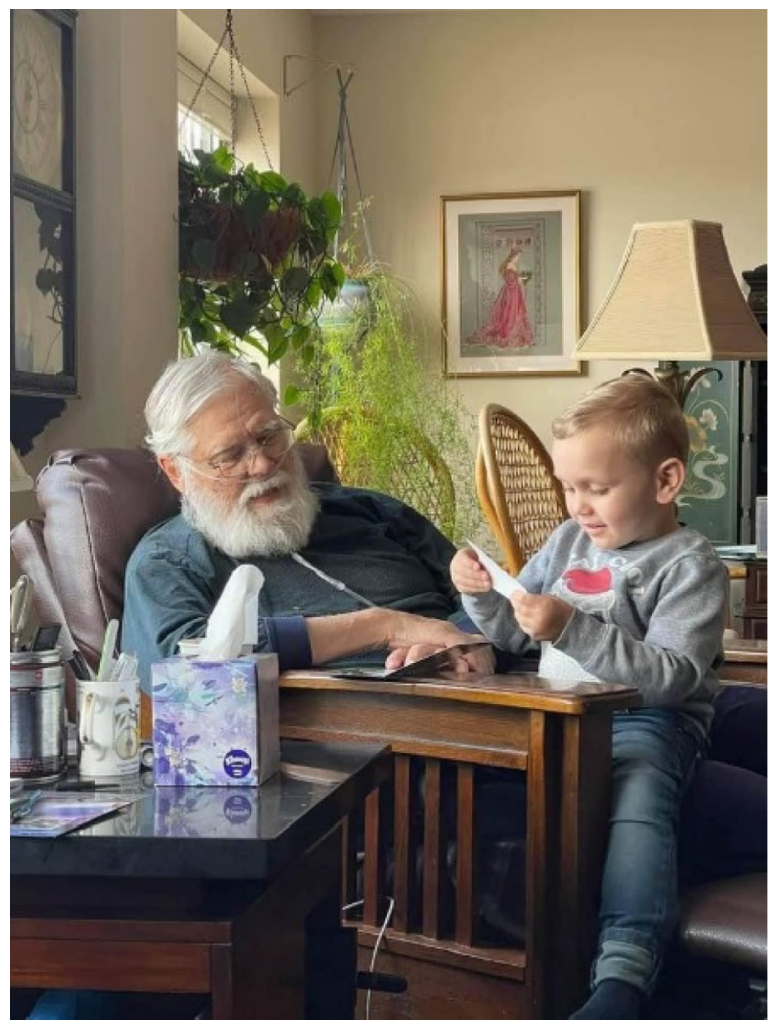

Fig. 8 [New figure.] 6 March 2021, in recovery at home

\section{One Year of Home Quarantine and Distance Education}

Peter Mozelius, Stockholm, Sweden, 20 March

[Updated biography.] Peter Mozelius is a senior lecturer and researcher at the Mid Sweden University in Östersund, Sweden. After the pandemic broke loose in March 2020, Peter has worked by distance, from his home quarantined in Stockholm for more than a year now.

Around 1 year ago, I attended a conference on technology enhanced learning in Valencia, Spain. On the last day of the conference, there were several reports on 
Covid-19 cases in Valencia, and also some changes in the conference routines. When my return flight landed in Stockholm, the first pandemic wave had started, and I decided to stay in Stockholm and not to take the train up to the Mid Sweden University campus in Östersund. Today, 1 year later, I am still stuck in home quarantine with technology-enhanced teaching, learning, and working as my everyday routine.

I still work for the same department at the same university, and with the same courses, supervision and projects as 1 year ago. In several aspects, it has been a quite boring year, but looking at outcomes and research publications, it has been a bit better than average. My blended learning programming courses, supervision, and project work have been adapted to fully distance learning. This has been a bit time consuming, but not too difficult or stressful, since I have 20 years of experience in technology enhanced learning and distance work. My guess is also that at a department of computer and system science, online teaching, learning, and research are easier to handle than in other domains.

Our university's strong recommendation is to work from home until the pandemic ceases: at the moment, on-campus activities are few. Without any special support or reward from the university, most staff have coped well with the challenge of distance work. We are supposed to work full-time, but unlike workers in some private companies, university employees have not received any subsidiaries for ergonomic furniture and extra computer equipment. For my own home office, I have bought an additional large screen, a printer with a built-in scanner, and a new comfortable chair (see Fig. 9).

The pandemic has not caused too much trouble for my family. We have the luxury to live in a $140-\mathrm{m}^{2}$ duplex apartment, which allows three persons to simultaneously participate in different online meetings without disturbing each other. Considering the social aspect, it has been a year of isolation where social events have been replaced with watching TV series, reading books, playing online games, and a lot of cooking. There are some new bad habits, like too much screen time, but also new good habits worth keeping in the post-pandemic new normality. Some examples of new good habits are more of physical exercise, more efficient staff meetings, and the development of new online collaboration activities in my courses. 


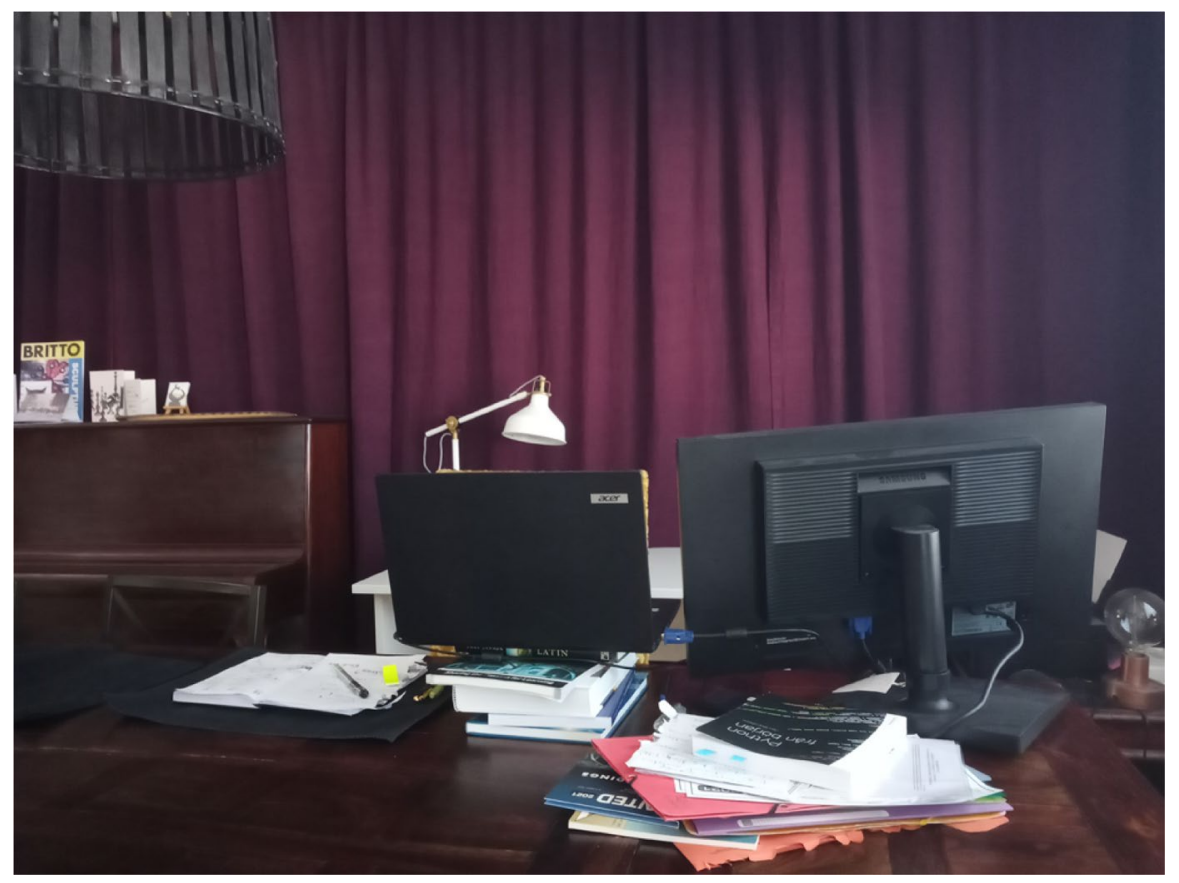

Fig. 9 [New figure.] My home workplace

\section{Pandemic: 1 Year Later}

Harry G. Nejad, British Columbia, Canada, 22 March

[Updated biography.] Harry G. Nejad, Ph.D., MACP (Master of Arts in Counselling Psychology), BA (Liberal Studies) and BA (Arts and Sciences), is a Canadian citizen and a quantitative research analyst and investigator; an associate professor in Behavioural Sciences and Forensic Psychology at O. P. Jindal Global University in India; a lecturer in psychology at Wenzhou-Kean University; an online university lecturer at the University of The People; a program and curricula examiner with the International Baccalaureate (IB), England; and was an academic-Level Lecturer/ Tutor and research assistant at the Faculty of Education and Social Work, at the 
University of Sydney, and program coordinator and lecturer at the Faculty of Behavioural Sciences, at the University of Notre Dame University, Sydney, Australia. He is an educational/psychological researcher and an educator.

$* * *$

One year later, in British Columbia, Canada, I just count my blessings that I left India in mid-June and returned to Canada, even though I had to pay almost twice as much for my airfare. It was money well spent.

During the lockdown months in India and due to the host university and community's lack of care and accountabilities, my health was seriously impaired and compromised. I suffered physically, mentally, and emotionally. Thanks to Covid19 , the Indian government's unrealistic, irresponsible, and poor-managed programming, and the university and the community I was placed in, I became a pre-diabetic patient. The government officials and the university governing personnel did not even bother to think about the fresh foreigners in their country who had no idea how to get their necessities during a restricted and poorly thought-out lockdown regime that lasted for over 3 months.

I became a pre-diabetic patient because, within the $35-\mathrm{km}$ radius, there were no real or clean stores to buy healthy essential groceries. I had to rely on a little 'momand-pop' rundown shop with only a few unsanitary vegetable items, white bread, rice (a no-no for diabetic patients), eggs (just one kind), and some expired snacks. When I asked about options for healthy grocery shopping, I was presented with ridicule and mockery. Contrary to the Indian government's propaganda that Covid-19 was being handled exceptionally well, I was told that 'people are dying here every day,' and 'the Indians eat these sorts of food every day.'

The dire situation was made even worse with the presence and attacks of stray dogs in the community and my trips from home to the little corner shop. Those dogs would attack me for what I had purchased since they were also hungry, which caused me stress and anxiety. When I complained about their behavior, I was told that dogs have rights and that the Indian law does not permit displacement or 'shooshing' them. Since they are so concerned with 'animal rights,' I wondered about my 'human rights.'

I am happy to be back home in Canada. Although I still teach at the same university in India, I am grateful that we all teach online and hope things will remain like that for much longer. Teaching online has its shortcomings, e.g., the work and family-life blurred boundaries. The family members expect you to be involved in the household activities though they try to be considerate and understanding. Conversely, the workplace believes you are at home and are not engaged in 'real work' even though you are, maybe even more than before. Considering my given situation; however, I am happy to be at home. 


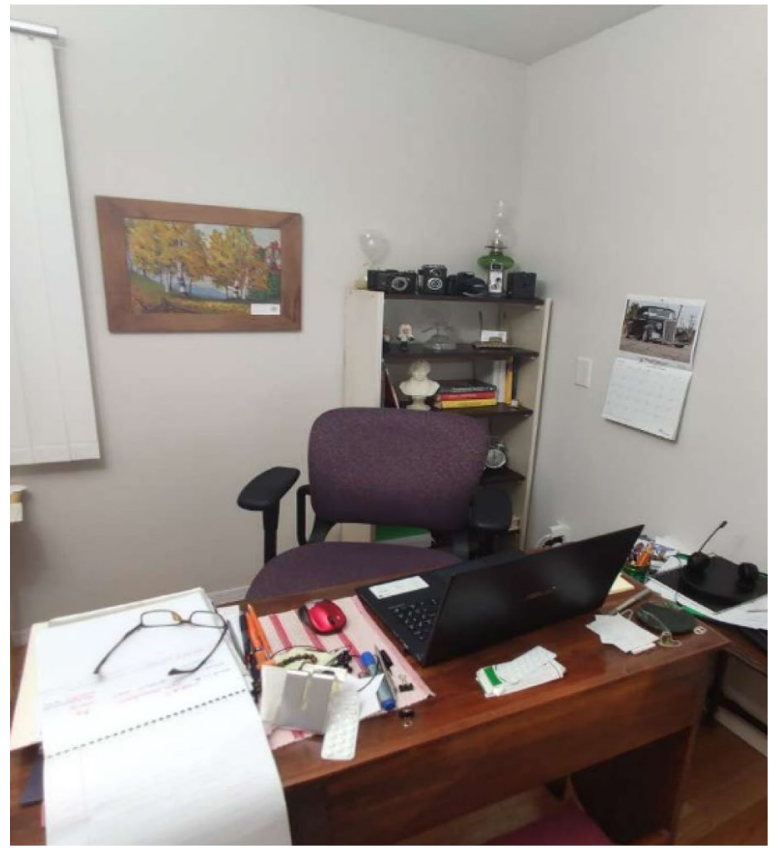

Fig. 10 [New figure.] Harry's workplace at home, happy to be here

\section{You Are Muted}

Ana Fuentes-Martinez, Lund, Sweden, 23 March

[Unchanged biography.] Ana Fuentes-Martinez was born in A Coruña, Spain, in 1975. She is a mathematics and computer programming teacher at Katedralskolan in Lund and a researcher at University West, Sweden. Her investigations concern integrating mathematics and programming from the perspective of teacher professional development.

How long does it take to form a new habit? This last year surely gave most of us a taste of this experience. Still, it is hard to believe that so much time has passed and so little has changed in the quotidian life of a researcher. I am still in Lund, working at the same university, writing and teaching from my walk-in closet. The world 
outside is fast-paced but I do not seem to be a part of it. New vaccines, new treatments, new mutations, new distancing policies, new borders, new US president, new protests and new protesters, a volcano eruption. But here at home, the same five people, slowly learning to know each other, and learning to learn in a new distanced way.

Reading my testimony from last year, once again, the word lockdown seems misplaced. Initially, I wrote shutdown - in my head, it was just schools that were at risk of being forced to close. By the time the editors suggested lockdown, the concept was so pervasive that I did not object. A year later, Sweden still has not had a lockdown worth that name. Schools, shops, and restaurants have remained open, and domestic traveling has never been a problem. However, working from home is the new normal, and we need a special permit to spend a day in the university office or to gather the students for any on-campus activity.

I have learned new teaching techniques to balance the focus on the presentation slides in favor of interaction and discussion, but I still have not figured out a good way of interacting with my students individually without having them feeling singled out, the way I used to do while roaming around in the classroom.

Coincidentally, new accessibility guidelines were to be implemented in Swedish universities this same year along with the digitalizing of teaching practices. Video recordings and other asynchronous material that is shared in the learning platform are now expected to include captions, a transcript, and an audio description of the content. While we are not all the way there yet in practice, the new directives have caused a second wave of resentment among teachers who feel that the timing was unfortunate considering the rapid adjustment to online teaching that the pandemic had triggered.

And then, there are these online conferences. I miss on-site teaching but, oh, I miss on-site conferencing! Now, we do our best: present our papers, choose among parallel sessions, prepare questions, and even mingle a bit on the chat column, but 2 days of online conferencing is among the most draining academic experiences I've endured. Meeting peers at conference venues was not only socially rewarding but an excellent form of gaining new insights and establishing new contacts and I hope we are back on track soon.

I am nevertheless grateful for what 2020 has granted me. It became a muchneeded quiet year in which time for reflection and writing was generously allowed and proved essential for my thesis. I have traveled a bit less and I have met fewer new people, but I have been healthier than ever and I got to be involved in my kids' schooling in a deeper and more gratifying way. There is a substantial difference between coming home tired and asking whether they have any homework and now being there, after each class or meeting and exchanging a few words on the subject. 


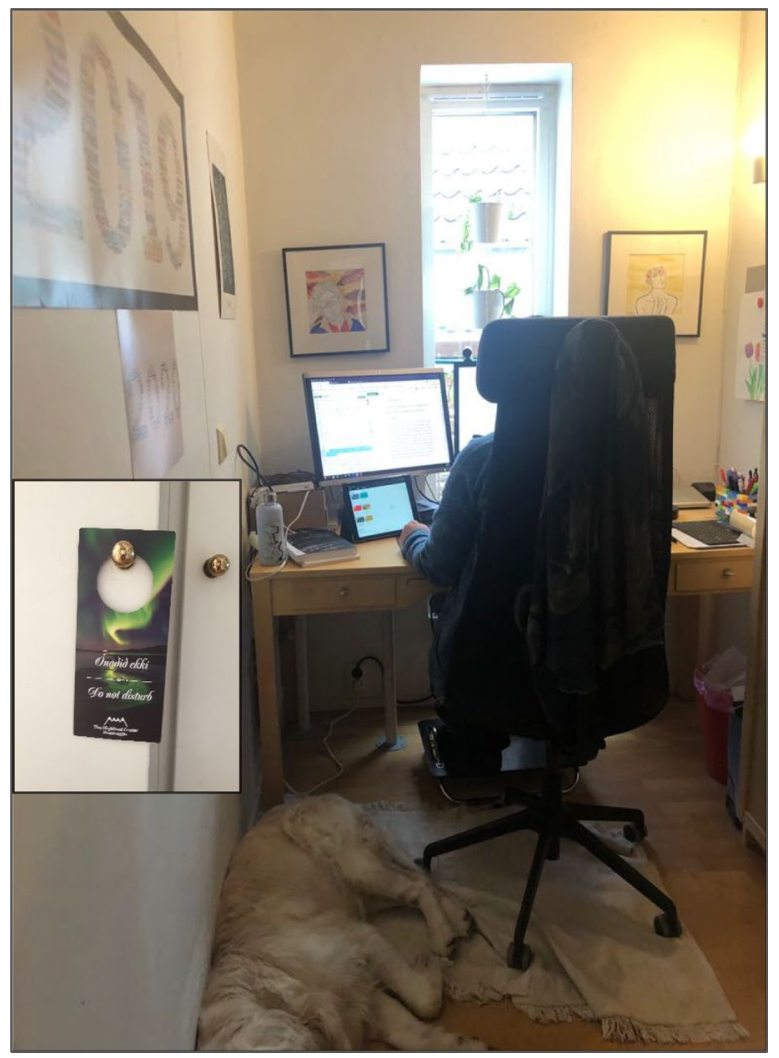

Fig. 11 [New figure.] My workplace in the former walk-in closet has been slightly updated. The fixed window served well as a natural light source, but ventilation was poor, and a trickle vent needed to be installed. The screen area has increased with two new displays to compensate for the lack of paper printing facilities. However, the most decisive upgrade was the do-not-disturb sign hanging on the doorknob. It indicates to the rest of the family whether I am up for a coffee break right then. Yet, the dog cannot read 


\section{A Different Direction}

\section{Janine Aldous Arantes, Melbourne, Australia, 25 March}

[Updated biography.] Janine Aldous Arantes is a Research Fellow with the Institute of Sustainable Industries and Liveable Cities (ISILC) and an Academic with the College of Arts and Education at Victoria University, Australia. Janine is 46 years old and lives in Melbourne, Australia, with her husband, two sons, and a Kelpie.

I write this testimony in our home in Melbourne, Australia. In 2020, the state of Victoria was in many ways the epicenter of Australia's second wave, accounting for roughly $91 \%$ of the state's 905 Covid-related deaths. It was during this lockdown that I submitted my Ph.D. and started full time work as an academic. The second lockdown lasted 111 days. Stressing how very grateful I am to have been able to have paid work, kept a roof over our heads, and safely educated my children from home-I begin by acknowledging my privilege. The lockdown for many, many others was very, very different.

The major change during this time was the hours I worked. To write my Ph.D. thesis and homeschool my children, I started writing at 11 p.m. and finished at 5 a.m. I then had time with my family, home schooled my children until 3 p.m., and then went back to bed around 4 p.m. I could juggle my hours and work remotely. After submitting my Ph.D., I began working full time, as an academic with Victoria University. Victoria University adopted a suite of offerings, delivered via remote synchronous classes; again allowing me to be flexible in terms of caring for children, whilst maintaining full time employment. My hours reverted back to 'normal' academic hours after I submitted my Ph.D., and this is how I currently spend my days. Our Covid-safe return to campus is expected in the coming weeks.

I finish by flagging that Australia is relatively Covid-free. And I am aware of the gross dichotomy between Australia and many other places in the world. We have family in Brazil. Brazil is currently experiencing intensive care unit occupancy rates of up to $96 \%$ and 2 days ago recorded 3251 deaths in a single day (Sousa 2021). This dichotomy has changed my thinking. In my previous contribution, I wrote about the Birth of a Data-Life Paradox, which is largely correct, as we have arguably witnessed the largest, relatively unregulated and forced collection of personal data in history. Undoubtedly, there will be huge impacts for us.

However, my thinking about what is important has changed. Life is so fragile-I am so privileged. And whether data is collected, whether privacy infringements are apparent or digital profiling occurs; my concerns have changed. Life and the power of simply being alive have taken priority. Slowly, but surely, I know the situation will improve in Brazil and around the world, albeit taking great sacrifice with it. As such I end, wishing that we all never had to experience such detriment - and that a new generation, aware of the need to collaborate globally on these and other issues, will emerge and take us all, in a different direction. 


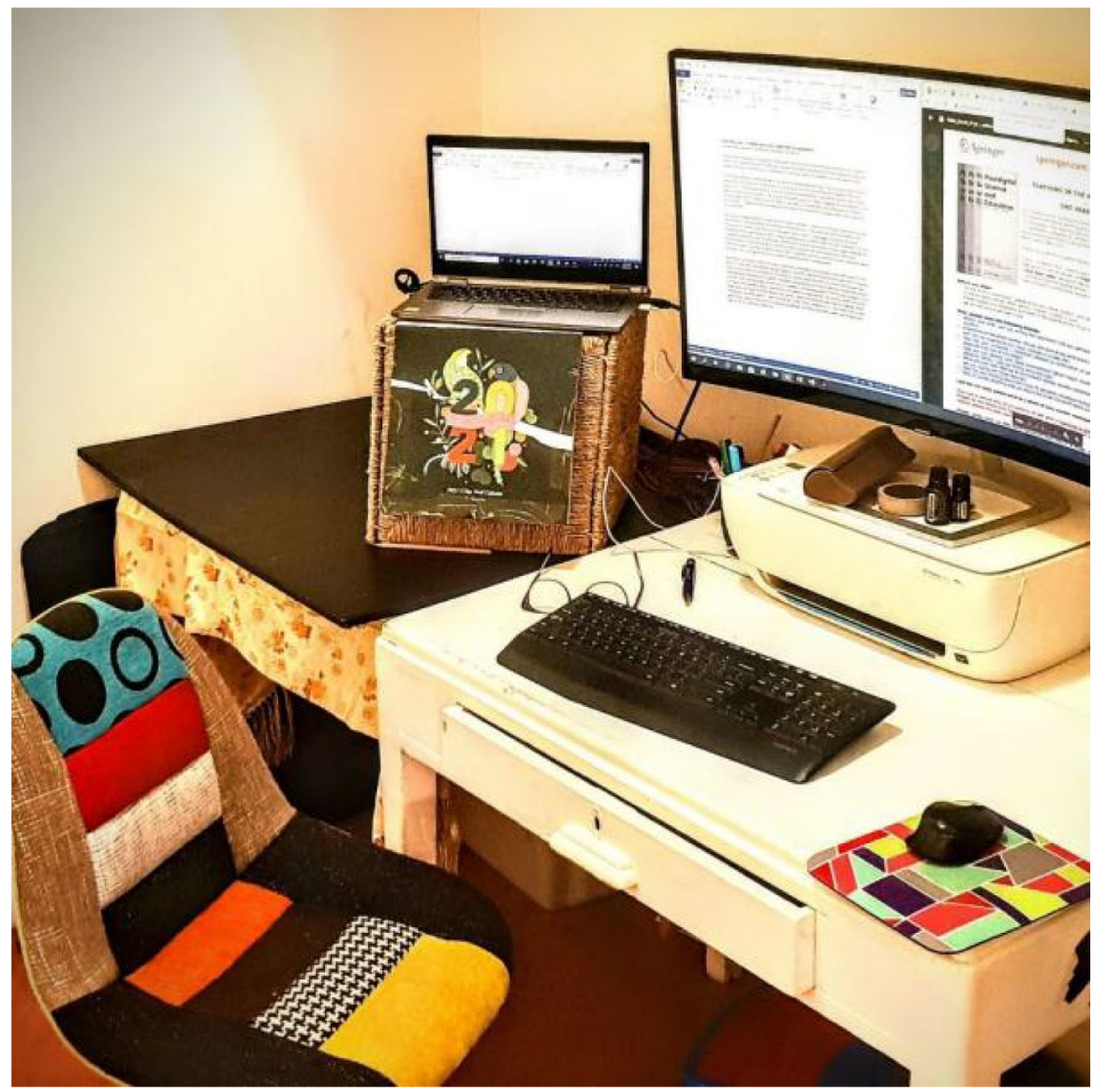

Fig. 12 [New figure.] We moved to a new house and my new workplace is in the walk-in closet. There is one window above eye height that provides some natural light, but the ventilation is poor. A big change is that my office is adjacent to the only bathroom. This means that shower time noise is shared with work each day! As we will move to our new home in another 6 months, my office is using temporary furniture that could fit into this space. I use a foldable card table and a desk from my childhood as my office furniture, coupled with a chair from the kitchen

\section{Steps Forward, Steps Backward}

Liz Jackson, Hong Kong, China, 26 March

[Updated biography.] Liz Jackson is Professor of International Education at the Education University of Hong Kong. She is the former Director of the Comparative Education Research Centre and Past President of the Philosophy of Education Society of Australasia. Her recent books include Contesting Education and Identity 
in Hong Kong (2021), Beyond Virtue: The Politics of Educating Emotions (2020), Educational Assessment in Tanzania: A Sociocultural Perspective (2020), and Questioning Allegiance: Resituating Civic Education (2019).

$* * *$

Moving house and changing jobs are supposed to be among the most stressful events in a person's life. However, in the past year, these were antidotes to the pressures I faced, since the Hong Kong anti-National Security Law protests of 2019, and Covid19, which hit last January. When I look back to that time, I was in a desperate place: drained of adrenaline and trapped in a tiny (by international standards) flat, due first to the political upheaval and then to social distancing requirements. The new, unpleasant 'normal' in many parts of the world was already my normal (Jandrić et al. 2020; Jackson 2020). One year on, we as educators here in Hong Kong are not sure whether and how to adapt-to accept this normal, or stay frustrated about ongoing challenges.

Last spring, the flat I shared with my boyfriend became far too small. Hong Kong flats are not for staying in. Hong Kong people eat out; it is what we do. Or what 'we did'. Fifty-five floors up, we had great views of Victoria Peak and the sea, but no balcony. When we learned that a friend we recently saw contracted Covid-19, we stayed indoors for a few weeks. After that, we had to move. Outdoor space, and space in general, was high on our list - to have people over, something Hong Kong people never did, and to work in different parts of the flat, besides the living room and the bedroom.

We found a great new spot in May-over three times the space, with a large balcony and porch. In an older building on the ground floor, we began a more traditional lifestyle slightly outside the city center: perfect for get-togethers, and sitting at home for days, weeks, months, and years. In June, we got two kittens, something unimaginable for us in the past as we, typical Hong Kong people, used to travel abroad at least once per month, for work or short breaks. Laat ('spicy') and Geng ('fearful') are very spoiled. They know nothing of Covid-19 or the Chinese Communist Party.

Over the summer, I got a new job. I was hired as Professor at the Education University of Hong Kong, an institution I have always admired, but rarely visited, since it was on the other side of Hong Kong, over an hour away. It turns out that many colleagues normally work from home due to its remoteness. I was also attracted to working at a university that was not central within the recent protest politics. Today, political discussions continue at the Education University, while they have become deeply strained at the other major universities. To my great relief, my teaching load decreased with the promotion, giving me space to adjust to teaching online, which academics here in Hong Kong continue to do.

A new job, a new home, new family members... It seemed almost perfect. A few weeks into our new life, my boyfriend got an important call: Due to downsizing in the Hong Kong financial industry, he and most of his colleagues were being retrenched. Getting a new job has not been easy since. It seems that no one wants to hire, and not on full salaries, until Hong Kong society stabilizes. Who knows when that will be? 
Meanwhile, the world continues to shift and change. From Hong Kong, we all hope things can improve, politically, socially, and economically, going beyond Covid-19.

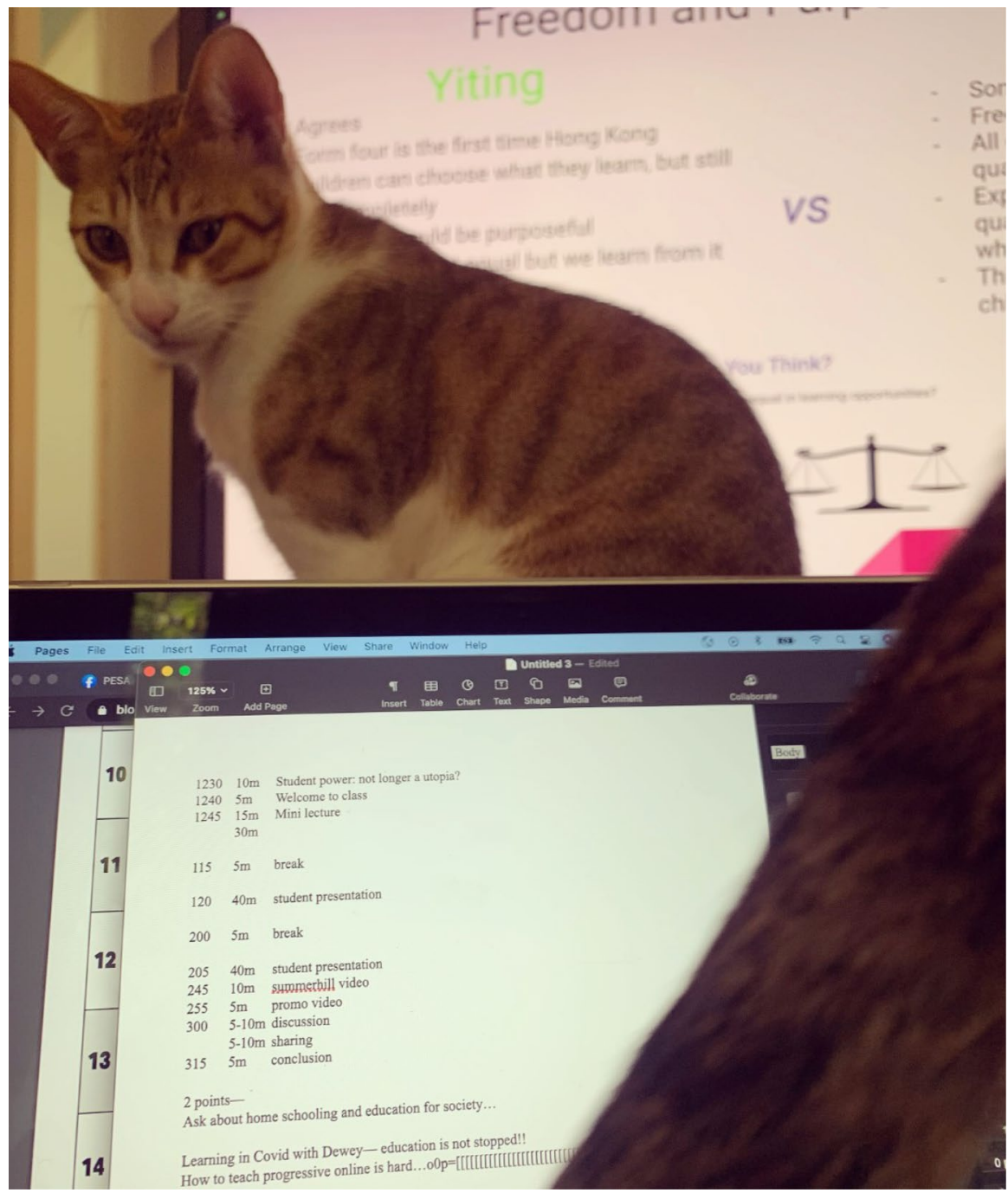

Fig. 13 [New figure.] Teaching online with help from Geng and Laat 


\section{The Life of a Swedish Doctoral Student-A Year of Covid-19}

Ulrika Gustafsson, Umeå, Sweden, 29 March

[Unchanged biography.] Ulrika Gustafsson is a doctoral student at the University of Umeå, Department of Applied Educational Science, Sweden. She is 47 years old and lives in Umeå, Sweden, with her partner and their two children.

$* * *$

Being a Ph.D. student working from home for a year, I have now managed to install a permanent desk in the hallway. The university generously supplied a docking station, screen, and keyboard. I also found a broken chair which I repaired. In comparison to my initial home-working conditions, I now sit quite comfortably. In my third year of doctoral studies, much of my everyday work is reading and writing, so an ergonomic workplace is much appreciated.

Last spring, after the first turbulent weeks of the Covid-19 pandemic, things have settled down. By summer, the university had adjusted to new everyday routines. Social distancing, hand washing, Zoom meetings, and silent university corridors. The urgency of the pandemic faded away in a new normal. Against recommendations to work from home, some university employees and many Ph.D. students, myself included, went back to our separate offices. Working at the distance yet still at the same workplace seemed reasonable or comforting. I don't know. Around Christmas, when the second wave of the pandemic hit the region, we were yet again urged to stay at home. Moreover, each month, we were asked to report to what extent we have resided in our workplaces, and why. This scared most of us off. So here I am, at home again.

I carry on with my $\mathrm{Ph} . \mathrm{D}$. studies, reading and writing articles, taking courses (now transferred online). Despite the loss of seminars, conferences, and face-to-face meetings, the university has not offered Ph.D. students any particular support. This has been stressed by the student union, for which I am a local doctoral committee member. There are worries, of course, mostly about finishing on time.

Still, I do feel hopeful that good things may come out of this crisis. One positive example could be the possibility to attend defenses at other universities and listen to worldwide senior researchers' online presentations. For me, this has contributed to valuable updates within my research and new ideas on what goals I should set for myself. Another example could be an increasing prominence of discussions about the global environmental crisis asking how the academic community could become more environmentally sensitive, for example by 'responsible' travelling. A third and final example could be how people can work together constructively within a crisis. I think we all need to repeatedly remind ourselves that people are nice, brilliant, and amazing!

In these unusual times, it is strange to experience how fast a year may pass and at the same time feel like an eternity. I long for meeting family and friends, throwing birthday parties, visiting concerts, working at the university, listening to the soaring corridors of ideas and achievements. It should not take too long now. 


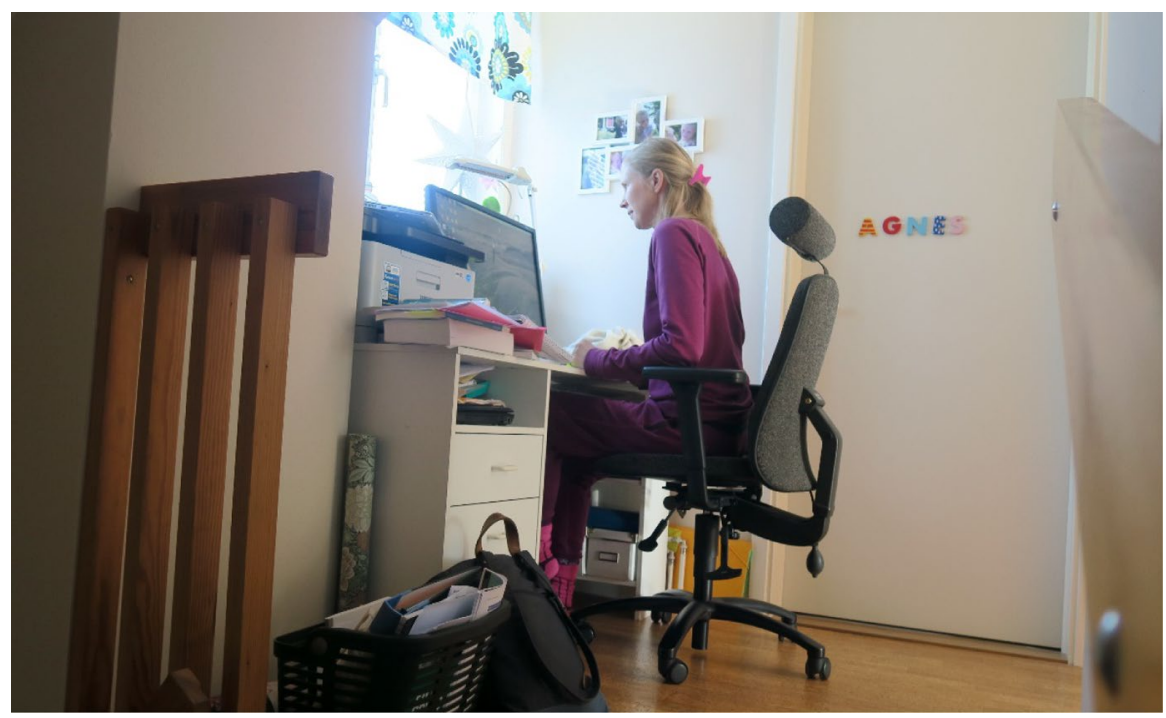

Fig. 14 [New figure.] I have arranged a small workplace in the upstairs hall. Most books are piled up at my feet

\section{Pivoting-1 Year On}

Sandra Abegglen, Calgary, Canada, Tom Burns, London, UK, Sandra Sinfield, London, UK, 31 March 2021

[Updated biographies.] Sandra Sinfield, Sandra Abegglen, and Tom Burns have worked and taught together at London Metropolitan University, London, UK, for many years with a special focus on praxes that ignite curiosity, harness creativity, and develop power and voice. Sandra A. left LondonMet in 2018 and is now based at the University of Calgary, Canada, where she works on research projects that look at learning and teaching in the (online) design studio. Sandra S. and Tom B. are still based at LondonMet. They teach on the PGCert and MALTHE courses for academic staff, which has expanded to developing 'education for social justice' for the whole of the University.

We are still situated at the same institutions: 'a post-1992 university in central London (UK) — with a diverse student and staff body — and a North American university (Calgary, Alberta) — with five campuses and over 33,000 students' (although Sandra A. now also teaches remotely in the UK - and while she loves her students attending meetings at three in the morning is far from pleasurable). The content of our work has stayed the same—-staff development, creativity, and inclusion, but the workload 
has increased, with a new, stronger focus on online education, digital pedagogy, and learning technology. As in the early lockdown, the technology is still giving us headaches: the loss of signal 15 min before assessed student presentations was hardly ideal. We write (and laugh) together, still, and this sustains us for sure in these unprecedented times.

The emergency measure of moving courses online in March 2020 is now the default, with all of us still working/teaching remotely since that day (although there is talk about a return to in-person learning in September 2021). The new normal has definitely merged the private and professional which is a struggle, more so for those of us with children who have also been working from home and with onerous study commitments requiring parental hands-on involvement. The 8 to 5 workday has disappeared: our private and personal lives directly intersect with our work. Home is workplace; the workplace is home. Our students engage in this struggle also-and for those of us who have staff-as-students, we see the emotional and workload burdens impinging as they juggle heavy teaching loads, family issues and illnessesand the family issues and illnesses of their own students.

There are definitely positives-we absolutely do not miss the many hours per week lost to commuting and moving around a large campus. We have attended many, many meetings - an inexhaustible supply of meetings, meetings that if attended in person could very well have been unbearable - thank the buffer of the screen.

But we do miss our colleagues and our students. When we are not teaching, we have an open door policy on our office(s), welcoming visitors with tea and biscuits - offering a humane, friendly space — contingent and emergent — and if lunch is the only thing to emerge-that is fine-but so much has sprung from these chance encounters, those important 'backstage conversations'. Reaching out to make contact with others is much more conscious now and requires a deliberate effort. Yet, we have forged new connections and joined new, creative initiatives that make use of the possibilities the digital presents (e.g. \#Take ${ }^{6}$ and TALON ${ }^{7}$-and also \#creativeHE ${ }^{8}$ ).

However, our fear a year ago has borne fruit: with tech companies successfully launching software and tools that manage and surveille, both students and staff. The government's push to outsource (billions given to inexperienced entrepreneurs to run key aspects of the pandemic response-badly), encroaching into educational space with 'catch up' money not given directly to schools but to private providers to offer tutorial support at a profit-for example, paying child labor dollars to coach English school children. The Covid-exacerbated power and reach of this outsourced, 'platform capitalism' into education is certainly palpable, at both ends of the globe (Srnicek 2016).

It definitely takes time, a lot of time, to develop new stories of hope-so we are in for the long haul for sure. Both our Universities are evolving new 'blended learning'

\footnotetext{
6 See https://lmutake5.wordpress.com/. Accessed 1 June 2021.

7 See https://taloncloud.ca/. Accessed 1 June 2021.

8 See https://creativehecommunity.wordpress.com/. Accessed 1 June 2021.
} 
strategies - in the hope of learning from our experiences. In the UK, the idea is that all courses offer between 25 and $50 \%$ of tuition online with-whisper it - staff having to offer both face-to-face and online office hours. In Canada, the plan is more tentative but definitely pointing to a mixed delivery of courses with choices for students - and, again, less so for academic staff. So, we reach for a new hope-that these instantly emerging responses will be seen as temporary-and that staff will be allowed to shape and turn them into something more elegant and workable. If the best courses are born digital—not just a transfer of the face-to-face, online-we can start exploring what the potential of a more blended university experience could be-and how it can work for all participants in emancipatory ways.

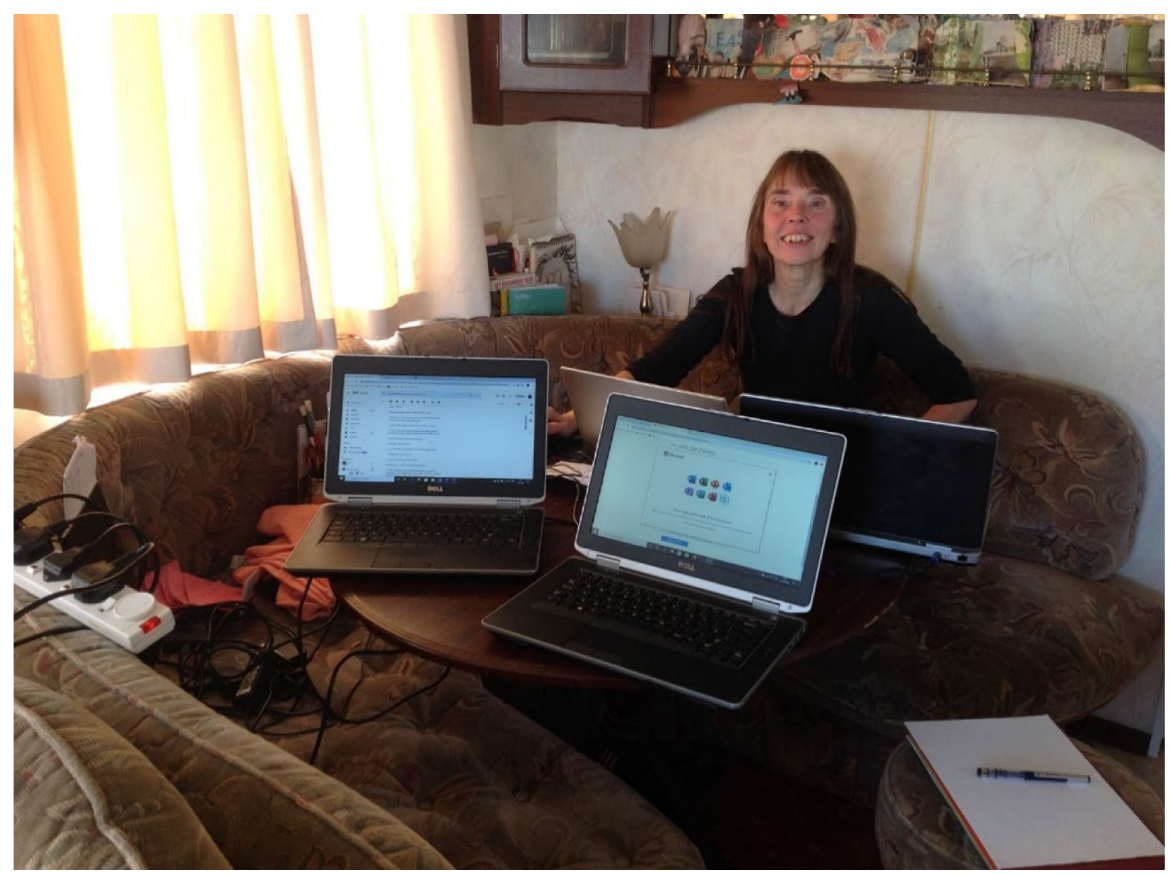

Fig. 15 [New figure.] Sandra S. Juggling laptops and a dongle at the caravan (Sandra S. and Tom had to buy FOUR laptops and one PC to stay on top of the work-not to mention paying for the most expensive Broadband package on this earth.) 


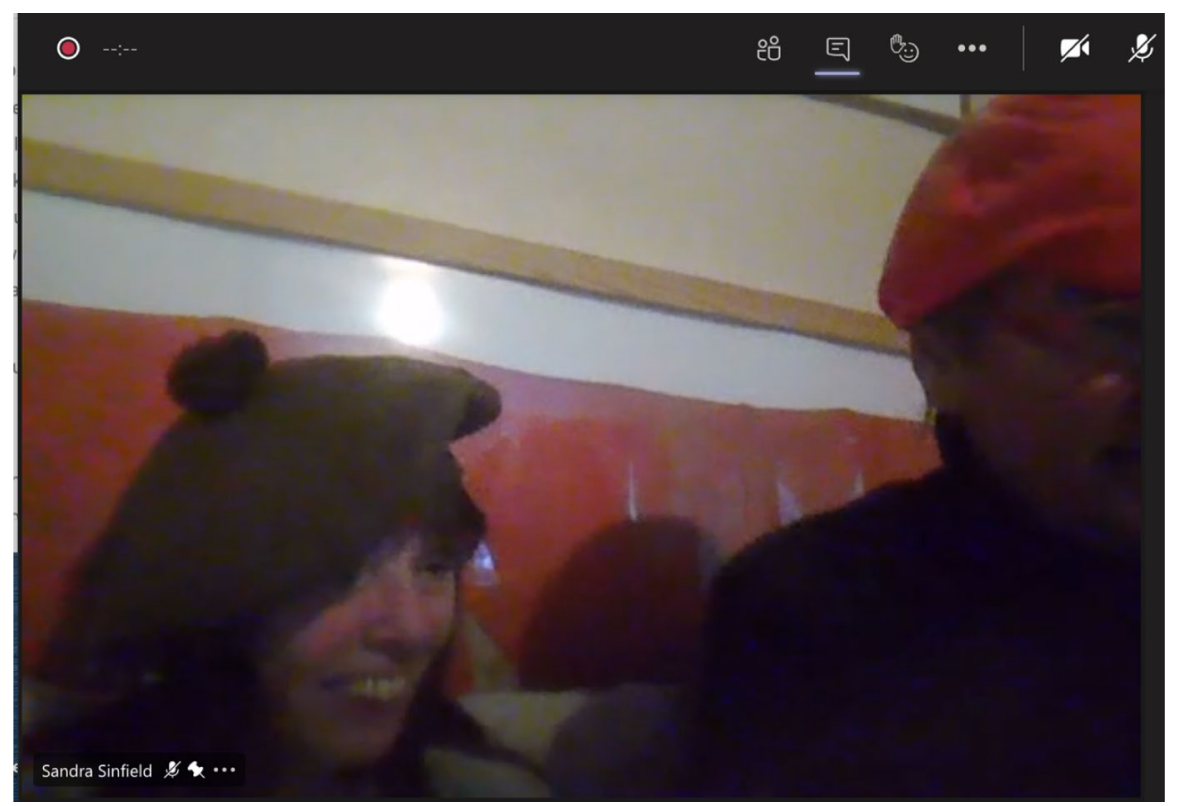

Fig. 16 [New figure.] Tom and Sandra S: Attending a \#creativeHE jam in Microsoft Teams

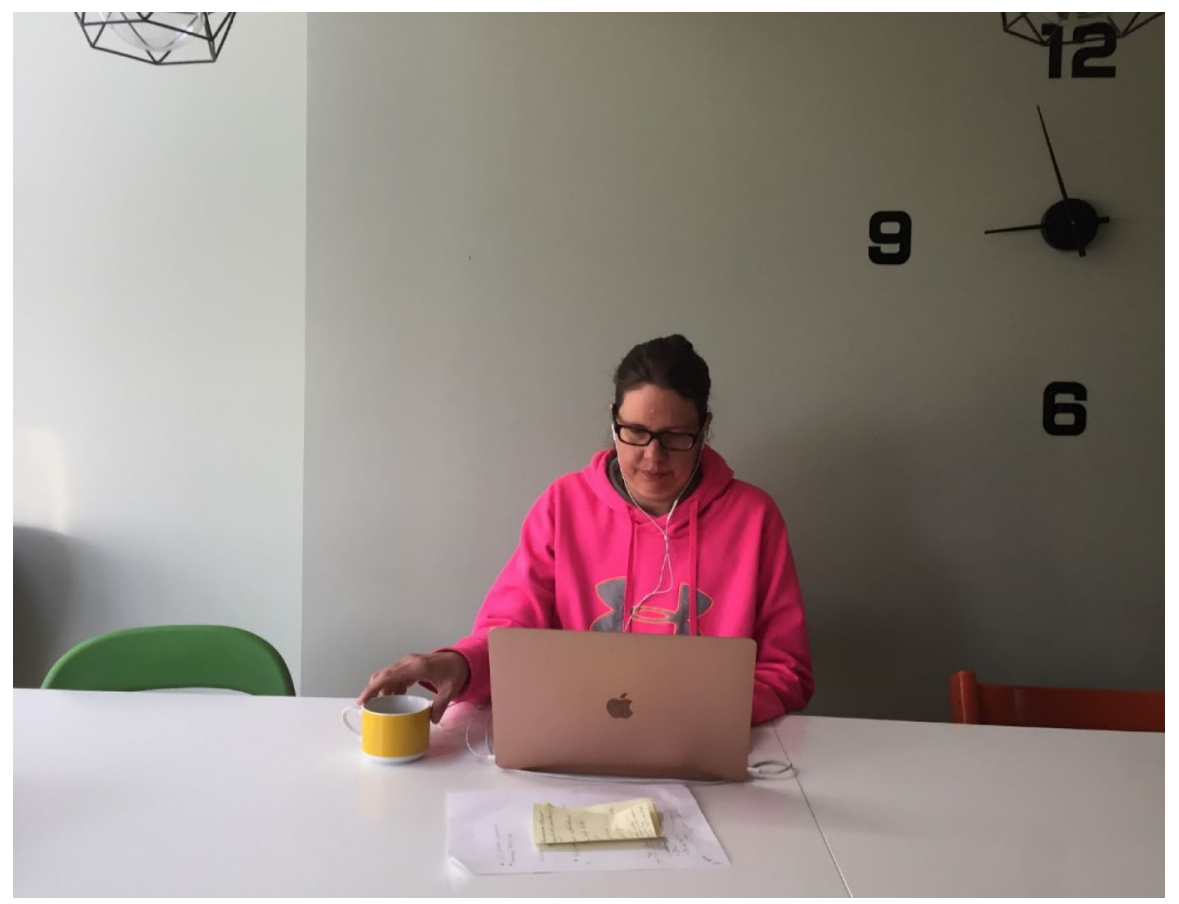

Fig. 17 [New figure.] Sandra A. working from home, skyping with Tom and Sandra S. 


\section{Online Teaching-Ongoing Adjustment and Adaptation}

Michael Hogan, Galway, Ireland, 1 April

[Unchanged biography.] Michael Hogan is a Lecturer at the National University of Ireland, Galway, where he teaches Social Psychology, Developmental Psychology, Positive Psychology, Critical and Collaborative Thinking, and Applied Systems Science Design Methods. Michael is 47 years old and lives in Moycullen, Galway, with his wife, Vicky, also a Lecturer at NUI, Galway, and three children, Siona, Oisin, and Freya.

\section{$* * *$}

Tomorrow is the first day of April 2021, and it is strange to think I have been working from home since 12 March 2020. The roll out of the vaccine is slow, and my view of the pandemic is that great uncertainty still abounds, which compounds the hardship experienced to date. In the Irish context, we have suffered like other countries with the tragedy of the disease and we have had a protracted lockdown that has everyone on edge. We are not sure if we will be back on campus for September. At the same time, work continues apace at the university. We are adapting as best we can, and my bonds of solidarity, friendship, and learning with students have strengthened. I am very proud of my students, and it was a humbling experience to be nominated for an NUI, Galway teaching excellence award during the year and also to be granted a Teaching Hero award by the National Forum for the Enhancement of Teaching and Learning and the Union of Students in Ireland. The nominations and award says more to me about the goodwill of my students than it does about my teaching - they have responded with the effort and engagement required to learn in these difficult circumstances and I have simply guided them as best I canand if there were a mechanism in place, I would give the excellence and hero awards to them.

Reading over my reflection from last year is interesting as it brings to mind the challenges throughout the year. When we left campus on 12 March 2020, I was working that same morning with students in our Collaborative Enquiry and Applied Systems Science class. As I pause briefly to write this reflection, we are preparing for the same class tomorrow, only this time, we are working to build skill in systems modeling and systems design using online and offline tools at our disposal. For example, tomorrow morning, to simulate the large wall space used to generate 'field representations' - a core step in John Warfield's Applied Systems Science method-we will be using MURAL, ${ }^{9}$ an excellent online tool that allows everyone to work simultaneously on the idea wall, akin to what we would do in the classroom on campus.

In some ways, we are lucky as the ecosystem of productive teamwork in relation to online teaching tools and methods has developed well since March 2020, and we are fortunate to have some great support in our University. But it is also challenging and exhausting, and even in the simple case of working with MURAL tomorrow

\footnotetext{
9 See https://www.mural.co/. Accessed 11 June 2021.
} 
morning, we will work today to simulate usage and workflows. No doubt, as in previous weeks, when using different tools (e.g., online argument mapping, interpretative structural modeling, etc.), we will anticipate a slower work rate with additional communication challenges associated with the technology-mediated process. But we will do it, and we will do it well, because we will work at it until we find a good workflow solution. I work closely with Dr. Owen Harney on this module, and we talk about the importance of 'simulation' of workflows for classroom activity - it is hugely important.

In general, my experience of teaching online is that it is labor intensive and somewhat exhausting, but also deeply rewarding when students are learning and doing well. Part of the initial source of exhaustion when first pivoting online derived from the energy needed to speak 'into the void,' that is, with no direct view of students (and particularly for 'pre-recorded' lectures for the large groups of 500+ students). Significant energy was needed to 'simulate' a connection that was physically absent, and there was a somewhat foolish 'evaluation apprehension' for recorded and live lectures.

I decided after my experience last March, in preparations for Semester 1 2020-2021, that teaching and supporting students was the only priority. I anticipated that all my energies would be needed for this task. I decided that research was not a priority but I would work to meet all existing commitments. I was also fortunate to have had the experience of teaching my third first year block afresh in March 2020. Interesting, the block focused on collaboration and teamwork. This gave me a sense of the requirements and trade-offs that would be needed to deliver across five modules in the next academic year. I decided going forward to deliver all my lectures 'live' and also to record them. The 'live' teaching I found more energizing, as it included an opportunity to connect with students before teaching begins, and use of the chat function for large groups $(500+)$ and interactive engagement (e.g., with Mentimeter) for medium-size groups (80-100). For seminar sessions (5-10 students), we could also use 'microphone on' voice engagement in an effective workflow.

Again, my three children have spent most of the year learning online and have done well broadly, and Vicky teaches online like me. Vicky and I have tried to maintain a routine of taking a short pre-lunch walk and talk, and we laugh and solve many problems along the way. But it would be fair to say we have struggled at times. Much like last year, we are still very much in medias res: doing, adapting, working to get 'over the line.' Again, I am not sure where that line is exactly. The world is still in flux and problems abound. But the same strengths sustain us - the wonderful compassion, cooperation, creativity, solidarity, and collective strength all around us every day. We will continue to teach, and we will continue to work hard. 


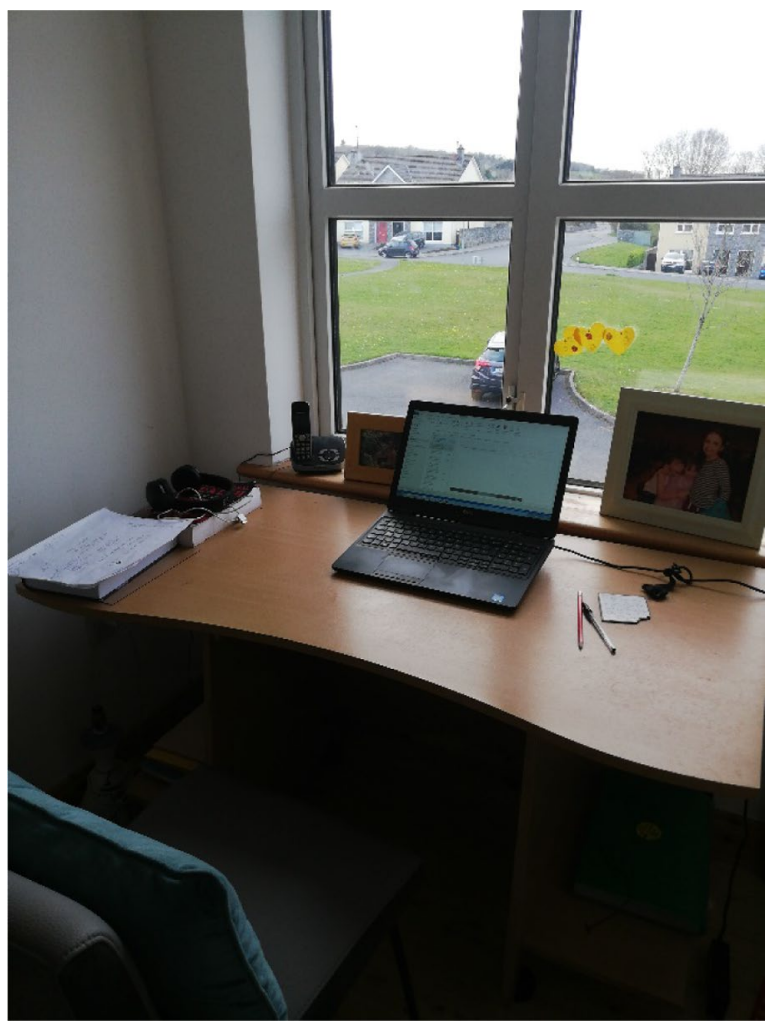

Fig. 18 [Unchanged figure.] This is my workspace in the upstairs box room. It has not changed since last year. Vicky is in the new room downstairs. My eldest daughter, Siona, is above working in the attic; my son, Oisin is two doors down working in his bedroom, and my youngest child, Freya, is now back to the primary school. Of course, this week and next week, they are off on their Easter break

\section{Life in the Time of Covid-19-1 Year Later}

Pallavi Kishore, New Delhi, India, 5 April

[Unchanged biography.] Pallavi Kishore is professor at Jindal Global Law School, O.P. Jindal Global University, Sonipat, India. She lives in New Delhi, India.

$* * *$

I was not expecting this call for contributions a year later. It makes me wonder how many such calls will be issued in the future, given that the pandemic shows no signs of abating. 
I am writing this testimony in my home in New Delhi where I wrote the previous testimony exactly a year ago. I still teach at Jindal Global Law School, some $60 \mathrm{~km}$ away, but now I teach online. My last offline class was on 3 March 2020 and I celebrated its first anniversary this year.

I have been working very hard during the pandemic. By way of example, I am working on some articles as well as a translation, supervising dissertations, and acting as a coordinator (coordinating with fifteen faculty members) for the course that I am teaching. I also attended online courses as a student, reviewed articles, participated in online conferences, directed a blog, and performed administrative tasks such as providing help in finding internships for students and sitting on a committee. In addition, I won a Research Excellence Award from my university. The usual work of teaching, student assessments, and drafting question papers goes on. I have managed my response to the pandemic in such a way that my efficiency and productivity do not go down.

Since the beginning, it was obvious that the pandemic was here to stay but the actual experience of it is challenging since it calls for a lot of care and precaution. The second wave is here and its intensity is much higher. Despite this, I did visit some places in my city. And for about 10 min every day, I try to read things other than work. I also made a few paintings and continued my walking.

This pandemic seems unending and the vaccines have not shown much promise. In any case, with the virus mutating, the vaccines were not destined to show much promise, especially when they have been developed in such a short period of time. So as much as the vaccine sounds like the only option at present, I have still not decided if I want to take it.

Unfortunately, my following the Covid-19 protocol may not protect me if others violate it. Clearly, the violators have high immunity levels or do not have any plans for life. Irrespective of my immunity level, I have many plans for life. However, given the present uncertainty, I am not sure where we are going from here. 


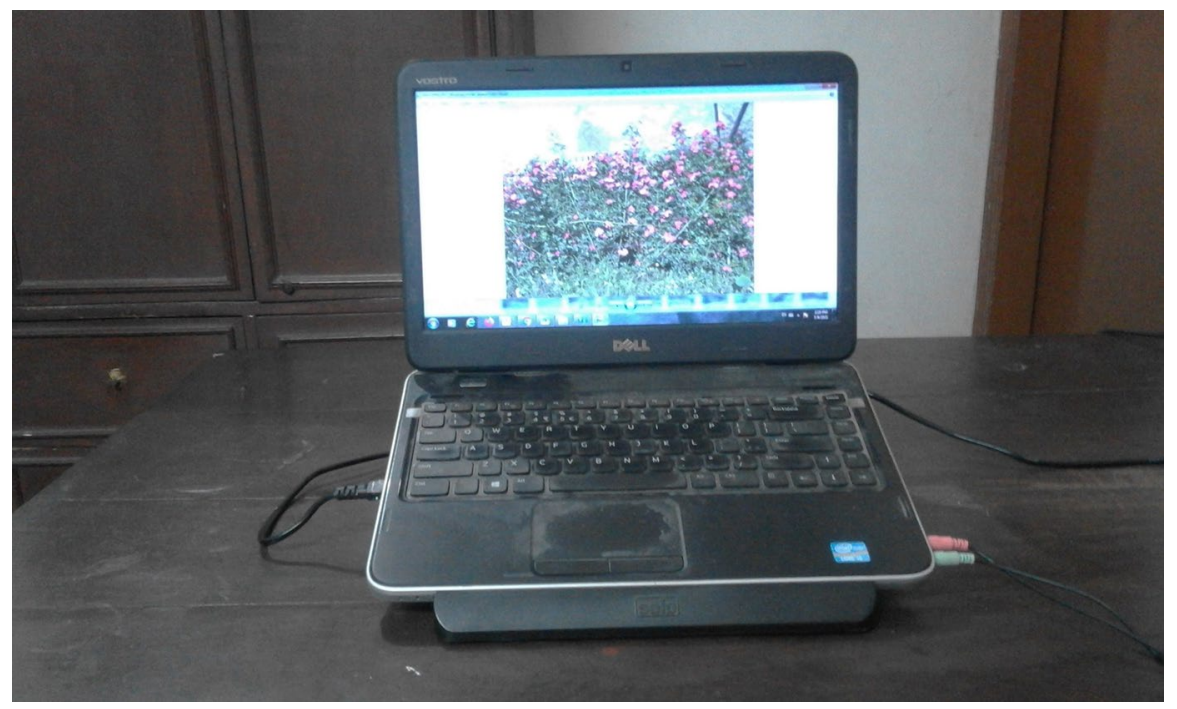

Fig. 19 [New figure.] This is my workspace in my bedroom where I pursue my studies and practice my hobbies

\section{One Year of This and That}

Paul R. Carr, Montréal, Canada, 5 April

[Updated biography.] Paul R. Carr is a Full Professor in the Department of Education at the Université du Québec en Outaouais, Canada, and is also the Chair-holder of the UNESCO Chair in Democracy, Global Citizenship and Transformative Education (DCMÉT).

\section{$* * *$}

I am writing this from my make-shift workstation in our living room, where I was a year ago when this project started. The main difference is that I am collecting more and more objects, products, and sundry items around me, including specialized lighting, a teleprompter, a larger monitor, headsets, microphones, and a range of other stuff that is accumulating like a patch of mushrooms. My real office, which I share with my wife, who is also my colleague, is upstairs but with so many Zoom, Teams, and other meetings, it is difficult to be in the same place because of the feedback and sound quality with two systems working at the same time.

There have been no professional changes except the obvious, that now all teaching, meetings, committees, and the like are online. I have not been to the university in a year but I cannot say that I am any less occupied; on the contrary, the online, no-time-zone Covid-19 environment means that there is now endless accessibility. I very much appreciate the faculty union for its leadership and guidance. There are a lot of updates and changes in relation to teaching, evaluations, meetings, etc. but there still is uncertainty, despite many good-faith efforts, in relation to regulations 
and public health measures. I do not put this on the university, which is trying to interpret government directives and public health information.

Surprisingly, like everyone else, I suppose, the adaptation has been somewhat relatively fluid, although I do miss meeting, seeing and spending time with people, including colleagues and students. After so many years of travelling (and I am increasingly sensitized to the environmental issues therein), it is jarring to abruptly hit the wall of confinement.

I have been relatively productive on the research level, and our team is organizing an international symposium in May 2021, which has really taken over my life in the last few months. Putting together an online event with a hundred presenters from 25 countries in three languages on three platforms related to the three themes of the UNESCO Chair DCMÉT ${ }^{10}$ has really been a wonderful experience, despite all of the challenges. We had originally planned a much more modest, in-person event at my university last year. The up-side is that we can include many voices that would not have been able to participate in the in-person event.

While the technology is enabling us to do many innovative, exciting, and engaging things, and this is continuing to be a learning process, it is also unusual to think of an academic meeting without some of the best parts: chatting between sessions, the receptions, the book fair, the social gatherings, and all of the encounters that help build collaborations and friendships that are sustained over a period of time. Meeting friends year after year at annual conferences is a real pleasure, and I am not convinced that the online world can offer the same level of intimacy, solidarity, and humanity.

My own feelings on this period vary, but the professional situation seems to be relatively stable, productive, and healthy. Being able to get out, for physical activity after a long winter, to restaurants, to cultural events, to family gatherings, to encounters of all kinds, is something that I, and I suppose everyone, am naturally negotiating, and trying to reconcile. At a personal level, I have been writing more poetry, reading things that had fallen off of the radar, taking daily walks through the park next door, and engaging in a few other activities that are of great interest to me, stuff that may not have been as omnipresent before the pandemic. And I have even surprised myself with my sustained interest in cooking and trying to innovate in the kitchen, again perhaps the side effect of too much time at home (Ceviche is among the most startling culinary experiments I have embarked on, inspired by a trip to Peru 3 years ago).

How has my thinking about Covid-19 changed over the last year? I am heartened that there are many acts of kindness and solidarity, and overwhelmed with sadness that there continues to be unbridled militarization in the world, capitalism without a human heart, and the break-neck speed of wealth accumulation among so few people. I am hopeful that the vaccine(s) will enable us to move forward, concerned about notions of 'returning to normal' and really excited about the creativity that is, has been and will continue to be cultivated throughout the pandemic. While I understand the desire to move forward, I am more fully aware that Covid-19 is as much

10 See https://symposium.unesco-dcmet.com/. Accessed 14 May 2021. 
about public health as it is about public politics. I dearly hope that the world will be brought more closely together as a result, that the vaccine will be shared widely, and that we will collectively chart a more socio-environmental course for the betterment of everyone everywhere.

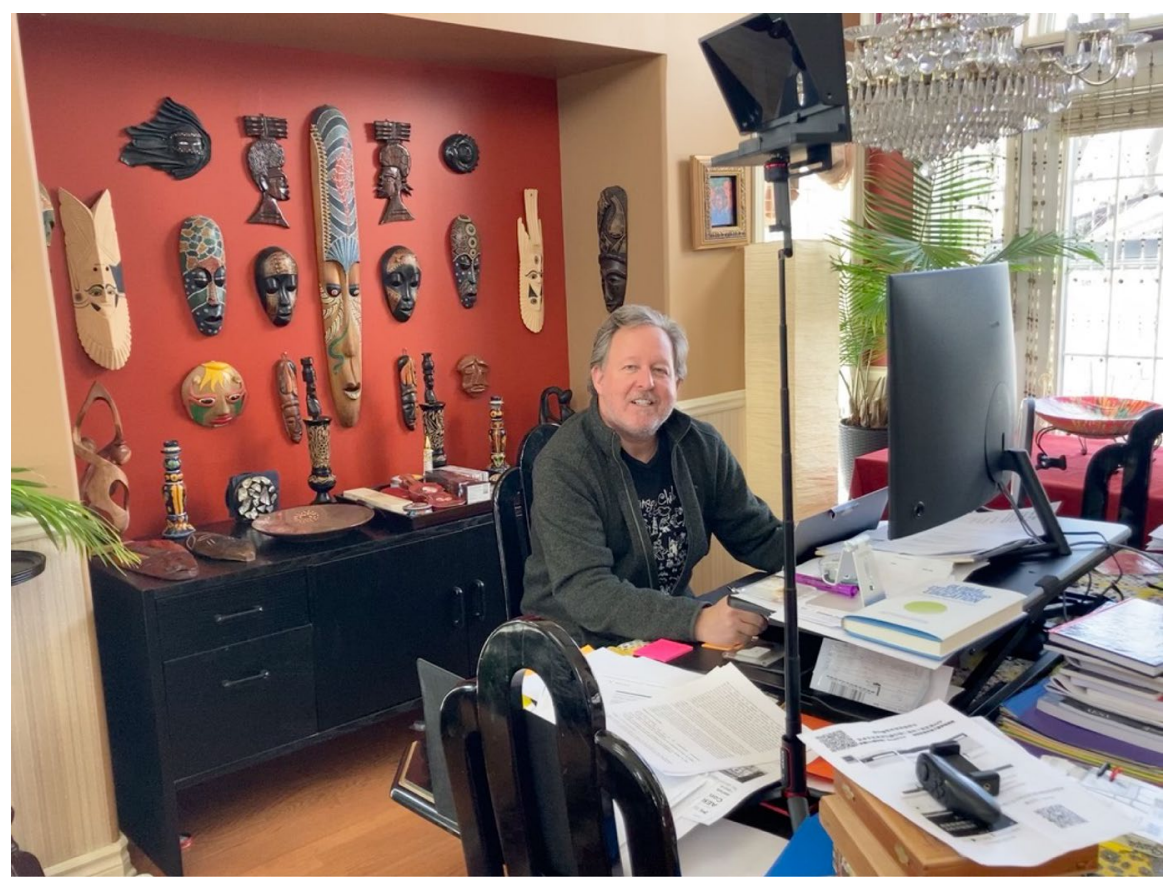

Fig. 20 [New figure.] Home-work or work-home or hanging around, usually in shorts and sandals, to talk to and through my screen

\section{Waiting for a Future}

Ivana Batarelo Kokić, Split, Croatia, 6 April

[Unchanged biography.] Ivana Batarelo Kokić is professor at the University of Split, Faculty of Humanities and Social Sciences, Croatia. Ivana lives in Split, Croatia, with her husband and two children.

$$
* * *
$$

I am writing this years' testimony on the same computer and at the same desk in my study room. During the current academic year, teachers in my institution combined online teaching and teaching in traditional classrooms. At the beginning of the semester, we taught in the classroom, while half of the students followed online lectures from their homes. We selected this approach to lower the number of students 
in the classrooms. The model functioned for a couple of weeks, but as the virus's dynamics have changed, we ended up teaching entirely online.

Although I had significant distance teaching experiences in the past, last year changed my distance education perspective. The initial surprise and wonder about fast adjustment possibilities to distance teaching were at the later stage exchanged with awareness about alternative time management benefits. While having the same teaching load as in previous years, under the new conditions, I had a chance to devote significantly more time to writing. Also, I appreciate a positive experience with the online course that I designed from scratch to fit the distance learning environment. The course design and teaching experience changed some of my preconceptions about higher education students' readiness for online learning. This practice confirmed the idea that students' overall positive attitude relates to the course's interactive design. Another benefit that I noticed is that teacher education students grow to a better understanding of technology's role in education, which is likely related to the fact that rich education technology experiences facilitated the understanding of phenomena.

In these extreme educational and living conditions, it is necessary to think out of the box. In a time of uncertainty, from the scope of strategic planning in education, I wonder about students' prospects at all educational levels and how teachers, administrators, and policymakers support their learning.

While I was at ease with online and hybrid teaching, I cherished that my children still attend lower elementary school grades and that their classes were in a traditional classroom. In general, throughout the year, my main focus was on how the new living conditions influence my children's friendships, education, sports activities, and overall childhood. From that point of view, I believe that we are doing well so far.

All through the year, I felt lucky to have steady job placement and work on most of my work tasks from home. With the new strains of the virus, I feel the increase of suspense. We are keeping the distance and feeling puzzled about the future.

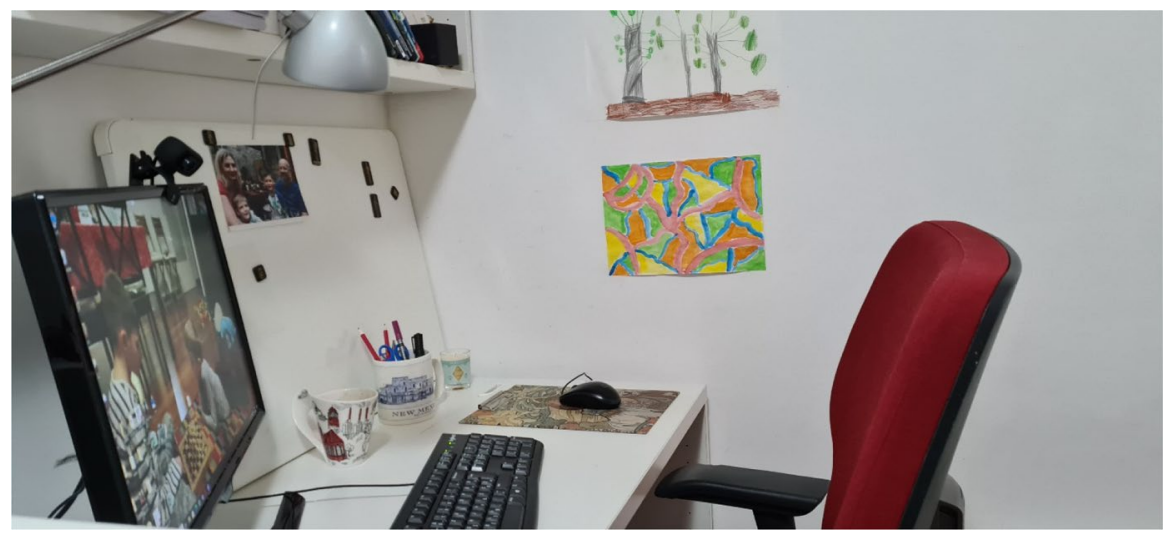

Fig. 21 [New figure.] This picture shows my work desk at home, where I did most of the teaching in the last year 


\section{What Do We Count During a Pandemic? How Do We Count?}

Paul Prinsloo, Pretoria, South Africa, 6 April

[Unchanged biography.] Paul Prinsloo is a Research Professor in Open and Distance Learning in the Department of Business Management at the University of South Africa (UNISA), South Africa. Paul is 62 years old and lives in Pretoria, South Africa, with his partner.

How does one calculate time during a pandemic? It is a year since I shared a personal reflection on Teaching in the age of Covid-19 (Jandrić et al. 2020). What is 'a year'? Reflecting on the last close to 400 days while there is no end in sight for the pandemic, the notion of calculating time during a pandemic in terms of days, or years, suddenly becomes a theoretical exercise, of significance to planners, bureaucrats, politicians, and bankers, to mention but a few.

Looking back since my previous reflection, I do not think firstly in terms of 400 plus days, but of losing a mother and my younger sister, 10 days after each other. How does one bury your dead in a time of a pandemic? How does one say 'farewell?' Due to the country being in lockdown, I could not visit my mom, and I saw her last 2 months before she died. I signed PDF documents authorizing her cremation. I asked the funeral parlor to wrap her in her favorite blanket and add her favorite teddy. There was no farewell. The day she was cremated, I sat in silence. Ten days later, my sister died. On the way to my sister's memorial, I picked up my mom's ashes.

So how does one think about time during a pandemic? Shall we count the days? The number of farewells? The grey mist of depression that settles and does not move for days?

What does one count in a time of a pandemic? Will I count the number of compulsory reports required by the management of my institution to ensure that I remain productive? Should I count the number of email reminders that my submission of reports is late, or that my review report for the journal is late by 2 weeks? Or could I count the number of emails to students, reaching out to them to find out whether they are coping, responding to requests for extensions, sending condolences to students losing mothers, fathers, grandparents, and/or children?

In a higher education sector obsessed with the quantification of research outputs, rankings, and tables, what do we count during a pandemic? How do we count? What do I include in my monthly report on whether I am reaching my research output targets? Could I report that I submitted one article, got notification of rejection of another paper, that I am late with resubmitting yet another, that I lost my mom, that I have not yet done that required review, that I lost my sister, that the application for that prestigious international research grant is still in process, that I picked up my mom's ashes on the way to my sister's memorial, that I apologies for this report being a week late?

There are some things that just do not fit in my weekly, monthly, quarterly, annual reports on my teaching and research. There is so much that cannot be counted, and 
even if they can be counted, they do not fit into the neat Excel spreadsheets and prepopulated answers where you are required to select only one from the drop-down menu.

How does one calculate time during a pandemic? How do we count our research outputs, number of teaching hours, numbers of articles submitted, and reviews done, and all the other metrics that are important for managers, bureaucrats, politicians, and bankers?

What do we count during a pandemic?

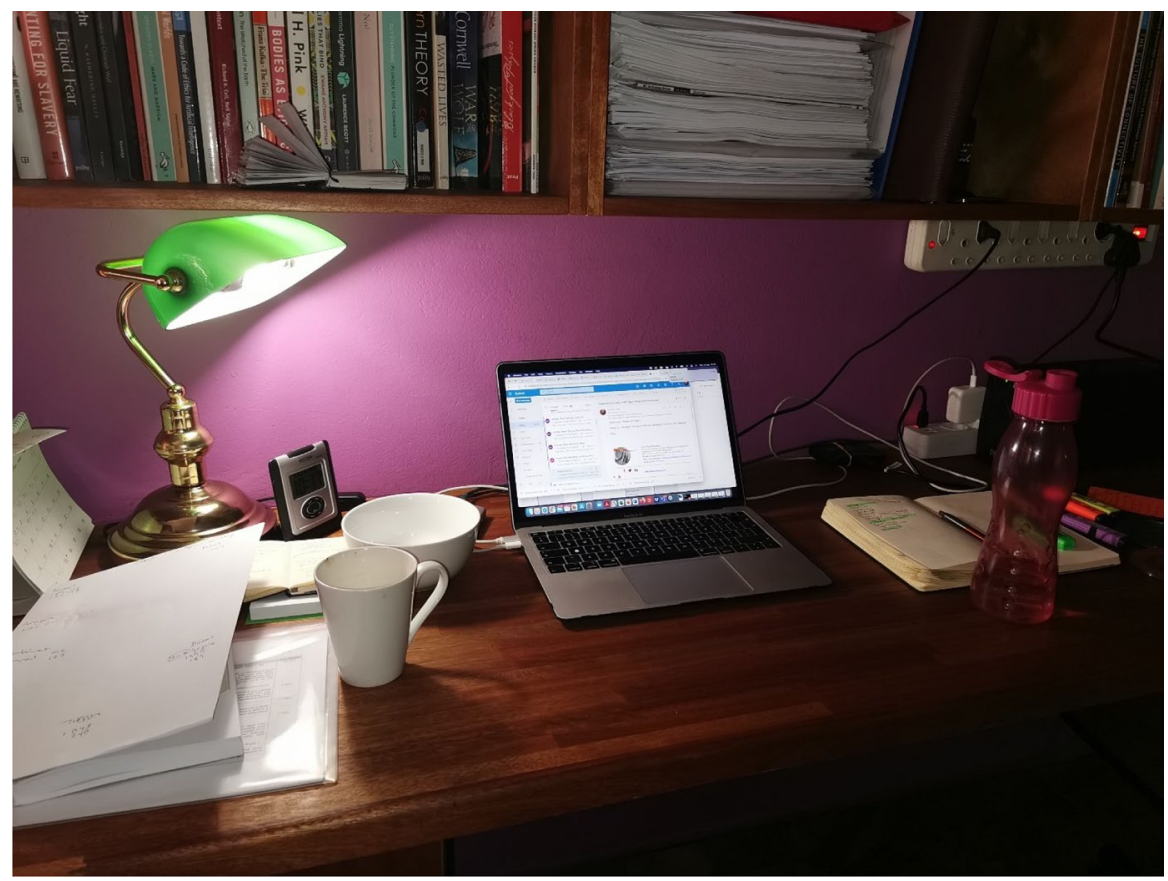

Fig. 22 [New figure.] Still here-somehow just messier and more cluttered

\section{The Sky Is Blue With a Few Clouds}

Dennis Grauslund, Aalborg, Denmark, 22 March, last paragraph added 8 April

[Unchanged biography.] Dennis Grauslund is an assistant lecturer at University College of Northern Denmark, Denmark. Dennis is 31 years old and lives in Aalborg, Denmark, with his partner and two children.

$* * *$

As I write this testimonial, I am sitting at home in Aalborg, Denmark. When looking outside the window of my home office, the sky is blue with a few clouds. I still work at University College of Northern Denmark, teaching and researching. When 
thinking about what significant changes I have experienced in the past 12 months, not much spring to mind, yet, I feel that I have become a better father and partner: calmer and better at adjusting to the chaos that family life with small children offers.

Since December, we have been in lockdown - the second lockdown after we were allowed to return to work in August. Since then, my institution has faced the music and now provides more offers to help students and staff meet their challenges. I see a greater focus on mental health, which is fortunate, as many students find it troubling to be in lockdown. I am expected to support the students, obviously, yet it can be difficult. How do you help others to cope with isolation when you struggle with it yourself? Besides that, I am expected to continue teaching, supervising, etc., yet I miss the face-to-face interaction greatly. Even though I have re-designed my classes to accommodate the online reality we are facing, it is not just the same. The students are pretty pleased with how I have re-designed the classes, so that is really something that means a lot. Still, I miss being together with my students, not 'being together apart'.

To deal with these expectations, I discuss a lot with my partner. We work at the same institution, but at different departments, so she is at home too. I consider myself lucky to have her by my side, and we help each other a lot. Re-designing classes, conducting research, and caring for students can be challenging tasks, yet sharing your frustration and being met with nothing but understanding (and a gentle 'pull yourself together' once in a while) is great.

But how do I feel? A year ago, I was afraid and stressed. Now, I am still scared and stressed, yet I am also confident that we will 'make it'. But it is easy to feel that at the moment, as birds are singing, flowers sprout, and the spring has arrived. I feel less and less worried about the pandemic itself but more worried about how lockdown affects people. Perhaps that is caused by how I see my students coping with it. Some of them suffer greatly in lockdown, and I would love nothing more than to see them feel better.

Since I wrote the above, we have seen changes, positive changes. It has been announced that the society will re-open, and there is a somewhat clear plan. This means that I can return to work in the coming weeks. That is great for me, my colleagues, and my students. That said, I still plan on executing my classes online in the coming weeks, as I fear the effects of shoving +500 people into buildings with none of them being vaccinated. 


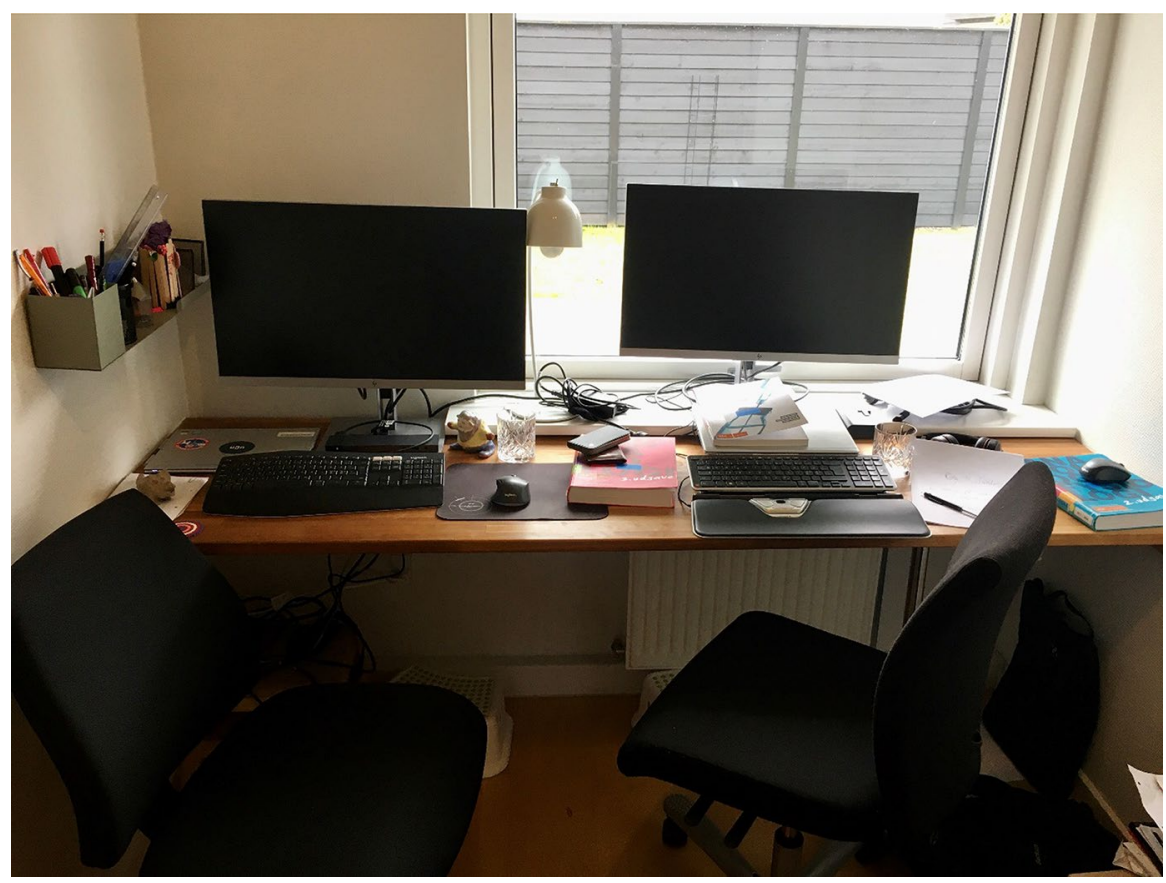

Fig. 23 [New figure.] My main working space is in our home office, right next to my partner. The picture is taken mid-day

\section{Covid Meets Godzilla}

Anne Steketee, Santa Ana, CA, USA, 19 April, updated 9 June

[Updated biography.] Anne Steketee, Ph.D., is an Assistant Professor of Education at Millikin University, (Decatur, Illinois) and provides dissertation support for Northcentral University (La Jolla, CA). She was also named the Louise Berman Fellow from Kappa Delta Pi (international education honor society); this will support her research of teacher secondary traumatic stress.

A year has passed in California. Strangely, Covid-19 has been my teacher. With the world, I watched Covid-19 transgress geographic boundaries, shift into new mutations, and surge again and again. So, I considered these lessons from my new viral instructor. After successfully defending my dissertation on Zoom, I researched the job market for newly minted Ph.D. graduates of a seasoned age during a global 
pandemic with universities at financial risk. The prospects were not promising. I reasoned that I would need to expand my geographic boundaries, consider new job possibilities, and surge through lockdown inertia. After applying for 150 different jobs and being invited for ten different campus interviews, I accepted a part-time job in an online university and a full-time tenure-track position out-of-state. I also submitted four articles for publication (two have been published; two are in revision) and am revising a book chapter. I was determined to learn from, but not be bested by, Covid-19.

A year has passed in my advocacy practice, which was the topic of my last submission. Zoom kept me in meetings, but texting kept me in close touch, that dayto-day, minute-by-minute touch. By text, I have kept in touch with the three families I mentioned in the previous article. The young college mother with children with disabilities dropped out of college to take full-time work. The family of ten in one apartment all had Covid-19 at the same time. All ten. And the mom with disabilities just had to tell her two children that their birthfather died of complications. The pandemic pressures faced by these families have been overwhelming, only to be eclipsed by their resilience.

And a year has passed for children in these families. They attempted to learn at home, learn by Zoom, and even learn in small groups or pods. As I probed deeper, I discovered that several students tried (unsuccessfully) to complete the entire year's education by cellphone. The resulting deficits, especially in literacy, were staggering. Again, the three Covid-19 lessons resurfaced: cross boundaries, consider new ways, surge. So, the picture I have attached for this testimony shows me with one of the youngest students. We are involved in the important work of 'new literacy': Godzilla and YouTube. He is sitting on my desk, describing different iterations of Godzilla as we look at various YouTube media. While we watch, I am pointing out letters and words: 'This is Godzilla. See the $z$ ? You have $z$ in your name, too. Let's read this together. God-zi-lla. Here is Mechagodzilla. Can you see the word Godzilla hiding in here? Wow! You are using great reading to find new things!'.

As I pack to travel 1,939.7 miles from California to Illinois, I recognize that I will need new strategies for equipping preservice educators to support students so we can cross new boundaries, consider new ways, and surge together. It is not the life I expected when I started my Ph.D. program in education-before a global pandemic_-but it is the 'new things' life I have come to embrace. 


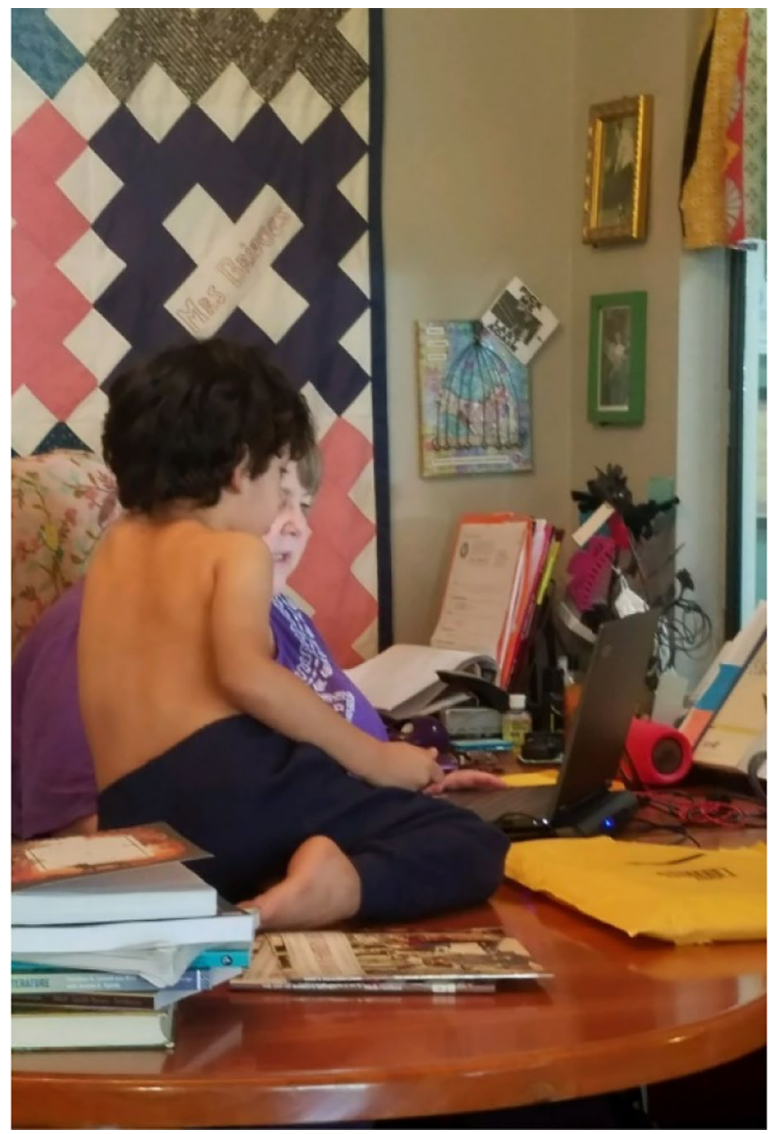

Fig. 24 [New figure.] Remediating pandemic literacy loss any way possible, with extra motivation from Godzilla and YouTube

\section{But Toward What?}

Charlotte Achieng-Evensen, Los Angeles, CA, USA, 20 April

[Updated biography.] Dr. Charlotte Achieng-Evensen is a K-12 practitioner and university lecturer. Her scholarly work is centered in the intersections of African Indigenous Philosophies and decolonization, culturally responsive praxis, and professional learning for teacher practice. Currently, she serves her school district as a Teacher Specialist focusing on research, policy, and program coordination.

$$
* * *
$$

In the USA, schooling, with its normative practices, has a predictable nature of maintaining the status quo. We follow a rhythm set by bell schedules and bell towers 
demanding that it is time to move from this content to the next. One year into the Covid-19 pandemic and the nature of this predictability continues to be disrupted.

The California Department of Public Health (2021) states that 3,645,341 Californians have contracted the Covid-19 virus with 60,765 people dying as a result. Of those above age 18 who have died, $21.4 \%$ are White and the remnant $78.6 \%$ are Black, Indigenous, and people of color. Certainly, this virus has brought into sharp relief the disparities between the dominant White class outcomes in terms of health, wealth, and safety and those of other ethnicities. And still, as a society, we engage in debate as to whether or not systemic racism and other institutional forms of dehumanization are factors to human thriving. This trend of institutionalized racist practices shows up in schooling.

One year later, students in my district have internalized the national outcry at the filmed murder of George Floyd and the continual killing after disproportional killing of Black folks - the visceral reminder that there is a USA for Whites and then there is the other one. For Black people like me, we learn to be hypervigilant in most societal spaces-lest we die. Our students took up protests-filing their concerns, cries, pain, on social media, and putting the district's policies on watch.

One year later, it is 20 April 2021. Hybrid learning has commenced. Students can select in-person instruction or remain online. I am required to be on site. Today, though, is tough. I am deeply anxious. I have returned home in anticipation of the court's verdict regarding the murder of George Floyd. Tonight, I am presenting at our governing board's meeting. I am part of the team tasked with providing an update on how the district is addressing student outrage at systemic racism and other forms of oppression they have encountered within our institution. As I watch the news, I am pacing, on the verge of tears. Hanging on some sort of uncertain precipice. Staring into a void wondering if there might be hope. This nation has been here before. Countless times. Watching as Black people are attacked and dehumanized egregiously-with impunity. The Covid-19 pandemic has held us in place. Allowing space to make unavoidably evident to a wider swath of society the shattering inequities that exist.

One year later, I find myself, an educator, reeling from the constant struggle to shout: Life is not normal! Let us stop the rhetoric of returning to a schooling 'normal,' to a life as usual concept that does not address our depth of alienation.

One year later, I am back in my office but still on Zoom. I am meeting with colleagues, students, families. I'm occupying a strange sort of liminality-I know we have been propelled forward... but toward what? 


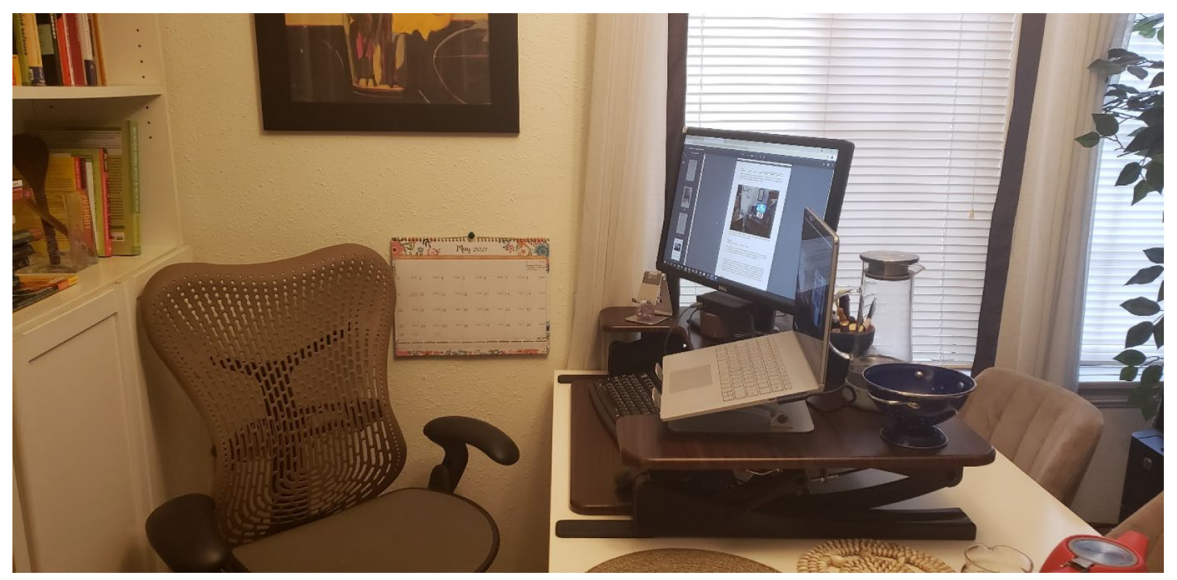

Fig. 25 [New figure.] The home workspace is at the dining table. A standing desk riser now takes up most of the table, but really helps with sitting fatigue.

\section{Back to School}

Blessing Funmi Komolafe, Jinhua, China, 21 April

[Unchanged biography.] Blessing Funmi Komolafe is an assistant lecturer at the Adekunle Ajasin University, Nigeria, and doctoral scholar at the Zhejiang Normal University, China (ZJNU), under the sponsorship of Chinese Government Scholarship. Blessing lives in China with her husband.

Finally, tranquility sustained. A lot has changed within 1 year of the global pandemic, and how the Chinese government had contained the crisis is a pacesetter to the world at large. At the time of writing my last year's response, little did I know that the Covid-19 pandemic would spread like wildfire. My experience within the last year can be likened to a body trying to achieve an equilibrium state which depends on various factors, such as pressure from my son, parents, friends, and other immediate family members residing back home. Toward the middle of 2020, my school initiated the back-to-school process, whereby international students need to apply and get approval from their various colleges and international office before returning to school.

School activities had fully commenced; all registration and most of the courses were taken online. I defended my mid-term doctoral examination face-to-face, while other international students outside China did theirs online. In the quest to know how effective this online pedagogy adopted for international students across China is, I and some other colleagues surveyed the effect of the process (Komolafe et al. 2020).

Early this year, another notice was sent to all ZJNU international students that entailed the new policy, direct quotation as shown below: 
1. Under the severe situation, from January 11th, 2021, all ZJNU in-campus students outside time should keep less than 3 hours and return to school before 8 pm each day. If you want to leave school for more than 3 hours, you should strictly ask absence from your college teacher.

2. Don't organize or participate in indoor gathering activities, maintain a safe social distance, make sure to wear masks.

3. During the winter vacation (after January 25th, 2021), the campus only opens the southeast gate. And off-campus students should apply to your college teacher for E-PASS if you have necessary study and research needs.

4. If you have to go to other cities during winter vacation, please strictly ask absence to your college teacher. Students who have left the school during winter vacation can't return to school without approval.

I got the leave approval to proceed for my winter vacation at Suzhou city to stay with my husband, for the Chinese New Year festival. This year, festival was a noteworthy event, as normalcy had returned to almost all the cities. I had a lot of fun with my husband, Chinese families and friends. The shopping malls, groceries shops, and attraction centers were fully opened. After the winter vacation, I applied for back-to-school permit to continue my study at Jinhua City.

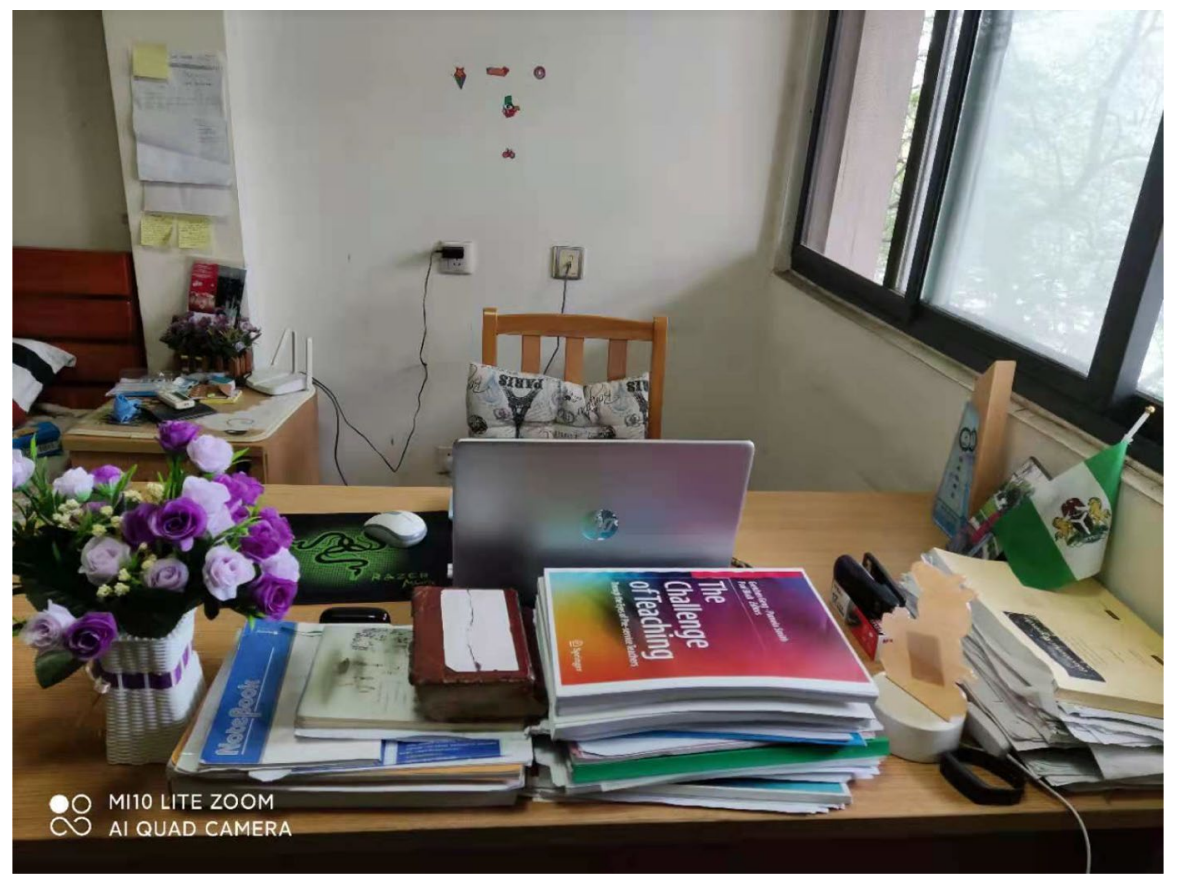

Fig. 26 [New figure.] Workspace at my room in ZJNU International apartment, Jinhua City 


\section{Underneath, Life Flows Like Sap}

Juha Suoranta, Tampere, Finland, 21 April

[Unchanged biography.] Juha Suoranta is Professor of Adult Education in Tampere University, Finland. He is 55 years old and lives in Tampere with his spouse Anna and their three children.

Did I tell you about my nightmare last night? I am in the concert hall, and after the concert, one of my departed relatives comes to me and expresses his condolences on my grandfather's death, who died in 2007. The moment I step outside the concert hall, I am at the railway yard trying to dodge trains from opposite directions until I wake up sweating at 4:30 a.m.

I was talking with the dead at night. What did it tell? I have stayed safe in our house for a year, teaching entirely online. I have not moved around much except for necessary shopping, unlike many others who have been forced to work in the front lines of Covid-19 in hospitals, food stores, schools, public transportation, and construction sites. The fear of getting infected and bringing the virus home has brought worry and stress into their households.

In the meantime, I have had the luxury of escaping to theory and pondering the pandemic from a bird's eye view. Like others, I have learned that the Covid-19 (or SARS-CoV-2) virus is a biological fact that no one can wish away; knowing this has not brought comfort to those under an imminent threat of contagion.

However, while the virus functions according to the laws of nature, I can, at least in theory, try to take those laws into account in my voluntary actions like a navigator who senses the wind's strength and direction. Neglecting them can result in a fatal multi-organism disease like a mistake in navigation can cause a shipwreck.

When I cannot escape the presence and fact of the Covid-19, I may have the relative freedom to try to manage the psychological effects I allow Covid-19 to have on me and my actions. However, when forced to work under the constant threat of contagion, it is no wonder if it may be impossible to fully control those effects. This situation can lead to 'biographical disruptions' (Bury 1982) in which the mental and social structures of everyday life are discomposed, and the possibility of death is realized.

The dramatic situation can also force us to face social relations' darker sides, which can break routines and rules of reciprocity, disrupt mutual support and solidarity, and bring extra burden to intimate love life. The recommendations of health experts could have been clear, but not enough in guiding people in these complexities of social and psychological lives. They are like the top of the iceberg while the bulk of ordinary life, the essential elements, remains below sea level.

What did the nightmare tell me of the year past? Everything's lost, turned into stone, came up against a wall? Maybe nothing. Or, perhaps, in the words of Éric Vuillard (2018: 120), my 'true thoughts have always been secret, since the beginning of time. We think in apocopes, apneas. Underneath, life flows like sap, slow and subterranean.' 


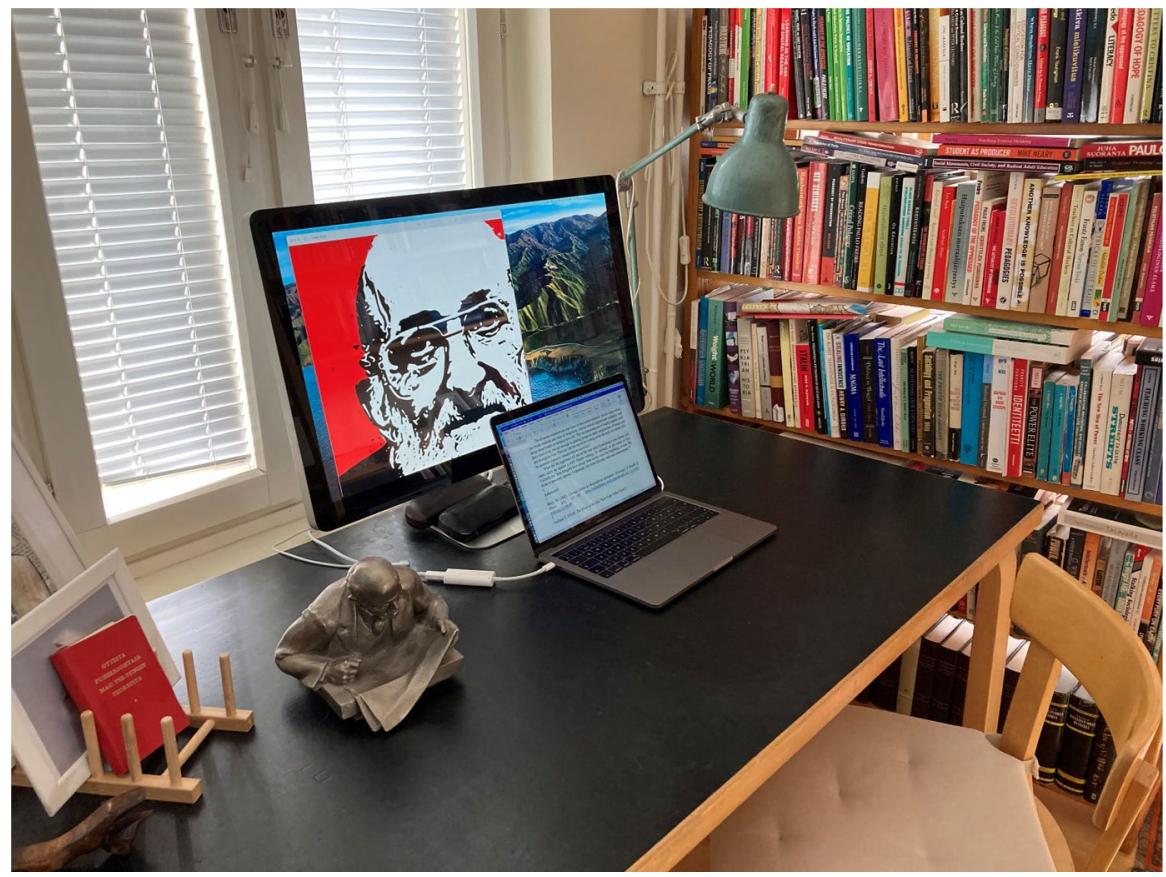

Fig. 27 [New figure.] My workspace at home a year after looks the same. The only difference is the Lenin statue on the left to celebrate his birthday on the 22nd of April

\section{Covid-21: Ontology of Academic Subjects Revisited}

Nina Hood and Marek Tesar, Auckland, Aotearoa New Zealand, 21 April

[Unchanged biographies.] Nina Hood is a Senior Lecturer at the University of Auckland and the founder of the not for-profit organization The Education Hub. Marek Tesar is an Associate Professor and Associate Dean International at the University of Auckland. They live in Auckland, New Zealand, with their 2-year-old son.

We write a year on from New Zealand's first lockdown. While a lot has changed in Aotearoa New Zealand in the past year, in many ways, compared to the rest of the world, life continues with relative normality. Schools, early childhood centers, and universities are operating as normal. People have parties, have meals in restaurants, visit museums and galleries, and attend sports events. Gone are the supermarket trips that were so carefully planned and organized, the 'escape' from lockdown. 
They are now a chore again. If not for the mandatory masks on public transports and posters on shops and cafes prompting us to 'sign in,' life would be largely the same. However, unlike much of the rest of the world where vaccination programs are ramping up and people are exploring opportunities for the return to international travel, the vaccination program in New Zealand remains in its nascent stages, and international tourists are a thing of the past (although just this week, a travel bubble between Australia and New Zealand has opened).

We are, compared to many around the world, incredibly fortunate. We both have remained in the same jobs. Our toddler, William James (WJ), is well settled into childcare, experiencing somewhat postdigital childhoods (see Hood and Tesar 2019; Tesar and Hood 2019). We continue to live in the same house (albeit we are in the midst of renovations). There are, however, two major changes with the multiple lockdowns over the past year, our home office set up has become more elaborate, and we are expecting a brother for WJ in May.

So, as life largely returns to normal across New Zealand, what has been the impact on our education institutions? The multiple lockdowns in Auckland (ranging from 3 days to 8 weeks) have tested the resilience of the university campus as an everyday agora — meeting place — of ideas and human bodies. Most of the academic and professional staff have adjusted to the idea that they should (or could) be working from home at least 2 days a week. And despite the university being open for business, many meetings continue via Zoom. There is a growing expectation that more and more courses will be taught in a hybrid or fully online mode, with seeming limited consideration of what might be lost by removing teaching and learning from the physicality and materiality of classrooms and lecture theatres.

Borders remaining firmly closed, international students continue to enroll into our courses from offshore, requiring staff to deliver their courses simultaneously face-to-face and online (something for which they have received little training or support and no additional workload). The loss of international student numbers also has impacted the university and in particular its bottom line. The loss of revenue is prompting a rethinking of teaching and learning structures, faculty size, shape and composition, and the 'type' of university that we want to be. However, this thinking operates in an unusual way. For it is not a whole-scale transformation but rather appears to be a tinkering, a slow evolution eroding structures and systems and ways of being and doing that were once taken for granted. What remains to be seen is what the end point will be. What the aspiration for this rethinking is. What the university will mean in a (post)-Covid era. 


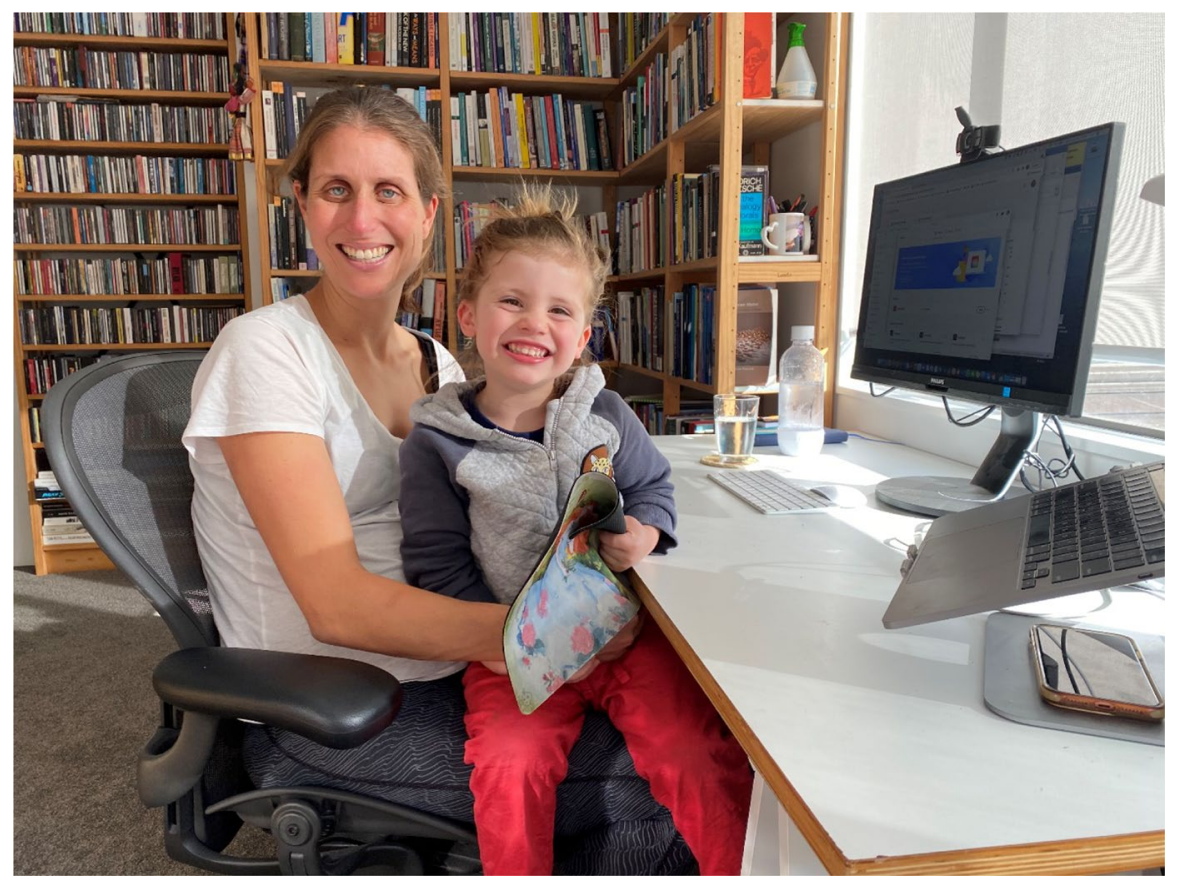

Fig. 28 [New figure.] Our slightly updated home office where we continue to entertain our toddler while awaiting baby number 2

\section{Covid Contemplation}

\section{Jennifer Rose, Short Beach, Nova Scotia, Canada, 22 April}

[Updated biography.] Rose is from Nova Scotia, Canada, and completed her Ph.D. at Queen's University Belfast, Northern Ireland. She is an adult educator focused on course development and delivery in community and corporate contexts.

It is 22 April 2021, 12:36 pm (ADT), and I am writing this testimonial from Short Beach, Canada. This year, I am in a different location than last year; however, it is not due to the pandemic. Family illness (not related to Covid-19) has prompted me to uproot from my Western Canadian nest and fly east. There have been some changes in my activities and focus over the last 12-13 months. One year ago, uncertainty and ambiguity were rampant when the pandemic was recent to my part of the world, and our government was still problem-solving. I was preoccupied with managing basic survival needs, checking in with my family and friends, and working toward submitting my thesis. This year, my $\mathrm{Ph}$. D. is complete, most of my family and friends are vaccinated, the shortage of survival goods has been replenished, and 
fear has been reduced. I have settled into 'Covid life'; wearing a mask, handwashing, physical distancing, self-isolating, quarantining, and following lockdown rules are routine practices that do not affect me other than my behavior and consciousness as I have incorporated them into my thinking and follow them in daily living.

Before the pandemic, I was situated in Canada studying remotely from my Northern Ireland University. When the pandemic reached Canada, my studies did not change. My university already had well-established remote access to services and resources, which I continued to use during the last year. However, when I attempted to take courses that had moved to be offered online, I typically had to get up at 2-3 a.m. (depending on the start time of the course), so I could attend the online courses which were scheduled primarily in the mornings, UK time. Because of the difference in time zones between the UK and Canada (and when I took an online course), my study days were extended to 12-16-h days because once I was awake (even in the wee morning hours), I stayed up until bedtime.

I do not anticipate my life (or life in general worldwide) to return precisely to its pre-pandemic state. And in fact, I hope it does not. The pandemic has illustrated that there are urgent changes required to the operation of societies and how we treat one another, our environment, and the species with who we share the planet. According to the World Bank (2020), the pandemic has magnified global extreme poverty. Many people are living on the brink of desolation and have lived (or are still living) in anguish because Covid-19 has left them in bleakness. This must change.

The pandemic has exacerbated some people's hatred toward others and nonhuman animals, reinforcing age-old social problems as people have loathed each other for centuries; however, we must not continue to re-enact these ancient problems. Pre-pandemic, we were destroying our environment, and we must stop doing so. According to NASA (2020), the earth's environment has improved because of the pandemic. Being coerced into working from home, for those who did not already, clearly reduced travel time, and therefore pollution. Factories shut down, airline flights were reduced, and human activity that damaged our environment decreased overall.

The pandemic fundamentally altered the way we live and work; however, the positive changes in the environment will likely be temporary. Across Canada, for example, municipalities have been searching for ways to re-open the economy and continue on, at least diachronically, as they did pre-pandemic. This behavior does not instill conviction or hope that some of the positive changes to the environment (that keeps us alive) will continue. There seems to be resistance to change that catapults us temporally backward to old habits, old political-economic ways of thinking, and outdated social relations. While the pandemic has brought germination and flourishing to the environment, it has engendered new problems and exacerbated old ones.

The insights gleaned from living through a pandemic explicitly expose a dire need for new ways of thinking, being, understanding, living, working, learning, and knowing - and most of all, a different way of relating to our comrades, and the environment. Education has role, but as the pandemic has taught us (or some of us?), it is only collectively and cooperatively that we can stop the worldwide devastation. 


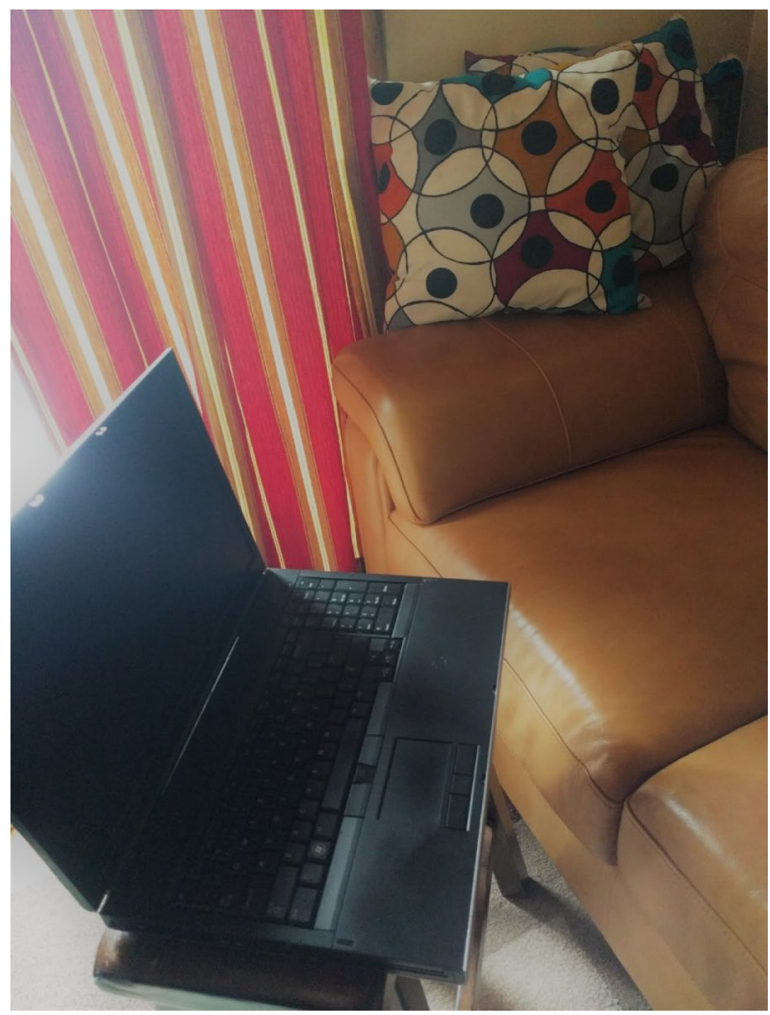

Fig. 29 [New figure.] In Nova Scotia, I do not have a designated workspace but use different spaces based on how quiet it is around me. Today, I secured this quiet spot and occupied this couch in the corner for a short period of time before being displaced again

\section{One Year of Quarantine and What I Have Learned}

Niklas Humble, Gävle, Sweden, 23 April

[Unchanged biography.] Niklas Humble is a Ph.D. student in Computer and System Science at Mid Sweden University. Niklas is 34 years old and lives in Gävle (Sweden) with his wife and son.

I am a Ph.D. student in computer and system science at Mid Sweden University in Östersund, and it has been little over a year since I wrote my last testimony. I am still working from home but I, my wife, and our son have moved to be closer to our friends and relatives. We now live in a small town outside of Gävle, about a 5-h drive from Östersund.

Although my department had been quite experienced with online meeting and online teaching before the pandemic, it feels a bit strange that we have not seen each other face-to-face in a year. Online work-life has become my new normal. I connect 
to Zoom when I have a work-related meeting, and I connect to our daily virtual coffee-breaks in Teams when I want to socialize.

I research the use of programming tools in K-12 education. It has been difficult to get access to schools during these times, so my work has been affected. This caused me some stress in the beginning, but now, I have found other ways to collect data and conduct research. Since many K-12 schools have moved online, I am no longer restricted by geography. I can conduct interviews with teachers from different parts of the country, or the world, all in the same day.

The past year has been challenging. Although we (me, my wife, and our son) are geographically closer to our friends and relatives than before, it still feels like we are further apart. I miss inviting them to our home. Big family dinners, or just meeting friends at a café or a pub, feel like another life. On the other hand, I have probably never been healthier than now. We take long walks with our dogs in the forest and I run 3-4 times a week. Frequent exercise has probably helped me stay (relatively) calm during this year.

I hope that we all will be able to take some lessons from this past year. That we will not just return to what was normal, but that we will grow in some way. Maybe you have acquired a new set of skills or learned something about yourself, others, or the world around you. Personally, I feel more appreciative of what I have today than I did 1 year ago. I have also learned how to do those really cool virtual backgrounds in Zoom and Teams!

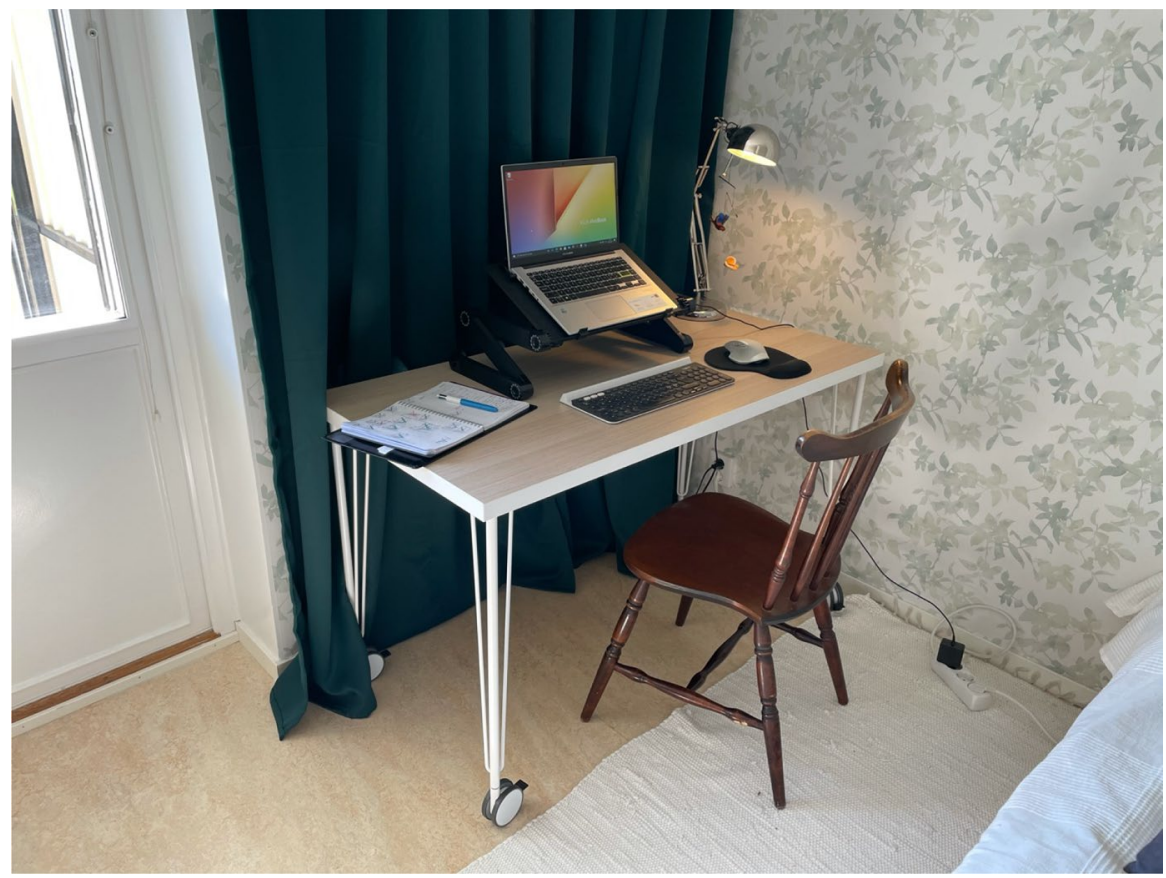

Fig. 30 [New figure.] This is my workspace, located in the bedroom at our new apartment 


\section{Covid-19 and Some Musings of What has Been Learned}

James D. Kirylo, Columbia, SC, USA, 24 April

[Updated biography.] James D. Kirylo is Professor of Education at the University of South Carolina. His published books, among others, are The Thoughtful Teacher: Making Connections with a Diverse Student Population (2021, Rowman \& Littlefield), Reinventing Pedagogy of the Oppressed (2020, Bloomsbury), and Paulo Freire: The Man from Recife (2011, Peter Lang).

$* * *$

It is incredible to ponder that it has been over a year since Covid-19 appeared on the world scene, disrupting just about every aspect of our lives. As I did last year, I am writing this piece from the same location at my home office.

On one hand, with respect to my work as one who teaches pretty much exclusively in our online curriculum studies program, not much has fundamentally changed because of Covid-19. That is, I taught online prior to the pandemic, continue to do so during the pandemic, and the plan is to continue with this format on the other side of the crisis. But, on the other hand, a lot has changed which has required me to adapt, has acutely heightened my appreciation for technology, and has prompted me to admire my students even more.

Over the last year, when it came to either committee, department, or college meetings, all have been conducted through digital media, such as Zoom and other similar formats. Moreover, when it came to dissertation defenses, prior to the pandemic, we encouraged our online students to come to campus to conduct these momentous events. And most did. Since the pandemic, however, all of these proceedings have been held electronically. Finally, confined to conducting most all my work at home, I simply missed walking around our beautiful campus, bustling with students, faculty, and activities. The collective disembodiment of this reality has naturally forced me to adapt my natural desire to be around others; this certainly is no small matter as we are obviously wired to be in relationship in its multiple forms.

Yet, while adapting to the proverbial 'new normal,' I gained a new-found awe with technology. It has indeed been a saving grace in keeping people in contact from all parts of the world, and obviously, it has been the major engine to keep schools, universities, and multiple other institutions open. It is difficult to conceive how we would have coped without the marvel of digital media.

Because of our online graduate program, I have students spread out all over the USA and some in other countries. The majority of them are K-12 educators who, during the pandemic, have demonstrated unwavering commitment to furthering their education. And within that commitment, they were also met with monumental challenges at their respective K-12 work settings, taking every measure possible to keep schools open in some form or fashion. In addition to those challenges, my students were also naturally tending to the needs of their own families, along with several of them dealing with their own cases of Covid-19. In my book, this is nothing short of heroic on their part, indicative of their simultaneous commitment to their families, craft, and the community at large. 
As I conclude this short piece, I see a light at the end of the pandemic tunnel with the rollout of the vaccine. My only hope is that the world community places political partisanship and division aside to make sure we are equitable, responsible, and just when it comes to the vaccine distribution.

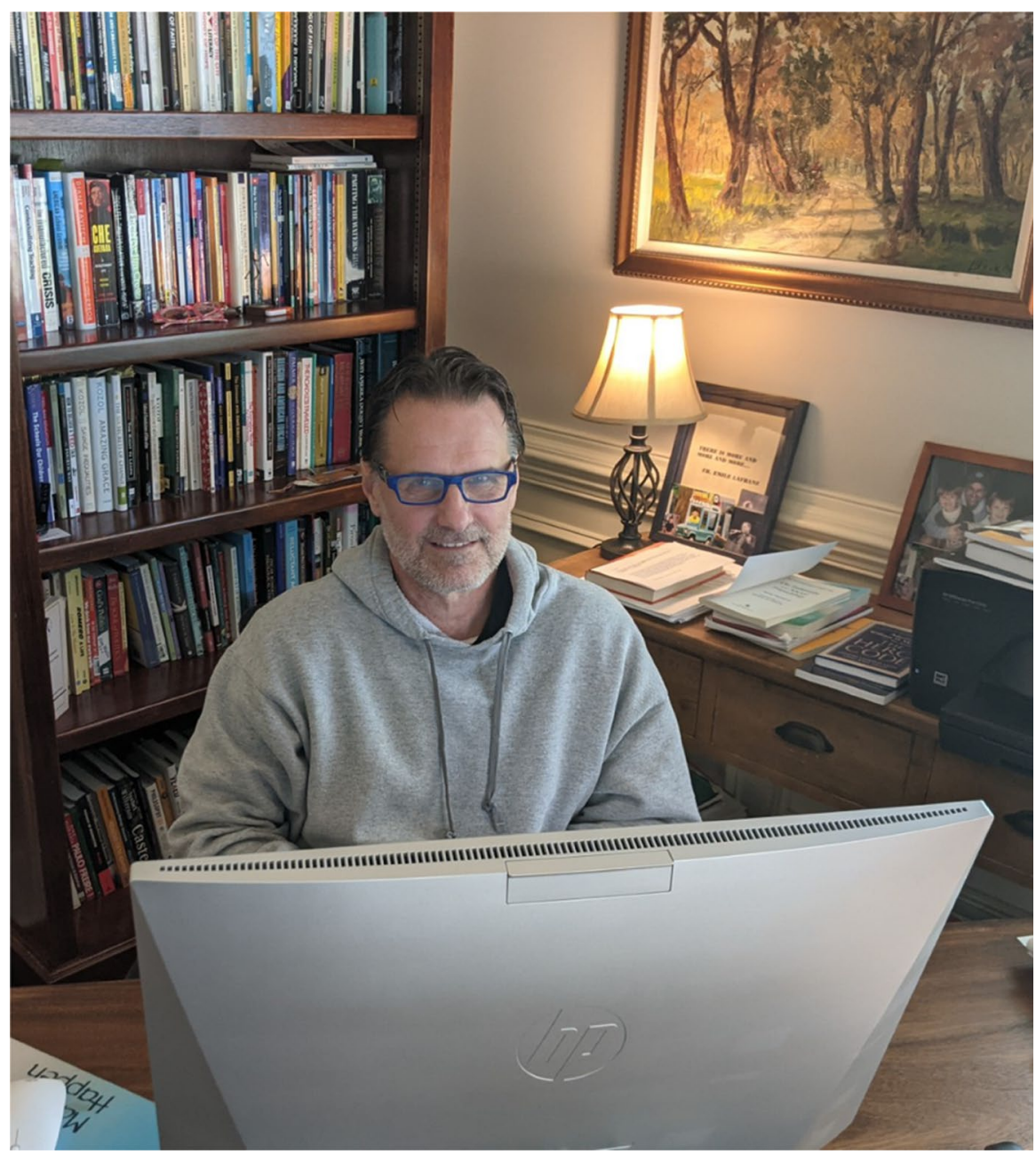

Fig. 31 [New figure.] Working from my home office

\section{Postdigital Hidden Shadows}

Julia Mañero, Seville, Spain, 25 April

[Updated biography.] Julia Mañero completed a Ph.D. in Education (University of Seville, Spain, 2020). She is member of Research Group Education and Audiovisual Culture (HUM401), Lecturer at University of Huelva, and has collaborated as a teacher in Massive Open Online Courses and in the Master of Communication and 
Education on the Network at The National Distance Education University (UNED). Her current research interests include art education and digital education from a critical and social perspective.

$$
* * *
$$

One year ago, I wrote some lines trying to express my concerns about the initial stage of a worldwide pandemic. Trying to complete my Ph.D. and lecturing from a folding table were my main tasks for several weeks. This was followed by moving house and therefore a new workspace from where today I am writing a new testimony. To be honest, my life has been shaken up completely. I am not sure if it was optimism or unawareness, but in general, the forecasts for the current academic year were favorable. The emphasis was on physical presence in university classrooms without taking into account the consequences of a summer without too many restrictions. Looking back I guess that-at the core of the massive interest in a physical presence in classrooms and not abandoning face-to-face education-there were some fears associated with digital education.

While our private life embraced digital gadgets in order to maintain relationships, leisure, or consumption, most public universities in Spain were unwilling to accept change. The academic year began normally and as part-time lecturer, I started working at the University of Huelva, which was subsequently combined with a temporary contract at the University of Seville. Two different institutions with many discrepancies when it comes to dealing with the pandemic but with a common bond: a lack of knowledge about what digital education is.

There was resistance to acknowledge that the most cautious thing to do was to specify some common action points, supply resources, and provide training to academics. Thus, the academic course has been going on with ups and downs, confusion, general discomfort, and a kind of discouragement. A wide range of feelings shared by students and professors. What we have been able to observe during these months is what really inhabits in the shadow of these decisions: stereotypes associated with digital education. Machines will take away our positions, digital education does not provide quality, it is unviable to educate through a screen... To this, I could add a long list of arguments devoid of theoretical support, real experiences, or simply lack of interest. Complaints arose as large corporations sold licenses for platforms and resources for providing lessons. The use of private software and the manipulation of students' personal data and information was established without so much commotion. Our postdigital existence at its peak.

As with other areas of knowledge, those who underestimate digital education are often due to a lack of training. But it is easier to dismiss it than to recognize our weaknesses as human beings and distance ourselves from a humanistic perspective. That means there is a lot to be done, which results in an optimistic perspective for those who seek to explore new possibilities. In a blink of an eye, we have faced an unprecedented postdigital reality, and it is part of our pedagogical commitment and our research practice to redefine educational spaces and work for a critical, emancipatory postdigital education. The pandemic has only revealed hidden shadows. 


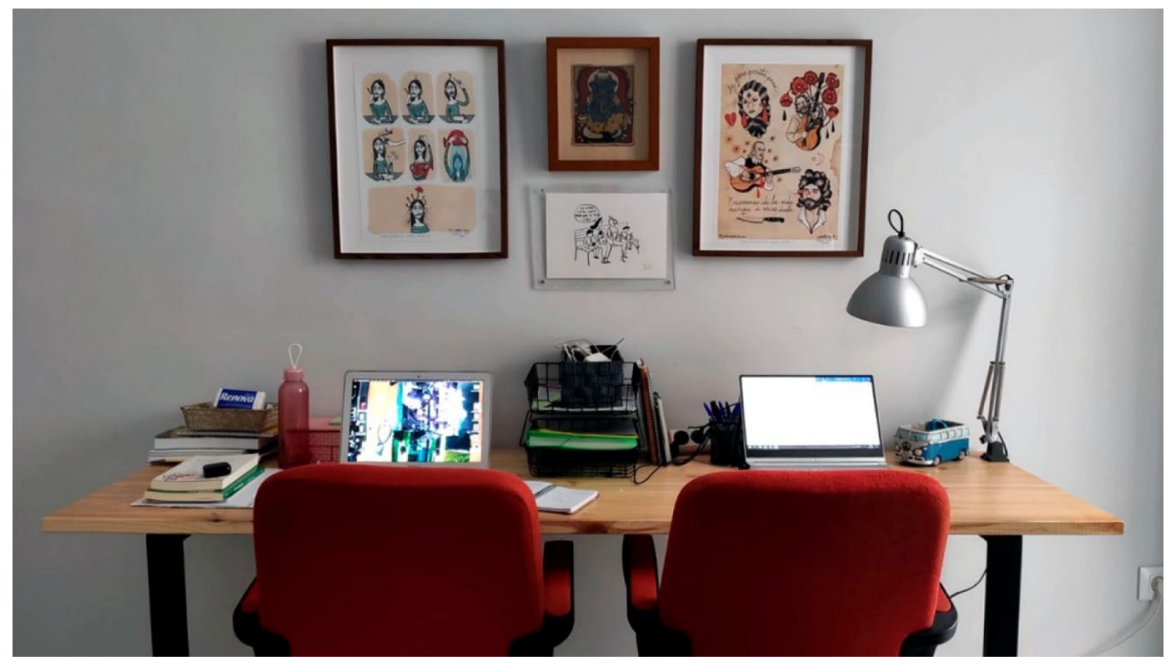

Fig. 32 [New figure.] I spend most of the day sitting at my new and shared workspace. Organized and equipped for both teaching and research remote working needs

\section{Against the Odds: Health Care in Communities of Color}

Lilia D. Monzó, Pasadena, CA, USA, 26 April

[Updated biography.] Monzó is Associate Professor in the Attallah College of Educational Studies at Chapman University and Co-director of the Paulo Freire Democratic Project. She is the author of A Revolutionary Subject: Pedagogy of Women of Color and Indigeneity. Monzó teaches on social movements and history and philosophies of education.

\section{$* * *$}

One year ago, classes at Chapman were shifted to a virtual format. I was scrambling to learn the technology and adjust to teaching within my home while attending to my 15-year-old son whose schooling had also gone remote. As a middle-class professor with tenure and a good income, my greatest personal concern was the health of my parents who as seniors, ages $80+$, Latinx, working class, immigrants, and with chronic disease, were significantly at risk for Covid-19. Already, reports were showing the greater count of Covid-19 cases and deaths among Communities of Color and the unequal access to testing and care. 
Indeed, my greatest fear became a reality when my mother tested positive and had to be taken to hospital due to low oxygen levels. This was during the greatest surge in Covid-19 cases in Los Angeles, and many hospitals were overwhelmed, lacking oxygen tanks, and turning patients away. Fortunately, a physician familiar with the county hospitals directed us to take my mother to the hospital in the more affluent city of Flintridge/La Cañada. She received immediate and excellent care and has since recovered. This city has seven times less population density than the city where my mother lives. As a result, they had both the resources and personnel to offer appropriate and more humane services to their patients.

One year later, I am still teaching from home. The process of social distancing has been difficult and teaching on Zoom has taken its toll on both myself and my students. Although being at home affords more time, the Zoom is exhausting, and certainly, I have found the social distancing from family and friends difficult. Many of my students have also been affected, with many contracting Covid-19, some losing family members or needing to miss class in order to attend to their family's well-being, and many more reporting mental health issues. Due to reports of difficulty concentrating and sitting still in front of the screen for hours at a time, I have replaced one-third of face-to-face instructional time with asynchronous work, allowed greater flexibility with assignments, and been more strategic with providing time within the Zoom class for students to get to know each other and connect as persons rather than just students.

The Chapman campus has partially returned to face-to-face instruction, with classes accommodating a third of enrolled students in classrooms. However, to provide a similar instructional experience to all students, instruction remains online regardless of whether students are on their computers at home or sitting in the classroom facing their computers. This is obviously not ideal and many, including myself, wonder whose interests are being served in this scenario? Yet, the country seems to be prepared to resume normal face-to-face operations across institutions by mid-May. The question that remains is what the fallout of opening too soon may be and who will be most affected. Although vaccines are now widely available and free of financial cost, studies show that again, communities of color are trailing behind with respect to vaccinations. 


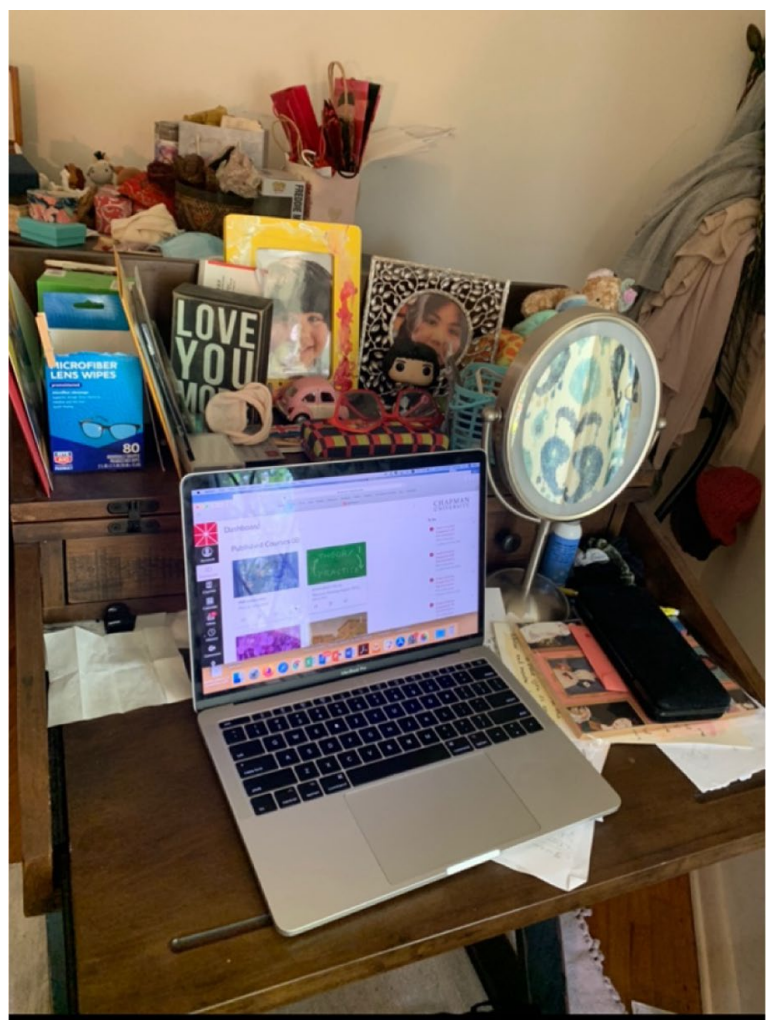

Fig. 33 [New figure.] Working at a small desk in my bedroom

\section{New Business, Same Usual}

Mikkel Lodahl, Randers, Denmark, 27 April

[Unchanged biography.] I still teach at Dania Academy's games department, Dania Games, in Grenaa, Denmark.

I'm writing this from a child's bedroom. At the moment, it is my Covid-19 office, because the child is still too small to use it. When the lockdown began last spring, the joke was that young(ish) couples would either get divorced or have another child. We went for the latter, so now we have three young children.

In Denmark, we have experienced various versions of lockdown throughout Covid-19. Most universities have committed to online teaching for much of the period. More trade-focused further educations have languished-it is not particularly easy to learn how to weld or do carpentry over Zoom—struggling valiantly to get back to physical teaching. 
Dania Academy has charted a middle road. In the fall of 2020, we went back to teaching classes physically. Meetings, business, and exams were almost exclusively conducted online. We had our traditional Danish Christmas Lunch over Zoom. Then, over the holiday break, everything was closed again, including schools (but excluding daycare for no reason other than productivity). It was also then that the new child in the household was born, sparing me some exam duties as I took a fortnight of paternal leave.

In the first lockdown, the central leadership of Dania Academy was very understanding that business could not continue as usual. In the second lockdown, that understanding had evaporated. New research and development projects, demands for productivity, and major organizational shifts were all introduced and expected to be worked at with the usual amount of energy. All employees in student-facing positions were experiencing Covid-fatigue. Personally, I estimate every task takes around 20-30\% more effort now. Through efforts of our workplace environment organization-where I am an elected representative-and some local leadership, many of the initiatives were thankfully paused.

In April, physical teaching opened again, under strict rules from the central ministerial authorities. A negative Covid-19 test or proven vaccination is the centerpiece. This has led us to establish our own supervised self-test facilities on our campuses at quite some expense and effort. Students queue up for an hour or two for a test. When they get in, they must still wear masks and keep distance. They are only allowed $30 \%$ attendance, so we admit one class each day. My feelings on this are very negative. I see very little point in having the students-many of whom have changed living arrangements and work habits in the last year-suddenly be disrupted to a new, new normal instead of a return to normality.

In Danish society at large, this is also the case. Intricate new laws-including contracts for well-connected private companies developing software and medical equipment—create a financial and work hurdle for everyone in the private and public sector alike, not necessarily matching the benefits of the limited re-opening. Entire new infrastructures are created, only to be presumably rendered obsolete in a few months, once vaccinations are rolled out. It is an incredible waste of public, private, and personal resources.

I expressed hope in the original article that we as academics could learn from the pandemic how people outside our ivory towers worked and lived and how our work depended on theirs. We may have. But clearly, the people in actual power have the same disconnect from the lives of those they lead, manage, or govern that they have always had. 


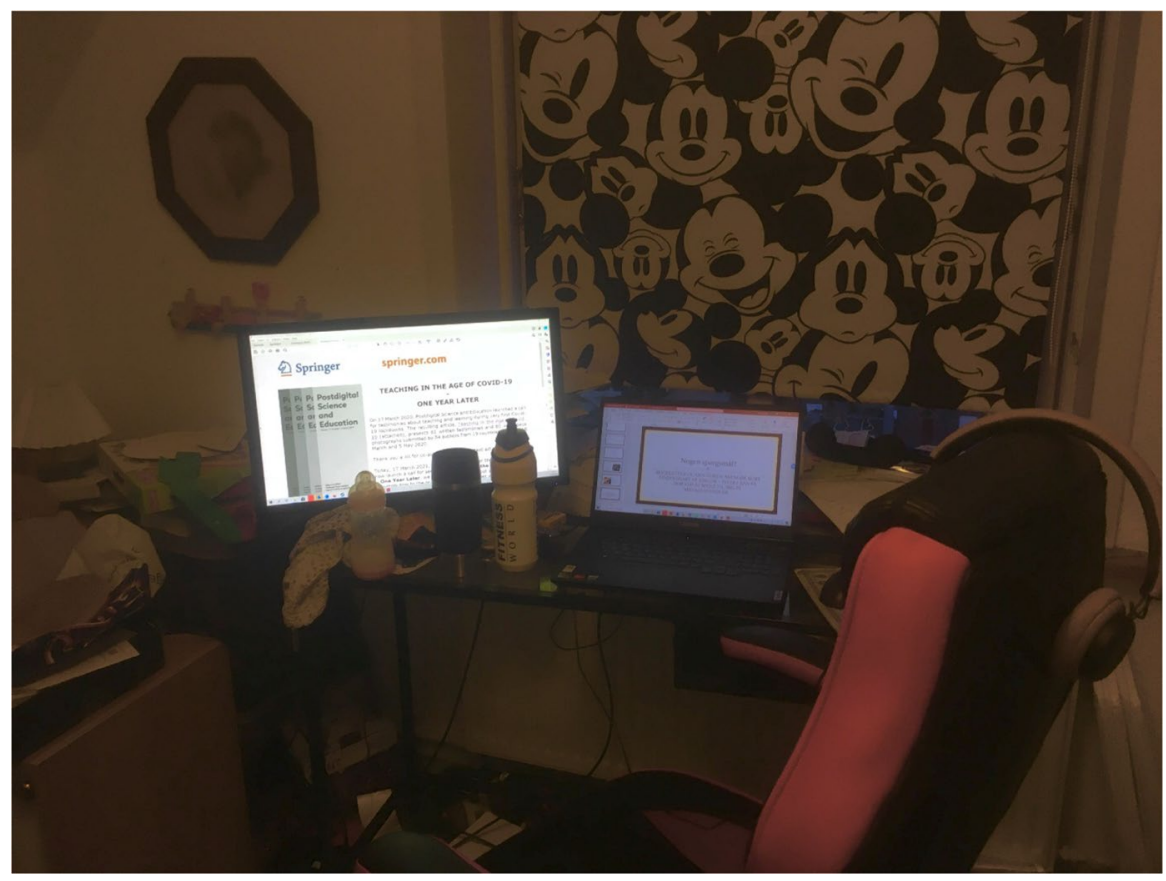

Fig. 34 [New figure.] This is my workspace at the end of a long day. I am squatting in my youngest son's room until he gets old enough to use it (he is 4 months old as of this writing). The chair is a cheap gamer chair, which I purchased after too many hours on a dining room chair in Spring. I wanted to have something nicer, but I cannot really afford it. On the table are a water bottle and a coffee thermos, since I am working on the second floor and do not have easy access to the kitchen. I sometimes have to take care of my baby son during meetings and student consults, and you can see an empty milk bottle there indicating he has had a snack during my work today. You might spy some of my own snack wrappers, a minijack-adapter, my earphones, and a microphone strewn about. There is also the Mickey Mouse drapes which should indicate that I am not in an actual office environment all by itself, as well as some mess on the floor and on the dressers beside the desk and in the windowsill. Most of this mess is gonna be there until my son moves in. When he does, I am not sure where I will work, but I will not be far from my second round of paternity leave-13 weeks this time-when he does, so it might not be a huge problem

\section{The Best is Yet to Come: the Post-pandemic Condition}

Jimmy Jaldemark, Härnösand, Sweden, 27 April

[Updated biography.] Jimmy Jaldemark is an associate professor of education at Mid Sweden University (MSU). He is a 50-year-old homeowner living in Härnösand, 
Sweden, with his wife and their five children. He commutes to the office by train 50 min one way.

I am sitting in my home office reflecting on the year that passed and the post-pandemic condition that eventually will come. Sweden has applied a soft lockdown, emphasizing temporary legislation and advice from authorities built on citizens' ability to make wise decisions. This approach has been less problematic for MSU as we have several decades of experience in distance education. Many programs apply blended and hybrid models comprising digital teaching, gathering students in study groups, and campus-based physical meetings. We experienced a smooth transition to solely digital practices with digital resources, learning management system, videoconferencing, and other digital tools. Nevertheless, teachers struggled in courses illsuited to increased implementation of digital technology but found solutions in line with both the temporary policies of MSU and The Swedish Higher Education Act (Swedish Ministry of Higher Education and Research 1992: 1434). This struggle was particularly apparent in teacher training programs, including curricula demanding campus-based physical activities and assessment.

The student union found that some students that moved to Sundsvall experienced mental health issues. Living in small apartments and not having a place to meet and socialize with co-students also affected their ability to perform successfully in their studies. Consequently, MSU decided to reverse the policy of abandoning student presence on campus.

We found a window of time between the first and second wave of the pandemic to bring beginner students to campus. In effect, the design of the meetings at campus departed in the physical distance between students and a small number of students allowed in each hall. These beginners need physical meetings with other students and teachers to build trust and confidence, get to know each other, and create study groups that enable affective, cognitive, and social support. Since mid-November 2020, campus-based teaching was abandoned once again.

Following authorities' recommendations, staff are allowed to visit campus but encouraged to work from home. I have invested in better office furnishing at home. Nevertheless, network connections and access to IT services are worse at home. The increased load of videoconferences requires stable network conditions. Sharing a wireless network with emergency home-schooling older children and a partner working from home resulted in an unreliable network and bad conditions for technology-enhanced work. It created better network conditions for the family if I continued to commute. The train to campus is not crowded and allows safe travelling several times a week.

I had experienced good work conditions with fewer disruptions than expected, mainly afforded by a strong network of colleagues and many years of experience in developing and applying digital practices. Nevertheless, I am worried about the pandemic impact on collegial and social cohesion at work. It has weakened and, I think, new and inexperienced colleagues suffer the most from the emphasis on digital practices and the exclusion of meetings at the office. They need physical meetings for 
networking and learning to know people: and to be able to learn how to be successful in their endeavors and how to participate in academic communities.

After the overturn of the lockdown, we need to find ways to rebuild lost grounds. Among the issues for productive post-pandemic conditions, collegial and social cohesion stands out. What post-pandemic conditions do we need to create to avoid the risk of having digital practices leading to high levels of isolation and low levels of collegial and social cohesion? Prudent solutions may eventually lead to even better practices in the post-pandemic condition. Maybe the best is yet to come.

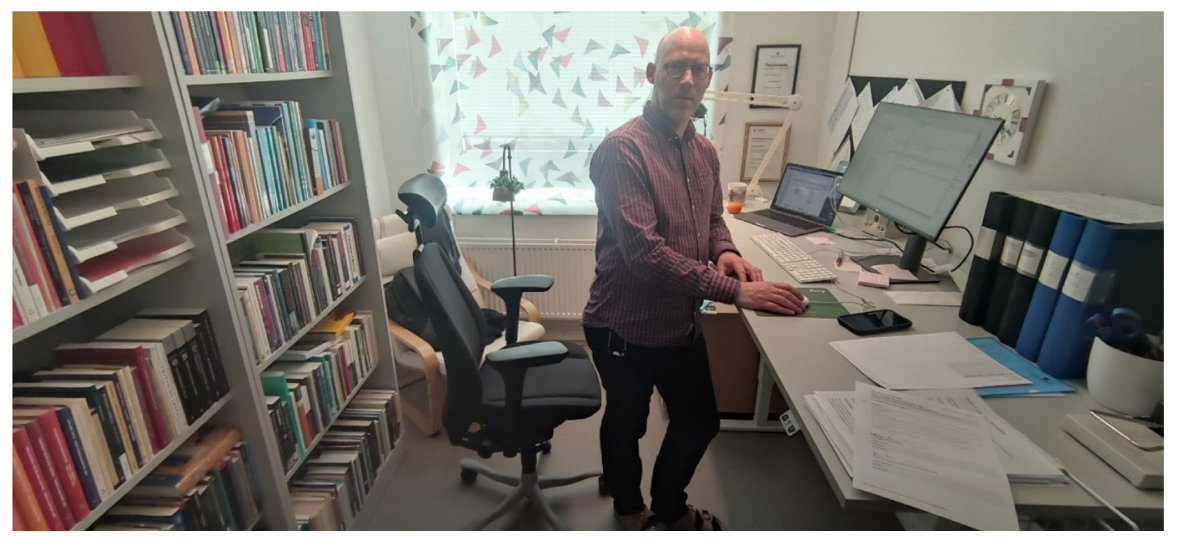

Fig. 35 [New figure.] My office at Mid Sweden University

\section{Twelve Months Later}

Susan M. Bridges (nee Hawthorne), Hong Kong, China, 28 April

[Updated biography.] Susan Bridges is an Associate Professor and Director of the Centre for the Enhancement of Teaching and Learning at The University of Hong Kong who teaches qualitative methodology. Her adult family has been separated between Australia and Hong Kong due to Covid-19 border closures. They continue to enjoy 'virtual wine tastings' with dad as sommelier.

This text revisits my 'Two Months In: Covid-19 in Hong Kong' poem from March 2020 (Jandrić et al. 2020: 1091). I continue to reside, teach, and research in the Hong Kong Special Administrative Region (HKSAR) and retain my identity as 'bi-located' between my two homes of Hong Kong, China, and Queensland, Australia. By February 2021, the rest of my family was in Australia. I remain with the same university and in mid-2020 took a leadership role as Director of the Centre for Teaching and Learning (CETL) working with a dedicated team to support colleagues' transition from our initial 'emergency remote teaching' experience to online/dual-mode/hybrid/hyflex/scenarios (Hodges et al. 2020).

Since January 2020, Hong Kong has endured various COVID-19 'waves' addressed by responsive and mostly successful public health 'restrictions.' The 
language of 'lockdowns' has only arisen recently with the advent of a new strategy to isolate and test entire residential buildings or blocks where cases were identified. These strategies have kept Hong Kong safe, but, as elsewhere around the globe, their ever-shifting nature can be somewhat disorientating. We have continued to adapt to partially closed borders, government quarantining, social distancing, and selecting the best facemasks and work from home (wfh) equipment.

As an immigrant and diversity advocate, sensitivities are aroused when 'superspreader' events are attached to ethnic populations. Criticisms of 'expat' non-compliance in my March 2020 contribution were again evident in March 2021 following a gym superspreading event. Vaccine choices in Hong Kong may be read as political with travel passport discussions a hot topic. We have prevailed, and hopes are raised for travel home. This poem shares one academic's account of life with Covid-19 since March 2020.

\section{Twelve Months Later: Covid-19 in Hong Kong}

Focus narrows to digital flows from inscribed groups - WhatsApp, Instagram, my 'go-to' ed-tech \& epidemiology tweeters; chp-dashboard.geodata.gov.hk; @hku.hk; HKU Zoom

6 months in: becoming (not Michelle) and diving headfirst (as Director)

Emergency remote teaching/Education 4.0/ Summer Sandbox on course re-design:

Connect, nurture, sustain, inspire...choosing to be an eagle

Three waves endured with loved ones, the fourth solo sustained by friends and colleagues; $2^{\text {nd }}$ home seems further away

Ursus 'superspreader': isolate, wfh, avoid accusatory stares

Talk centres on vaccine choice, government quarantine facilities and the future

Finding new rhythms: waterfront walks, YouTube yoga; virtual meeting hangovers - 'AERA broke me' tweet summed it up

Count blessings: still healthy and employed; first jab done; family well and safe in Australia Hong Kong is 14 months in, is there an end in sight?

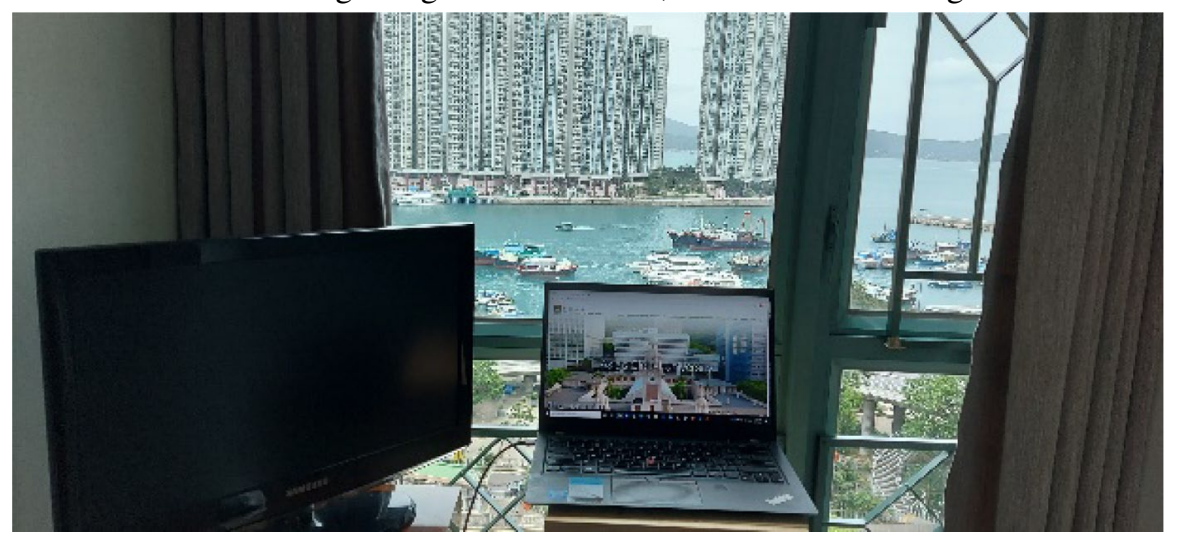

Fig. 36 [New figure.] My work from home (wfh) workspace: Repurposing a bedroom with an improvised standing desk, laptop with Zoom update (5.6.3) installed and audio linked to AirPods 


\section{And the Struggle Continues... Covid-19!}

Navreeti Sharma, New Delhi, India, 28 April

[Unchanged biography.] Dr. Navreeti Sharma is an assistant professor, Global Languages Centre of O.P. Jindal Global University. She has done her Ph.D. in French studies and lives in New Delhi, India.

$$
* * *
$$

I am writing this testimony from my residence in Delhi. I did plan to visit my O.P. Jindal Global University at Sonipat and my second home on the campus this month, but unfortunately, that has not happened. In fact, it has been more than a year now, since the onset of the pandemic, and I have not been able to visit my workplace.

The situation in India is very painful at the moment. At the beginning of 2021, it seemed that we will soon win the war against Covid-19, with vaccinations and the efforts to open up the economy. Unfortunately, we are back to square one. The virus is spreading like wildfire and endangering people's lives. Here, in Delhi, we are all locked down in our homes. For me, the month of April has been very challenging and traumatic, as my family members are in the grip of the deadly virus. Stressed and anxious, I try my best to carry out my official duties and commitments.

Being a professor, I continue to work from my home. During the ongoing pandemic, my university continues to play a pivotal role in the lives of the students and the professors. It has left no stone unturned, to provide quality education and intellectual growth to the students. During these challenging times, the university management also continues to provide every possible emotional and moral support to our students and professors.

At the same time, the university provides free access to various e-Resources, e-Books, and e-Journals to students and professors across all domains. Various online interactive sessions and webinars are organized on regular basis, which involves constructive debates involving students, professors, and guest speakers, on various themes. Through the official online platform, MS Teams, I am able to establish a close contact with my students and continue to teach French grammar, culture, and civilization. Students participate in online classes and interactive sessions with enthusiasm.

At the end of 2020 and the beginning of 2021, I had an opportunity to organize various webinars/interactive sessions on various themes such as French language, culture and civilization, ${ }^{11}$ opportunities for studying in France, ${ }^{12}$ and experiences in the Francophone world. ${ }^{13}$ My students had been quite engaged in these sessions, which resulted in fruitful exchange of knowledge.

Students and the professors are trying to give their best; yet our online academic journey since the beginning of the pandemic has not been easy. We all hope that someday the situation will change for the better and that we will soon return to our normal life on campus.

\footnotetext{
11 See https://youtu.be/CjomjjghtIw. Accessed 28 April 2021.

12 See https://youtu.be/jv6iEJ1uOJ4. Accessed 28 April 2021.

13 See https://youtu.be/NaNiZtrHnoY. Accessed 28 April 2021.
} 


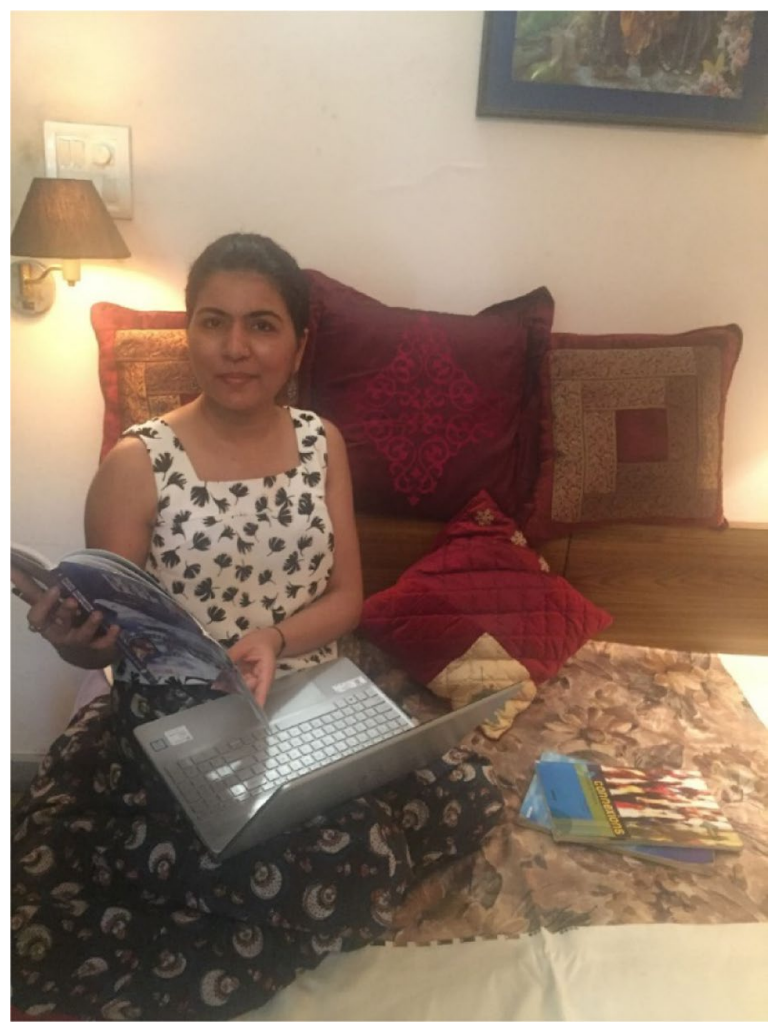

Fig. 37 [Unchanged biography.] My workspace at home in Delhi: One of the rooms is my workspace. It is a nice and a cozy room, which permits me to carry out various official tasks

\section{Were We Ever Social?}

Jacob Davidsen, Nørresundby, Denmark, 29 April

[Unchanged biography.] Jacob Davidsen is Associate Professor of digital learning at Aalborg University, Denmark. Jacob is 37 years old and lives in Nørresundby, Denmark, with his wife and three children.

Last year, I tried to hide myself from the rest of the family in the basement during the complete lockdown in March-April. Since then, I have moved my office to the 
top floor of our house. Compared to last year, I now have a much better physical arrangement, and most importantly, the kids are back in school and kindergarten. In my new temporary office, I can see the fjord and the city of Aalborg when looking out of the window. Some days the fog is so heavy, and everything is unclearexactly like my work life is some of the days. When the sun beams through the window, everything is getting clearer and brighter.

At Aalborg University, management decided to merge the Humanities and Social Science faculties in the middle of the pandemic (January 2021). We are not only trying to cope with teaching and researching in the age of Covid-19; we are also under extreme organizational conditions - where doubt and misbelief are common feelings among staff.

In Denmark, Higher Education institutions are allowing $30 \%$ of students in the campus. Teachers and students have not been in university buildings since before Christmas. Ahead of us is major re-boarding task-what is a workplace in the aftermath of the pandemic? Have we forgotten how to be together with colleagues and students in the same room? It will be one big breaching experiment, when we try to re-board social life again.

Teaching in the age of Covid-19 has been a mixed experience- I am teaching in different programs and each class is very different. These differences are not newbut they are enhanced in the digital age. I have faced the plague of dark screens (no bla-sha-ming of students), but I have also experienced very engaged students bringing energy and good spirits. When I look back at last year, I think that one of the biggest mistakes we have made as educational institutions was to keep the traditional time slots for lecturing. In a sense, we have been giving the ultimate freedom for organizing our teaching, but we ended up with the most traditional setup one could imagine. While we have seen a lot of interesting pedagogical experiments, we have also seen that the structure of teaching in Higher Education is very difficult to change at a large scale.

My most positive teaching-related experience during the pandemic has been the introduction of QiGong to a group of master students. Every Friday, we do 4-h blocks and it is very tiring. To shake things up a bit, I mixed in an introduction to QiGong with Don Fiore ${ }^{14}$ (a YouTube phenomenon) into my class. Now, the students expect 5-10 min of QiGong in all classes-it is adding some of that social glue that we are missing these days.

14 See https://youtu.be/xiTSC2KUAyU. Accessed 1 June 2021. 


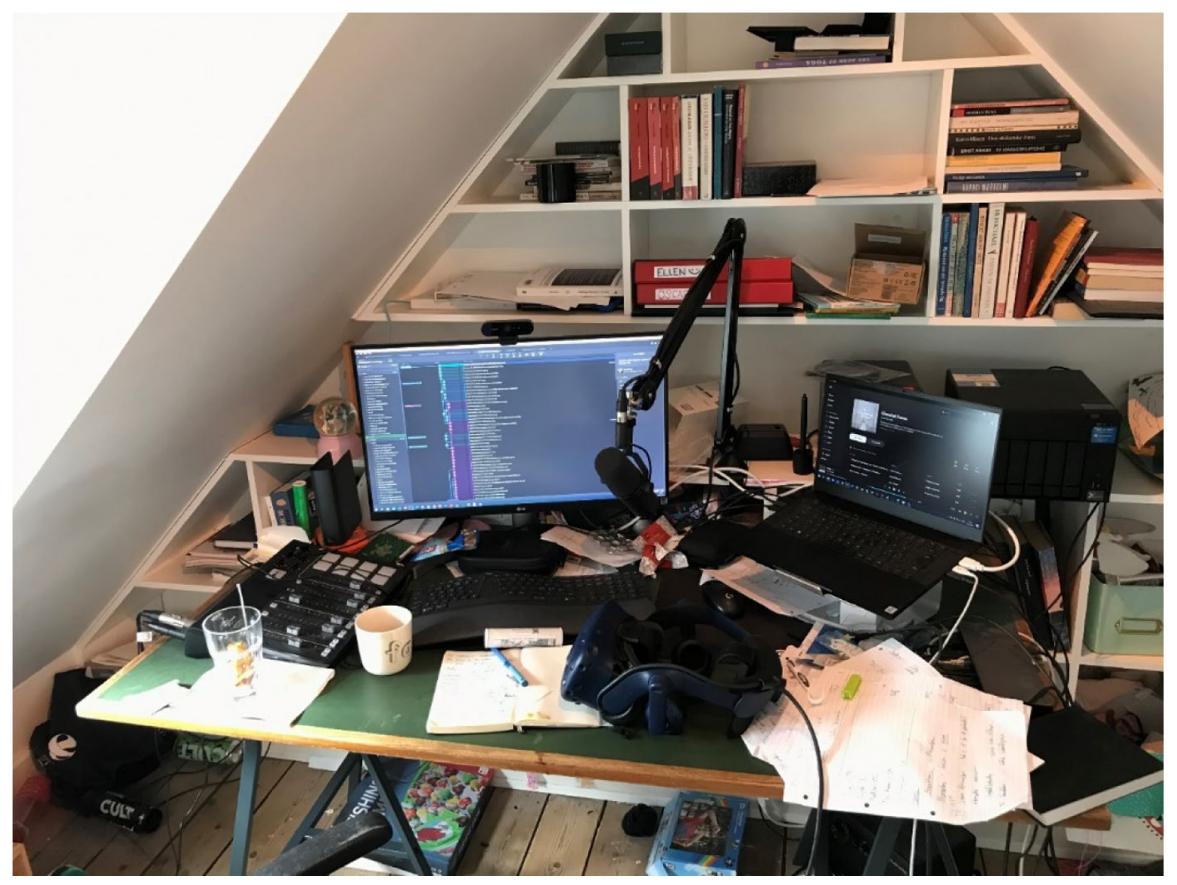

Fig. 38 [New figure.] New office with a bit more space for new technologies and experiments. Currently producing tutorials using Volumetric Capture in our Virtual Reality software AVA360VR

\section{Living in a Covid-19 World - 1 Year Later}

Jānis (John) Tālivaldis Ozoliņ̌s, Ballarat, Victoria, Australia, 30 April

[Unchanged biography.] Jānis (John) T. Ozoliņš is Professor at the University of Notre Dame Australia, Visiting Professor at the University of Latvia, Latvia and Adjunct Lecturer, Catholic Theological College, University of Divinity, Melbourne, Australia. He lives in Ballarat, Victoria and also in Riga, Latvia with his wife. He has four adult children.

Just as last year, I am writing this from my study in Ballarat, Victoria, in the same place and in the same house. Here in Victoria, we endured many months of strict lockdown, unlike the other states in Australia. After a brief lifting of lockdown in May 2020, a rapid rise in hotel quarantine Covid cases that subsequently escaped 
into the general community resulted in draconian lockdown procedures for Melbourne and slightly less stringent lockdown in the rest of the state. Out of a total 910 deaths from Covid in Australia thus far, 820 of these have been in Victoria, which shows the severity of the outbreak mostly in Melbourne.

Due to the large number of cases at its peak in Melbourne, residents were prohibited from travelling more than $5 \mathrm{~km}$ from their homes. Residents could only travel to the supermarket, for medical care, or if they were carers. A curfew was also imposed. A 'ring of steel' was erected around Melbourne to prevent anyone leaving Melbourne for regional Victoria and vice versa. Visitors to your home were prohibited, save if they were carers. Life became very isolated, as we were allowed to go to the supermarket once a day. State borders with Victoria were closed and checkpoints set up to prevent people from sneaking across the border. The wearing of masks was made mandatory. People in aged care homes could not be visited at all. Bars, restaurants, and hotels were closed, with takeaway meals only available. Fines were imposed for breaches of these restrictions. Universities and most workplaces were also closed. Interstate and overseas travel became virtually non-existent. Melbourne became a ghost town.

Lockdown continued until October when restrictions began to ease. The influx of visitors from Melbourne to regional towns like Ballarat, however, was not uniformly welcomed, as fears of Covid transmission remained. Interstate travel has resumed but is still well below pre-Covid levels, as much business travel has been replaced by Zoom meetings. International travel out of Australia is presently only possible to New Zealand, with whom a 'travel bubble' has been established. We cannot return to Riga.

For most of 2020, teaching was conducted online, and this meant significant modifications to the way in which classes could be conducted. Materials for a new course had to be prepared almost in their entirety prior to the commencement of the course, so that the students could have access to the resources they needed. This was especially important because campus libraries and other university facilities were closed. On the plus side, it was not necessary for anyone to leave their homes, as everything could be done online. Face to face classes recommenced at the end of February, though with social distancing in place.

Vaccinations against the virus have commenced but are proceeding somewhat slowly. With the gradual opening up of workplaces, restaurants, places of worship, the return of sporting events, life is returning to some semblance of normality. It will never be the same as it was, since the lockdowns have left their scars. People remain on their guard. 


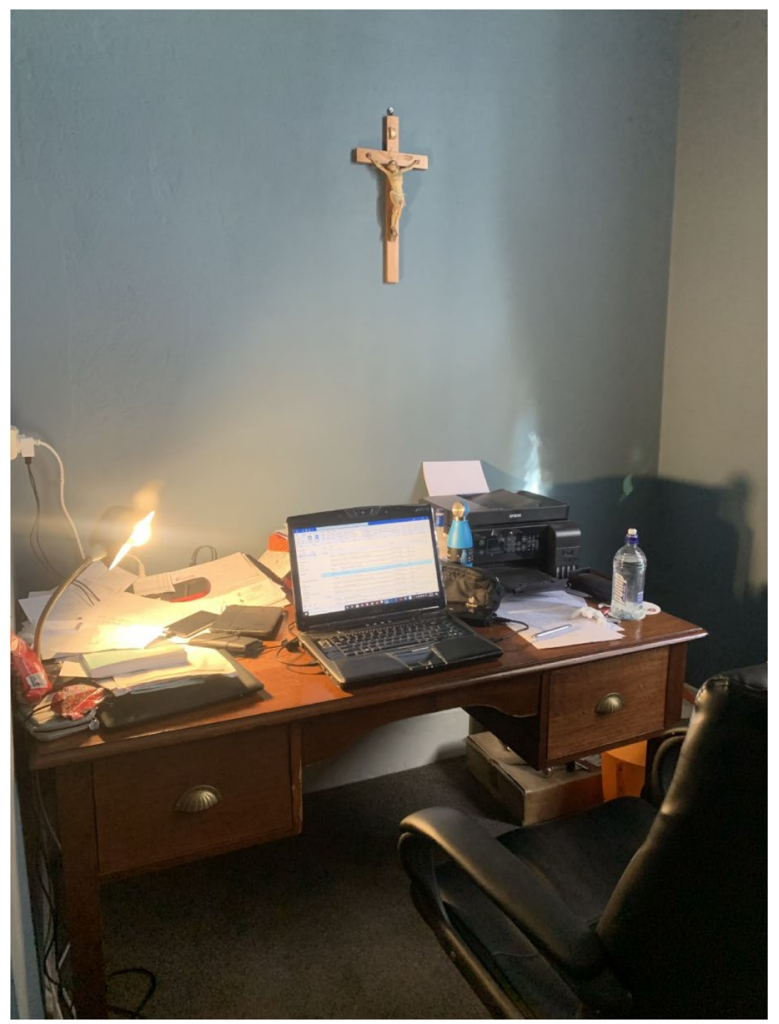

Fig. 39 [New figure.] My desk in my study at home in Ballarat, Victoria, Australia. From it, I taught online, had many Zoom meetings, did research, and occasionally prayed during 2020

\section{London No Longer Exists: Re-Defining the Rites of Passage into a Post-Crisis} World

Peter Bryant, Sydney, Australia, 30 April

[Updated biography.] Peter Bryant is Associate Professor of Business Education and Associate Dean Education at the Business School of the University of Sydney (Australia). He has spent the last 16 months pivoting, reacting, and learning through implementing pedagogical change in a time of crisis.

London no longer exists. This is a line from the 1988 song by the Go-Betweens called Love is a Sign. It is 12 months since I started the last article referencing another Australian band, the Aerial Maps, who declared that London still exists. 
Why did the metaphorical London cease to exist over the last 12 months? I am still working from my desk at home for some of the week, but Australia's isolation, closed borders, and effective response to Covid-19 has meant I can go back to the office 3 days a week. The same cannot be said for our students, with $60 \%$ of the University of Sydney Business School population located overseas. The domestic students are slowly returning to the normalcy of classrooms and tutorials, with their online friends looking into the campus bubble through a camera. Our view into their worlds and spaces is equally limited to the tiny windows offered by Zoom.

The pandemic has broken down many of the social structures underpinning higher education. Borders and iframes have replaced communities and lecture theatres. The university experience of 2021 is rent with uncertainty, ambiguity, and messiness. Our students have been thrust into a liminal journey shared in social isolation, asynchronous interaction, and a fear that this way of learning will become the new normal. As Thomassen (2006) notes, people in liminality '...live outside their normal environment and are brought to question their self and the existing social order, [they] come to feel nameless, spatio-temporally dislocated and socially unstructured'. Our students have gone from having structure within their social and educative societies to experiencing anti-structures, where the inversion of teaching and learning rituals and the dislocation from their cohort and their institution defines their experience.

Along with the mandated online pivot, the school made several existential pedagogical changes to support students and staff through their liminal journey, as well as find ways to learn from it. We built our online lectures on principles of information engagement, chunking them into more digestible components, encouraging teaching teams to incorporate multiple perspectives and add interactive elements. We shifted assessment to more authentic modes using technology and testing advanced skills of problem solving and application. We built programs of intra and extra-curricular engagement to support connection-making between students through research, through leadership development, and through crowdsourcing critical global, local, and personal challenges.

But most importantly, we tried to understand and adapt our practices to how lonely and isolating these pandemic years have been for students and staff. We have built and nurtured online communities of sociality and practice sharing, encouraging our school community to find fleeting and lasting meaningful connections. We remain a fractured community, but we are not broken. Our worlds just intersect less frequently. London still exists, of course it does. It is just that the windows we use to see those other worlds are still a little small. My hope is that they continue to open up and to allow for all the affordances of virtual and face-to-face teaching and learning to breathe together once again. 


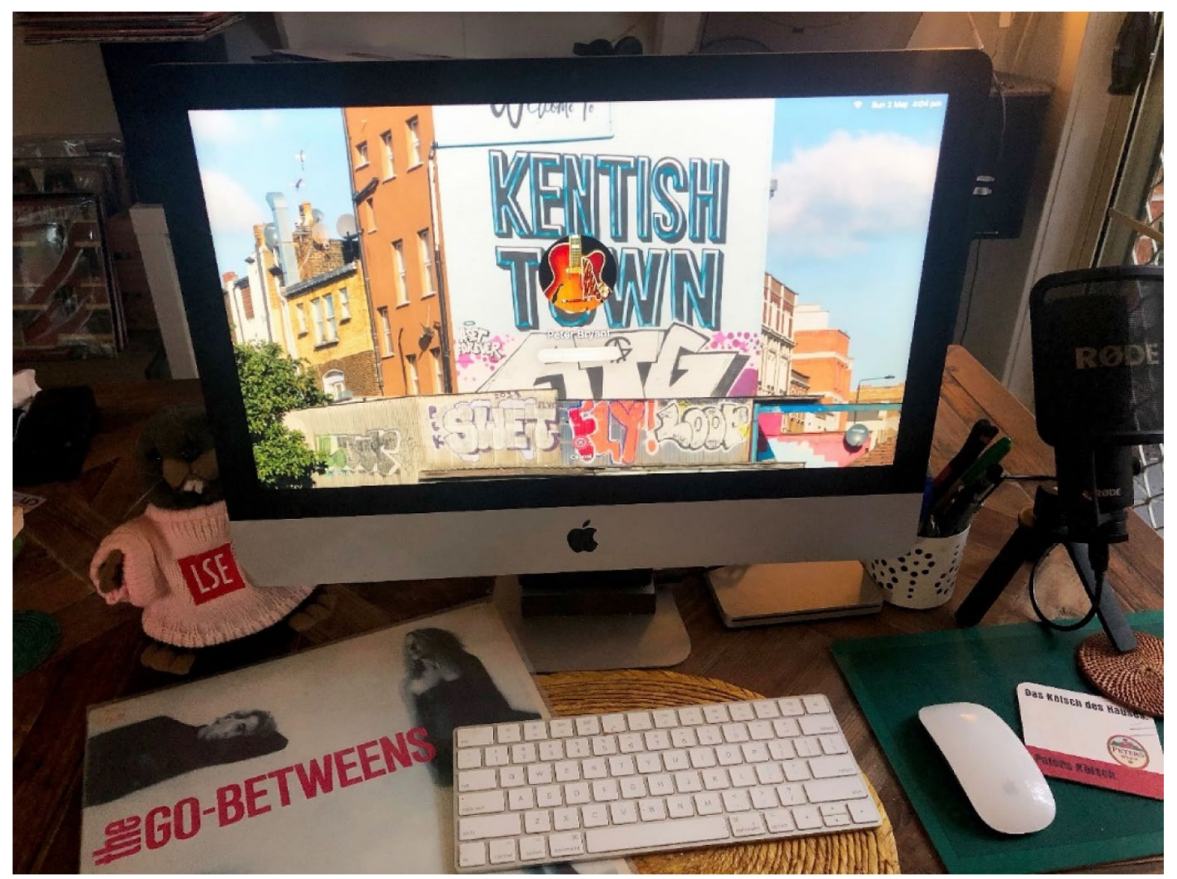

Fig. 40 [New figure.] My desk at home, 1 year on. I have memories of my homes, past and current around me. Kentish Town in London as the background of my computer and a copy of the Go-Betweens LP 16 Lovers Lane, the last thing I had listened to on my stereo before I took this picture

\section{Paradoxes and Parentheses}

Carlos Escaño, Seville, Spain, 30 April

[Updated biography.] Carlos Escaño is an Associate Professor of art education at the University of Seville, Spain, and Visiting Professor at UNED, Spain. He is director of the Research Group Education and Audiovisual Culture (HUM401) and Editor in Chief of Communiars ${ }^{15}$ journal.

Seville. Spain. One year later. Nowadays, I enjoy a little more than 50 square meters of creative freedom. The computer and Internet connection have continued to accompany me in my professional university tasks (as before, during, and after the

15 See https://revistascientificas.us.es/index.php/Communiars. Accessed 14 June 2021. 
months of lockdown). The pandemic made me move out, within my own city, and to value a few meters of outdoor space. A terrace as a priority and as what it really is: an everyday luxury in the city center. Luxury that used to be a little more unnoticed in a daily life that was suddenly accelerated even though paradoxically, we were in times of parenthesis and self-isolation. Throughout this year, I have said goodbye to loved ones who, in one way or another, left in an accelerated way because of this situation, directly or indirectly due to the action and damage of the Covid-19 virus. I firmly believe that in an alternative parallel time, it would not have been their time of departure yet.

This time of supposed parenthesis has also been a time of paradox at the professional level. Generally speaking, the university has suffered a year of expectations and frustrations: postponed grants, postponed congresses, postponed projects, postponed stays, and impossible trips. The entire academic community, like so many other professional sectors, remains mortgaged to the times of the advance of medical science. A life postponed. But probably (and here is where the paradox appears), this vital parenthesis has provoked a space for social reflection on the meaning of vital postponement in contemporary life. On many occasions, what was postponed was not only life, but also that which probably prevents life from developing: an excess of work that operates as an excellent tool of control and biopower. And I fear that this time of so-called reflection in the context of university education has not borne its best fruits.

The pandemic time has torn the seams of university educational environments on an international scale. A deficit in technological infrastructure in many centers, institutes, and faculties has been revealed, and the precariousness of teacher training in digital pedagogy has also been evident. A few professors, with little or even no training, have pontificated on what should or should not be done with education in digital contexts. But the most disturbing issue has been not so much this lack of training in digital pedagogy, but the lack of pedagogical training in general. The main effect of the pandemic in educational terms can be summarized as follows: a transfer of face-to-face pedagogical vices directly to the digital context. The pedagogical actuality is not essentially different from the pre-Covid-19 era. But in this pandemic time, it has only been accelerated and its precariousness has become more visible. I firmly believe that in an alternative parallel time, a radical educational transformation would have been just as urgent and necessary (regardless of paradoxes and social parentheses). 


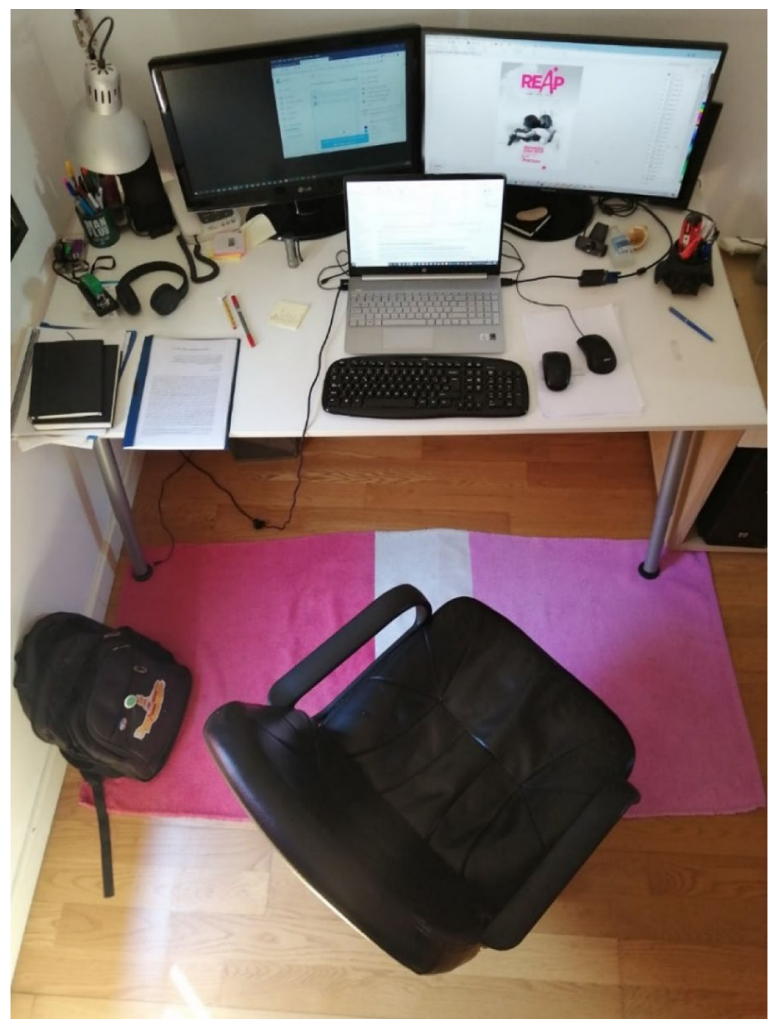

Fig. 41 [New figure.] My workspace, my network node.... In an alternative parallel time my workspace would have changed little

\section{A Pedagogy for Empowerment and Hope}

Jones Irwin, Dublin, Ireland, 1 May

[Unchanged biography.] Jones Irwin is Associate Professor in Philosophy and Education, Dublin City University, Republic of Ireland. Jones lives in Dublin with his family.

This time last year, I contributed to Petar's Call for Papers on 'Teaching Under Covid 19' and I noted the need to see the positives amidst the pain and disorientation of the worldwide pandemic. I quoted the ' 68 revolutionaries and their prescient cry of 'No Return to Normal.' 
More than a year later, on May Day, I write this updated response from Dublin, Ireland. May Day is the day to highlight the often-denied rights of workers and employees but also their often-unsung achievement. Certainly, there are many stories to tell of such valour this year of front-line public workers especially who have kept people alive literally or watched over the last hours of citizens with care and love. The tragedies of such people and their families and communities have been immense, made worse by the inability to actually mourn our loved ones properly and authentically. Moreover, the toll on front line health-workers most particularly has been heartrending - whether in terms of emotional-traumatic impact or simply, and shockingly, in terms of the health workers lost to the disease (often through lack of proper protection and foresight from the authorities).

What sense can we make of this acute crisis in society and in environment, as educators? This is our front-line worker task, as workers of the places of education. These pedagogical spaces have been overturned from dynamic and energized environments of critique and learning to effectively Ghost Towns. I have been lucky enough to live within the allocated radius to get to my university during the week, although the teaching is all online. This is the double alienation of the teachers working in empty warehouses of learning while students work at home in bedrooms and side corridors, often sharing these spaces with siblings and parents working from home.

In this, then, 1 year later and with lockdowns only slowly beginning to open up in Europe, while in India and in Brazil, for example, the crisis takes on a frightening intensification, it is clear that there indeed has been no return to normal. In this subversion of so-called normal existence, there have been some emergent aspects which do not bode well (as if Covid-19 was not a crisis enough). Demagogues of the Right have used the opportunity to prey on the gullible and weak, whether with Trump or Johnson, or even more catastrophically Bolsanaro or Modi in Brazil and in India, where the current failures of public service and vision are causing immense suffering to so many vulnerable people.

Bolsanaro's attack on public service and healthcare is a thoroughly consistent fascism. This type of inversion of the social good has happened before, as we know from Paulo Freire's work in Brazil and his subsequent exile. But we should also remember, with Freire, that 'una pedagogia per l'emancipazione e per la speranza' [a pedagogy for empowerment and hope] does not come without effort and pain. Moreover, the greatest danger is to consider that there is no alternative to this monstrous politics and to abandon ourselves to 'fatalism'. Who has not been subject to a certain thought of fatalism, in this immensely challenging year of Covid-19? Nonetheless, more than ever, we need to regenerate what Freire spoke of in the Popular Culture Movement. Against the current ubiquitous fatalism, if we are able to create culture - 'if I can make a vase out of clay' (Betto and Freire 1986: 24) - then we can also recreate and revivify our social and economic conditions, which, just like that vase, are also man-made elements of human society. 


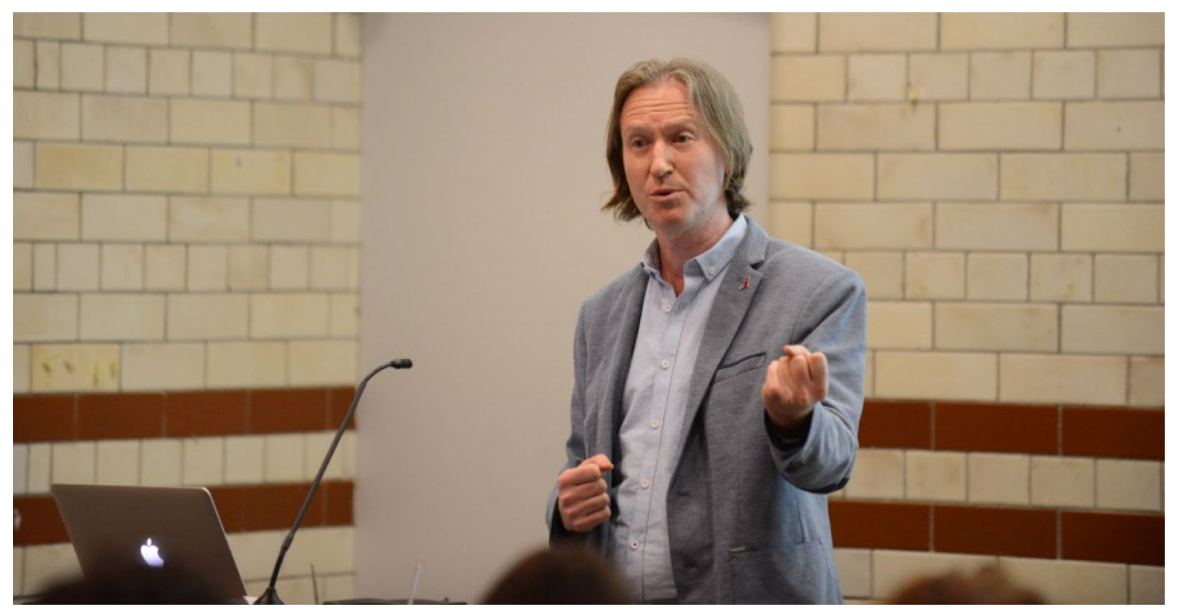

Fig. 42 [New figure.] Jones Irwin, 2021, hoping for a post-Zoom world

\section{Exploration 2.0-A Lost Me}

Kulpreet Kaur, Delhi, India, 1 May

[Updated biography.] Kulpreet Kaur is an associate professor at Jindal Global Business School and senior fellow at Jindal Institute of Behavioural Sciences at O.P. Jindal Global University, Sonipat, India. She lives in Delhi with her mother, spouse and two sons.

I belong to the land of Gods and Goddesses, where currently no extent of orison is offering any succor to survive through this second wave of Covid-19. The figures of nearly 400,000 new cases and 5000 deaths everyday seem to understate the collapsing condition of health infrastructure. As the unknown enemy spiraled into an uncharted territory, the hotels, stadiums, and worship places are being converted into hospitals. In absence of drugs, doctors, and oxygen, breathing exercises, yoga, and ayurvedic medicines are presented as lifesaving alternatives, and canine crematoriums are set up for human cremations. 'According to pandemic experts, the worst peak is yet to arrive'; a faint echo wrecks my subconscious nerves even during sleep. As I write this article under yet another lockdown, what I currently hear is only the cacophony of ambulance sirens, vailing cries of sufferers and holy verses.

The second wave has not only crippled the already fractured outcomes of distant teaching process; it has entirely shifted the pivot of learning from beyond the curriculum toward acquisition of life skills. Teachers have turned into mental health professionals striving to spread equanimity and tranquility despite mental fog and fatigue they themselves are experiencing. The science of happiness, wellbeing, and resilience has taken precedence over deliverance of content, concepts, and theories. 
I use embellishments to camouflage my excruciating pain and give students a glimpse of positivity and cheerfulness. Offering gratitude to the universe in the beginning of the class reinforces corroded hope. Students' unconditional listening is a means of catharsis experienced when I and my husband were admitted to the hospital with severe Covid-19 symptoms. After we recovered in November 2020, I have cared for nearly four more Covid-19 patients in my family. As an extended family, my students and I exchange notes of personal physical and mental health and remain connected through informal platforms. Few students are engaged with various NGOs to provide help and care to the victims.

Over the past year, my university's student-centered academic regulatory authority has left no stone unturned in their attempts to relieve students from pandemic stress. With no attendance compliance policy, lectures are being recorded and placed in the repository for later use. Central Board of Secondary Education's decision for cancellation and postponement of specific exams galvanized us to reduce the assignments for internal component of the assessment, extend submissions deadlines, and slash syllabi. To maintain the esprit de corps among the 2020 graduates, various research positions are on offer. As the admission process for Fall 2021 continues online, the possibility of onset of physical classes looms in the darkness.

I feel stuck and unable to climb beyond the second step in Maslow's hierarchy of needs. I hereby stand together with the whole world and seek blessings to emerge as pillar of strength and resilience from this catastrophe.

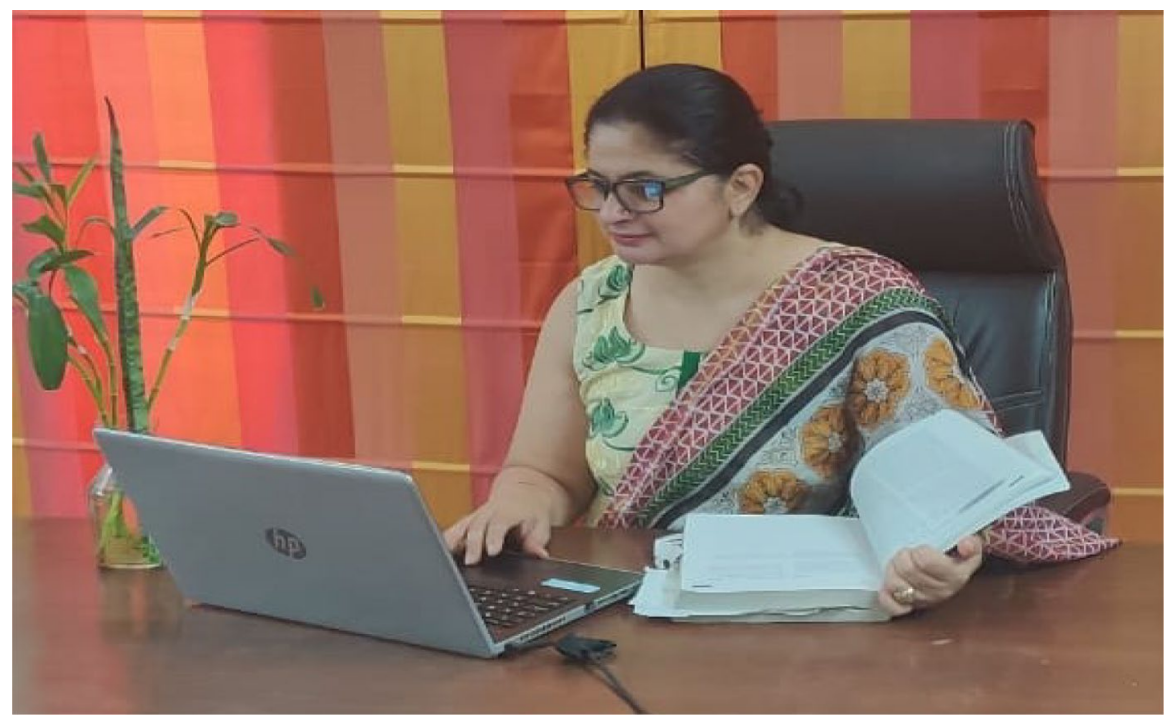

Fig. 43 [New figure.] As a mirror of my coherent mind, I have customized my personal workspace in this one year to exhibit stability. This indicates the astounding adaptability skills humans possess 


\section{Things That Make Me Sick}

Sarah Pfohl, Indianapolis, IN, USA, 1 May

[Updated biography.] Sarah Pfohl is a disabled, chronically ill artist and teacher. She makes work about the value, power, and complexity of a rural hill, the disabled body, and classroom teaching. Sarah runs the photo and art education areas in the Department of Art and Design at the University of Indianapolis, USA.

$$
* * *
$$

I wrote my prior testimony from a rental apartment 2 blocks away from my current location; I am writing this one in an apartment I purchased with my husband in July 2020. I still work as a photography professor at the University of Indianapolis. The biggest private changes I have experienced in the last year are homeownership and not seeing my immediate family (Mom, Dad, 2 sisters, and 1 brother) in person since August 2019, which totals 21 months at this time-the longest we have ever gone without visiting in person.

I wrote last year that it seemed unlikely that this pandemic would not bring about a shift in ways we think about and manage health but I think now I was wrong. All around me in the USA, after 14 months of distancing, I witness calls to return to pre-pandemic norms and life.

The pandemic brought about a paradigm shift. But without lenses through which to decode much of what surfaced relative to health and the body, the shifted paradigms cannot be metabolized, and in some cases cannot even be recognized and named. I appreciate that the past 14 months of life within the context of a global health crisis have been life under long-term duress and can understand cleaving to one's version of normal in the face of the unknown, but there are more and other important stories out there I would urge folks longing to get back to locate and heed.

This is also where education can come in and where I enter my work as a teacher, through the experiences of the pandemic, with a greater and deeper knowledge of the power and point of my work-to help people decode the world around them in more meaningful ways, toward service to others. There is so much work to be done to dismantle ableism, much more than I previously realized.

The normalization of wanting desperately to return to environments I experience as inaccessible reminds me constantly that I do not belong. Through the lens of the medical model of disability I find myself thinking, 'I don't fit in'. Through the lens of the social model of disability I find myself thinking, 'the site seems unable to recognize ways in which it could welcome and fit itself into the lives of more people more deeply'. I find myself concerned for my students with disabilities, who also must be subjected to righteous claims for the return to an in-person community that may also actively, both implicitly and explicitly, deny core aspects of their personhood through rationalized exclusion.

I did not think it was as bad as it definitely is. When you are disabled and primary aspects of your reality suddenly become social mandates, you learn what folks really think of your lifestyle. People have been judging you in ways you never would have realized. Oddly, this increased access to public perceptions of sickness and health, 
brought about by the pandemic, has helped me grow as an advocate as it revealed ways of thinking to which I did not previously have access.

While I critique the ableism within which I live and work, I have learned to perform something like thriving there, and do not know myself as well in a world in which I experience more accessibility. Due to the increased access I have experienced since March 2020, I have gotten sicker. I do not know how to live in a world within which I have the privilege of more access and subsequently took on too much, became too excited, overextended myself in a way I am less able to do when the world does not meet as many folks' ability-related needs.

I realize now that I am more experienced and hence comfortable in the world as permeated by ableism than the alternative for which I also advocate to the absolute best of my ability. What I advocate toward is a predominately theorized world I am unsure as to how I would encounter.

I want to live in a world I cannot and do not know how to navigate. I want to live in a world I do not recognize. I want to live in a world I have still never known.

So perhaps in sum, I am made of and by the worlds around me in ways that continue to take me by surprise. I continue to want to teach and move forward with a measure more resolve.

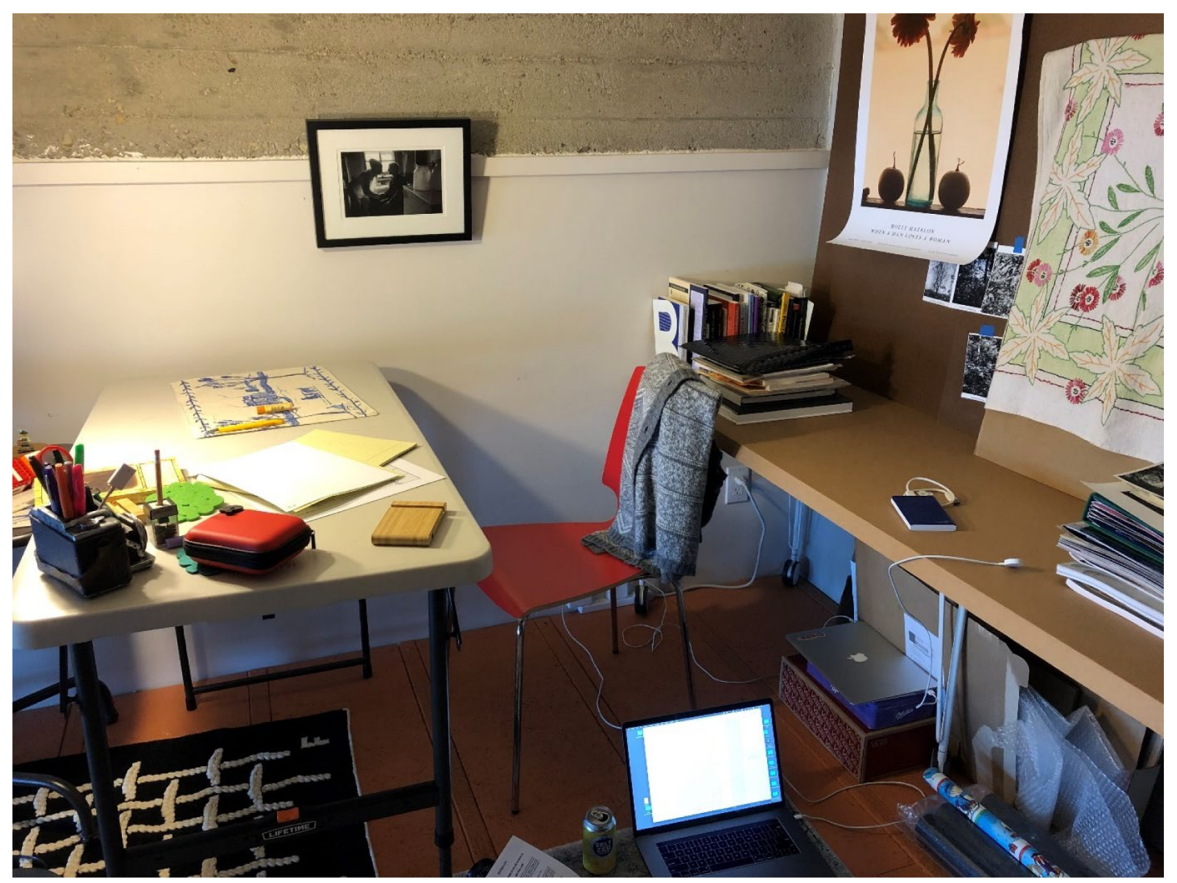

Fig. 44 [New figure.] Prior to buying a home in July 2020, I worked in a walk-in closet. Now, I have my own workspace! 


\section{Meanings Change}

Kevin Stockbridge, Santa Ana, CA, USA, 2 May

[Unchanged biography.] Kevin Stockbridge is a clinical assistant professor of teacher education and student affairs liaison at Chapman University, USA. Kevin is 40 years old and lives in Santa Ana, CA, with his fiancé.

I am presently writing at the same house in Southern California in which I wrote my first reflection. This is the same residence in which I and my partner weathered the Covid-19 lockdowns over the past year. Specifically, I am sitting next to a small wood burning firepit that is keeping me warm on an outdoor patio under the stars in my backyard. The firepit, the patio, and even the outdoor furniture that I am using are new additions to our home.

A year ago, I was musing on the difficulty of completing my first full-time teaching position in higher education while wrestling with crippling anxiety. I learned new coping strategies for dealing with uncertainty and loss through this difficult time. I now serve as an assistant professor and student affairs liaison, in which capacity I assist graduate students who are facing challenges that affect their academic performance. As one might imagine, there have been quite a few challenges. There have been many tears shed by both me and the students that I serve over innumerable realities that they have faced. It has been a busy and taxing year.

Currently, the number of Covid-positive cases is falling rapidly as the number of people who have been vaccinated is rising. My university has moved to offering hy-flex classes since mid-March. All instructors have been required to teach online from their empty classrooms or offices on campus since the beginning of February and, starting in late March, students have been given the opportunity to attend class in-person. Very few students physically attend classes. In fact, some of my students attend class virtually from other parts of campus, steps away from the classroom in which I am gesticulating in front of two cameras while keeping an eye on the chat. By next year, the university has noted that students will no longer have the option to take classes in a fully online format. Since receiving the full course of a vaccine, my anxiety about being on campus has abated, and I am finding a lot of joy in returning to university grounds. I feel a sense of happiness in teaching when students join me in the physical classroom that had been missing in the virtual experience.

In my first reflection, I noted that I hoped that we would make important meanings from our experiences of the Covid-19 pandemic. I am not sure that we have moved far enough from this time to clearly make sense of all that has happened. A social desire to make meaning of all this has led to innumerable articles, webinars, and presentations already, and I expect many more will come. As a nation, we have seen righteous unrest take shape over the last year as many have pushed for racial justice and equity. We have also seen the rise of violence and the deepening of social divisions. What will we make of the time before us and which meanings will hold as we build a post-pandemic future? 


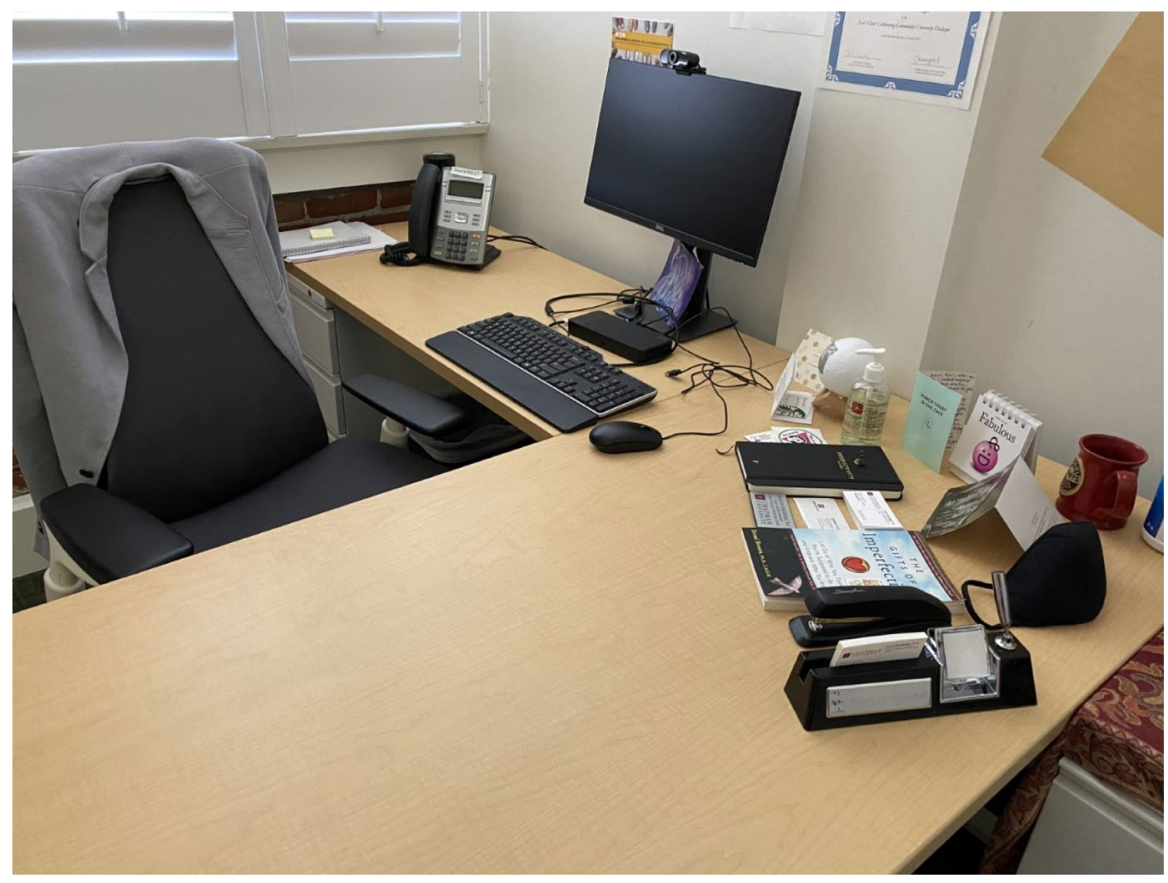

Fig. 45 [New figure.] This is my office at the university that I have had the chance to return to since the lightening of restrictions. This serves as both classroom and workspace when I am on campus

\section{Gaps and In-betweens}

Thomas Ryberg, Aalborg, Denmark, 2 May

[Updated biography.] Thomas Ryberg is Professor of PBL and digital learning in the Department of Planning at Aalborg University (AAU), Denmark. Thomas is 44 years old and lives in Aalborg, Denmark, with his partner and their two daughters.

$$
* * *
$$

I am writing this updated testimonial sitting in my home, which seems to have become the new normal. After a brief period in the autumn/winter where we were allowed back to the university, we have been working from home since December (and until February with the kids being home-schooled simultaneously). While in other workplaces people are allowed to come to office, the universities, and the public sector more generally, are working from home to minimize Covid-19 spread. 
In November, I took up a new professorship in a different department at Aalborg University. This was in many ways a welcome change for me, but it has also been difficult to enter into a new research group amidst a pandemic, where it has been difficult to meet all my new colleagues face-to-face and to get a grasp of all the new people in the department. Adding to this, we were also informed that our research group and center would enter a new cross-faculty Project Based Learning institute that is under development. In many ways very turbulent times with loads of changes.

And yet, strangely, I have had to experience all of this from home. At home, the greatest change is that I have switched from sitting mainly in the living room to now occupying my oldest daughter's room while she is in school (so if I am not using a virtual background, people get to see a glitter-ball hanging behind me from the ceiling). There is an odd sense of one-dimensionality to the work. Although working with people from all over the world and shifting quickly from meeting with colleagues in Australia to people living close by, it is all happening within the confines of 'home sweet home'. Sometimes, it feels like the world is your oyster, but simultaneously, you only have access through looking at the whole wide world through the keyhole of the World Wide Web. Although we often talk about 'meeting online,' we are all hyper-localized, and we are meeting people in their bedrooms, kitchens, or living rooms. We are everywhere, but always very much 'here', at home.

The switches between meetings in vastly different contexts are often hyper-efficient. At 9:50, you are together with people from your research center. At 10.00 A.M. sharp, you hyper-jump to Australia, and at 11.00 A.M., you teleport to an online conference hosted by a Malaysian University. While in many ways efficient, it often leaves little time in-between. Normally, we would move to another building, walk to another room, travel for extended periods. These gaps or in-between have been removed, and it leaves less time on the move, for being in the gaps and the in-betweens. These gaps are perhaps, I am now thinking, valuable spaces for reflection, for processing a meeting or a conference session. While I am still thriving and coping well with work, the one-dimensionality of experience and the super-efficient schedule leaving less time for the thoughts and reflections in-between all the hyper-jumps. In the future, I think more of my work (meetings and presentations) will likely become online. There are many advantages to that. It is more flexible, and it allows wider participation. However, I will be more attentive to the gaps and in-betweens, and how to design and plan for these. In their absence, I have realized their value. 


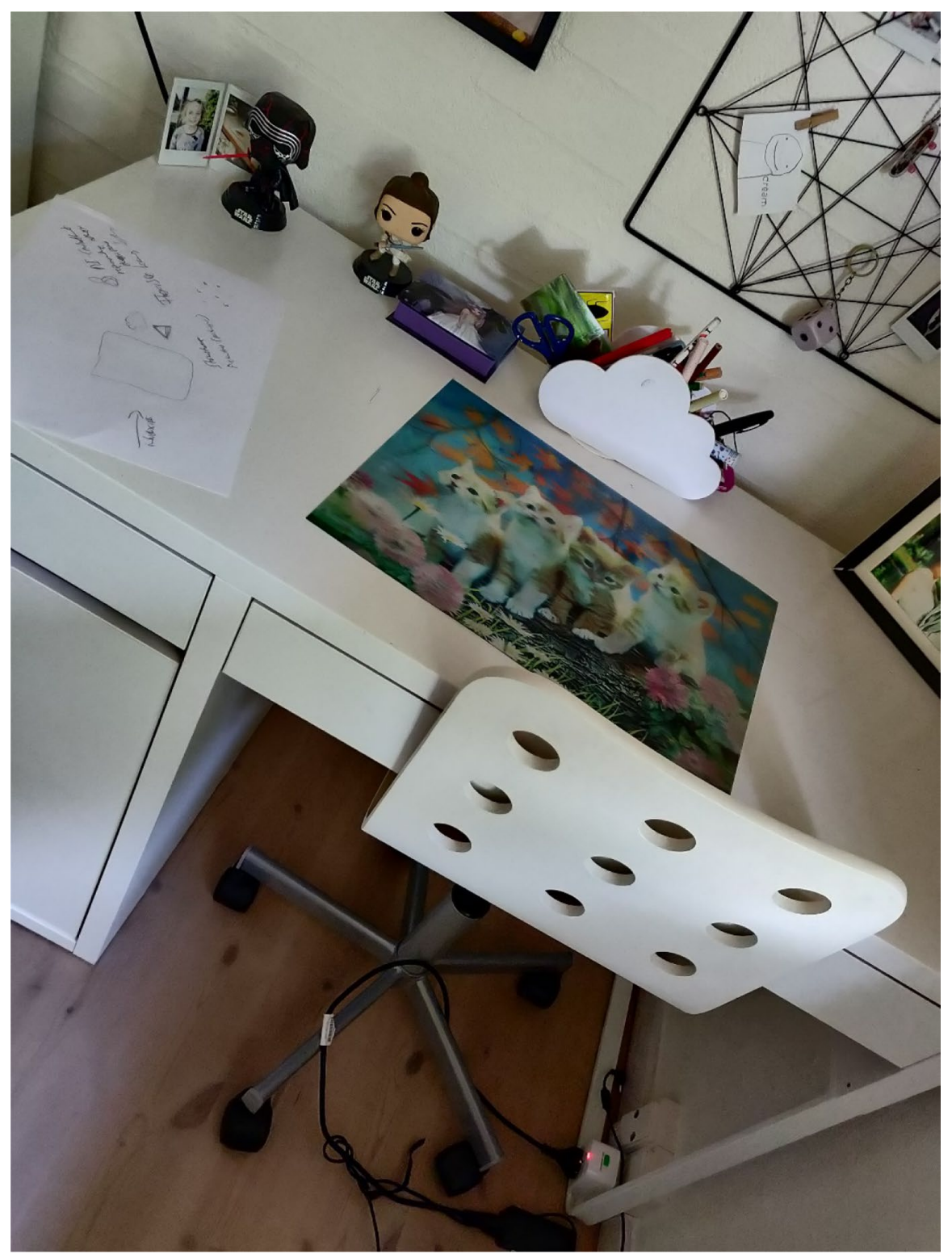

Fig. 46 [New figure.] Working at daughter's desk 


\section{Covid-19 as a Perspective Machine}

Olli Pyyhtinen, Turku, Finland, 3 May

[Unchanged biography.] Olli Pyyhtinen is Associate Professor of Sociology at New Social Research (NSR) program, Tampere University, Finland, and the founder of Relational Studies Hub (RS HUB).

$* * *$

In 1525, the painter Albrecht Dürer built a perspective machine to make it easier for the artist to translate the three-dimensional world into two dimensions. The machine consisted of a square wooden frame with horizontal and vertical threads stretched across it at regular intervals forming a grid. By looking at his chosen subject through the grid, Dürer could represent space using the single-viewpoint perspective that is very familiar to us today but was unknown to artists until then. I have been thinking about Dürer's machine a lot during the past months and how seeing necessitates a labor of abstraction, that is, selecting some features of what appears before us and leaving others out.

I am tempted to think of the Covid-19 pandemic as a kind of perspective machine. It has made me see the world perhaps more accurately than what would be possible with the naked eye (though of course we never see anything just by opening our eyes, but our vision always depends on concepts, culture, and other viewing instruments). I am not only talking about how it has set the suffering of others and the suffering of the earth into a new perspective, but also about how we are forced to invent. Recovery from the crisis cannot mean restoring the earlier condition, returning to how things were before-we cannot have our old life back—but we need to come up with new solutions; create the world anew. If not, we will just fall back to the original course which has led to the crisis and end up in a state of crisis in a loop-like manner (see also Serres 2014). Compared to Spring 2020, I am now feeling a new kind of hopelessness in the face of the persistence and constant mutability of the virus. The crisis seems so complex that it is close to unsolvable, and yet we are desperately in need of solutions. We cannot turn a blind eye to it and just wish it all would go away.

The affinities of Dürer's perspective machine and the crisis extend to personal life as well. Both fix you in place. Movement becomes impossible. However, not having to commute to work and travel for conferences and the fact that my social life has been limited to a minimum amount of contacts have brought certain calmness to my life. I was not the outgoing type before, but still I have come to realize the accelerated pace of my pre-coronavirus life, a pace that was moreover largely self-inflicted. While previously I was constantly on the move from place to place, commuting on several days a week, now I divide my time between two cities (Helsinki and Turku), staying in each for 1 week at a time. The last time I visited my office in Tampere was in March last year, and all my teaching has taken place online ever since.

The shift to remote learning has taken place smoothly, but recently, I have been troubled by the smoothness of it all to an increasing extent. Will the neoliberal university seize this as an opportunity to cut costs and render online teaching the new 
normal? Will we soon be out of our offices and classrooms for good? Perhaps we should not have done such a good a job of moving our courses online? Been less accommodating and docile? Right now, more than ever, it is vital to show resistance and strive for a more caring university where we would engage with the life struggles of our students.

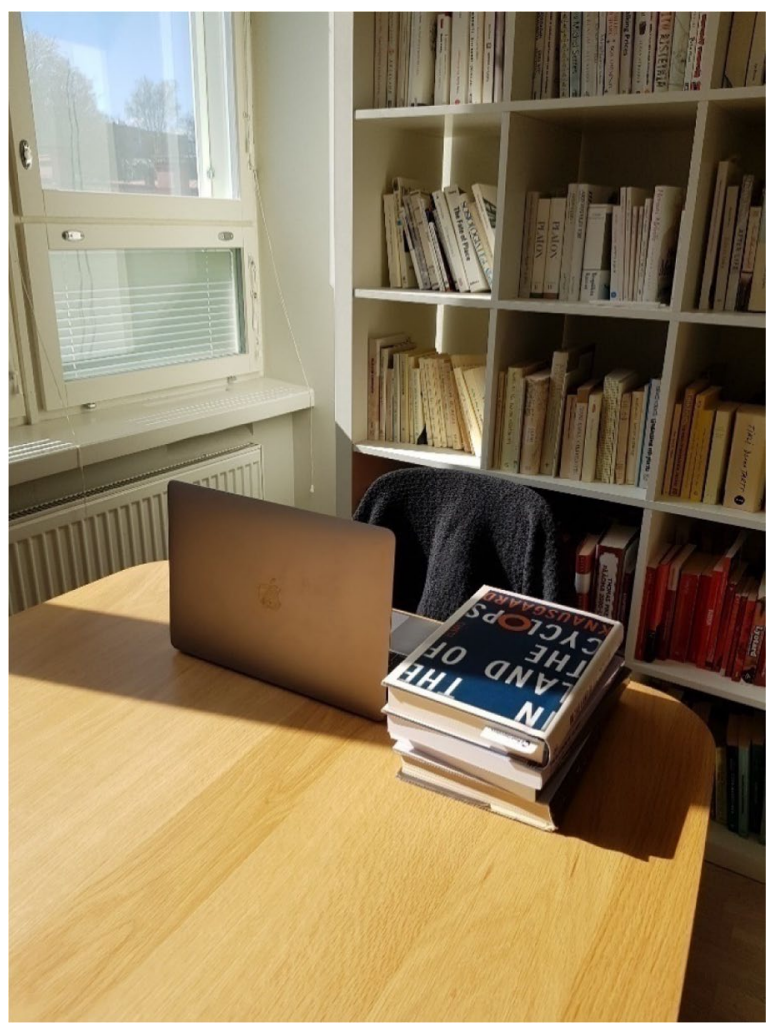

Fig. 47 [New figure.] This is my workspace at home in Turku. The table is also the center of to-gethering for me and my partner and children, gathering us together for all kinds of activities, from meals to doing homework, reading books, having tea and coffee, serious discussions, and mundane catchups

\section{A Year After the Pandemic Lockdown}

Suzanne SooHoo, Orange, CA, USA, 3 May

[Unchanged biography.] Suzanne SooHoo is Professor Emeritus at the Attallah College of Educational Studies at Chapman University in Orange, California, USA. She 
teaches part time and is active on dissertation committees. She has two grown children and lives with her husband and dog, Chewy.

It was less than a year as faculty emerita when the pandemic lockdown in March 2020 compromised our research agenda. My study, critical pedagogy in China with Peter and Angie McLaren, and the precious human relationships we nurtured over the past 5 years, were abruptly curtailed as both the USA and China closed their borders to international visitors. I was to enjoy my retirement studying the impact of critical pedagogy among Chinese graduate students. Instead, I spent most of this past year grounded, in isolation, wondering what research was indeed the most important work if I died of Covid-19 this year? What scholarship, if any, was worthy of pursuit in one's final days. What would be my legacy?

While life slowed down due to retirement and travel restrictions, moving at warp speed at the university was the pandemic-related acceleration of technology in the classroom. The pre-Covid slow creep of technology adoption vaporized, replaced by a plethora of high-speed technology training pelting faculty like paintballs. Multiple possibilities overcame me as I prepared to teach part-time in my online class.

Students seem to favor online classes over traditional bottoms-in-the-seats classrooms. I wondered, was it the familiarity with digital platforms, or semi-pajama attire, or the convenient bed roll out 2 min before class that drew them to online learning? When students were invited to return to campus a few weeks ago, they had a choice to stay online or return to in-person classrooms. Many online students opted to return to campus but not to classrooms, choosing instead to stake out a table with their computers outdoors in the California sun and common grassy areas. It appeared that students were engaged in discovering new learning environments. Geographic variability was highly desirable.

What does student engagement look like after a year of online classes? Did Covid-19 derail traditional norms of teaching? What transformational impact did online teaching make on the learner/teacher?

At a recent town hall meeting with faculty and staff, it was reported that faculty attitudes toward technology had changed significantly over the year. Altogether, there appeared to be an enthusiastic lean toward technology-enhanced teaching and learning with an accompanying interest to examine how this affects student outcomes. What followed was a brief dream sequence of what-ifs, brainstorming untested feasibilities.

Administration quickly arrested this enthusiasm by informing us that there would be absolutely no options for virtual learning in the fall semester because according to our accrediting agency, online classes can only be granted to institutions when they are intentionally designed and not for convenience or flexibility. To offer online courses, there must be waivers and reciprocal agreements in place. Utopian visions restrained; faculty pivoted to limit their discussions to technology-enhanced classrooms.

I've learned to find the silver lining in the pandemic. I hope there are lessons learned that I can carry over to fight other threatening viruses like racism and fascism. Guarding my re-entry to the physical world is an outbreak of anti-Asian hate 
incidents, linking Asians to the Covid virus. I emerge from the lockdown with a target on my back. Although anti-Asian hate incidents are not new phenomena in America, I search for a new vaccine.

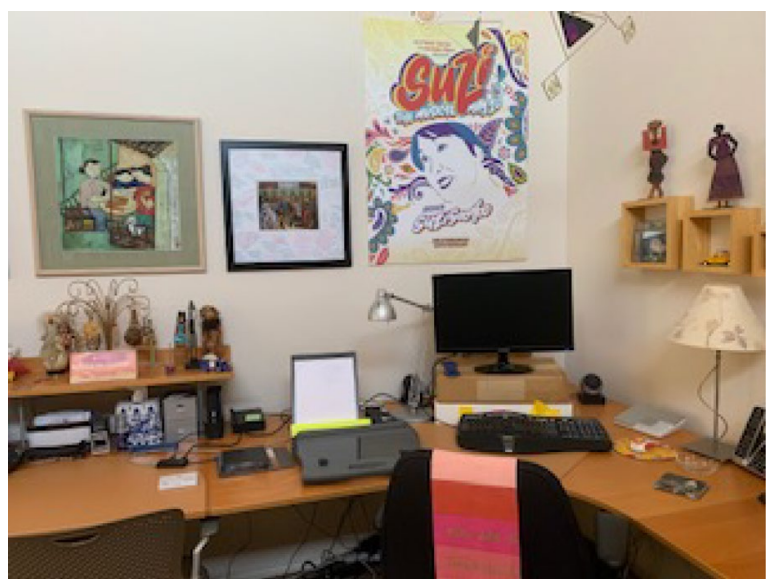

Fig. 48 [New figure.] This is my starship communication hub: Zoom center, writing workbench, classroom, library, research lab, meditation perch

\section{A Glimpse into Vagaries That Have Characterized the Current National Educational Twists and Turns Occasioned by the Pandemic}

Hazzan Moses Kayode, Ibadan, Oyo State, Nigeria, 3 May

[Updated biography.] Hazzan Moses Kayode lives in Ibadan, Oyo State, Nigeria. Hazzan is a Ph.D. student at the Department of Educational Management, University in Ibadan, and a teacher in Great Visionary Educators (a center for training ' $O$ 'and 'A'-level students) in Ibadan. He has recently taken up a teaching appointment under the Teaching Service Commission (TESCOM), also in Ibadan.

$* * *$

I am writing this testimony from my abode in Ibadan, Oyo State, Nigeria. I did not move to another house or country, rather I usually 'peregrinate' online classes for seminar and conferences and sometimes present papers both nationally and internationally. I did not change my job, though I recently took up another teaching appointment with the TESCOM (Oyo state chapter) aside from my being self-employed through private teaching engagement. Anyway, and not unexpectedly, an exponential increase in the prices of goods and services (most especially, both private and public cost of education) has indeed affected the cost of living and therefore makes it imperative to seek additional means of income.

Significantly, I have been unarguably influenced by some of the online classes, conferences, and publications from various scholars (both at home and abroad). Notable among these are the online classes (connected with a friend residing outside Nigeria) of distinguished Professor Michael Peters on Knowledge Socialism 
(KS) and Foucault and Education. Indeed, the KS classes increased the crescendo of my interest in the philosophy of education and opened a new vista of intellectual engagement. Also, AERA conferences organized by the University of Oulu, Finland, could be aptly regarded as pedestals for x-raying some of the burning questions in education. However, after losing a session to the pandemic, the authority of my alma mater (the University of Ibadan) adopted the blended mode of teaching and learning to cushion the excruciating effects of gridlocks in the university education created by the pandemic.

The university went online for the undergraduate lectures and or interactions while the blended mode of interaction is used for the postgraduate students with limitation to the number of students and lecturers that could attend the seminars physically. Nevertheless, the operation of this 'new' mode of teaching and learning faces various challenges such as erratic power supply, the financial inability of some students to obtain functional devices for the new mode of interaction among students and their lecturers and spasmodic network problems, etc.

One of the major challenges is the slow pace of the Ph.D. seminars in the department. This has resulted in a backlog of several theses (both the pre-field and postfield) yet to be defended both at the departmental and faculty level. This has slowed down the hitherto envisaged and calculated pace of my own Ph.D. program.

Meanwhile, professionally, the number of students patronizing my private teaching engagement drastically reduced. This may be partly due to the pandemic and most importantly the economic doldrums which has gravely affected the cost of living in the country. My feeling at present is primarily concerned with the opportunities offered, at this threshold, by the new vistas of teaching and learning via the online mode. My anxiety before was the issue of the closure of the school. This affected the pace of academic work which made my thesis remain in 'suspended animation' for at least a year, before the adoption of coping mechanisms offered by the blended mode of teaching and learning. This mode was at first greeted with several challenges which have been partly surmounted.

Globally, the world is faced with a common enemy (Covid-19), but it seems not all countries are faced with common risk. This observation was made when I visited (recently) most of the market places in Ibadan metropolis, Oyo State, Nigeria. For instance, in some of these market centers, all the procedures stipulated by the government such as social distancing, constant watching of hands, and constant use of face marks were not strictly observed by most of the traders. Even those (the traders) that I subsequently interviewed 'sincerely trivialized' the effects of the pandemic either because they could not locate any victim of the pandemic in their locality or they were frustrated by constant rhetoric from the government. 


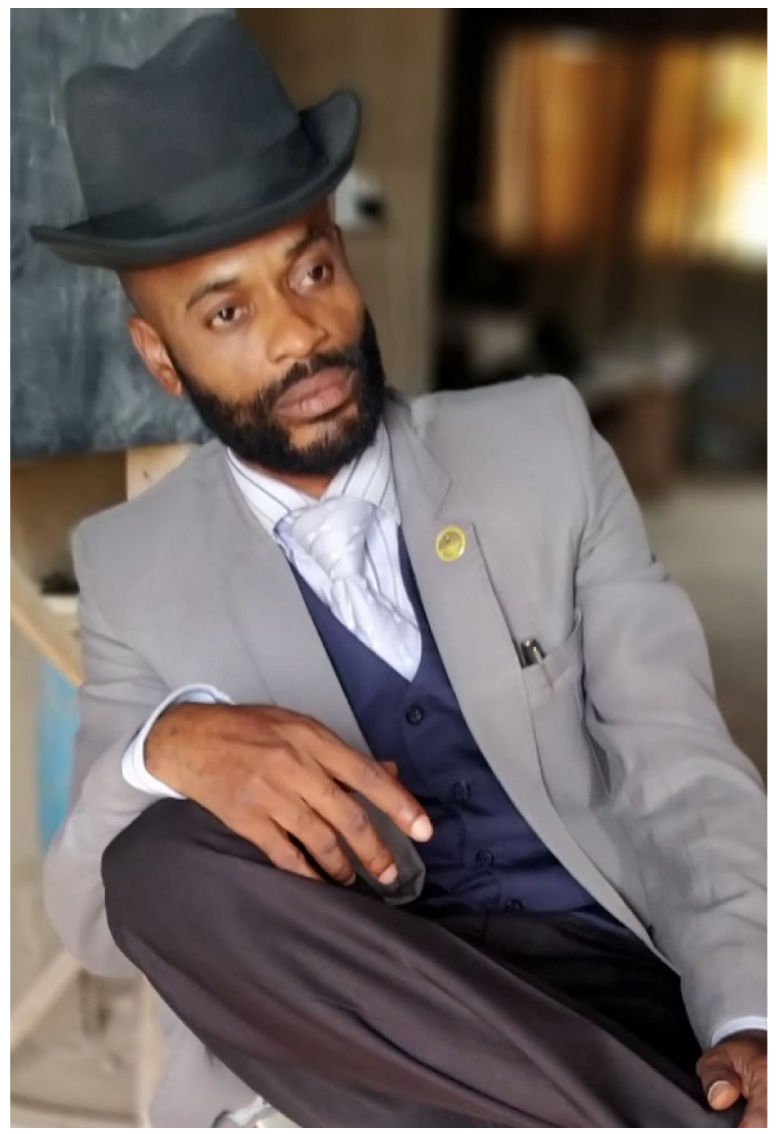

Fig. 49 [New figure.] This is my workspace near our living apartment where I was in a cogitating mood over the eventualities and vagaries that have characterized the current global and national twists and turns of the pandemic

\section{Must One Imagine Sisyphus Happy?}

Jake Wright, Rochester, MN, USA, 4 May

[Updated biography.] Jake Wright is Senior Lecturer of Philosophy at the University of Minnesota Rochester's Center for Learning Innovation, where he teaches philosophy courses and conducts research into the ethical and pedagogical justifications for in-class practices at the introductory level.

$$
* * *
$$

Naturally, more than a year later, the pandemic has impacted essentially every aspect of my life. I have been double vaccinated for 1 week and will be able to do things like eat in a restaurant without worry in a matter of days. I have not seen my students 
live and in person since mid-November, and I miss them terribly. Aside from the occasional holiday meal exchange drop-off, I have not seen my colleagues since March of last year. I miss many of them terribly, as well.

I am writing from my living room sofa as my two sons take their afternoon nap. I am able to do this because of the autonomy provided and trust shown by my university, which has allowed faculty to more-or-less unilaterally decide how best to deliver courses during the pandemic based on the relative risks, benefits, and impact on our lives. I am fortunate to live in a part of the country that has taken the pandemic quite seriously; being the site of one of the nation's best hospitals-employing about $30 \%$ of the local workforce-will do that.

Even with a supportive employer, a community that generally takes the dangers of Covid-19 seriously, and the benefit of over a year to adapt, everything remains overwhelming. A colleague of mine likes to remind faculty that new courses need to be offered three or four times before a professor will be satisfied with the result under the best of conditions. The radical revisions required by Covid-19 have not taken pace amidst ideal conditions, and my teaching — which I take great pride inhas suffered accordingly. My research, which has slowed in response to the demands of pandemic life, has naturally refocused on the pandemic itself and what lessons we can learn from our experiences. What had previously been a respite and welcome change from other demands has become another way to engage with a pandemic I just wish would go away. I feel like I am a worse friend, worse husband, and worse father than I was pre-pandemic. Though the professional impact on my life has been significant, it is the personal impact that hits me hardest.

My overwhelming emotional response to this experience has been one of grief, failure, and fear. Grief in the sense of everything we have lost, from loved ones to experiences we will not get back - to say nothing of what we have given up in the name of public health, only for significant swathes of our fellows to reject any sense of togetherness or shared sacrifice. Failure in the sense that despite my intellectual understanding of Covid-19 as a global pandemic to the contrary, I cannot escape the quintessentially American response that my dissatisfaction and failings are somehow my fault, as though everything could be cured by my simply trying harder. Fear in that I worry we will not take the time to process what has happened and will plunge too quickly back into something akin to normal, denying the necessary space to understand how Covid-19 has affected us personally, and societally, how we can adapt the lessons we have learned over the past year to our post-pandemic lives, and ignoring the long-term effects of the pandemic because we all need to 'move on'. 


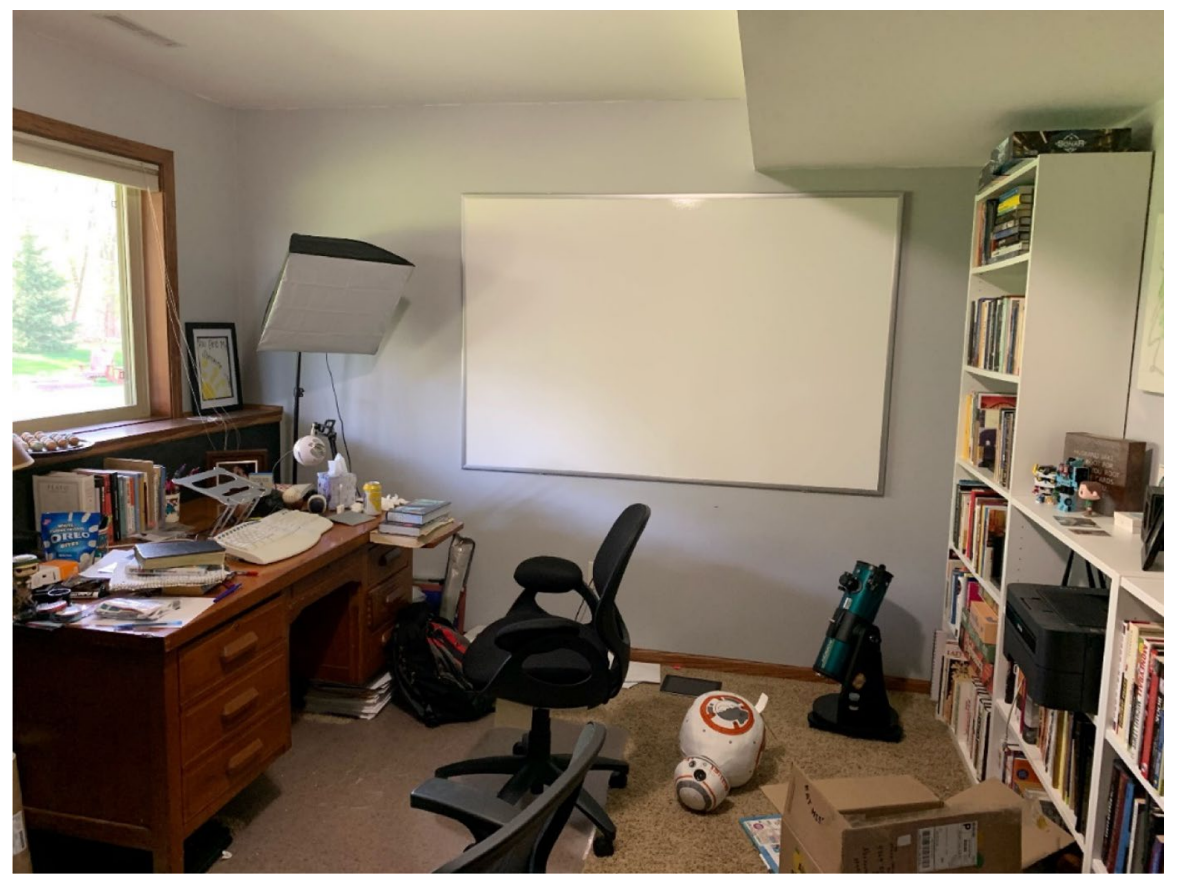

Fig. 50 [New figure.] My home office, a converted bedroom. In addition to the usual end-of-semester clutter, it shows the effects of doubling as a classroom recording studio for me and my wife, as well as a storage space for toys and other gifts grandparents have sent to my children because they have been unable to see their grandchildren since the beginning of the pandemic

\section{An Uncontrollable Year Later}

Stephanie Hollings, Phoenix, AZ, USA, 4 May

[Updated biography.] Stephanie Hollings is a 3rd Ph.D. student at Beijing Normal University's Faculty of Education, who will be graduating in summer 2021. Her research interests are generally centered on international education, global competence, and global citizenship.

In some ways, life of the past year has regained a sense of normalcy. Lockdowns have been lifted, and life is beginning to gain some consistency. My sister has gone back to her office and that means that I am no longer confined to my closet to get a 
quiet working atmosphere. I now spend most of my working day between two locations. The first is my small bedroom desk filled with sticky notes of trivial reminders, looming deadlines, and the never diminishing projects to engage my time. The second location, my preferred one, is the kitchen table where I can gaze out of the window and watch the impending summer.

However, summer reminds me that the school year will almost be done and how uncontrollable life is during a pandemic. I am still in the USA and perpetually coming to grips that I may not be able to return to campus life in Beijing for the rest of my Ph.D. life. I have now entered my third year-a year that was supposed to be filled with the pressure to finish and defend my thesis, graduate, find a job, and sprinkled with good memories. While the pressure is still there, the time with my cohort is not, and this has been rather difficult to digest.

While both China and the USA have lessened lockdown measures, rolled out vaccines, and my university in Beijing has enjoyed some semblance of normalcy, international students are still not allowed back. I often see social media posts of the students who had not returned home that fateful Spring Festival, enjoying their newfound freedom on campus and in Beijing. But I cannot partake. I must spend my hopefully last semester living vicariously through social media photos. Yet, that does not alter the expectations for students like me.

It seems that some have used the pandemic as a sort of scapegoat but I, in constant fear of extending my Ph.D., refused to allow myself to do so. I adapted to being a Ph.D. student during the inopportune Covid-19 pandemic. My research that should have been conducted in China was conducted virtually from the USA. I analyzed my data with brief WeChat calls from my supervisor. My pre-defense was held virtually, and the original time I was slotted to defend was after 11 p.m. my time, although it was changed. Now, my thesis is in the process of external review, which means now, it is out of my control.

It is these uncontrollable factors that I have had to come to grips with. Some may be marginal like the possibility of going another summer with the majority of my summer clothes being in my dorm room in another continent. Yet there are many more pertinent factors, both pandemic-related and not, like the external review, travel restrictions, and the possibility of one last late-night defense. However, as a Ph.D. student during the time of Covid-19 and hopefully soon Ph.D. graduate, these uncontrollable factors are not only affecting my sleep and virtual awareness but are shaping my research, my research interests, and my identity. Soon, perhaps, I will be able to say I am a Ph.D. graduate during Covid-19. 

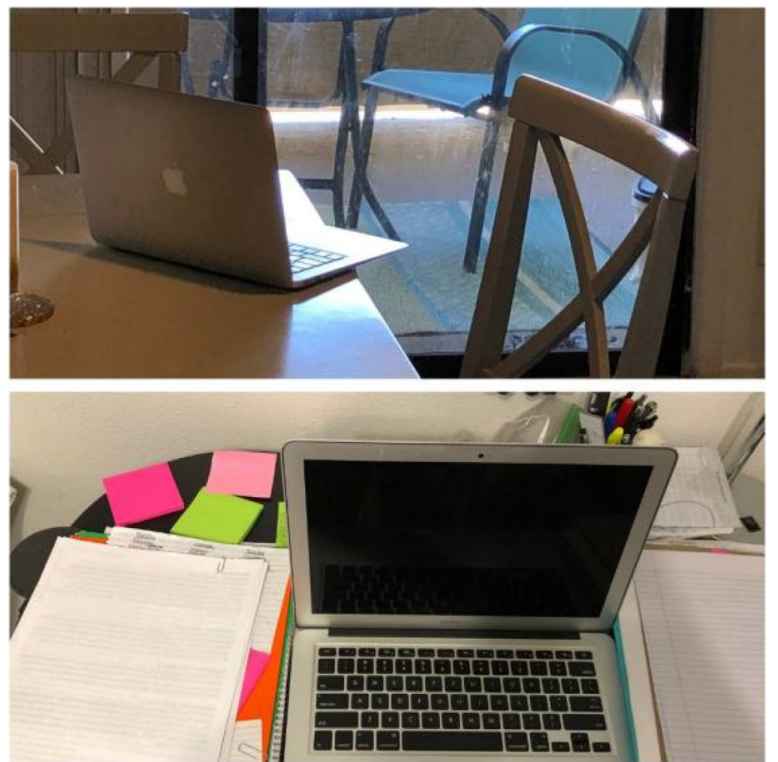

Fig. 51 [New figures.] These two images are the two areas in which most of my work is done. The top one is the view of my kitchen table in which I watch summer approaching and the bottom one is my small and perpetually crowded and slightly messy bedroom desk

\section{Letter from Brunswick East}

Sonja Arndt, Melbourne, Australia, 4 May

[Updated biography.] Sonja Arndt is a Lecturer in the early childhood team at the Melbourne Graduate School of Education, University of Melbourne. Her teaching and research intersect philosophy of education and identity, philosophical methods, and contemporary research methodologies in ECE.

Well, here we are, 1 year on from my last testimony, and, here in Australia, we worry about individual Covid-19 outbreaks. While living a much freer life than many, it is with daily devastation that we read of friends and colleagues in countries where infection and death rates are rising. I have moved a little further east in the suburb I have now come to see as home: closer to the Creek (that feeds into that mighty Yarra River snaking through the city of Melbourne), closer to the bush, closer to walking/ cycling trails, and closer to the university and city life that I have missed so much over the past year. 
Melbourne spent a lot of 2020 in a quick, harsh lockdown. Following medical advice intent on reducing what at its height were 700-800 cases per day, periods of lockdown resulted, like in so many other places, in all but essential businesses being closed, and hospitality venues reduced to serving takeaway food and coffee. Further sucking the life out of the city, restrictions meant we were allowed out for no more than $1 \mathrm{~h}$ per day, within a 5-km radius from home and able to connect only with our own household 'bubble' - boy, did we feel that!

Having only migrated to Melbourne from New Zealand shortly before Covid-19, looking for a permanent home suddenly became secondary among the much bigger urgencies of Covid safety, personal and family health issues, managing students' learning — and just as importantly their wellbeing — and ensuring daily walks did not exceed the prescribed hour. Besides, inspecting properties, interacting with a real estate agent, not touching door handles or paperwork all became too difficult. Meanwhile, our university was committed to strengthening the experience of online teaching, offering support for redesigning courses, developing new methods, videoing content, etc.

In our field in early childhood education (ECE), despite settings remaining open - at least to cater for the children of 'essential' workers (Arndt et. al. 2020) student placements were adapted into online formats. 2021 was to have been the year for recalibration; however, even for those of us who work with philosophical or theoretical framings of uncertainty, sitting with discomfort, or unknowing ourselves, the realities of uncertainties remaining are taking their toll. Grappling in various ways with the need to actually own, do and be, what we perhaps a little too easily promote from a distance, is more difficult than we thought!

While I did find an apartment, and still work mostly from home (my current warm weather workspace is shown below), the family reasons for migrating back to Australia remain tricky to navigate. We are lucky to be able to fly interstate (and now have a travel bubble with New Zealand where my children and many dear colleagues are!). Even so, new Covid-19 outbreaks, clusters, and lockdowns perpetuate the precarities of post-Covid-19 travel, with cancelled flights, delays, and major inconveniences becoming the norm. Even with Covid-19 relatively 'under control,' a need to work flexibly means reducing handwritten notes for every aspect of work, printing, and keeping just a tiny paper diary (because some of us still rely on such a relic of pre-Covid-19 times to keep track!).

Finally, the most motivating and deeply resonating feeling that returns during the now occasional face-to-face meetings explains the creative twists and turns we have explored in the past $1 \frac{1 / 2}{2}$ years to remain in touch. And increasingly, it becomes clear that even in the depths of the lockdowns, perhaps we did not realize the true and crucial value of being together!

Looking forward to reconnecting in real life with you all!

Sonja 


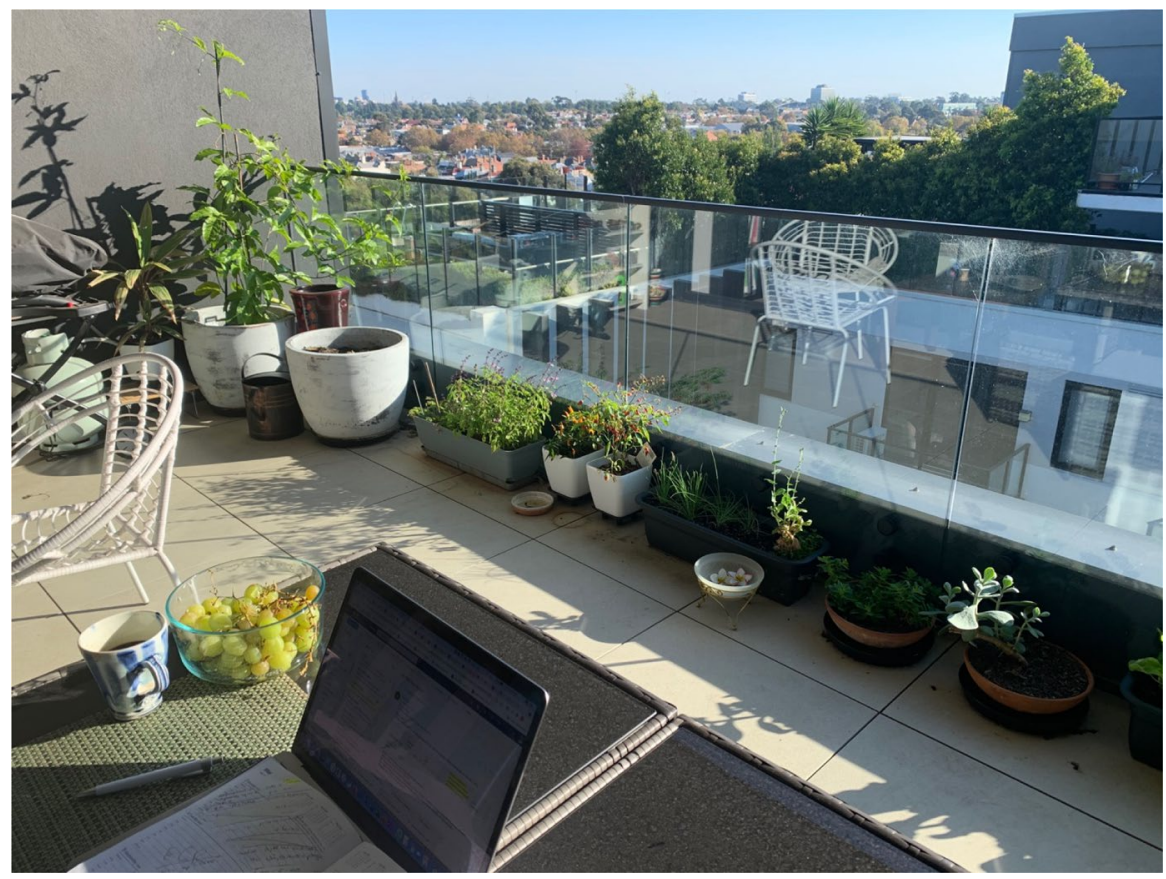

Fig. 52 [New figure.] View across Melbourne from my Brunswick East 7th Floor outside office

\section{Nowhere Near a Year of Solitude: But Back in the Basement}

Andrew Gibbons, Auckland, Aotearoa New Zealand, 5 May

[Updated biography.] Andrew Gibbons is Professor at Auckland University of Technology, Auckland, New Zealand. He has published widely on topics including early childhood teaching, the philosophy of education, the role of technology in education, and the future of the university.

It is 8 a.m. On this cloudy autumnal Auckland day, the met service is expecting a high of $19{ }^{\circ} \mathrm{C}$. At present, it is $13{ }^{\circ} \mathrm{C}$. The commuter traffic produces a steady drone outside our block of units, amplified in this underground basement office by the open garage door. The door is open in an attempt to get a little natural light into this office space during 6 months of research leave. Being back in the underground basement office provides a good backdrop for reflecting on a year of the pandemic. A year ago, I had intended to work from the basement throughout the lockdowns. Realizing the hostility of the conditions, I decamped to the spare bedroom for warmth and light. That was during the first national level 4 lockdown in Aotearoa New Zealand. Since that first lockdown, there has been a relatively successful program of pandemic responses. The last week-long lockdown occurring on the week of my 50th birthday. As luck would have it, I had planned a family get together to celebrate a week early. 
Feeling lucky and at the same time feeling guilty about feeling lucky is arguably an ongoing collective response in Aotearoa New Zealand.

As a result of the effective government and public response, for most of 2020 and 2021, I have been able to move freely around the Auckland University of Technology campuses, to teach classes face to face with early childhood student teachers, play sports, go to the pub, watch bands, and so on. Not a year of solitude. Certainly, a year of scanning $\mathrm{QR}$ codes to track my movements.

And yet, back in the basement all the same, for a bit longer, before the cold and dark again forces me into the light and warmth of the office at Akoranga campus. As this is research leave, I am trying to drag out that return as long as possible. Being on campus seems to undermine the more nuanced benefits of a sabbatical-the benefits not directly associated with the outputs that are required for approval of this, and future research leave.

Not that outputs are an issue. Over in the Writing Department, the last 12 months have been no different in terms of productivity, particularly with the addition of calls to engage with the pandemic in writing. The first piece of pandemic-focused writing was in response to the call for which this here reflection is the sequel. That first reflection of notes from the basement was followed by a range of pieces dealing more specifically with early childhood education in a time of pandemic (see for instance Gibbons 2020). There were also two whole Knowledge Cultures ${ }^{16}$ special $^{2}$ issues on the pandemic to co-edit with Sean Sturm. The piece on Camus and Tragedy which I had prophetically proposed 6 months before this global plague was published (see Gibbons 2021).

More recently I worked with Marta Cabral on a project motivated by observations of the breadth of pandemic writing across the academy and a question as to whether it would be better to respond to something that has not happened yet. A brief nod to that paper helps to give a sense of how I have been thinking and feeling during the pandemic. The submitted paper (currently in review) is entitled 'Inter-galactic pedagogy, pedagogy inter-galactic'. Excited by the first efforts in speculating on the future of education, the paper has grown into 'Pedagogica Intergalactica,' a pedagogical take on educational unpreparedness in a galactic context.

This series of entries that are currently in peer review for Pedagogica Intergalactica plays critically with the idea of first contact. Each entry plays with imagined reiterations of the failures of education systems in response to a new knowledge and experience of the galaxy. These reiterations are evident around us during a time of pandemic in, for instance, the increased governing of academics in their production of standardized course materials for generic online learning student experiences. Rieux wept. Would it be reasonable to require all instructional designers employed to standardize the student experience of online learning management systems to read and be assessed on their proper reading of The Plague (Camus 1960)? Rieux wept.

\footnotetext{
16 See Knowledge Cultures, 8(2) and 8(3), https://addletonacademicpublishers.com/contents-kc\#catid 2097. Accessed 3 May 2021.
} 


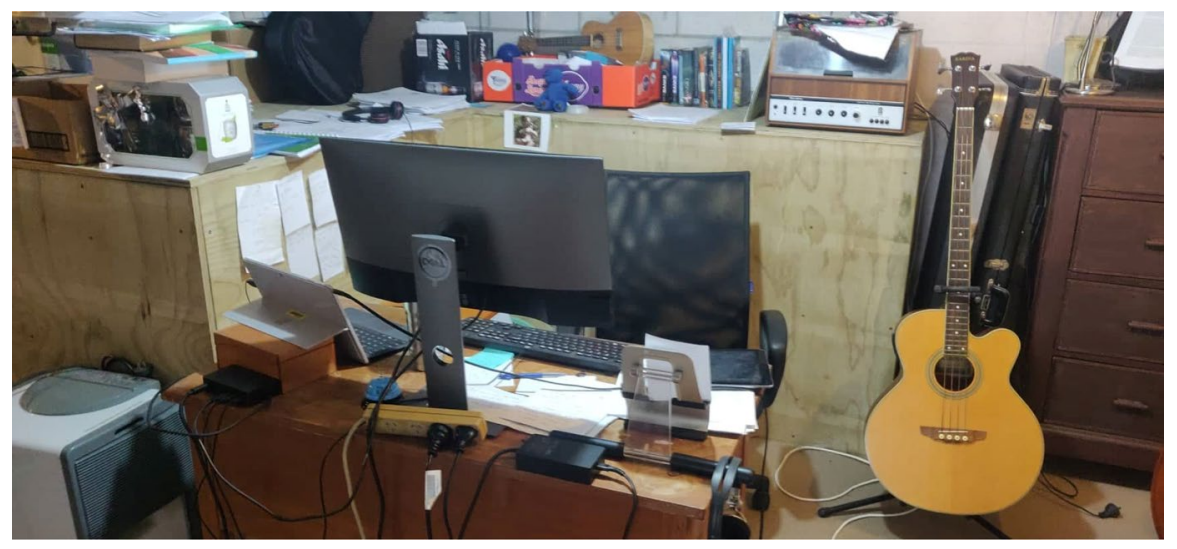

Fig. 53 [New figure.] The 'refurbished' basement office including freshly boxed out earth wall (high impact factor), recycled carpet (low impact factor), and the old family 1970 s turntable made in New Zealand...

\section{University in the Times of Corona-1 Year Later}

Shreya Urvashi, New Delhi, India, 5 May

[Unchanged biography.] Shreya Urvashi is a sociology researcher based at Tata Institute of Social Sciences, Mumbai. Her academic profile consists of degrees in physics and sociology. Her research interests include sociology of higher education, sociology of identity, and politics.

I write this account after over a year of being away from the university, which I had left in a rush leaving half my belongings and books in a small hostel room. Since then, life and time have shown a lot. While the initial days were full of optimism, and with probably no one in the world realizing the extent of influence the virus will play in our lives, the past few months have been much more surreal. When the first lockdown happened, people resorted to Zoom calls and cooking new recipes to while away time. However, gradually now, people need breaks at a level that is apparently not possible. While 2020 meant more about adjusting to a new disease and trying to figure out its complications, the new strain that has gained prominence in 2021 has been devastating in more ways than one.

The past couple of months have been particularly difficult in India. None of my colleagues or friends are not affected by the virus in some way. Some have got the virus themselves while others have lost their loved ones to the virus. Workplaces have struggled to adapt. Some have closed for a few weeks to let their employees 
recover; others have shifted to more flexible working patterns. Job losses have also taken a massive surge, and helplessness seems to increase every day.

The public health system has collapsed. Many social media posts are about finding hospital beds, oxygen cylinders, and medicines - all of which are in acute shortage. This has resulted in deaths not just due to the virus, but also due to unavailability of medical equipment. The authorities are working in varying capacities to take cognizance of what is happening on the ground, but no concrete steps have materialized - with the daily level of cases and deaths reaching new heights constantly.

At this juncture, I return to the question from my previous write-up-how responsive is higher education to societal conditions? Higher education institutions have reacted, yet the apathetic attitude remains. There are also cases of deadline extensions not being provided or classes not being cancelled even in the gravest of situations. Institutions, faculties, and students have reacted nothing short of extraordinary, but there is a lot that academia needs to learn and adapt from 'real life'.

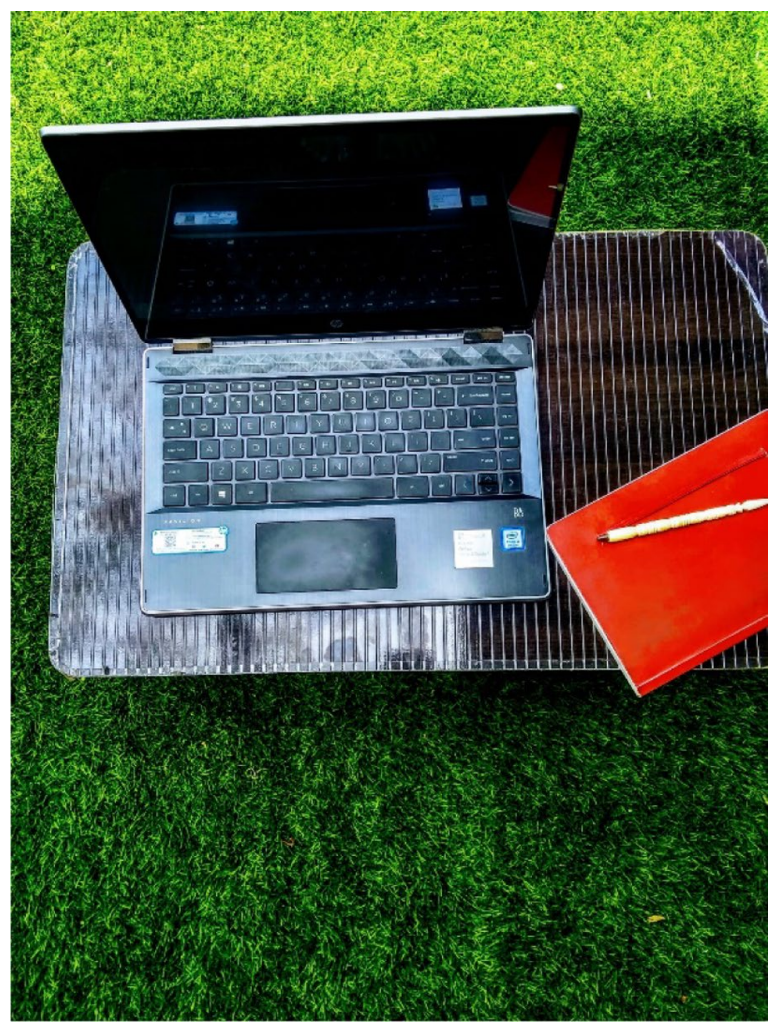

Fig. 54 [New figure.] After a year of constant backaches and headaches due to sitting upright at chairs and staring at screens all day long, I have now made a cozy workspace in my garden (at least until the Indian summers come) 


\section{Small Acts of Kindness Against a Tidal Wave}

\section{Daniella J. Forster, Newcastle, Australia, 6 May}

[Updated biography.] Dr. Daniella J. Forster is a philosophy teacher educator with experience in primary and secondary schooling. She researches educational ethics, moral epistemology, and the normative case study methodology. Her knowledge of codes of conduct provides expertise for teacher misconduct investigations. She received a DVC(A) Educator Innovation and Impact Award (2020). $* * *$

I am at my home office desk looking out on my front garden in the inner city of Newcastle. I have just come back from an early morning Mother's day breakfast at my children's primary school which had the most enormous turnout of community. The queue for a celebration breakfast extended all the way from the old schoolhouse to the front gates! The teachers serving us breakfast called it the 'post-Covid line'.

Since our brief 6-week lockdown last year, I've found solace in gardening, especially water-gardening. I often imagine in the evening my plans for the changing autumn season as I clear my head from the day's academic work. My academic role has intensified considerably in the past year, not simply in terms of teaching demands or administrative work but an emotional burden borne of uncertainty and loss, which is a reflection of the university's euphemistic 'change process'. Research has increased in intensity and urgency. I seek out colleagues further afield, feeling driven to engage in collective work. It has been a fruitful time for Educational Ethics during Pandemic Times with many early morning/late night meetings across global time zones. ${ }^{17}$

Over the past 12 months, I have spoken to, read transcripts of, and closely analyzed ethical themes arising from our discussion group sessions in several countries across the world. My first sessions with Australian educators emerging from lockdown contributed to public discussion about some of the dilemmas teachers experienced trying to balance learning and wellbeing during lockdown (Forster 2020). We have written, presented, and discussed educators' ethical issues about teaching during Covid-19, offering the tools of philosophy to clarify and make sense of them, and are about to launch into a second follow up round of discussions. I am especially concerned about teachers in the devastating conditions in India right now, and the group hopes to be speaking with some in the coming month. Australian teachers are facing very different conditions to many of their worldwide colleagues given our low public infection rate, although hotspots crop up and Covid-safe check ins at all venues continue to allow close contacts to be traced.

But the university sector is hemorrhaging. The University of Newcastle instigated an extensive cost cutting process to stem a budget deficit said to be caused by the loss of international students and other Covid-related damages. This has changed the face of the workplace, with faculties cut and merged into super-colleges in order to 'streamline' management and excellent academic staff under a cloud of job

\footnotetext{
17 See https://www.justiceinschools.org/event/educational-ethics-during-global-pandemic-discussiongroup-research-study-educators. Accessed 6 May 2021.
} 
insecurity. Many good people have had a tumultuous and stressful time waiting to see if their job would be made redundant while continuing to serve students and colleagues. Our school made the cuts by offering enticements for retirement age professorial academics to leave their role, and with them, decades of knowledge. The stakes seem higher for everyone, and this is just a small view.

My thoughts are often preoccupied with people's suffering a long way from my privilege, of the future of the global natural environment and our children. I deal with these feelings through small acts that are quite insignificant; listening to others, helping, giving, supporting, and am grateful for receipt of the same. It makes the overwhelming-ness ease a little.

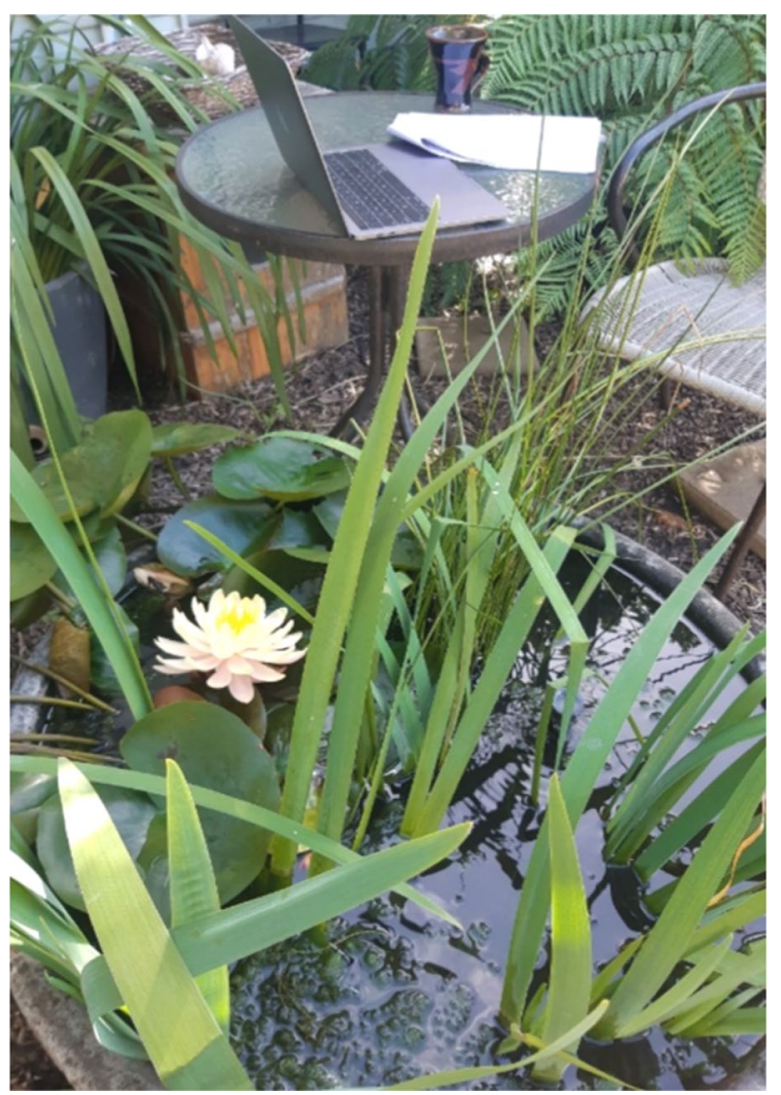

Fig. 55 [New figure.] I move my 'office' from my dedicated indoor space (pictured previously, 2020) to my water garden (pictured here, 2021) when working from home, which is most of the week. Due to university cost cutting and the demolition of our building, the School of Education no longer has on-campus private offices for academic teaching staff; we all share an open plan space 


\section{Uncertainty and Creativity}

Ian Truelove, Leeds, UK, 6 May

[Updated biography.] Ian Truelove is the Course Director of the BA Illustration course at Leeds Beckett University, UK. His research, which is predominately technology-led, is informed by philosophy, quantum theory, and art history. Ian is currently investigating the potential for using virtual and augmented reality technologies in a variety of creative contexts.

$$
* * *
$$

It is well over a year since I reflected on the move from in-person to online learning for me, my colleagues, and our students on the BA Illustration and MA Graphic Design courses at Leeds Beckett University. A lot has happened in that time and while not wanting to play down the serious nature of the pandemic and the extreme difficulties we encountered when translating our programs to online delivery, a lot of good things happened.

Many students who had previously struggled with extreme social anxiety in the physical studio environment found a confident voice in the fully online versions of our courses and flourished. Colleagues who previously resisted the already inevitable move to digital delivery of briefs and digital submissions for assessment found that these methods were not that bad after all. Things that we previously imagined impossible online, such as practical studio sessions, came to life as we screwed document cameras to our ceilings to show students how to do things with hands, masking tape, and found materials. We went on virtual tours of online galleries and set projects that asked students to turn parts of their homes and gardens into artworks. We got students to apply silly Instagram filter to the tutors' faces in Teams meetings and post them online. We screen-shared the view from inside a Virtual Reality headset on one computer while streaming a web-cam view showing how daft the tutor looked while using Tilt Brush on another. We all got used to feeling present, just in a different way, in a video call-based class. We thoroughly enjoyed the process of experimenting with different ways we could connect with students through shared practical endeavor, all filtered through an imposed digital lens. We all-students and tutors alike-made a lot of artworks, and together we reveled in the joy of making.

Central to the success of our online stint was the decision to teach together. While on paper this seemed like it was not a great use of limited staff resources, in practice, it greatly enhanced the online taught sessions and helped to keep the tutors sane. The feeling of isolation that was a constant threat was eased by the humorous banter of long-time colleagues enjoying spending time teaching together, albeit in a little window on a screen. My stated aim in my reflection at the start of Lockdown 1.0 on 19 March 2020 was to offer a calm and upbeat voice as an uncertain situation unfolded. I am extremely fortunate that I work with a team of tutors who are experts at rooting out the creative potential in uncertain situations. It was a right laugh, as they say in Yorkshire. 


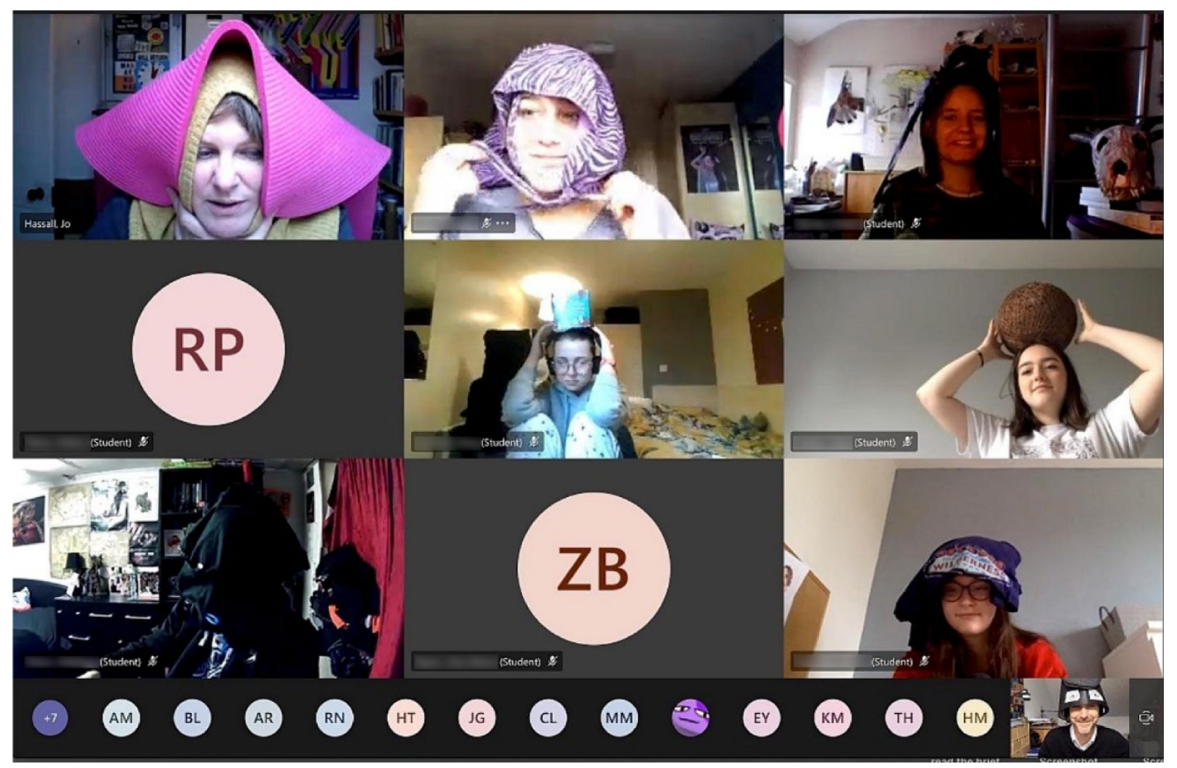

Fig. 56 [New figure.] Screenshot of an online studio session with first year BA Illustration students. The brief invited students to use items and objects they had at home to make a wearable head as a way of exploring the course ethos: the potential of processes and the importance of resourcefulness, adaptability, and most importantly, having fun

\section{Untitled}

Peter Mayo, Paola, Malta, 6 May

[Unchanged biography.] Peter Mayo is Professor at the University of Malta and is the author of Higher Education in a Globalising World. Community Engagement and Lifelong Learning (2019). Peter lives with his wife and cat in Paola.

$* * *$

There was an opening of several public buildings and spaces early last summer, and there was pressure for schools to reopen. This seemed to come a trifle too soon, and we witnessed a spike by the end of August, and a lockdown was eventually called after Christmas. Even Churches in a predominantly Catholic country were closed slightly before the Roman Catholic Easter period though they reopened soon after as the numbers of Covid-19 cases lowered considerably. We are now eagerly awaiting the return of travel possibilities this June. The year also saw the gradual and systematic rolling out of the vaccine with people of my age about to receive their second jab around this month. 
Most university teaching is still going on online which, as you can imagine, and as is the case with other countries represented in this volume, has been offering interesting international possibilities. Lots of academics are involved in webinars and the amount of invitations to be guest speakers, with next to no travel and accommodation costs for the organizers, having multiplied considerably. The Paulo Freire Birth Centenary has also prompted the organization of close encounters of the digital kind. Our university is also planning a similar event in connection with what looks to be an impending UNESCO Chair in Global Adult Education. We are also planning, in connection with the UNESCO Chair, an online Master's course program in Global Adult Education and a series of online open-access exchanges with adult education researchers and practitioners tentatively titled Close Encounters in Global Adult Education. We plan to reactivate the adult education movement's flagship journal Convergence as an online open-access journal in the manner that we have been producing Postcolonial Directions in Education ${ }^{18}$ which has entered its 10 th volume year.

The great challenge however is to teach the popular educator engaged in rural village communities in certain parts of the geographical majority world. This is a great ask.

While I am not convinced that online teaching is a viable alternative to face-toface teaching and in the flesh academic and school encounters, it offers an important string to one's bow. It certainly enables one to act and think globally. Nothing is foolproof, and the local and global digital divide provides one major obstacle. The other is of course students' reliance on safe home spaces which is not always the case with regard to the availability of electronically equipped spaces and safe spaces at that.

The signs and hope are that, under the new normalcy, we will see greater blending of education approaches involving both public and private. Of course, none of this is to be taken on board uncritically. As far as schooling is concerned, more students of particular social class and ethnic background disappear off the radar than might have been the case previously. This remains a key concern from the social justice standpoint which continues to drive us forward in our work.

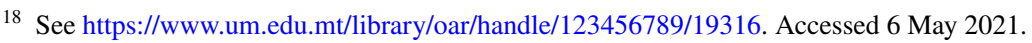




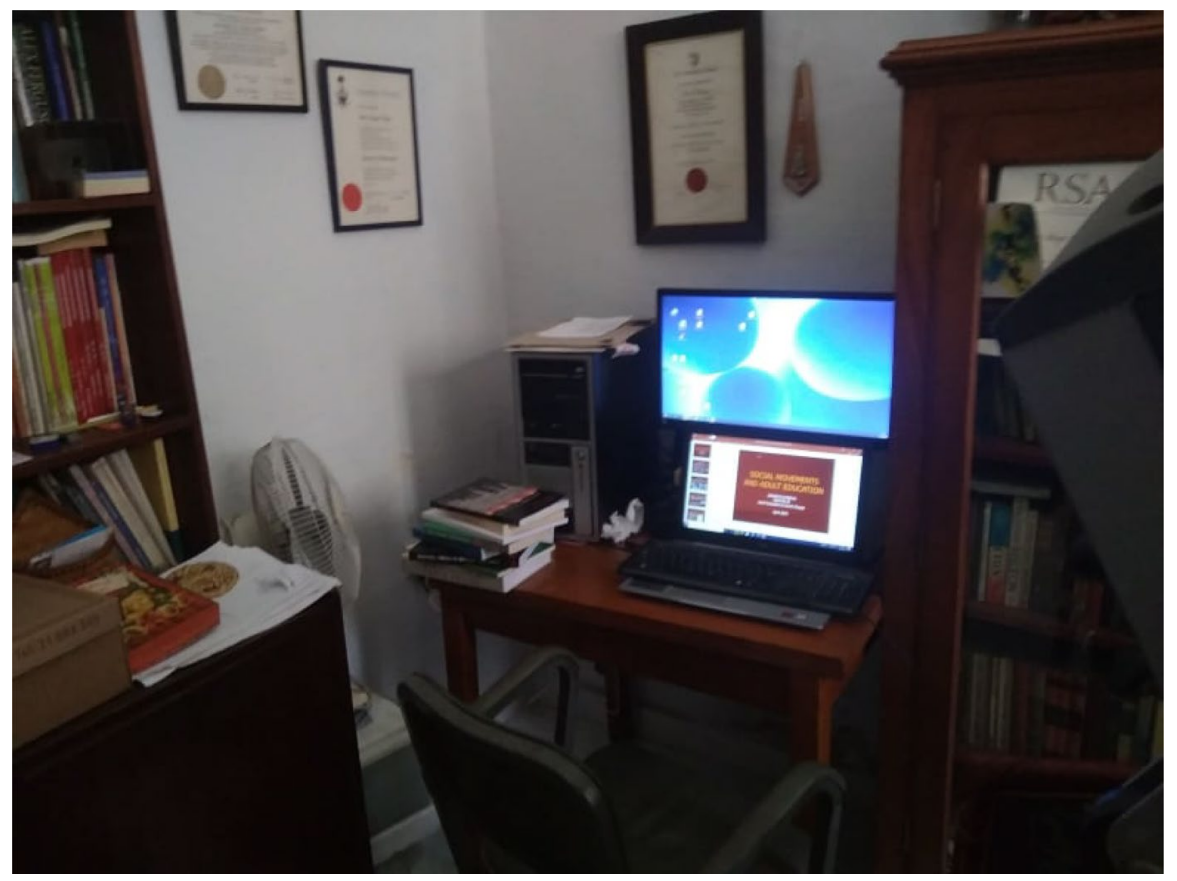

Fig. 57 [Unchanged figure.] This is the computer corner in my study at home where I write my research and teach online with students in Malta and abroad

\section{The Old Virus}

Glenn Rikowski, East London, UK, 6 May

[Unchanged biography.] Dr. Glenn Rikowski is a Visiting Fellow in the College of Social Science, University of Lincoln, UK. Glenn is 69 years old and lives with Ruth, in Forest Gate, east London.

I have nothing to add from what I said a year ago, apart from this: all three of our sons have had Covid-19; all three of our daughters-in-law have had it (one of them in the latter stages of pregnancy); and Ruth, my wife got 'long Covid' from March-June 2020, and has not reacted too well to her first AstraZeneca vaccination. I seem to have avoided it, but then I could be an asymptomatic kind of guy. 


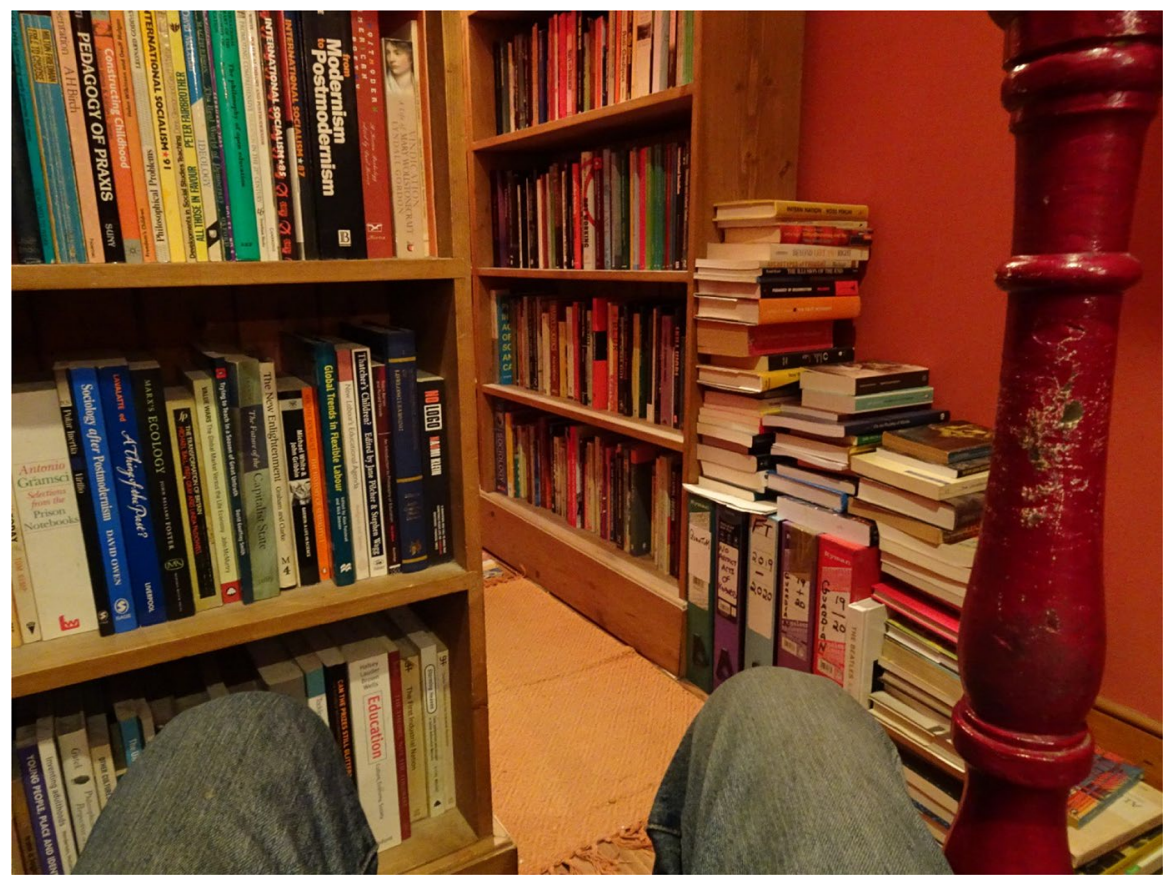

Fig. 58 [Unchanged figure.] View of the first floor landing. Piles of books = lack of space!

\section{Chaotic Normality}

Paul Alexander Stewart, Gateshead, UK, 6 May

[Updated biography.] Dr. Paul Stewart is an artist and researcher based in Newcastle, who makes curatorial and installation performative works through text, sound, and karaoke. His first book Art, Critical Pedagogy, and Capitalism was published December 2020 with Routledge. He is a senior lecturer in Fine Art at Teesside University.

Looking back over my previous account at the beginning of lockdown felt quite unaware of the longevity of the COVID crisis. At that point, I felt immediate and reactive to solve and secure the learning of my students and our work/life balance. A year on, I am unsure whether we have arrived at a good place for learning but I do feel I have arrived at a place where I know my limitations and ability. I do feel that the approaches are clearer, and both learners and tutors are able to know what is possible in our hybrid and blended delivery in the UK. I have been teaching face to face studio sessions that have proven to be a life line for the learning experience alongside digital classrooms.

This time round, I am penning the testimony from my attic room in Gateshead, England. Nancy was born on the 23 June 2020, and her whole life so far has been 
in lockdown; the previous office/spare room is now a nursery. It is a Thursday, and I am trapped in back-to-back online meetings. The novel experience of thinking about how to set up or curate my surroundings for teaching has passed.

I am still working full time at Teesside University and co-run the BA Fine Art course. It has been a non-stop year; academically, we have gone from $100 \%$ online to hybrid 4 separate times this academic year. The inconsistencies have made delivery a little more difficult, but when we do get back to the studio-focused learning, the experience is refreshing.

I remember trying to work out what teaching a practical course in this manner and how it would look, smell, and feel. What I can conclude is a lot more work, support, patience, empathy, and resources are needed. The panic buying has stopped, and the chaotic normality of the pandemic has set in. The world we are a part of is still full of hope and transgressions, and from these, I am looking forward to being social and together again.

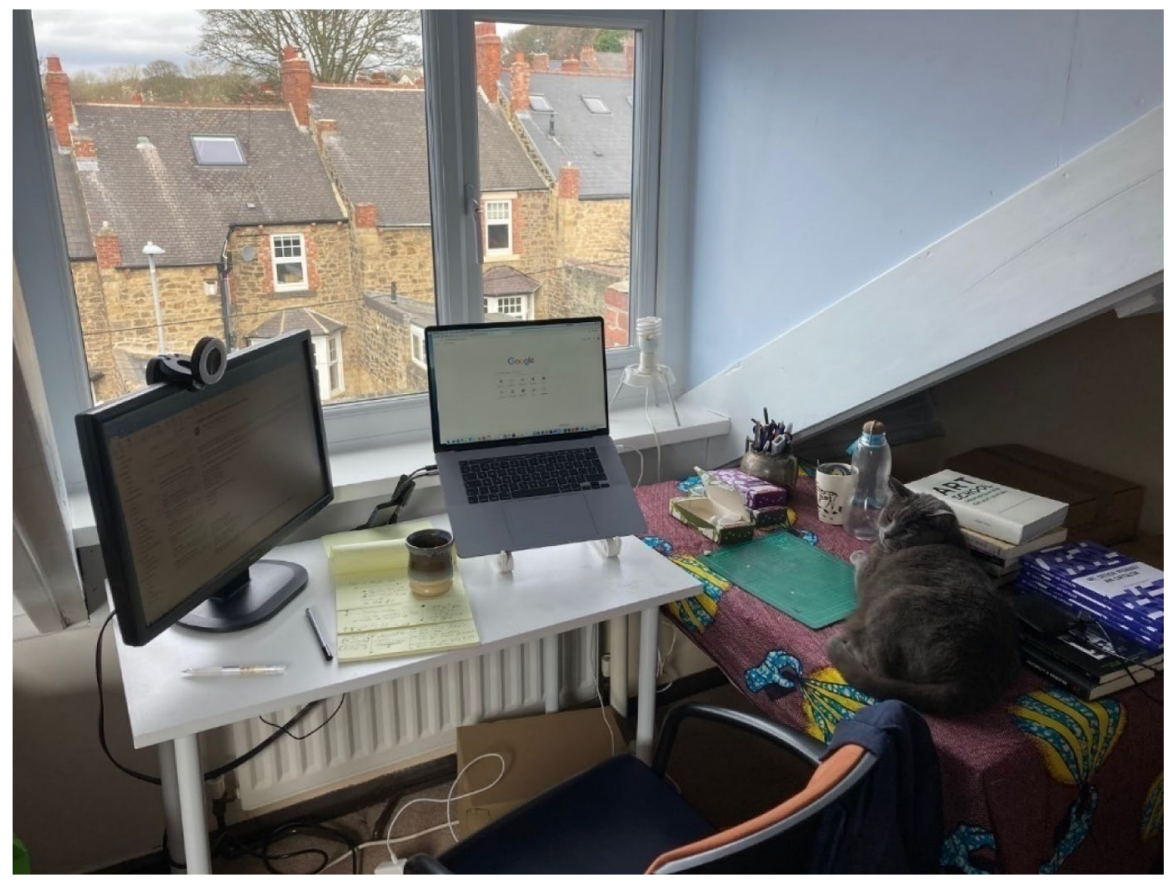

Fig. 59 [New figure.] My attic office and hot desking colleague, Princess the Cat 


\section{Mimetic Pandemic}

Michael Jopling, Berlin, Germany, 6 May

[Updated biography.] Michael Jopling is Professor of Education and Director of the Education Observatory in the University of Wolverhampton, UK. He has lived in Berlin since the beginning of the pandemic and rather likes it.

A year ago, I was working on the sofa in this study, spending most of my day in meetings online. One year later, I have a timeshare at the desk and spend most of my day in meetings online. Then, the UK was reacting much more sluggishly to Covid-19 than other European countries, and I was trying not to feel self-satisfied. Now, most of my colleagues have been vaccinated, and I am still waiting for an appointment.

I still lead the Education Observatory, a research center located at the University of Wolverhampton in the UK. My professional responsibility is for research, and we have been very successful at keeping things going. Teaching and doctoral supervision remain online, where the intimacy of the supervision sessions work rather better than larger teaching sessions. There, screen fatigue seems to have taken its toll. Moving research online was remarkably straightforward, but the pandemic seems to have messed with the fabric of time, and most projects have been extended, mainly because online 'fieldwork' is much harder to control. New projects have come in: some are directly Covid-related; all are Covid-inflected. And while a year ago I hoped that the pandemic would lead to lasting change, today, I am not so sure. Large organizations like universities are not good at flexibility and, as so often, respond to any kind of uncertainty with micro-management. As a result, I and most of my colleagues look like we need a long rest.

This does not mean I do not feel fortunate. In 2020, I wrote of the unexpected pleasure of being able to exile myself in Berlin indefinitely with my partner and there I remain. I do not have caring responsibilities. I have not had Covid-19 and I still feel lucky to have access to books and a garden (which has benefitted from the attention). While I have not completely addressed my writing backlog, I have written quite a lot. Yet, while my children might be adults (although my daughter was not when I last saw her in August), I miss them, and the uncertainty of not knowing when I will be able to see them again niggles quietly at me.

A year ago, I used the image of Erich Auerbach writing Mimesis, his celebrated study of Western literature, written in exile in the 1940s without his library, to highlight how much less isolated a halfway decent Internet connection makes us. Now, I think what I was fumbling toward was the recognition that the pandemic has pushed us into a slightly twisted mimesis of the life we had experienced up to then. Unlike then, I now know that Mimesis is available online. Like then, I still have not read it. But I have just read Edward Said's introduction to the 2003 edition (Auerbach 2003: xxxi), where he writes of how, influenced by Joyce and Woolf, 'Auerbach explicitly rejects a rigid scheme, a relentless sequential movement, or fixed constructs as 
instruments of study'. And perhaps, the uncertainties unleashed by the pandemic's mimesis have shown us that we should reject all that too.

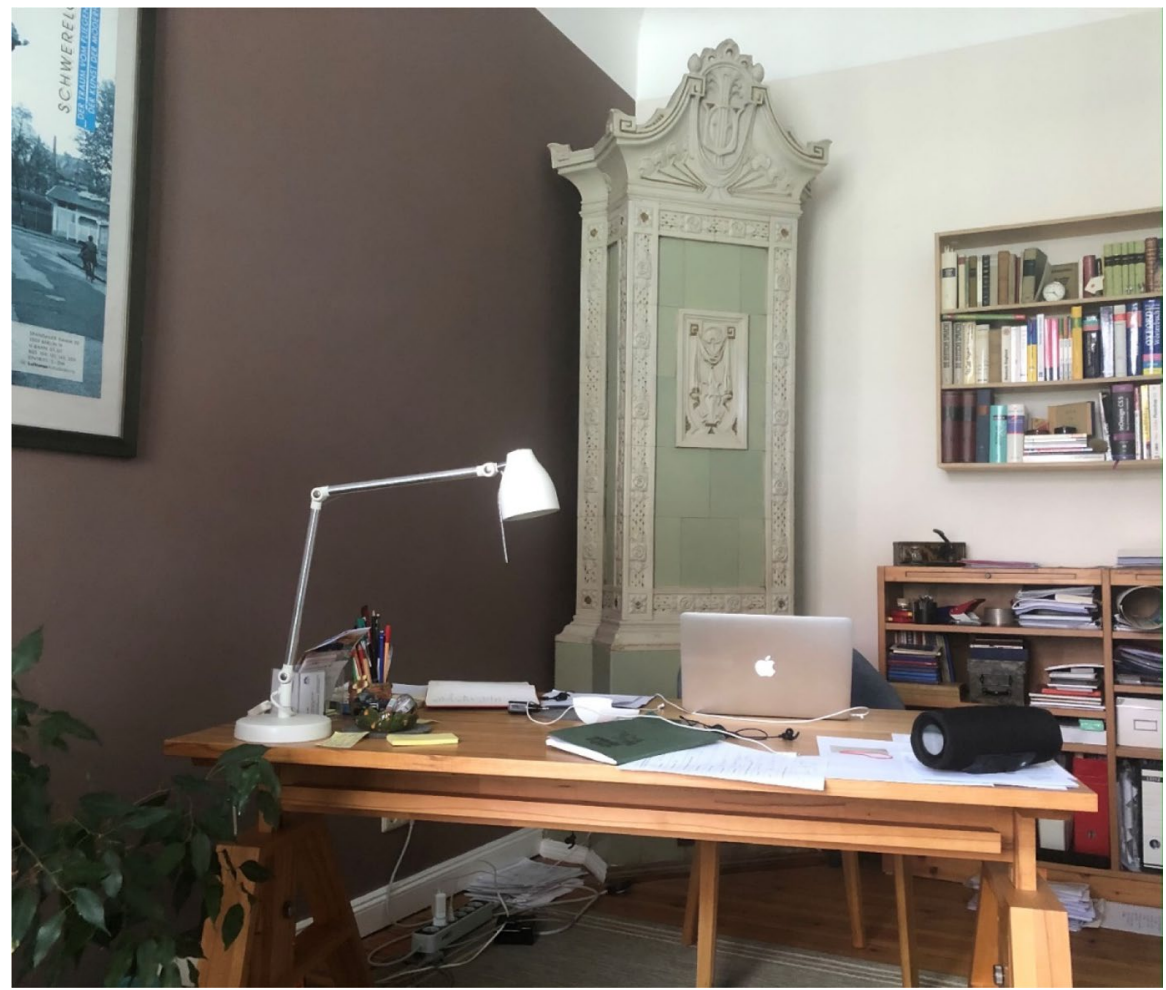

Fig. 60 [New figure.] The jobshare desk in front of the (much admired on Zoom) oven

\section{Not Much Has Changed...}

Georgina Tuari Stewart, Wellington, Aotearoa New Zealand, 7 May

[Updated biography.] Georgina Tuari Stewart is an associate professor in the School of Education at AUT (Auckland University of Technology) in Auckland, Aotearoa,New Zealand. When time permits, she heads north to spend a few days with her family in Whangarei.

Presently, I am enjoying a few days in Wellington, an hour by plane away from Auckland, as a guest speaker to the Philosophy program at the university here, a welcome change of scene and a return to some kind of academic normality, after not flying or conferencing at all in 2020. 
Outwardly, little has changed about life in Aotearoa New Zealand, compared with before the start of the pandemic, either for myself personally or for the general population. Public health measures are still in place: masks must be worn on buses and planes, and everyone is asked to continue to record their movements, to minimize risk and enable contact tracing in the event of another outbreak. Like everyone else, I have become used to wearing a mask and seeing others wearing masks - it is simply the new normal.

There are still occasional infected individuals arriving in the country, and managed isolation and quarantine systems are still operating for overseas arrivals from most countries, but there has been no community transmission for months. Our government has purchased sufficient vaccination doses for the entire population and made them freely available. A staged vaccination program is currently proceeding, starting with border workers and other high-risk groups, then the more vulnerable members of the community, and so on. Public information has been distributed so people know when they will be able to receive their vaccinations. I look forward to being vaccinated in a couple of months.

The universities here have been hit financially by the lack of overseas students due to travel restrictions, but increased numbers of domestic students have helped to offset the losses. Before the pandemic, we were being expected to incorporate an online component in each course we taught, but those expectations have greatly increased-last year in a sudden, emergency way, and now as a matter of course. Research supervision remains the same as before, but a blanket prohibition is in place on all staff and students conducting research overseas. Difficult debates are ongoing about how to manage international data collection for research that was already underway before the pandemic.

Conversations with other academics reveal niggly changes for the worse. At one place, the university now charges for a guest Wi-Fi code. At another, academic staff have been encouraged to leave without being replaced, causing unreasonably high teaching workloads. At my own university, before the pandemic, each academic could apply to receive a small annual sum of research funding, but this was made unavailable last year in the face of the pandemic. There has been no mention of its return this year, apparently because, since travel restrictions make it impossible for us to attend overseas conferences, we are seen as having no need of it. Some such changes can be attributed to the pandemic, but overall, they seem part of a larger, gradual process of worsening conditions of academic work.

Life is much the same as before the pandemic started. A year ago, I expressed hope that the pandemic might be the start of a new era for humanity, but today, I find it hard to be optimistic about that. 


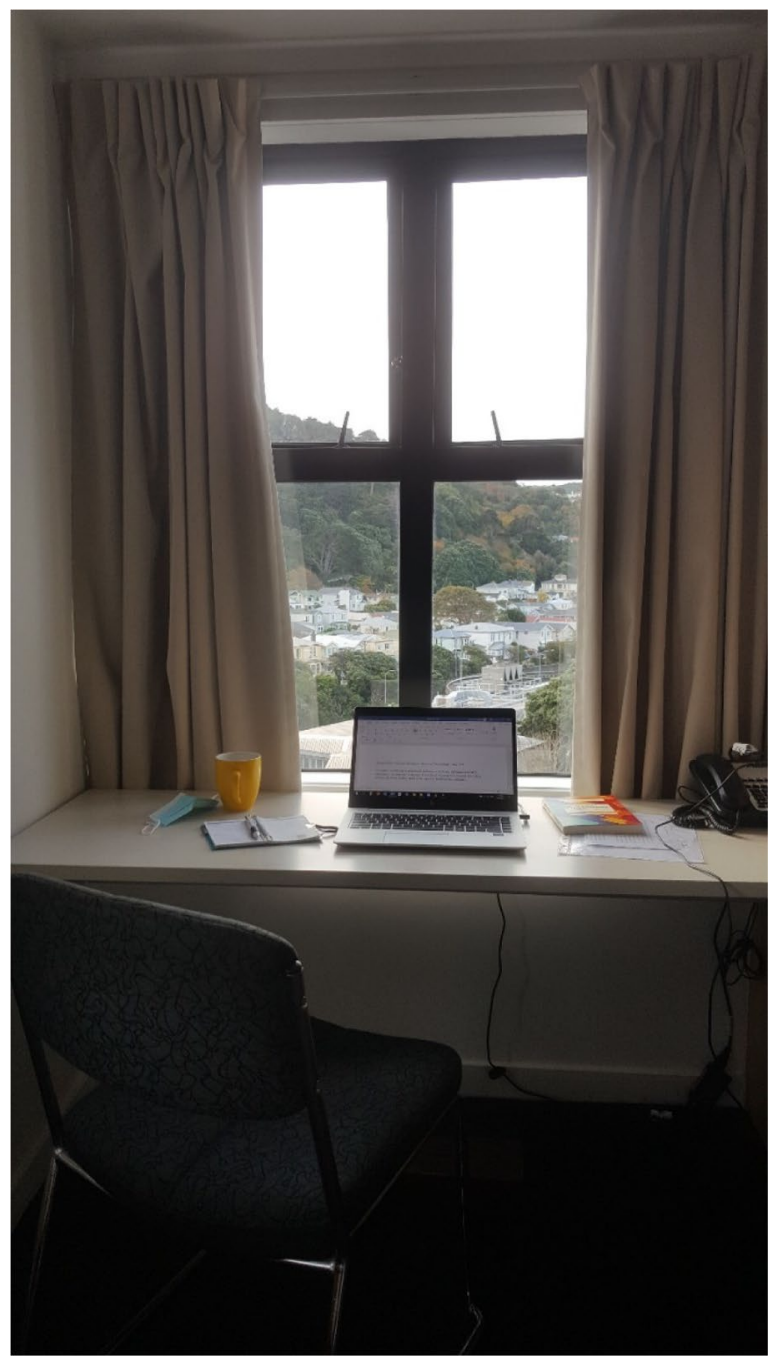

Fig. 61 [New figure.] Working at the desk in my Wellington hotel room

\section{Reviewing the View from a School of Education in the Time of Covid-19}

Rachel Buchanan, Newcastle, Australia, 7 May

[Updated biography.] Rachel Buchanan is an associate professor in Education, and the Deputy Head of School (Postgraduate Teaching and Learning) for the School of Education, University of Newcastle, Australia. Rachel is 42 years old and lives 
in Newcastle, Australia, with her husband, three children, two dogs, and a cranky parrot.

This testimony is being written from my office at the Callaghan campus of the University of Newcastle. This is a new office for me, as the building where I worked from 2010 to 2020 has been condemned. Outside my window, I can see what was previously the Mathematics building being refurbished in order to become the new School of Education. So, I cannot get too attached to this space as it is temporary accommodation.

Much has happened in the last 12 months. Although lockdown did not last too long in Newcastle, and semester 2, 2020, commenced with much of the student body back on campus (with concurrent online provision available for those who needed or preferred it), the university is a smaller and emptier place. Almost 20\% of my colleagues in the School of Education have taken voluntary redundancy or early retirement packages so we are a leaner workforce serving an increased number of students. (In times of economic uncertainty, teaching becomes an attractive vocation, and we are experiencing an increase in the number of students entering our education programs.) Our five university faculties have been reconstituted as three colleges, and we are in the midst of a change process that is resulting in academic and professional staff job losses as positions have been deemed to be surplus and are to be 'disestablished.'

The end of 2020 involved a curriculum 'renewal' process that aimed to reduce the number of units that are taught across the university by $30 \%$. At least $20 \%$ of subjects that were taught here are no longer available.

The relatively brief period of lockdown in Newcastle (a matter of weeks) that was caused by the pandemic has been less disruptive than the subsequent lockout we have experienced institutionally. We have been locked out of decisions about institutional viability and identity as the university has shifted from having many courses available to a strategic narrowing of offerings. We have been locked out of decisions about staffing numbers. Locked out of decisions about academic identity as schools have been put into new college structures with ambiguous identities. (I now work in the College of Human and Social Futures rather than the Faculty of Education and Arts.)

While the physical impact of the pandemic has been light here, the psychological impact of the panic regarding the sustainability of the university has eroded institutional trust. I am not suffering from corona but rather from change fatigue. There is a feeling of being trapped. We cannot travel overseas, and the vaccine rollout in Australia has been very slow, so we do not yet know when we will be able to leave these shores. At the same time, many universities across Australia are shedding jobs so it is also unknown when changing institutions will again be an option.

Twelve months, ago my view was of a 'post-apocalyptic, eerily empty' campus on the verge of being closed (it did not end up being closed, but instead opened up for face-to-face classes after June). Now, my view is similar, yet it is not Covid-19 directly that has reduced staff numbers here, but rather a managerial and government response to the economic uncertainty. People not working in areas deemed to be of 
strategic importance to the university are being treated as rubble to be cleared away, the way the machines working under my window are clearing the detritus of the building's previous inhabitants. As I look forward to a post-pandemic academy, I am waiting for the virus to play out- the virus that is the institutionally initiated change process.

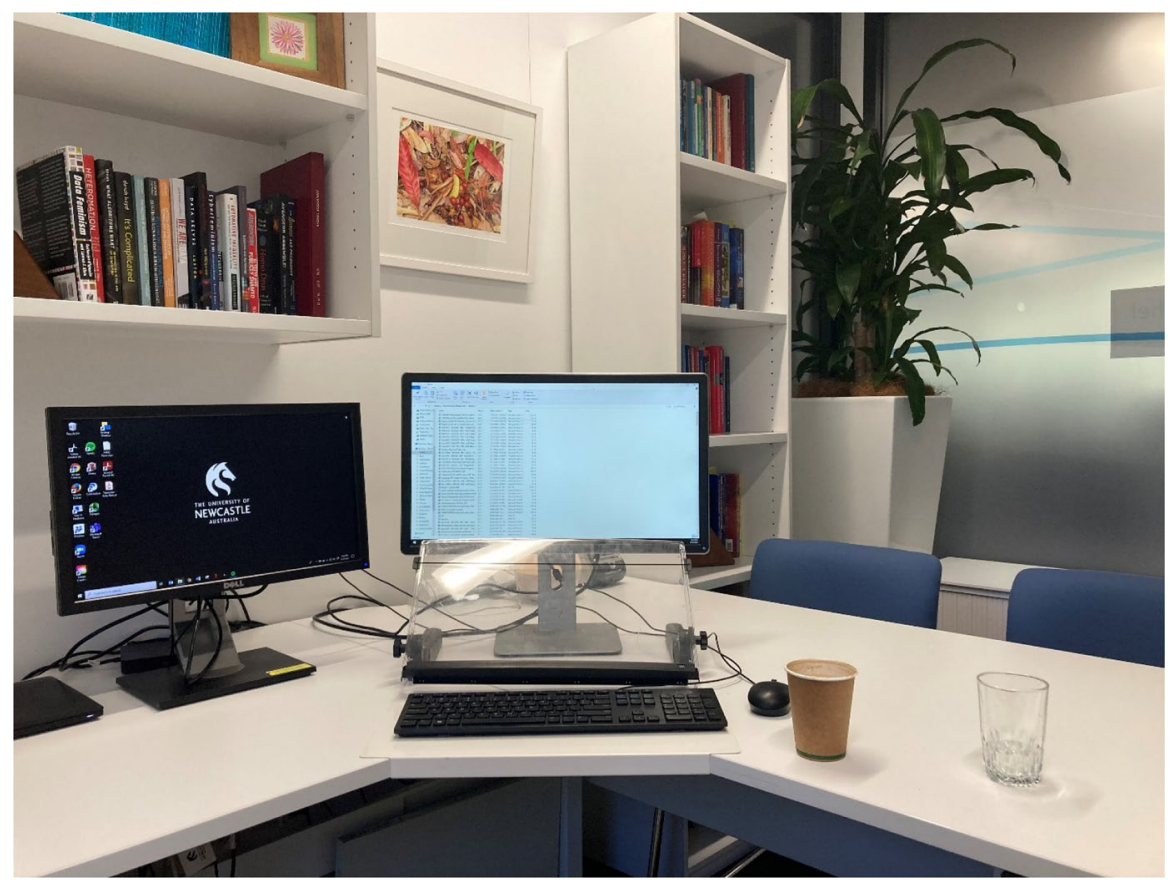

Fig. 62 [New figure.] Pictured is Rachel's office on campus. The orderliness of the space belies the disruption being experienced across campus and the higher education sector

\section{A Year On...}

Nesta Devine, Auckland, Aotearoa New Zealand, 8 May

[Updated biography.] Still a professor at the Auckland University of Technology, but more detached from the committees and administration and more focused on my graduate students, my writing, and reading, and the three journals that I editACCESS: Contemporary Issues in Education, ${ }^{19}$ with Andrew Madjar; New Zealand

19 See https://pesaagora.com/access-journal/. Accessed 8 May 2021. 
Journal of Teachers' Work, ${ }^{20}$ with Christoph Teschers; and the New Zealand Journal of Educational Studies, ${ }^{21}$ with Georgina Stewart.

$* * *$

My life has settled down, and I am embarrassed to think how easy things are now, knowing what others have gone through and are still going through. New Zealand introduced stringent measures to eliminate the virus from the population early, and hard. As a consequence, although we have had lockdowns, and cannot travel, we are able to function pretty much as we do normally. Only citizens (and more recently, and unreliably, Australians) can come into Aotearoa New Zealand, and, except for the Australians, they must all quarantine for 14 days.

The big difference in the education world is the lack of international students. They cannot come into the country, and if they are here, they cannot leave-or if they do, they cannot come back. Some concessions have been made to students who were overseas and intending to return when Covid-19 struck, but not enough to alter the general situation. The consequences to the value of inner-city apartments and the businesses that depend on foreign students have been dire, although the universities in New Zealand have generally experienced an increase in domestic student enrolment which has gone some way-with government subsidies-to defraying the expected financial meltdown.

I am back in my own, renovated, home. My mother did not really recover from breaking her leg at the beginning of March, and the isolation of lockdown accelerated the progress of her dementia. She died in August, fortunately between lockdowns so her family could visit and surround her with love.

My university flipped and flopped-immediately in the first lockdown, they changed the whole structure of the undergraduate degree, which was immeasurably cruel to lecturers trying to put all their work online. The students complained bitterly and the decision was reversed... but the bad taste remains. We learnt (further to what we already did) to teach online through specific programs and email, but the whole experience has taken a toll. The workload for our teachers was incredibly demanding. One of the things we notice now is the university's enthusiasm to have us put all our work online-clearly this is a pandemic insurance, but we suspect it is also to make us as teachers less critically important to the university's delivery of its 'product.' The School of Education as a whole is scathing of the 'developers' understanding of pedagogic principles, especially with regard to the initial education of teachers. My response is an increasing sense of distance from the institution.

These circumstances have affected our graduate students, in different ways. Some of the international students could not get into the country, and their enrolment is indefinitely delayed. Others fled for the security of their own countries and families, and hence had to withdraw. Many had to alter their methods of research because they could not talk with people face to face, especially if they were aiming to interview

20 See https://ojs.aut.ac.nz/teachers-work/. Accessed 8 May 2021.

21 See https://www.springer.com/journal/40841. Accessed 8 May 2021. 
people overseas - they would not have been able to return. Some, who were already teaching in tertiary institutions, fell prey to the opportunism of their administrators, who saw in the lockdown a chance to introduce widespread redundancies. Although not made redundant themselves, they had to pick up the workloads of those who were. And some, embedded in poorer, collectivist, communities took on significant roles in organizing relief for the families associated with their own school. My heart aches for them, struggling with these difficulties, but I am proud too of the way they have responded.

But overall, my heart goes out to those who continues to work in a disease-ravaged environment, and to those who have lost jobs and loved ones in this terrible year. E hoa, kia kaha, kia mana, kia manawanui.

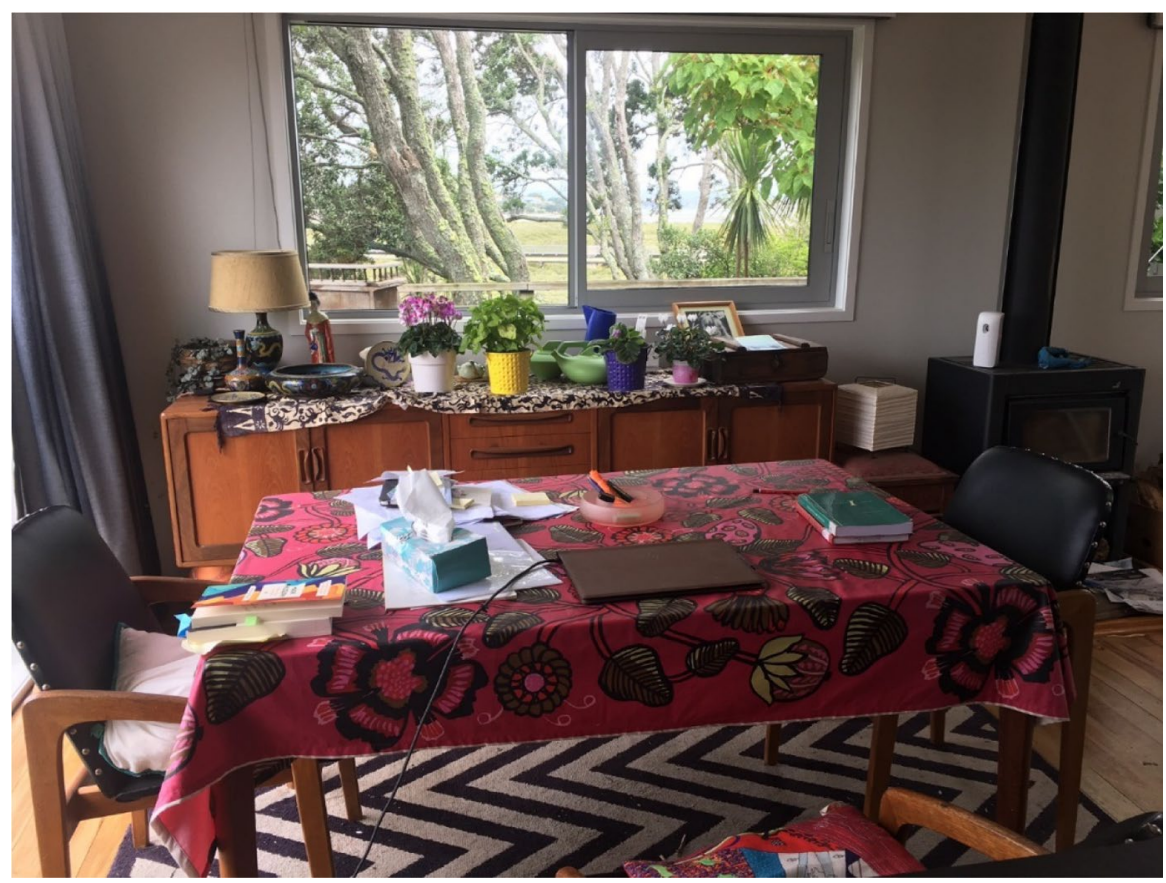

Fig. 63 [New figure.] A year on, and I am still working largely from home-on the dining table, sustained by my clutter and my trees

\section{Online Labor/Work Does Not Sleep!}

Richa Shukla, Sonipat, India, 8 May

[Updated biography.] Dr. Richa did her MPhil on Simone de Beauvoir's Philosophy. The dissertation was titled 'Webs of Identity: a Relationship between Self and Others in Simone de Beauvoir's Philosophy'. Her Ph.D. on Feminist Phenomenology 
is titled 'Dialogues in Silence: a Study of Mourning, Shame and Vulnerability in India'. Richa's theoretical leanings are in feminist philosophy, existentialism, ethics, and social and political philosophy. She has numerous peer-reviewed publications under her name.

Almost a year back, when Covid-19 knocked at our doors for the first time, it was greeted with unwillingness, finitude, temporality, and a sense of absurdity. We thought: just one day at a time, and we would be good to go. Slowly and gradually, we started to accept 'social distancing', 'masks as a new reality', and above all, the newly born idea of 'online teaching'. Today, I write this testimony from my home. I did not move to another house but decided to stay with my family. I still work at the same university. Initially, my university was thinking of opening the university, but with the rising number of cases, it was decided to remain teaching in online mode.

I am trying to be more equipped with the online world, its reality(ies) and rules. In the past year, I have experienced death turning into a number. The quantification of suffering and mourning has already started to happen. When someone close dies of Covid-19, we console ourselves thinking how much worse things could have been if death had resulted in more misery of the deceased soul. The biggest challenge these days is to learn how to live with this 'iceberg': we know, experience, and analyze, only $1 \%$ of the 'lived reality' of Covid-19.

We can see only what Covid-19 chooses to show us. The fear of the unknown gives rise to the fear of contingency. When Covid-19 is over, we will no longer be the same to ourselves, and we will no longer be the same to other survivors. As Heraclitus said, we cannot step twice in the same river. My feelings these days are ambiguous, just like our human existence. The reality of online teaching remains a constant, never-sleeping reality. Recently, I read The New York Times article saying that our feelings are languishing. While mourning my grandfather, I have come to realize that family makes us weak too.

I have been staying with my family these days. As home takes away 'our right to isolation,' the comfort of being unable to dig deep into my own emotional world leaves me puzzled. It is human nature 'to be.' Hence, I doubt whether my view of Covid-19 has changed in the past year. One of the constant ideas which managed to stay afloat was the existence of online teaching. Several times, this online space has given me a purpose. When most of us were cribbing for normalcy, my students and the space of teaching remained a never-changing, living idea, which I looked upon. This idea resembles one of my favorite cities, Bombay, which never stops and never sleeps. 


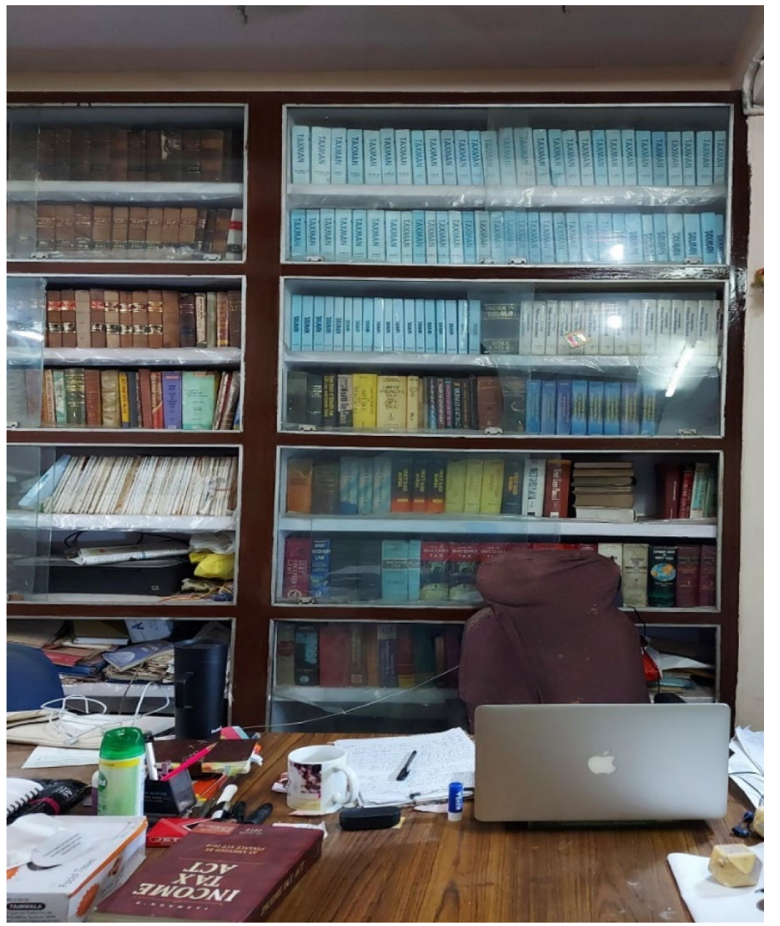

Fig. 64 [New figure.] Work in transition, changing workplace. These days, I have started working in my Grandfather's and Father's chamber

\section{Not In Lock-Down, But in A Lock-Away from The World}

Rene Novak, Christchurch, Aotearoa New Zealand, 8 May 2021

[Updated biography.] Dr. Rene Novak has a strong passion for early childhood pedagogy and technology education. He is currently supporting the southern centers as a Regional Professional Practice Leader for BestStart and is a published academic with his recently completed Ph.D. thesis focusing on developing new methodologies to study the importance of play involving Virtual Reality, as a tool and a method.

$* * *$

As I am writing the second contribution to this amazing collaborative endeavor, I am thinking about the international perception of New Zealand, regarding its privileged position of having been Covid-free for most of the year. I would imagine that most would think that people in our country have consequently also been unscathed by the situation in comparison to the rest of the world. However, if I consider my personal and professional development and changes I went through in the last year, this misconception could not be further from the truth. 
While I only went through one lockdown myself and while I was able to move freely for most of the year, Covid-19 triggered a number of societal, organizational, and structural changes in the educational and national infrastructure, which affected me and some of my colleagues and friends greatly.

Covid-19 triggered a restructure of my full-time position, which resulted in me having to apply for a different, newly established position. Six days before my scheduled interview, I was advised by my sister-living in my home country of Slovenia - that her cancer had returned. Two days later, she suddenly passed away. Covid-19 had not only triggered the restructure, but it also prevented me to travel to Slovenia, attend the funeral, and support my family. Considering extended quarantine times, the amount of required leave made travel impossible. This created a very difficult situation, through which I struggled greatly.

I interviewed well and was able to secure the new position-but not everyone did. Some of my colleagues demoted to lower positions and others left the organization. However, I felt greatly supported through the process. This situation also made me take a 3-month suspension from my Ph.D. studies, which, at that point (August 2020), were almost at their end. I needed some time to recover.

These events provoked me to rethink my life. I was asked to apply for an academic position outside my organization, which-with some reluctance-I did. My interview went very well, and I was offered the role. When I informed my current employer, they asked me if I would be willing to interview for a Regional Professional Practice Leader role for the South Island and Wellington. That would imply moving close to a thousand kilometers from Tauranga in the North Island to Christchurch in the South Island. Due to having very close friends living in Christchurch, who followed me from Slovenia to New Zealand, and due to the exciting new career opportunity, I have decided for the move.

Now, in May 2021, I am writing this at my new home in the South Island. I am now 4 months into my new job, which I enjoy greatly. I am spending a lot of time with my close friends and am about to defend my Ph.D. thesis in a month. This fresh start was good for me personally and professionally. Covid-19 created some of the hardest adversities I had to face in the span of my life, yet it also created some of the greatest opportunities.

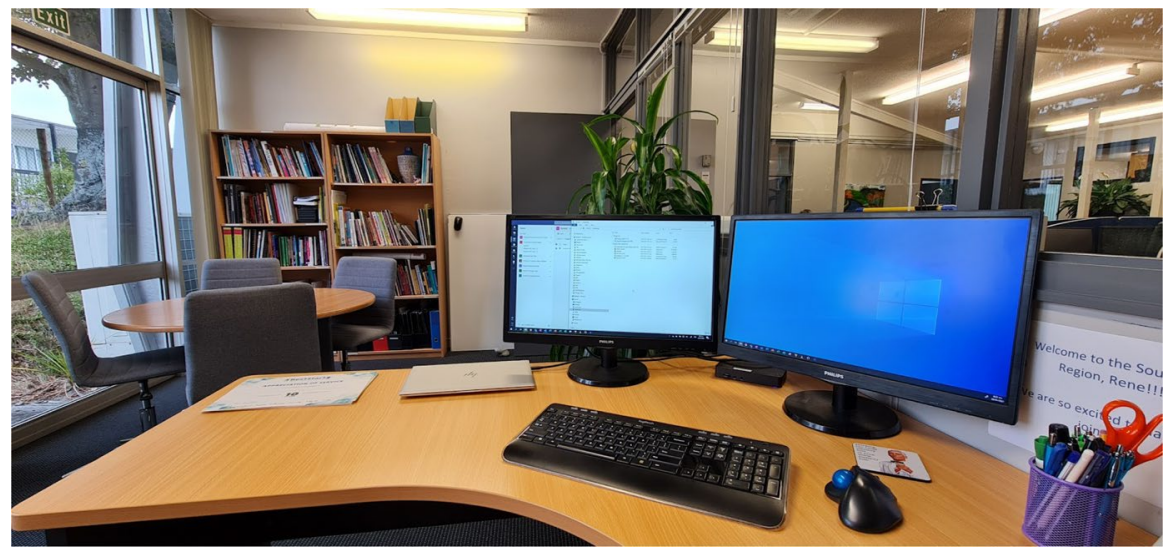

Fig. 65 [New figure.] This is my new workspace in the Christchurch BestStart regional office 


\section{A Year of Teaching Online-Optimistic No More}

Madhav Mallya, Sonipat, India, 10 May

[Updated biography.] Madhav Mallya is an Assistant Professor at the Jindal Global Law School, Sonipat, India. His research interests focus on international investment law, environmental law, and colonialism.

$$
* * *
$$

In March 2020, I wrote the prequel to this piece titled 'An Opportunity to Strengthen Alternatives to Classroom Teaching' (Jandrić et al. 2020: 1190-1191). I expressed optimism that it was possible to replicate classroom methods of critical thinking in an online system and that we, as academics, have the duty to help students think and analyze for themselves, whether inside or outside the physical classroom.

A year later, that optimism has been replaced by a sense of despondency and frustration. As I write this piece, India is facing a deadly second wave of the virus, with the highest death rate and daily case load globally. My colleagues and students are battling the virus or helping their families battle the virus. Every day, one gets news of death or illness. I and my family have also battled the virus-in fact, I taught one class from my hospital bed.

It is difficult, and perhaps unreasonable, to expect students and teachers to teach or participate actively in online classroom discussion when they face personal crises. But from a broader perspective, I believe that we are all facing what is popularly called pandemic fatigue. After a year of battling illness and being in social isolation, certain lethargy has set in. It takes effort for a student to sit before a computer screen for hours listening and participating in discussions. It is equally daunting for a teacher to go on speaking with enthusiasm when hardly anyone is listening or may not even be there!

Coming to the central theme of the previous piece, critical thinking. Are we to abandon our duty of helping students to develop their intellectual and reasoning skills and succumb to giving 'lectures' to fulfill our professional commitments? Or are we to keep forging ahead on full steam, as if online classes are normal, while the world outside is ravaged? I believe the answer is neither. It does not look like the pandemic will abate anytime soon, and the less said about the incompetency of national governments and institutions, the better. So, what are we supposed to do?

It is important to find a middle ground, acknowledging that there will be days where you or your students are unable to give your best. It is best not to expect in-depth critical discussions like ones in the classroom. At the same time, for both teachers and students alike, it is important to try and be healthy, both mentally and physically, to be able to give their best in the classroom.

Last year, I had written about the privilege we had of teaching physically in the classroom compared to many students and teachers who worked online on a regular basis. I wonder if I am being unreasonable in losing the hope and enthusiasm which I previously had that online classes could replicate the physical classroom. The pandemic has taken away from us the ability to meet our friends and family and lead a 
normal life. The classroom was a part of normal life, a part of normal human interaction. Therefore, I can be optimistic no more.

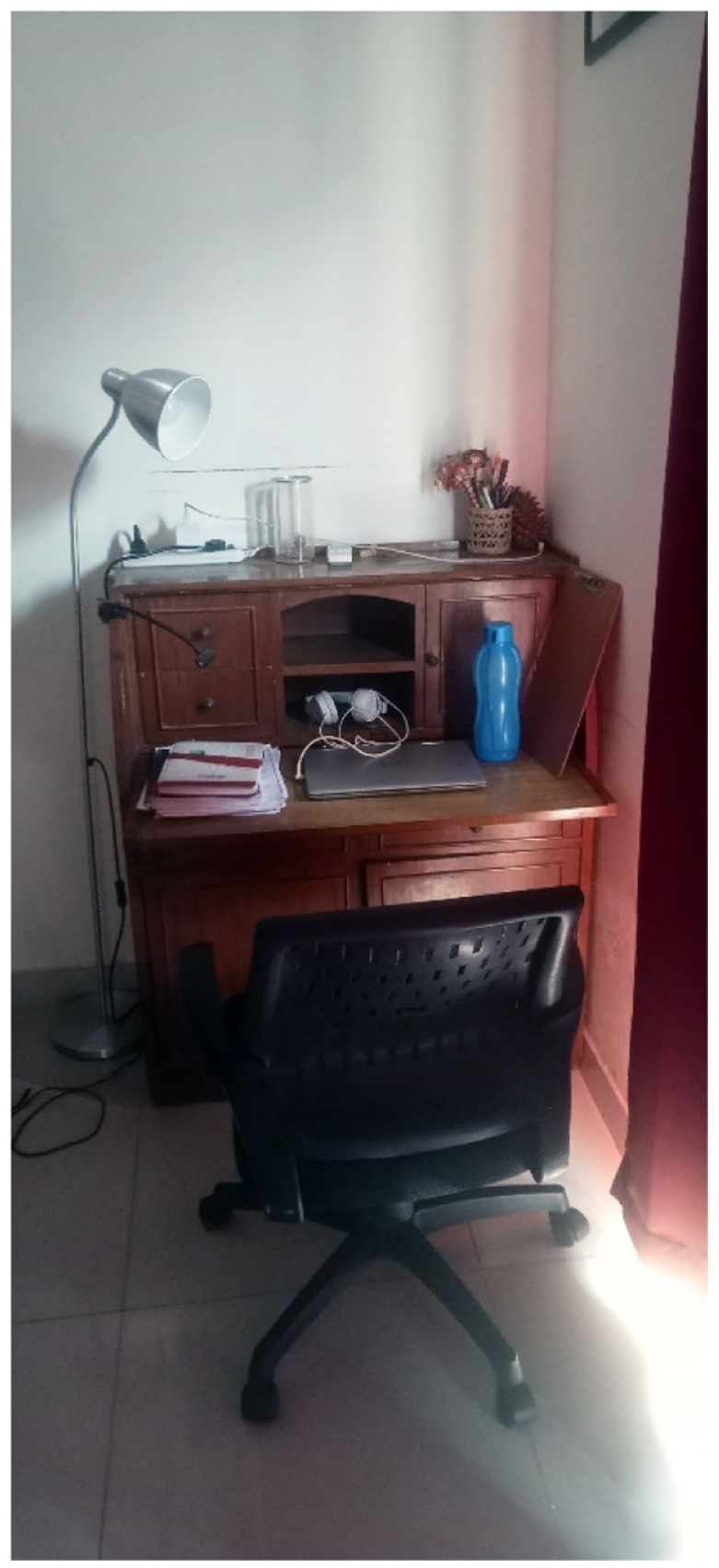

Fig. 66 [New figure.] Workplace at home 


\section{Life During Coronavirus-1 Year Later}

Eva Biličić, Zagreb, Croatia, 12 May

[Unchanged biography.] Eva Biličić is a student at the Zagreb University of Applied Sciences, Croatia, and is employed as a business analyst in a private company in Zagreb. Eva is 26 years old and lives in Zagreb, Croatia, with her partner.

$* * *$

A year later, life has remained pretty much the same. My partner and I still share the same desk, now only 2 days per week, since the other 3 days we work from the office. College is almost over, and I am currently writing my dissertation. Eventually, all expectations of meeting new colleagues and professors vanished, as the entire 5th year of college was online. Two years ago, I could not even imagine that I would finish my studies by looking at a computer monitor instead of smiling faces of my colleagues.

The last year has been a challenge in various areas, yet I also notice positive changes. After the government lifted coronavirus prohibitions, we returned to our offices. Constant work from home affected us all, and office time with colleagues is much more intimate. Everyone is much more open and willing to talk about private issues. I got a chance to do what I really want: web design. My employer did not want to lose me, so he gave me that opportunity, which makes me really happy. The end of college is approaching, which makes me a bit unhappy because everything will take place online, making my success seem somehow less important. Since I was a little girl, I have imagined the moment of graduation surrounded by family and friends. Now, this is not going to happen.

I also noticed changes in social relations and greater interconnectedness with people, which I talked about last year. Although I still feel an increase in compassion and understanding, it seems that we are going back to the old ways. I like that sense of interconnectedness, but as we are somehow moving away from each other, the increased use of technology remains. Great differences can be observed in different areas such as education and health that have improved due to the advanced use of technology.

Some things return to normal, while others remain in the new normal. One thing is for sure: the coronavirus has affected all of us. Many people have realized that family is most important, and now, they are trying to make up for lost time with them. Family is the most important, but I secretly hope for the end of all prohibition and a good concert surrounded by people of different ages and life stories enjoying the music. 


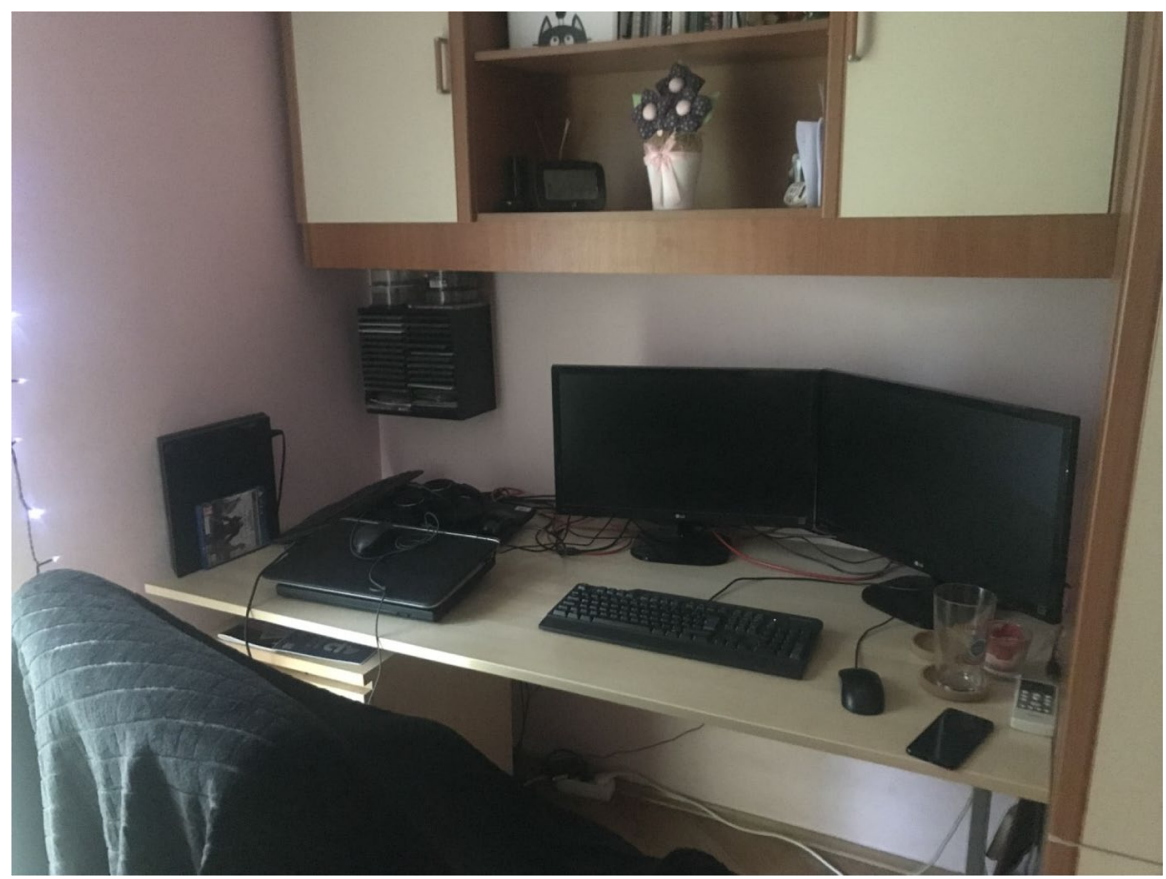

Fig. 67 [New figure.] This is my workspace in our bedroom, where I work and write my dissertation alternating with my partner Ivan

\section{Time Travelling}

Sean Sturm, Auckland, Aotearoa New Zealand, 14 May

[Unchanged biography.] Sean Sturm is a senior lecturer at the University of Auckland in Aotearoa/New Zealand. He is 52 years old and lives in the inner suburbs of Tāmaki Makaurau/Auckland with his wife, son, daughter (sometimes), two cats, and a fish.

It is now mid-Autumn in the south: the citrus trees hang heavy, the weather is turning, and the nights are closing in. The virus now a distant-but malignant-enemy for those of us fortunate enough to be marooned in the island idylls of the Southwest Pacific, absent the occasional case that escapes quarantine. Teaching halts into 'the future': teachers muddle through, half online, half off, teaching neither to their onor offshore students, working all hours of the day, while institutions muddle-headedly capitalize on the crisis that emergency remote teaching in the lockdowns offers them (e.g., a move to digital learning, assessment and analytics, viz., surveillance; workforce reductions and workload increases; savings in infrastructure through remote working and in travel costs through remote conferencing). 
I sense now a shifting of horizons. We cannot travel. We are on the other side of the day from European colleagues (meetings with them take place early in the morning or late at night; conferences, in the depths of the night). Our thoughts shift to colleagues - and perhaps also concepts-from our timezone. We understand a little what it must have been like for our Pākehā forebears to live in the nineteenth century in the antipodes in a distant province of the English empire ('the Britain of the South', perhaps), more than a month away by mail from home. We also understand a little better what it might be like to live 'in the future' in a distant province of a different empire (an edge location in Amazon's Asia Pacific global infrastructure region, perhaps), a future in which we are, as it were, here (local) but not here (digital).

In between times, I have left my bed-office for my new garden shed-office. I am settling into a more circumspect existence. I am coming to understand a different kind of care from that which drew our little family inward in the immediate crisis of a virus that seemed such an urgent 'intrusion of Gaia' (Stengers 2017). This new kind of care involves a careful 'think[ing] beyond the Anthropocene' (Stiegler 2017: 389), careful in that it is tentative and curative. Such careful thinking attempts, through its otherworldly encounter with the virus and immersion in the digitas, to rethink the "cosmotechnical triangle "human/animal/machine" in a way that is other-than-colonial, or 'strategically primitive' (Viveiros de Castro and Hui 2021: 398). But the rude joy that I feel in this thinking cannot help but remind me of the 'strange gaiety' of lockdown that I wrote about 1 year ago...
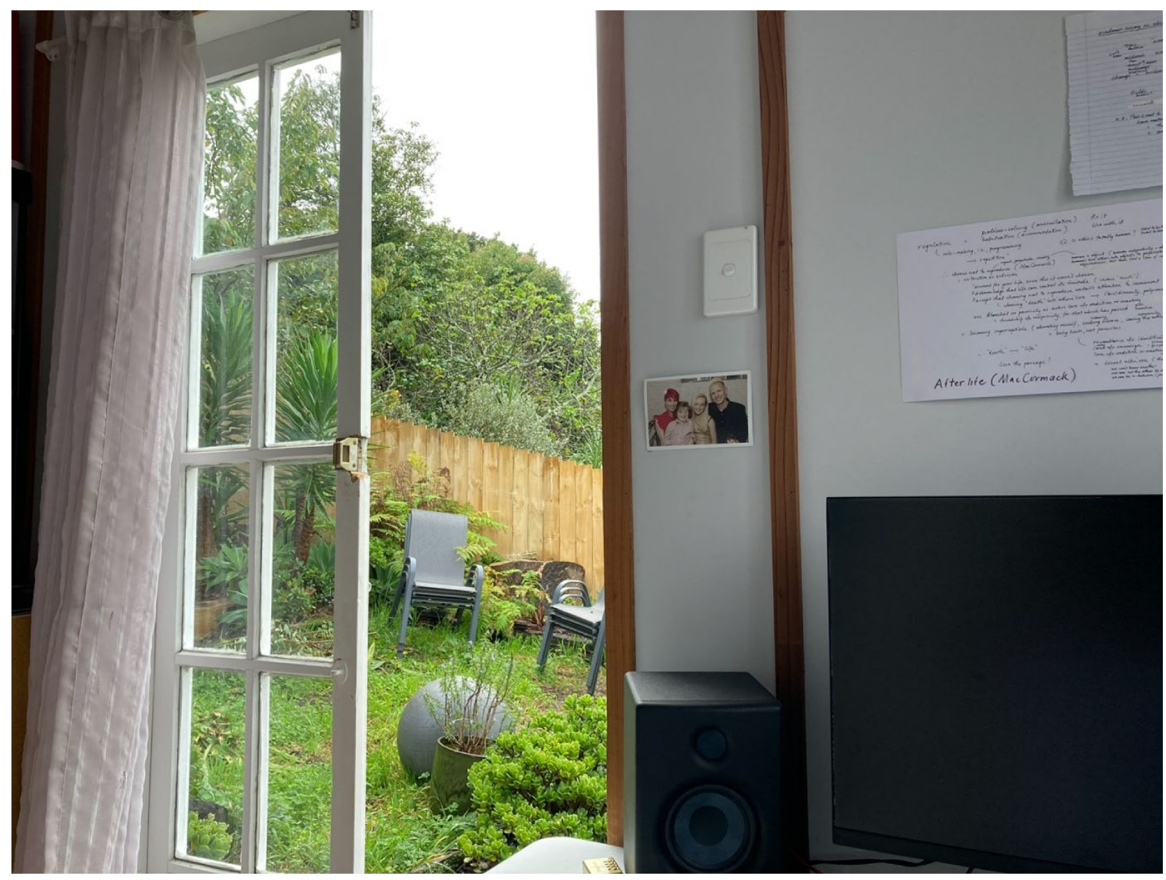

Fig. 68 [New figure.] This is the view from my new workspace since the Covid-19 lockdowns of 2020: the garden shed-office 


\section{Dis/connections Between Teaching and Learning}

Sahar D. Sattarzadeh, Indianapolis, IN, USA, 15 May

[Updated biography.] Sahar D. Sattarzadeh is assistant professor of Education Studies at DePauw University and Research Associate with the Chair for Critical Studies in Higher Education Transformation (CriSHET) at Nelson Mandela University in Port Elizabeth, South Africa.

Teaching remotely during the Covid-19 pandemic has yielded a crucial, humbling personal education and learning in dis/connection. Dis/connection as in a combined lack, loss, or severance and preservation and building of relationships - with the earth, humans, nature, opportunities, privileges, resources, and/or rights. Such dis/connection is simultaneoussometimes contradictory, sometimes symbiotic, sometimes a combination of both.

Dis/connection has manifested infinitely ... on the ancestral, traditional, and unceded lands of Delaware, Piankashaw, Wea, Miami, Kickapoo, Potawatomi, and Shawnee relatives-Indigenous communities-on territories paradoxically translating to the settler colonial name 'Land of the Indians,' even though they remain unrecognized by the government here. ${ }^{22}$ Dis/connection. My husband and I moved here 5 days after our summer Zoom-based wedding, between two academic calendars. Although physically isolated from our wedding guests, Zoom connected us with over 230 loved ones from all over the globe. Dis/connection. My maternal grandfather's absence at the wedding was deeply felt. His body surrendered to stage 4 lung cancer almost 1 month prior, but his memory was centered in my heart that day. Dis/connection.

We moved because I accepted a new faculty position at DePauw University, but we also had an abundance of justified fears about relocating here. Dis/connection. Fortunately, we started our new life together teaching remotely from our respective home 'offices', superficially 'safe' from the world outside it. Yet the walls still could not protect us from feeling the tragedies, nor the accompanying grief, loss, and pain evoked beyond them. Dis/connection. The rapid accumulation of non-/familial antiBlack violence and/or non-/Covid-19-related deaths, the amplification of injustices, and inequities also penetrated the computer screen between my students and I and hijacked/transformed our course syllabi-pedagogy, praxis, and all. Dis/connection.

During my first semester at DePauw University, the faculty was granted the option to choose between teaching either hybrid or fully remote courses. I chose the latter, because I did not believe it was safe for any of us to meet face-to-face, and courses were asynchronous. At the time, I thought an asynchronous course would be most convenient for students, but we missed real-time communication and community-building opportunities. Dis/connection. To complement asynchronous courses, brief, intimate, synchronous weekly check-ins were scheduled with all students-in small groups-in order to maintain a consistent connection for the students and me. It did not stop me from wishing I could do more to assure and support them. Dis/connection.

\footnotetext{
${ }^{22}$ For a critical, insightful read on the politics of Indigenous/Native recognition, please read Kim Tallbear's (2013) Native American DNA: Tribal Belonging and the False Promise of Genetic Science.
} 
This subsequent semester, courses were still remote-synchronous this time. Like countless others - those privileged to work remotely-around the globe, human interactions - outside the household - have been limited to the digital landscape. Dis/connection. I am affiliated with a campus community I have yet to connect with physically. Dis/connection. Courses became mirrors to the social realities of the world, extensions of my heart, mind, and soul. Education relevant to individual and collective affect, compassion, creativity, equity, health, justice, and wellbeing were prioritized in our courses. Again, course syllabi adapted to the climate of students' energies and the social environments we were all dis/connected from/to. What a year of teaching/learning it has been... Dis/connection.

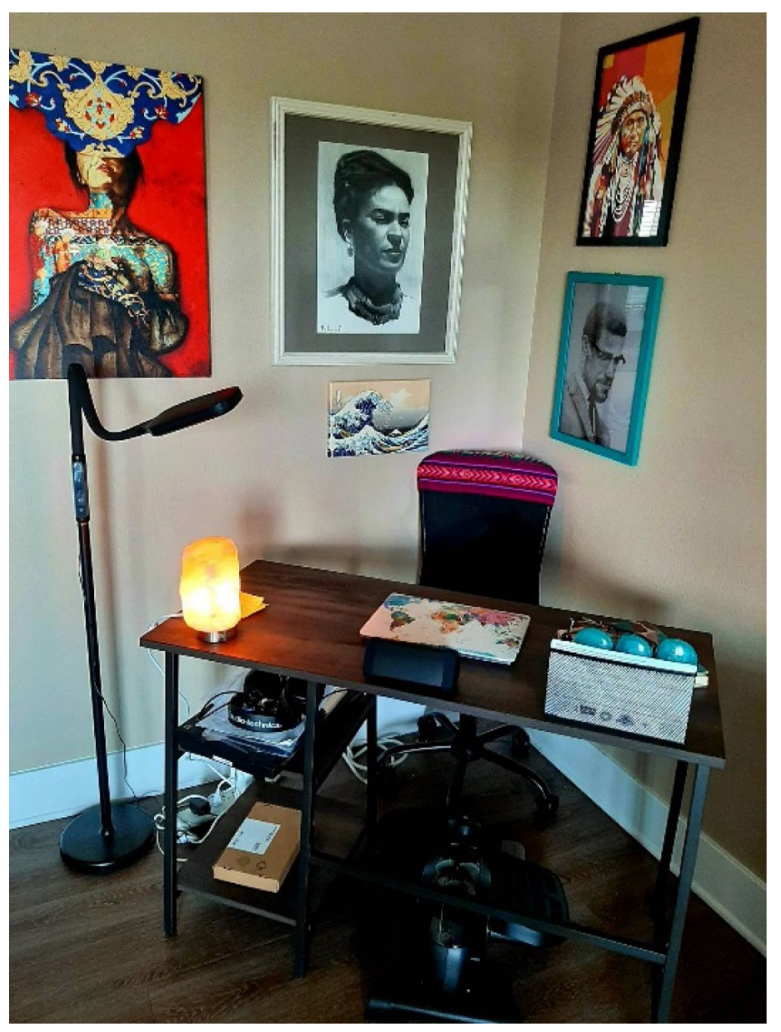

Fig. 69 [New figure.] The humble 'office,' blessed with the energy of some beloved ancestors in my corner 


\section{One-Year-Later Perspectives on Online Learning}

Abey P Philip, Miri, Malaysia, 15 May

[Unchanged biography.] Abey Philip is a senior lecturer at the Curtin University Malaysia, in Northern Borneo. He lives in Miri, Sarawak, with his wife and three sons.

***

I am writing this testimony from my home in Miri, still working from home for Curtin University, Sarawak. Following last year's lockdown, there were few months, when the number of cases was coming down in Malaysia, and we were allowed back to the university campus to work online from our offices. With the second wave and the rising number of cases, the university closed again, and I am back to working from home with my three sons in their second year of online school.

During daytime, our house looking like a call center. The main difference from last year is that no one is sharing their equipment because everyone has their own PC or laptop. I have migrated from a mobile phone-cum-projector system to a digital drawing tablet for my online teaching.

\section{Online Classes: the New Mantra}

Since the beginning of the pandemic and its now-common restrictions, we embraced the best of existing technology, and higher education has almost entirely moved online. Since March 2020, Curtin University Malaysia has been facilitating online learning through Blackboard Collaborate. These systems were already in place before the pandemic but were never used in their real capacity.

The university, to its credit, migrated swiftly to online learning. The pandemic, in a way, was an opportunity for higher education institutions to see how far they have progressed toward becoming twenty-first century institutions: adaptable, humane, and technology ready.

New online systems have opened up new possibilities for higher education institutions. Online classes reduce expenditure for day-to-day campus maintenance, minimize institutional losses, and maximize profits. Most universities will be happy with new possibilities that emerge with the normalization of online learning as their market potential is infinite. 


\section{Do Online Classes Substitute Face-To-Face Classes?}

After completing three semesters online, I am all for face-to-face classes. Online classes can be a contingency measure for sure, but I still miss my students and the vibrant campus. At my native home in Kerala, one of the southern states in India, my elderly mother lives alone. Every Christmas, we visit my mother. This year was different, because none of her children could visit her for Christmas.

Just like universities, we shifted online with Zoom meetings every week. Friday evening, Zoom sessions have become a routine for my mother, my family, and my siblings' families. Under the circumstances, my mother is happy and grateful that we are able to meet virtually at least once every week. Does that replace being with her and staying with her for Christmas holidays?

I feel the same way about online classes. Given the circumstances, online platforms and learning have done a great service to combat some amount of disruption. But in the long run, online classes will not be able to offer a holistic university environment, where learning is only one of many skills that students acquire. Online classes are similar to our family Zoom meetings; they are not a permanent replacement, but a good interim solution. The skeptic in me sees a possibility that some higher education institutions may choose to continue with online classes over the face-to-face classes after the end of the pandemic.

Interaction that takes place in a traditional face-to-face classroom is difficult to accomplish in an online class. Without the contribution of a lecturer, and without avenues for community learning, knowledge creation in any classroom is minimal. I hope that in post-pandemic days, when people reallocate their priorities, face-to face classes in the universities are going to be highly sought after. 


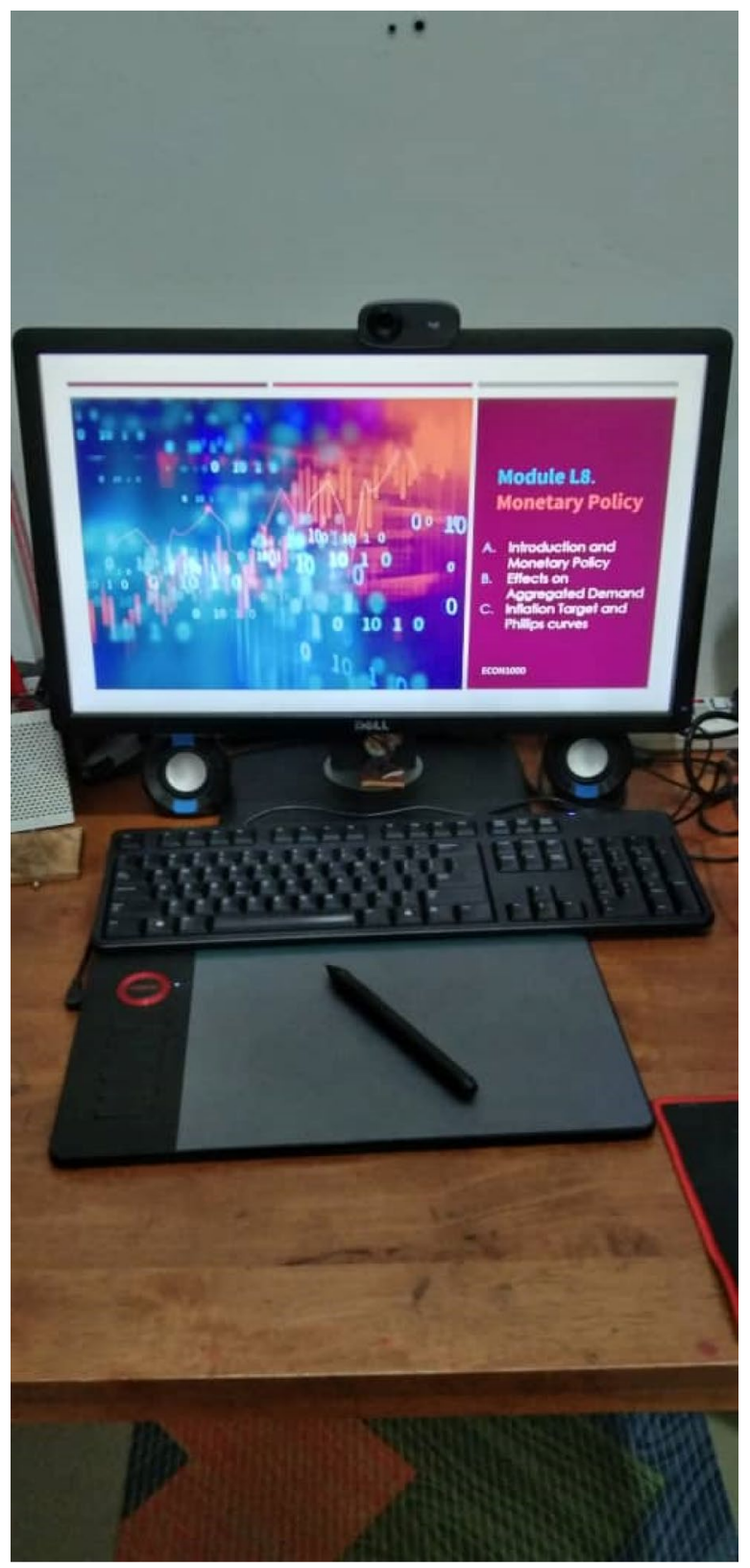

Fig. 70 [New figure.] Workstation during pandemic time 


\section{What A Difference A Year Makes!}

Bridgette Redder, Cambridge, Aotearoa New Zealand, 16 May

[Updated biography.] Bridgette Redder is a Senior Lecturer and researcher at Te Rito Maioha Early Childhood New Zealand. Bridgette teaches into a fully online postgraduate program.

$$
* * *
$$

One year later, the Covid-19 'lockdown' bubble has burst! I write this testimony from the same geographical bubble location as last year-my physical home space situated in a rural central North Island Aotearoa New Zealand town remains the same. Although Aotearoa New Zealand has experienced community transmission spikes over the last year, resulting in movement between alert levels 1 to 3 , there are presently no cases of Covid-19 in the community-I do not take this for granted.

As such, now that I have returned to driving $90 \mathrm{~km}$ to the same physical workplace most days, I have no hesitation in tracing my movements via a contact tracing app-too many people have lost people they love and suffered emotionally, mentally, physically, and financially for me not to do this to ensure any potential outbreaks are contained. I now contact trace when I enter and leave work via the government and workplace apps and when I enter any building outside of my home. Masks are part of the 'new usual' and a requirement for travel on public transport. The testing of sewage to detect the presence of Covid-19 is carried out to ensure there is no community transmission.

My desk at work is devoid of personal 'things' because I can keep it sanitized more easily, particularly if others have used it. My thinking is: less objects equals less risk of a virus lurking nearby. Hand sanitizers are commonplace in every space and viewed as essential in the effort to combat the Covid-19 virus as are visuals teaching everyone, regardless of age, how to effectively undertake hand washing practices. I no longer take for granted the freedom to move from place to place or to be physically and socially close to someone. As a consequence of Covid-19, my eyes have been opened wide to:

- The fragility of life;

- The value of online spaces to connect with others;

- The importance of finding time to focus on emotional, physical, and mental wellbeing;

- Decision-making that attends with love to the unique particulars of the situation people find themselves in.

Workday routines include taking my laptop home every night in case I am required to work from home. Zoom meetings that increased during lockdown a year ago remain a regular work life occurrence. I have noticed that decreasing energy levels and feeling more tired are a side effect of days when Zoom meetings are back-toback-to-back! Visiting students on practicum or at their home centers returned under the current alert level one status. 
Presently, the Pfizer vaccine is being rolled out across communities. It is free and available to people aged 16 and over. I will be vaccinated when it is offered to me; however, priority is presently being given to essential workers and their families and those aged 65 and over. Last year, I chose not to return to my physical workplace until 6 weeks after Aotearoa New Zealand moved to level 2 restrictions because I was not convinced the long tail of Covid-19 had been kept at bay. It took time for me to feel comfortable eating at restaurants again or buying a coffee from a café.

The non-existence of international travel opened opportunities for me to explore with my family, places, and spaces in Aotearoa New Zealand not previously discovered, at local rather than inflated tourist prices. However, it has meant facing the realization that travelling to my brother in the USA and vice a versa is not a possibility at this time in history-this is a major challenge as a family because we are close-thank goodness for Facetime. With no community transmission, I feel calm, settled, thankful that we can socialize safely, relieved that in a multi-generational home, there is less risk today compared to last year of bringing the virus home to family members, and fortunate that I can call Aotearoa New Zealand home.

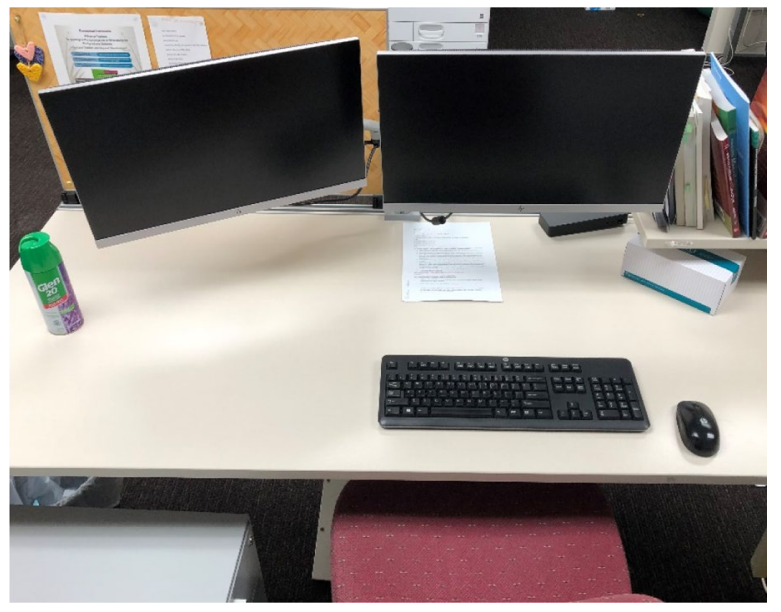

Fig. 71 [New figure.] Desk at work—-the absence of 'things'

\section{A Covid Homecoming}

E. Jayne White, Christchurch, Aotearoa New Zealand, 17 May

[Updated biography.] Having moved back to New Zealand, Jayne is Professor ECE at University of Canterbury in Christchurch. She continues to support colleagues at RMIT as Adjunct Professor and is concurrently Professor II at Western Norway University of Applied Science. Jayne is also Fellow of Philosophy of Education Society of Australia and President of Association of Visual Pedagogies. As Editor-in-Chief 
of open access Video Journal of Education and Pedagogy, she supports crossdisciplinary research which she applies to early years thought and practice.

Still in Melbourne, between mid-February and December, I continued to spend every day in a relentless and limited triangle of movement-from desk, to kitchen, to bed. In the early days, 'team' meetings seemed to offer some respite, but eventually, they, too, became testing encounters of perseverance. By halfway through, the year my world had closed in on me like a telescope. As Discipline lead, I had to summon every inner resource each day to support the many others for whom I felt responsible. My capacity to do so was greatly diminished amidst calls for redundancies, increasing workload pressures, cessation of contracts for sessional staff, and unrelenting pressures to publish and attract funding. Student mental health was a constant priority - not least in contemplation of the many international students now stranded in tiny city apartments.

Level-headed problem-solving strategies, institutional connection, and a constant watch on the shifting policy landscape consumed my world. Supporting students to complete placements when ECE services closed down (creating a snowball since students were unable to graduate), the rise of the 'essential ECE worker' now in fear of their lives (and livelihood), the freeze placed on any research with ECE services in Victoria and different state responses to ECE provision and, indeed, childhood 'immunities,' were just some of the many riddles we tried to solve and re-solve in the tides of change.

For me, it was a time of great darkness. I felt morally compromised daily as the profession I serve was sliced to pieces in a series of fiscal maneuvers. Where I once found my writing and research to be a great joy, it had now become an utter slog. I began to realize that my life comprised little more than labor (in the Arendtian sense) and eventually came to see that I was faced with two choices- to continue on until I was utterly subsumed, or find my way back. Fortunately for me, hope came in a job offer which led to my return to Aotearoa New Zealand at the end of last year, spending a reflective New Year alone in isolation.

I recognize that having the agency and good fortune to determine a change of this nature was/is not the privilege of many. It is one I do not take for granted as a citizen of a country barely touched by Covid-19. I see that my homecoming brings with it an accountability to those I have left behind, as we begin to carve out a sustainable future for what lies ahead. This will require imagination, courage, and creativity on the part of those who have the inner (and outer) resources to undertake this work in the interest of all. As I recover from the ordeal of 2020, I seek to harness the vulnerability I, with others, have lived and now girth my privilege in order to think through and act out of our collective pain. I am now in good company to embark on this journey. It is good to be home. 


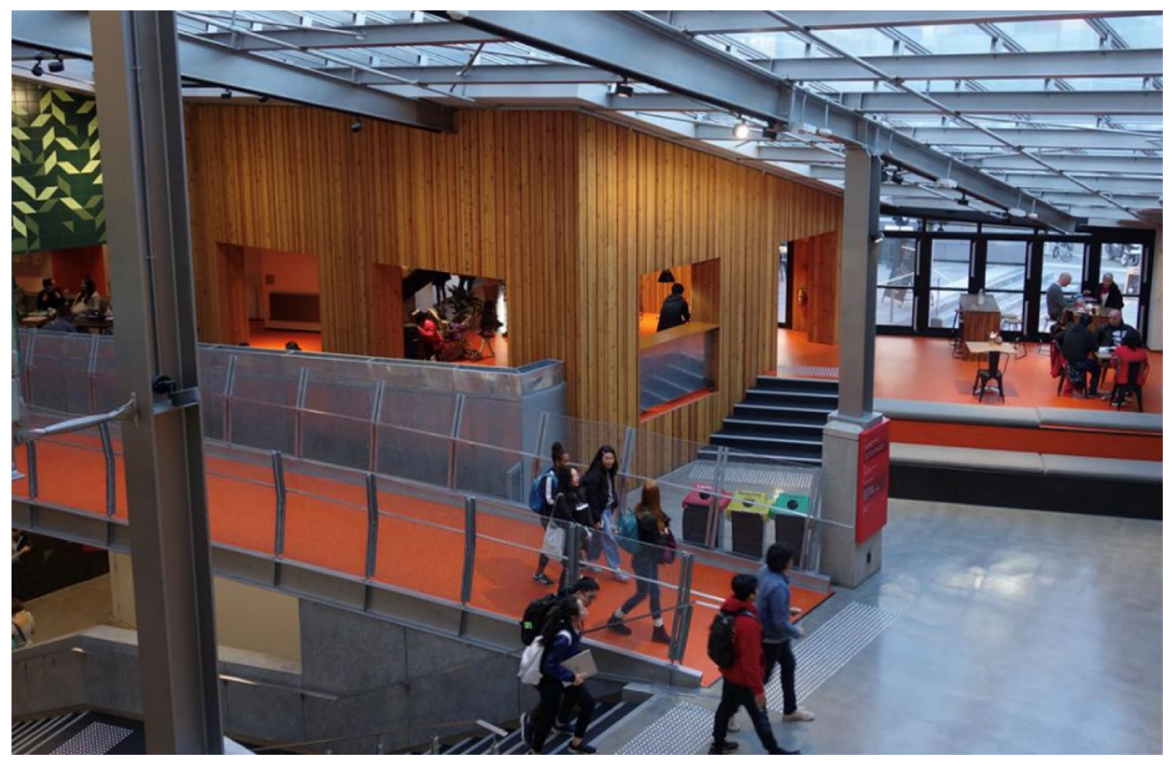

Fig. 72 [New figure.] My new, Covid-free, much expanded physical and social workspace on campus back home

\section{We Need More Suspension}

Derek Ford, Indianapolis, IN, USA, 17 May

[Updated biography.] Derek R. Ford is assistant professor of education studies at DePauw University, USA, where he teaches classes in philosophy and history of education. He recently released 'Reading Capital with Comrades,' a podcast series on Marx's Capital, Vol. 1. ${ }^{23}$

$$
\text { *** }
$$

One year later, I am trying to think what has changed, what has not, how my pedagogy and educational philosophy have or have not changed, and so on. What I have found upon reflection is that issuing a response now would be like returning back to 'business as usual' before the pandemic is under control. As such, I cannot think of any meaningful response at this moment because I-and I think we all—need more time.

${ }^{23}$ See https://liberationschool.org/reading-capital-with-comrades-podcast-series/. Accessed 17 May 2021. 


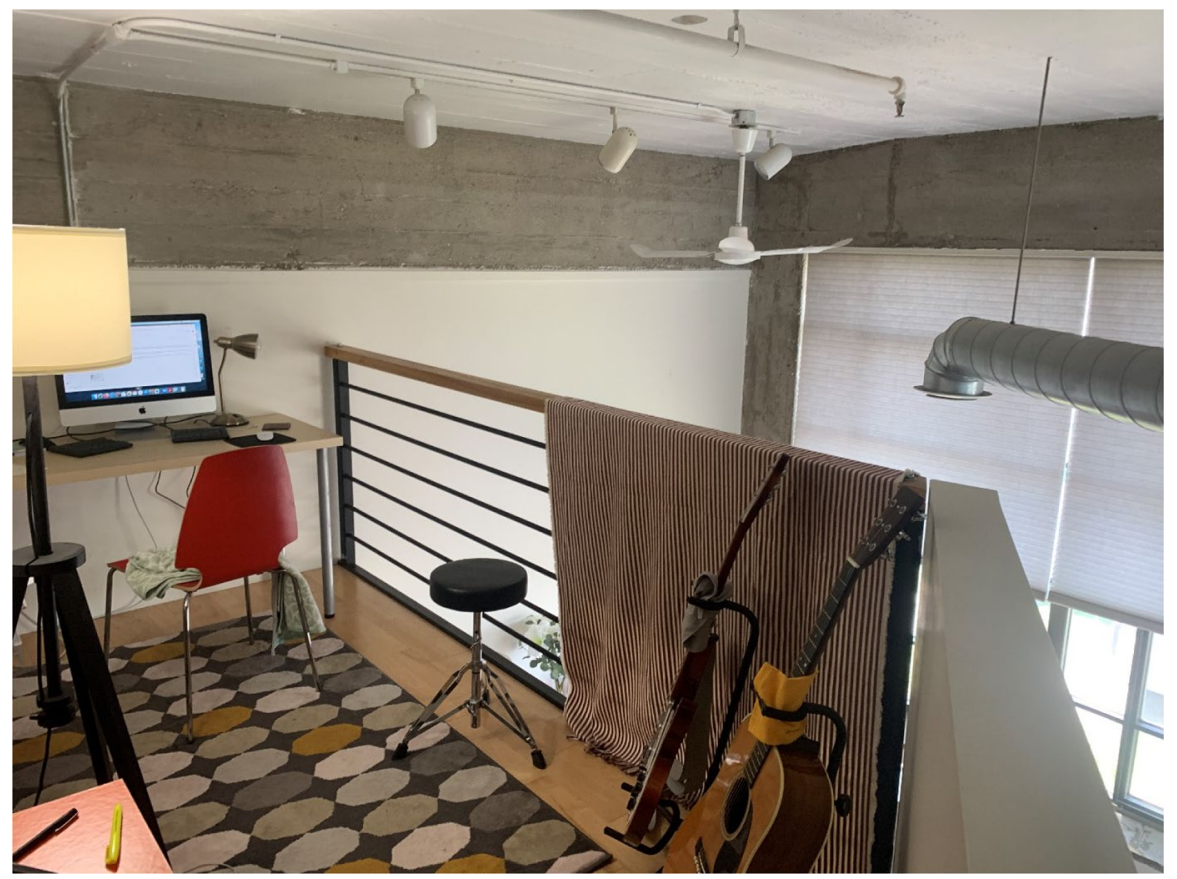

Fig. 73 [New figure.] This is a shot of my workspace in the new apartment my wife and I purchased last summer

\section{Zoom Fatigue is Real}

Quaylan Allen, Orange, CA, USA, 21 May

[Unchanged biography.] Quaylan Allen is an Associate Professor in the Attallah College of Educational Studies at Chapman University and Director of First-Generation Programs. He lives in Southern California with his partner, two children, and dog.

$$
* * *
$$

This testimonial is being written at a time when Covid-19 restrictions are gradually being lifted as more people continue to get vaccinated across the USA. Since the pandemic started, I have remained in Southern California where I am still teaching and running student programs completely virtually. The summer of 2020 was largely spent converting my course curriculum and student programming into virtual platforms, and like other educators, this was largely accomplished via Zoom. Spending a full school year in virtual environments has been both informative and also exhausting. I have become adept in teaching in virtual environments and have 
enjoyed being able to integrate the many available digital tools into my curriculum and pedagogy. However, Zoom fatigue is real, and by the end of the school year, most of my students and colleagues were burnt out. The Zoom screens that were filled with smiling faces at the beginning of the semester became checkered by the end of the semester with the once smiling faces replaced with black boxes.

Moreover, the pandemic and the resulting shift to virtual learning both revealed and exasperated the social inequalities that impact many college students and their families. Students from underserved communities, and particularly communities of color, often experience economic and health disparities which can impact their college experience. Many students on campus still lacked access to reliable technology and Internet, which limited their ability to attend and participate in classes in ways equal to their peers. Additionally, many of the families of my students suffered severe economic and health hardships as a result of the pandemic, and students were sometimes forced to decide between staying in school or focusing on supporting the family during a time of great need. This is a dilemma that no student should have to face, but I appreciate and value the strength and resiliency that many students and their families have demonstrated throughout this pandemic.

In addition to adjusting to virtual learning environments, many of our students and faculty have been engaged in racial activism regarding the fight for Black lives, stopping anti-Asian hate, and fighting White supremacy. Certainly, the historical and political events that have taken place over the past year both within the USA and abroad has provided a rich curriculum in which to engage in a critical pedagogy within the classroom. Many of the topics I teach on within the sociology of education were enriched by our ability to make connections to the social and political activities we were observing and engaging in.

The university expects that the entire campus will return in person in the fall of 2021 which means that I will readjust my curriculum and programming for an inperson or potentially hybrid format. For instance, I am currently organizing a student orientation program that will use a hybrid format allowing students and families to access the workshops in person or virtually. The ability to deliver content and programming in a hybrid format creates a tremendous opportunity to increase access to knowledge, particular for communities who have historically been underrepresented in higher education. However, I am most excited about the opportunity to be back in person and re-engage with the campus communities.

I have recently been fully vaccinated and am happy to be able to enjoy a life that feels a bit more normal. Initial fears of the vaccine were addressed through much education and dialogue with respected professionals. In reflecting on this past year of stay-at-home orders and social distancing practices, I recognize how disconnected I felt from many of the people and organizations I was accustomed to engaging with on a regular basis. At the same time, I greatly appreciated the opportunity to spend an incredible amount of my time at home with my young children and partner. The shift to virtual programming allowed me to achieve better work-life integration, and I am hopeful to continue some of these practices as part of this new normal. 


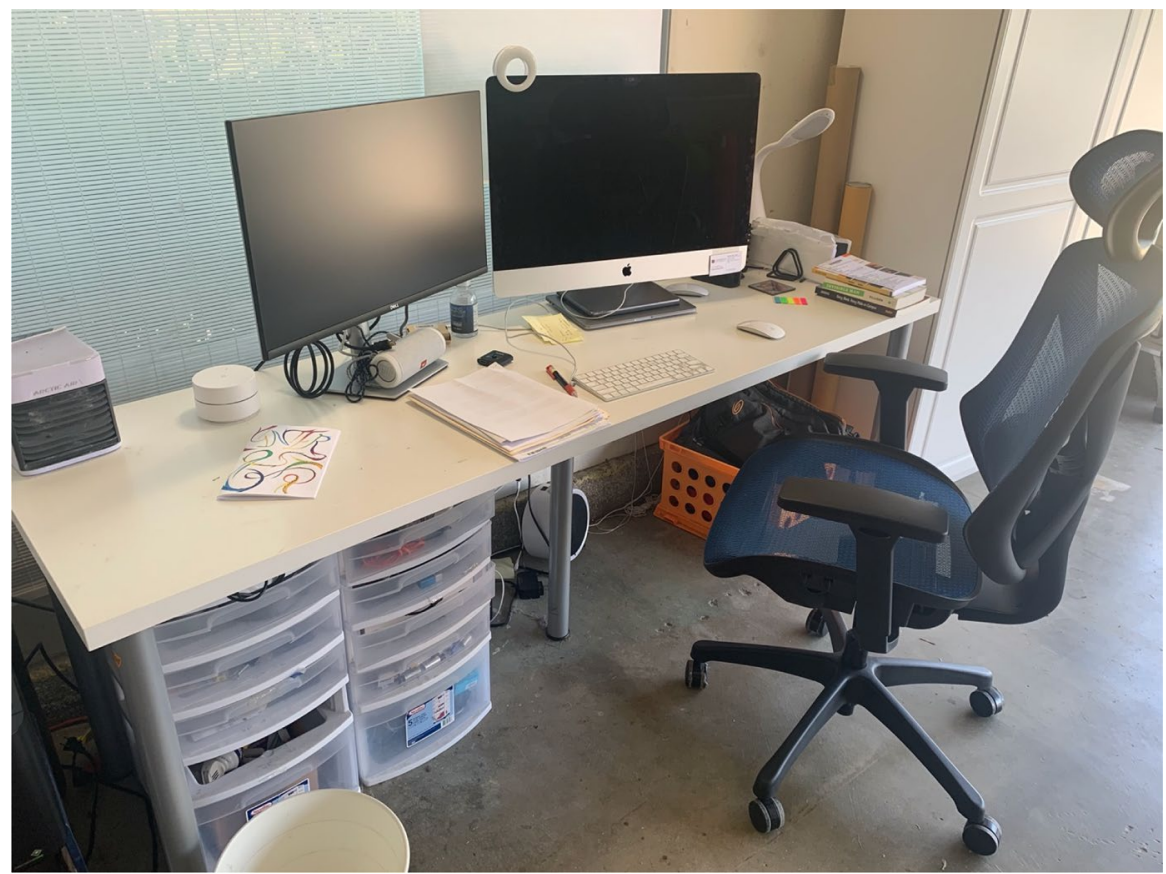

Fig. 74 [New figure.] Garage Office-I am still using my garage as an office and have grown accustomed to the space. I will be here less starting in the fall as I now have access to my office on campus

\section{Teaching 'Global Citizenship' In the Time of Pandemic}

Mousumi Mukherjee, Delhi, India, 28 May

[Updated biography.] Mousumi Mukherjee is an associate professor and deputy director of the International Institute for Higher Education Research and Capacity Building at O. P. Jindal Global University in Sonipat, India. She is a fellow of the Society of Transnational Academic Researchers and a Research Standing Committee member of the World Council of Comparative Education Societies. She is also a Steering committee member of the ACU Supporting Research Community. She has 20 years' experience in the higher education sector in the USA, Australia, and India.

$* * *$

These days I remember the following poem often from my early education in literature by Pablo Neruda:

You start dying slowly

if you do not travel,

if you do not read,

If you do not listen to the sounds of life. (Neruda n.d.) 
Aren't we all dying as a human civilization these days? Fifteen months ago, in the middle of the Covid-19 pandemic, I plunged into fully online teaching in India for the first time after years of experience abroad. I sought to invoke Bodhisatva inside me at that time to deal with the uncertainties of this journey (Jandric et al. 2020). However, over the past several months, I have come to realize that it is not an easy job to be a Bodhisatva in the middle of this pandemic.

Over these past months, I have witnessed the death of 4 extended family members, two prolific scholars and young colleagues, and a promising young student. Each day, I hear the news of deaths from my students, colleagues, extended family members, and friends. News on television and social media is flooded with the news of suffering and death. Not just old but young lives in their $20 \mathrm{~s}, 30 \mathrm{~s}$, and $40 \mathrm{~s}$. I remember Gray's Elegy written in a country churchyard...

Full many a gem of purest ray serene

The dark unfathom'd caves of ocean bear:

Full many a flower is born to blush unseen,

And waste its sweetness on the desert air. (Gray 1751)

There is just one news-the suffering of Covid-infected people and their death. Death seems to be dancing Tandava ${ }^{24}$ around all of us in full glory.

As I read the stories of dead bodies piled up outside morgues, crematoriums, and cemeteries waiting for long hours and days for their last rites to be performed, the world around seems just like the description of the Wasteland by T. S. Eliot...

April is the cruellest month, breeding

Lilacs out of the dead land, mixing

Memory and desire, stirring

Dull roots with spring rain. (Eliot 1922)

The general environment around is that of stress and anxiety. We are all locked in the middle of a dystopic world. With a 'willing suspension of disbelief' (Coleridge 1817), we are telling the students that this too shall pass and life would be normal again on campus. However, the experiences of students even from comparatively privileged backgrounds have been very challenging during the first semester emergency transition to fully online teaching and learning. This was revealed to us through a pilot study that I conducted with a couple of colleagues at the end of the first online spring 2020 semester (Mukherjee et al. 2021).

We are now running the third consecutive semester of online classes. Teaching a course on global citizenship fully online in the middle of this pandemic has been the most challenging experience. It is not an easy task to facilitate students to think beyond the boundaries of nation-state to exercise their citizenship rights and duties as global citizens, while they are all locked inside their homes. Arundhati Roy's (2020) article 'The Pandemic is a Portal' came as a Pedagogy of Hope (Freire 2014). It helped us to reflect critically on the problems of the 'old normal.' It helped us to

\footnotetext{
24 Ancient classical Indian dance form primarily associated with the deity, Lord Shiva, expressing the joy of creation (Ananda Tandava) and, expressing the grief and anger of destruction (Rudra Tandava).
} 
critically engage in online conversations about a new normal post-pandemic, where we learn to take our citizenship rights and duties seriously by taking local community engagement seriously geared toward solving global challenges, i.e., the Sustainable Development Goals. We concluded the spring 2021 semester connecting with a ray of hope from China by hosting a joint online class session with Dr. Sophy Cai and her students from Xiamen University, where they have been able to manage the pandemic much better than India.

Conspiracy theories about viral politics and biological warfare will abound in this post-truth, postdigital age (Peters and Besley 2021). But should we just sit back and get caught up in the depths of depression lamenting about "what man has made of man'? Or should we see the pandemic as a portal—a gateway for us to rethink and reimagine a new world-more equal, more just, and more sustainable? Let us regain faith in humanity to move ahead and walk through this gateway with renewed hope for building a better, more humane and sustainable world.

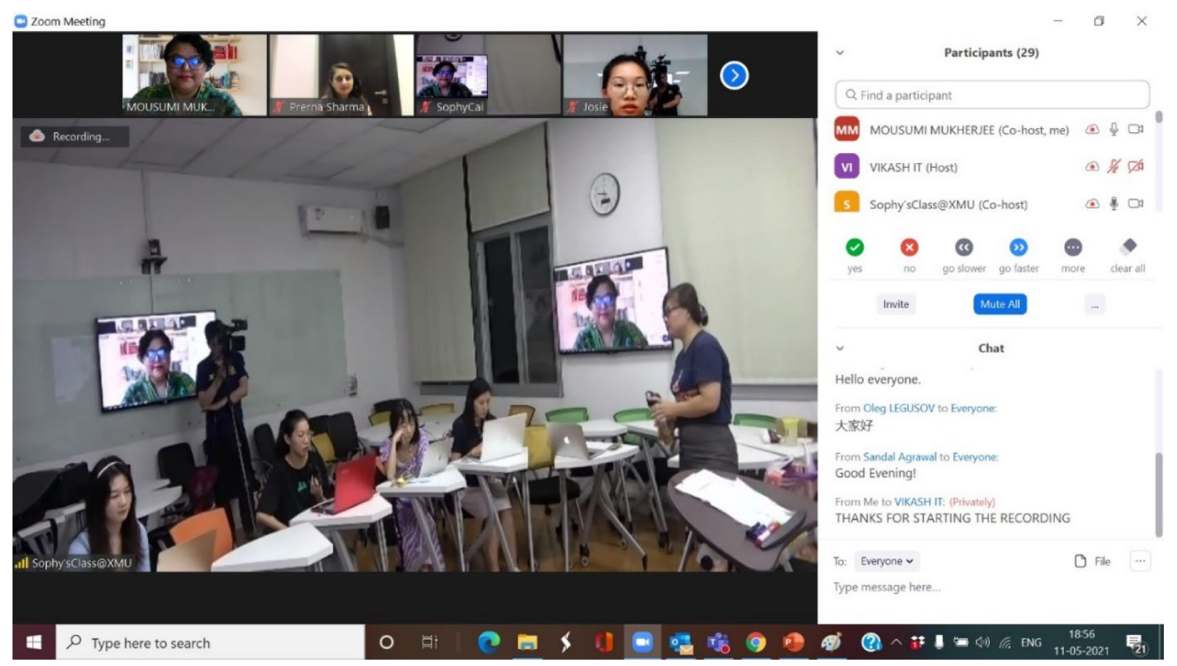

Fig. 75 [New figure.] Collaborative Online International Learning (COIL) with Xiamen University, China

\section{A Year Ago, and a Year From Now...}

Sarah Hayes, Worcester, UK, 31 May

[Updated biography.] Sarah Hayes is Professor of Higher Education Policy at University of Wolverhampton, UK. Sarah is 58 years old and she, her partner David, 
and her two sons are still collectively owned by a cat called Jasmine. Sarah's new book, Postdigital Positionality (2021), has just been published by Brill.

Exactly 1 year later, literally to the date, but I find this harder to write than before. Like others, I glanced at what I said last time, when our diverse experiences of the pandemic were still unfolding. Now, it feels like we are scrambling up sand banks and sliding back down (metaphorically, not physically, when we cannot visit the beach). Even with the promise of vaccinations (amid the global challenges of distribution), freedoms gained seem fragile, unequal, intermittent, amid new Covid-19 variants. I notice people now turn off their cameras a lot in virtual meetings, and I imagine they feel fatigued by the incessant nature of conducting life online.

I personally feel very fortunate though. I have been able to further research projects, make new cross-sector contacts, supervise doctorates from home, celebrate successful vivas, and complete my book on postdigital positionality (Hayes 2021). Together with my brother and my partner, we have taken turns to support my vulnerable father and sister throughout the pandemic, despite the distance between us all. My sons have remained in lines of work that are not conducted online, and I am glad that they are meeting with people. Three elderly family members passed away, but only one funeral could involve physical attendance (with no singing permitted). Yet to be among family after so long felt more special than usual. To share a drink with neighbors in their garden at the weekend felt novel too. As shops and restaurants reopen, the effort made is really apparent.

A golf course near us, which was so beautiful to wander round (read here...to trespass on...) during the lockdowns, has re-opened. We now have to stick to the right of way (I really miss the trespassing), but it is good to see how happy people are to return to such pastimes. As well as walking, I have tried to use a tatty rowing machine my 28-year-old son bought while in his teens and left behind in our garage. I take in my iPad, and I let YouTube decide what I listen to, based on what I have previously played, and I watch my speed get slower on days when I feel tired. It is a good place to think though, and ideas occur differently than when I sit behind a desk.

In educational institutions, we move people on quickly as they pass assessments and progress onto other things. Taking time though to notice and celebrate what has been achieved (and sacrificed along the way) is important (even more so when graduations in person are not possible). I wish that governments would stop talking of the need for children to 'catch up' as I worry about the stress that this imparts. Now is a time to consolidate our understanding of what has happened, to think about possibilities and not just familiar, linear forms of progress. Too often, academia involves the guilt of asking for extensions when time is short, and expectations are high. So, I find myself reflecting on how we are using this shared space right now, in this second round of written testimonies, to acknowledge such challenges alongside achievements. We are taking time to share what we have each managed to do, not to do, still hope to do, and survived through, as this pandemic wears on, and on. I am glad to read the big and small events each person has described. I can echo how 
I have come to value what may seem like small things, but maybe these are things that matter just now, at least until we can see where we are heading, yet another year from now.

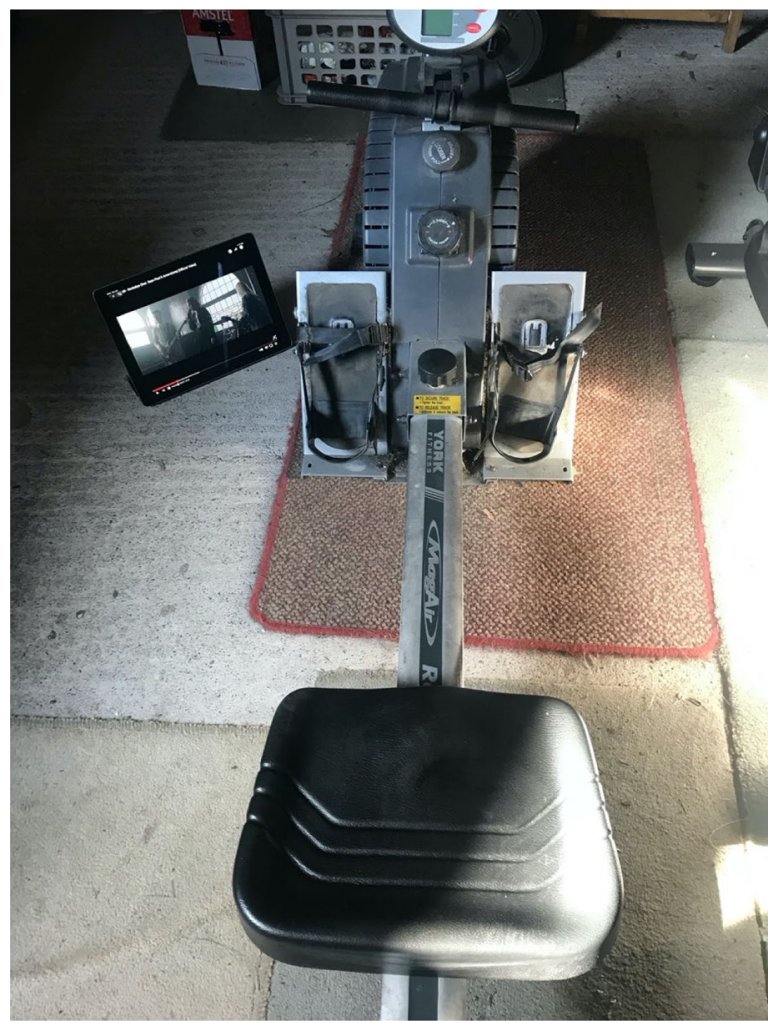

Fig. 76 [New figure.] A battered old rowing machine our eldest son left in our garage. I listen to music on my iPad, pretend to exercise, and look forward to a beer from a pack you can see lurking in the background

\section{References}

Arndt, S., Smith, K., Urban, M., Ellegard, T., Swadener, B. B., \& Murray, C. (2020). Reconceptualising and (re)forming early childhood professional identities: Ongoing transnational policy discussions. Policy Futures in Education. https://doi.org/10.1177/2F1478210320976015.

Auerbach, E. (2003). Mimesis: The Representation of Reality in Western Literature. Fiftieth anniversary printing. Princeton, NJ: Princeton University Press.

Betto, E., \& Freire, P. (1986). La scuola chiamata vita. Bologna: EMI.

Bevins, V. (2020). The Jakarta Method: Washington's Anticommunist Crusade \& the Mass Murder Program that Shaped our World. New York: Public Affairs/Perseus/Hachette Book Group.

Bogel-Burroughs, N., Eligon J., \& Wright, W. (2021). L.A.P.D. Severely Mishandled George Floyd Protests, Report Finds. The New York Times, 11 March, updated 29 March. https://www.nytimes.com/ 2021/03/11/us/lapd-george-floyd-protests.html. Accessed 14 May 2021. 
Bogel-Burroughs, N., Eligon, N., \& Wright, W. (2021). Los Angeles Police Exacerbated Chaos at Protests, Report Says. The New York Times, 12 March 2021. https://www.nytimes.com/2021/03/11/us/ lapd-george-floyd-protests.html. Accessed 1 June 2021.

Brown, J. B. (2020). From denial to acceptance: a turning point for design studio in architecture education. Distance Design Education, 11 May. https://distancedesigneducation.com/2020/05/11/fromdenial-to-acceptance-a-turning-point-for-design-studio-in-architecture-education/. Accessed 14 May 2021.

California Department of Public Health (2021). COVID-19 Race and Ethnicity Data. https://www.cdph. ca.gov/Programs/CID/DCDC/Pages/COVID-19/Race-Ethnicity.aspx. Accessed 20 April 2021.

Camus, A. (1960). The plague. Trans. S. Gilbert. Harmondsworth: Penguin.

Coleridge, S. T. (1817). Biographia Literaria. https://web.english.upenn.edu/ mgamer/Etexts/biographia. html. Accessed 28 May 2021.

Eliot, T. S. (1922). The Waste Land. https://www.poetryfoundation.org/poems/47311/the-waste-land. Accessed 28 May 2021.

Forster, D. J. (2020). Is learning more important than well-being? Teachers told us how COVID highlighted ethical dilemmas at school. The Conversation, 8 November. https://theconversation.com/ is-learning-more-important-than-well-being-teachers-told-us-how-covid-highlighted-ethical-dilem mas-at-school-144854. Accessed 6 May 2021.

Freire, P. (2014). Pedagogy of Hope: Reliving Pedagogy of the Oppressed. London: Bloomsbury Academic.

Gibbons, A. (2020). The negation of babysitting: Deconstruction and care in early childhood. Global Studies of Childhood. https://doi.org/10.1177/2043610620978507.

Gibbons, A. (2021). Camus and Tragedy in Education. Oxford Research Encyclopedia of Education. https://doi.org/10.1093/acrefore/9780190264093.013.1557.

Gray, T. (1751). Elegy written in a country churchyard. http://www.thomasgray.org/cgi-bin/display.cgi? text=elcc. Accessed 28 May 2021.

Greene, F. (1970). The Enemy: What Every American Should Know About Imperialism. New York: Random House.

Harcourt, B. E. (2018). The Counterrevolution: How Our Government Went to War Against Its Own Citizens. New York: Basic Books/Hachette Book Group.

Hayes, S. (2021). Postdigital Positionality: Developing Powerful Inclusive Narratives for Learning, Teaching, Research and Policy in Higher Education. Leiden: Brill.

Hodges, C., Moore, S., Lockee, B., Trust, T., \& Bond, A. (2020). The difference between emergency remote teaching and online learning. Educause Review. https://er.educause.edu/articles/2020/3/thedifference-between-emergency-remote-teaching-and-online-learning. Accessed 19 April 2021.

Hood, N., \& Tesar, M. (2019). Postdigital Childhoods in the Time of Anthropocene. Postdigital Science in Education, 1(2), 307-310. https://doi.org/10.1007/s42438-019-00062-x.

Jackson, L. (2020). Weary from the Future. Hong Kong. Postdigital Science and Education, 2(3), 628632. https://doi.org/10.1007/s42438-020-00116-5.

Jandrić, P. (2020a). Postdigital Research in the Time of Covid-19. Postdigital Science and Education, 2(2), 233-238. https://doi.org/10.1007/s42438-020-00113-8.

Jandrić, P. (2020b). The Postdigital Challenge of Pandemic Education. Journal of Contemporary Educational Studies, 71(4), 176-189.

Jandrić, P. (2021). Biology, Information, Society. Postdigital Science and Education, 3(2), 261265. https://doi.org/10.1007/s42438-021-00220-0.

Jandrić, P., \& Hayes, S. (2020). Writing the History of the Present. Postdigital Science and Education, 2(3), 1062-1068. https://doi.org/10.1007/s42438-020-00168-7.

Jandrić, P., Hayes, D., Truelove, I., Levinson, P., Mayo, P., Ryberg, T., Monzó, L.D., Allen, Q., Stewart, P.A., Carr, P.R., Jackson, L., Bridges, S., Escaño, C., Grauslund, D., Mañero, J., Lukoko, H.O., Bryant, P., Fuentes Martinez, A., Gibbons, A., Sturm, S., Rose, J., Chuma, M.M., Biličić, E., Pfohl, S., Gustafsson, U., Arantes, J.A., Ford, D.R., Kihwele, J.E., Mozelius, P., Suoranta, J., Jurjević, L., Jurčević, M., Steketee, A., Irwin, J., White, E.J., Davidsen, J., Jaldemark, J., Abegglen, S., Burns, T., Sinfield, S., Kirylo, J.D., Batarelo Kokić, I., Stewart, G.T., Rikowski, G., Lisberg Christensen, L., Arndt, S., Pyyhtinen, O., Reitz, C., Lodahl, M., Humble, N., Buchanan, R., Forster, D.J., Kishore, P., Ozoliņ̌s, J., Sharma, N., Urvashi, S., Nejad, H.G., Hood, N., Tesar, M., Wang, Y., Wright, J., Brown, J.B., Prinsloo, P., Kaur, K., Mukherjee, M., Novak, R., Shukla, R., Hollings, S., Konnerup, U., Mallya, M., Olorundare, A., Achieng-Evensen, C., Philip, A.P., Hazzan, M.K., Stockbridge, K., Komolafe, B.F., Bolanle, O.F., Hogan, M., Redder, B., Sattarzadeh, S.D., Jopling, M., SooHoo, S., 
Devine, N., \& Hayes, S. (2020). Teaching in The Age of Covid-19. Postdigital Science and Education, 2(3), 1069-1230. https://doi.org/10.1007/s42438-020-00169-6.

Kellner, D. (2003). From 9/11 to Terror War. Lanham, MD: Rowman \& Littlefield.

Komolafe, B. F., Fakayode, O. T., Osidipe, A., Zhang, F. Y., \& Qian, X. S. (2020). Evaluation of Online Pedagogy among Higher Education International Students in China during the COVID-19 Outbreak. Creative Education, 11, 2262-2279. https://doi.org/10.4236/ce.2020.1111166.

Levinson, P. (2020a). Popper and Evolution Over the Decades. 22 December. https://ourkarlpopper.net/ 2020/12/22/paullevinson/. Accessed 11 May 2021.

Levinson, P. (2020b). The Missing Orientation. Religions, 12(1), 16. https://doi.org/10.3390/rel12 010016.

Levinson, P. (2020c). Foreseeable. AcademFic, 1, 40-55.

Levinson, P. (2021). I'm a First Amendment scholar - and I think Big Tech should be left alone. The Conversation, 20 January. https://theconversation.com/im-a-first-amendment-scholar-and-i-thinkbig-tech-should-be-left-alone-153287. Accessed 11 May 2021.

Lindia, M., \& Levinson, P. (2020). Tetrads and Chiasmus: A Reclamation of the Tetrad Wheel. New Explorations, 27 December. https://newexplorations.net/tetrads-and-chiasmus-a-reclamation-of-thetetrad-wheel/. Accessed 11 May 2021.

McLuhan, M. (1975). McLuhan's Laws of the Media. Technology and Culture, 16(1), 74-78. https://doi. org/10.2307/3102368.

Mukherjee, M., Belousova, T., \& Maun, D. (2021). Students' Experiences with Distance Learning under COVID-19: Critical Perspectives from an Indian University. In R. Y. Chan, K. Bista, \& R. M. Allen (Eds.), Online Teaching \& Learning in Higher Education during COVID-19: International Perspectives \& Experiences. New York and London: Routledge.

NASA (2020). NASA probes environment, covid-19 impacts, possible links. NASA, 29 April. https:// www.nasa.gov/feature/nasa-probes-environment-covid-19-impacts-possible-links/. Accessed 8 June 2021.

Neruda, P. (n.d.). You Start Dying Slowly. https://www.goodreads.com/book/show/39657045-you-startdying-slowly. Accessed 28 May 2021.

Peters, M. A., \& Besley, T. (Eds.). (2021). Pandemic education and viral politics. London and New York: Routledge.

Petrou, K. (2021). Engine of Inequality. Hoboken, NJ: Wiley and Sons.

Reitz, Charles. (2019). Ecology \& Revolution: Herbert Marcuse and the Challenge of a New World System Today. New York and London: Routledge.

Robinson, W. I. (2020). The Global Police State. London: Pluto Press.

Roy, A. (2020). The Pandemic is a Portal. The Financial Times, 3 April. https://www.ft.com/content/ 10d8f5e8-74eb-11ea-95fe-fcd274e920ca. Accessed 28 May 2021.

Santayana, G. (1905) The life of reason: Vol 1: Reason in common sense. New York: Dover.

Scalia, A. (1992). R.A.V. vs. City of St. Paul 505 U.S. 377. https://globalfreedomofexpression.columbia. edu/cases/r-v-v-city-st-paul/. Accessed 14 May 2021.

Sinclair, C. (2021). Review of Sarah Hayes (2021). Postdigital Positionality: Developing Powerful Inclusive Narratives for Learning, Teaching, Research and Policy in Higher Education. Postdigital Science and Education.

Sousa, M. (2021). Brazil posts record single-day toll of 3,251 virus deaths. APNews, 24 March. https:// apnews.com/article/pandemics-brazil-jair-bolsonaro-coronavirus-pandemic-577cdd2ffe 855 c336768 bd981b49e896. Accessed 14 June 2021.

Srnicek, N. (2016). Platform Capitalism. Cambridge, UK: Polity Press.

Stengers, I. (2017). Autonomy and the intrusion of Gaia. South Atlantic Quarterly, 116(2), 381-400. https://doi.org/10.1215/00382876-3829467.

Stiegler, B. (2017). What is called caring? Beyond the Anthropocene. Trans. D. Ross. Techné: Research in Philosophy and Technology, 21(2-3), 386-404. https://doi.org/10.5840/techne201712479.

Stone, O., \& Kuznik, P. (2019). The Untold History of the United States. New York: Simon \& Schuster Gallery Books.

Swedish Ministry of Higher Education and Research (1992). The Swedish higher education act. Stockholm, Sweden: Fritzes.

Tallbear, K. (2013). Native American DNA: Tribal Belonging and the False Promise of Genetic Science. Minneapolis, MN: University of Minnesota Press.

Tesar, M., \& Hood, N. (2019). Policy in the time of Anthropocene: Children, Childhoods and Digital Worlds. Policy Futures in Education, 17(2), 102-104. https://doi.org/10.1177/1478210319831830. 
The World Bank (2020). Covid-19 to add as many as 150 million extreme poor by 2021. 7 October. https://www.worldbank.org/en/news/press-release/2020/10/07/covid-19-to-add-as-many-as-150million-extreme-poor-by-2021. Accessed 8 June 20201.

Thomassen, B. (2006). Liminality. In: A. Harrington, B. L. Marshall, \& H.-P. Muller (Eds.), Encyclopedia of social theory. Oxford, UK: Routledge.

Vine, D. (2015). Base Nation. New York: Metropolitan Books, Henry Holt \& Company.

Viveiros de Castro, E., \& Hui, Y. (2021). For a strategic primitivism: A dialogue between Eduardo Viveiros de Castro and Yuk Hui. Philosophy Today, 65(2), 391-400. https://doi.org/10.5840/philtoday2 021412394.

Vuillard, É. (2018). The Order of the Day. New York: Other Press.

\title{
Authors and Affiliations
}

Petar Jandrić ${ }^{1,2}$ (D) David Hayes ${ }^{3} \cdot$ Paul Levinson $^{4} \cdot$ Line Lisberg Christensen ${ }^{5}$. Happiness Onesmo Lukoko ${ }^{6}$. Jimmy Ezekiel Kihwele ${ }^{7}$.

James Benedict Brown ${ }^{8}$ (D) Charles Reitz $^{9}$ (D) Peter Mozelius ${ }^{10}$.

Harry G. Nejad ${ }^{11}$. Ana Fuentes Martinez ${ }^{12}$ (D) . Janine Aldous Arantes ${ }^{13}$ (D) . Liz Jackson ${ }^{14}$ (D) Ulrika Gustafsson ${ }^{15}$ (D) . Sandra Abegglen ${ }^{16}$ (D)

Tom Burns ${ }^{17}$ (D) Sandra Sinfield ${ }^{17}$ (D) Michael Hogan ${ }^{18^{(D)}} \cdot$ Pallavi Kishore $^{19}$. Paul R. Carr ${ }^{20}$. Ivana Batarelo Kokić ${ }^{21}$ (D) Paul Prinsloo ${ }^{22}$ (D)

Dennis Grauslund $^{23}$ (D) Anne Steketee ${ }^{24}$ (D) Charlotte Achieng-Evensen ${ }^{25}$. Blessing Funmi Komolafe 26,27 (D) . Juha Suoranta ${ }^{28}$ (D) . Nina Hood ${ }^{29}$. Marek Tesar ${ }^{29}$ (D) Jennifer Rose ${ }^{30}$ (D) . Niklas Humble ${ }^{31}$. James D. Kirylo ${ }^{32}$. Julia Mañero ${ }^{33}$ (D) . Lilia D. Monzó ${ }^{34} \cdot$ Mikkel Lodahl $^{35}$ (D) . Jimmy Jaldemark ${ }^{36}$ (D) . Susan M. Bridges ${ }^{37}$ (D) Navreeti Sharma ${ }^{38}$. Jacob Davidsen ${ }^{39}$ (D) Jānis (John) Ozolinšs ${ }^{40,41}$ (D) P Peter Bryant ${ }^{42}$ (D) . Carlos Escaño ${ }^{33} \cdot$ Jones Irwin ${ }^{43}$. Kulpreet Kaur $^{44}$ (D) Sarah Pfohl ${ }^{45} \cdot$ Kevin Stockbridge $^{46}$ (D) Thomas Ryberg $^{47}$ (D) . Olli Pyyhtinen $^{48} \mathbb{D}$. Suzanne SooHoo ${ }^{49}$. Moses Kayode Hazzan ${ }^{50}$. Jake Wright ${ }^{51}$ (D) Stephanie Hollings ${ }^{52}$. Sonja Arndt ${ }^{53}$ (D) . Andrew Gibbons ${ }^{54}$ (D) . Shreya Urvashi ${ }^{55}$. Daniella J. Forster ${ }^{56}$ (D) lan Truelove ${ }^{57}$ (D) Peter Mayo ${ }^{58}$. Glenn Rikowski $^{59}$ (D) Paul Alexander Stewart ${ }^{60}$ (D) Michael Jopling $^{61}$ (D) Georgina Tuari Stewart ${ }^{62}$ (D) Rachel Buchanan $^{63}$ (D) Nesta Devine ${ }^{64}$ (D) Richa Shukla ${ }^{65} \cdot$ Rene Novak $^{66}$ - Madhav Mallya ${ }^{67} \cdot$ Eva Biličić $^{68}$. Sean Sturm ${ }^{69}$. Sahar D. Sattarzadeh ${ }^{70,71}$ (D) Abey P. Philip ${ }^{72}$. Bridgette Redder ${ }^{73} \cdot$ E. Jayne White ${ }^{74}$ (D) Derek R. Ford ${ }^{75}$. Quaylan Allen ${ }^{76}$ (D) Mousumi Mukherjee $^{77}$ (D) Sarah Hayes ${ }^{78}$ (D)

\author{
Petar Jandrić \\ pjandric@tvz.hr \\ David Hayes \\ hayes210358@gmail.com \\ Paul Levinson \\ Levinson.paul@gmail.com \\ Line Lisberg Christensen \\ 1lc@hum.aau.dk
}


Happiness Onesmo Lukoko

happinessonesmo@gmail.com

Jimmy Ezekiel Kihwele

jikihwele@mzumbe.ac.tz

James Benedict Brown

james.brown@umu.se

Charles Reitz

charlesreitz@sbcglobal.net

Peter Mozelius

Peter.Mozelius@miun.se

https://www.miun.se/en/personnel/petermozelius/

Harry G. Nejad

mgnejad@jgu.edu.in

Ana Fuentes Martinez

ana.fuentes-martinez@hv.se

Janine Aldous Arantes

janine.arantes@vu.edu.au

Liz Jackson

lizjackson@eduhk.hk

Ulrika Gustafsson

ulrika.gustafsson@umu.se

Sandra Abegglen

sandra.abegglen@ucalgary.ca

Tom Burns

t.burns@londonmet.ac.uk

Sandra Sinfield

s.sinfield@londonmet.ac.uk

Michael Hogan

michael.hogan@nuigalway.ie

Pallavi Kishore

kishorepallavi@hotmail.com

Paul R. Carr

prcarr@gmail.com

Ivana Batarelo Kokić

batarelo@ffst.hr

Paul Prinsloo

prinsp@unisa.ac.za

Dennis Grauslund

dgr@ucn.dk

Anne Steketee

asteketee@millikin.edu

Charlotte Achieng-Evensen

achiengevensenphd@gmail.com

Blessing Funmi Komolafe

blessing.komolafe@aaua.edu.ng 
Juha Suoranta

juha.suoranta@tuni.fi

Nina Hood

n.hood@auckland.ac.nz

Marek Tesar

m.tesar@auckland.ac.nz

Jennifer Rose

Jrose02@qub.ac.uk

Niklas Humble

niklas.humble@miun.se

James D. Kirylo

kiryloja@mailbox.sc.edu

Julia Mañero

julmancon@gmail.com

Lilia D. Monzó

monzo@chapman.edu

Mikkel Lodahl

milo@eadania.dk

Jimmy Jaldemark

jimmy.jaldemark@miun.se

Susan M. Bridges

sbridges@hku.hk

Navreeti Sharma

navreeti@jgu.edu.in

Jacob Davidsen

Jdavidsen@hum.aau.dk

Jānis (John) Ozoliņ̌s

John.ozolins@nd.edu.au

Peter Bryant

peter.j.bryant@sydney.edu.au

Carlos Escaño

jcescano@us.es

Jones Irwin

Jones.Irwin@dcu.ie

Kulpreet Kaur

kkaur@jgu.edu.in

Sarah Pfohl

pfohls@uindy.edu

Kevin Stockbridge

kstock@chapman.edu

Thomas Ryberg

ryberg@plan.aau.dk

Olli Pyyhtinen

olli.pyyhtinen@tuni.fi

Suzanne SooHoo

soohoo@chapman.edu 
Moses Kayode Hazzan

moseshazzan4@gmail.com

Jake Wright

jwwright@r.umn.edu

Stephanie Hollings

shollings88@hotmail.com

Sonja Arndt

sonja.arndt@unimelb.edu.au

Andrew Gibbons

agibbons@aut.ac.nz

Shreya Urvashi

mp2018sss003@tiss.edu

Daniella J. Forster

daniella.forster@newcastle.edu.au

Ian Truelove

i.a.truelove@leedsbeckett.ac.uk

Peter Mayo

peter.mayo@um.edu.mt

Glenn Rikowski

Rikowskigr@aol.com

Paul Alexander Stewart

p.stewart@tees.ac.uk

Michael Jopling

m.jopling@wlv.ac.uk

Georgina Tuari Stewart

georgina.stewart@aut.ac.nz

Rachel Buchanan

Rachel.Buchanan@newcastle.edu.au

Nesta Devine

Nesta.devine@aut.ac.nz

Richa Shukla

rshukla@jgu.edu.in

Rene Novak

proronny@gmail.com

Madhav Mallya

mmallya@jgu.edu.in

Eva Biličić

eva.bilicic@tvz.hr

Sean Sturm

s.sturm@auckland.ac.nz

Sahar D. Sattarzadeh

saharsattarzadeh@depauw.edu

Abey P. Philip

abeypp@curtin.edu.my

Bridgette Redder

bridgetteredder@gmail.com 
E. Jayne White

jayne.white@canterbury.ac.nz

Derek R. Ford

derekford@depauw.edu

Quaylan Allen

qallen@chapman.edu

Mousumi Mukherjee

mmukherjee@jgu.edu.in

Sarah Hayes

Sarah.Hayes@wlv.ac.uk

Zagreb University of Applied Sciences, Zagreb, Croatia

2 University of Wolverhampton, Wolverhampton, UK

3 Further Education, Worcester, UK

4 Fordham University, New York City, USA

5 Department of Communication and Psychology, Aalborg University, Aalborg, Denmark

6 Institute of Development Studies, University of Dar es Salaam, Dar es Salaam, Tanzania

7 Department of Education, Mzumbe University, Morogoro, Tanzania

8 Umeå School of Architecture, Umeå University, Umeå, Sweden

9 Kansas City Kansas Community College, Kansas City, MO, USA

10 Department of Computer and System Science (DSV), Mid Sweden University, Östersund/Stockholm, Sweden

11 Jindal Institute of Behavioural Sciences, O. P. Jindal Global University, Haryana, India

12 Katedralskolan (Lund)/University West, Trollhättan, Sweden

13 Victoria University, Melbourne, Australia

14 Education University of Hong Kong, Hong Kong, China

15 Department of Applied Educational Science, Umeå University, Umeå, Sweden

16 School of Architecture, Planning and Landscape, University of Calgary, Calgary, Canada

17 Centre for Professional and Educational Development, London Metropolitan University, London, UK

18 School of Psychology, National University of Ireland Galway, Galway, Ireland

19 Jindal Global Law School, O.P. Jindal Global University, Sonipat, India

20 Département des sciences d l'éducation, Université du Québec en Outaouais, 283, boulevard Alexandre-Taché, C.P. 1250, succursale Hull, Gatineau, Québec J8X 3X7, Canada

21 Department of Pedagogy, Faculty of Humanities and Social Sciences, University of Split, Split, Croatia

22 University of South Africa, Pretoria, South Africa

23 University College of Northern Denmark (UCN), Aalborg, Denmark

24 School of Education, Millikin University, Decatur, Il, USA

25 Attallah College of Educational Studies, Chapman University, Orange, CA, USA

26 Science Education Department, Adekunle Ajasin University, Ondo, Nigeria

27 Curriculum and Pedagogy, College of Teacher Education, Zhejiang Normal University, Jinhua, China 
28 Faculty of Social Sciences, Tampere University, Tampere, Finland

29 Faculty of Education, University of Auckland, Auckland, New Zealand

30 School of Social Science, Education and Social Work, Queen's University Belfast, Belfast, Northern Ireland, UK

31 Department of Computer and System Science, Mid Sweden University, Östersund, Sweden

32 University of South Carolina, Columbia, USA

33 University of Seville, Seville, Spain

34 Attallah College of Educational Studies, Chapman University, Orange, CA, USA

35 Institute for Danish Game Development, Dania Academy, Grenaa, Denmark Republic of Ireland Jindal Global Business School, Jindal Institute of Behavioural Sciences, O.P Jindal Global University, Sonepat, India Nigeria 
63 School of Education, University of Newcastle, Newcastle, Australia

64 Faculty of Culture and Society, Auckland University of Technology, Auckland, New Zealand

65 OP Jindal Global Business School, OP Jindal Global University, Sonipat, India

66 BestStart, Christchurch, New Zealand

67 Jindal Global Law School, Jindal Global University, Sonipat, Haryana, India

68 Zagreb University of Applied Sciences, Zagreb, Croatia

69 Faculty of Education and Social Work, University of Auckland, Auckland, New Zealand

70 Education Studies, DePauw University, Greencastle, IN, USA

71 Chair for Critical Studies in Higher Education Transformation (CriSHET), Nelson Mandela University, Port Elizabeth, South Africa

72 Department of Banking and Finance, Faculty of Business, Curtin University, Miri, Malaysia

73 Te Rito Maioha Early Childhood New Zealand, Rotorua, New Zealand

74 School of Teacher Education, University of Canterbury, Christchurch, Aotearoa, New Zealand

75 DePauw University, Greencastle, IN, USA

76 Attallah College of Educational Studies, Chapman University, Orange, CA, USA

77 International Institute for Higher Education Research \& Capacity Building, O. P. Jindal Global University, Sonipat, Haryana, India

78 Education Observatory, University of Wolverhampton, Wolverhampton, UK 